\title{
SUSTAINABLE COOLING ALTERNATIVES FOR BUILDINGS
}

\author{
Jacobus Adriaan Vorster \\ Thesis presented in partial fulfilment of the requirements for the degree Master of Science in \\ Engineering at the University of Stellenbosch
}

Thesis Supervisor: RT Dobson

March 2010

Department of Mechanical and Mechatronic Engineering University of Stellenbosch 


\section{DECLARATION}

I, Jacobus Adriaan Vorster, the undersigned, hereby declare that the work contained in this thesis is my own original work and has not previously, in its entirety or in part, been submitted at any university for a degree.

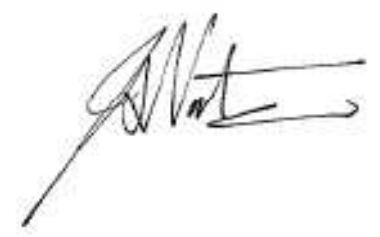

Signature of candidate

$17^{\text {th }}$ day of February 2010 


\begin{abstract}
The thesis was initiated by a Consulting Engineering Company (KV3) as a research project to investigate various options in which the efficiency and energy utilisation of conventional air conditioning systems may be enhanced by using alternative and renewable energy. Initially, eight options had been identified and through a process of determining the degree of commercialisation the alternative options were reduced to three. These options, referred to as the sustainable cooling alternatives, are active mass cooling, night flushing and roof cooling system.
\end{abstract}

The roof cooling system comprised a roof-pond, roof-spray, pump and storage tank. The roof cooling system was mathematically and experimentally modelled. The roof cooling experiment was performed under a variety of weather conditions with the roof-pond and storage tank temperatures continuously recorded. The experimentally recorded temperatures were compared to the temperatures generated by the theoretical simulation calculations for the same input and weather conditions. Good agreement was found between the mathematical and experimental model. The largest discrepancy found between the simulated temperature and the experimental temperature was in the order of $1^{\circ} \mathrm{C}$.

A one-room building has been assumed to serve as a basis to which the sustainable cooling alternatives could be applied to for theoretical simulation. The one-room building had four façade walls and a flat roof slab. Night flushing, active mass cooling and the roof cooling system were applied to the one-room building such that the room air temperature and space cooling load could theoretically be simulated. The theoretical simulations were also repeated for the case where the roof-pond and roof-spray were applied as standalone systems to the one-room building. The theoretical simulation calculations were performed for typical summer weather conditions of Stellenbosch, South Africa.

Under base case conditions and for a room thermostat setting of $22{ }^{\circ} \mathrm{C}$ the peak cooling load of the one-room building was $74.73 \mathrm{~W} / \mathrm{m}^{2}$. With the application of night flushing between the hours of $24: 00$ and 07:00, the room cooling load was reduced by $5.2 \%$ by providing $3.9 \mathrm{~W} / \mathrm{m}^{2}$ of cooling and reducing the peak room temperature by $1.4{ }^{\circ} \mathrm{C}$. The active mass cooling system was modelled by supplying water at a constant supply temperature of $15^{\circ} \mathrm{C}$ to a pipe network embedded in the roof slab of the one-room building. The sea may typically be considered as a cold water source for buildings situated at the coast. The active mass cooling system reduced the peak cooling load of the one-room building by $50 \%$ by providing $37.2 \mathrm{~W} / \mathrm{m}^{2}$ of cooling and reducing the peak room temperature by $6.7^{\circ} \mathrm{C}$.

When the roof-spray and roof-pond systems were applied as standalone systems to the oneroom building, the peak cooling load of the one-room building could be reduced by $30 \%$ and $51 \%$ respectively. This is equivalent to $22.3 \mathrm{~W} / \mathrm{m}^{2}$ of peak cooling by the roof-spray and $38 \mathrm{~W} / \mathrm{m}^{2}$ of peak cooling by the roof-pond. The roof-spray reduced the peak room temperature by $3.71{ }^{\circ} \mathrm{C}$ while the roof-pond reduced the peak room temperature by $5.9{ }^{\circ} \mathrm{C}$.

Applying the roof cooling system to the one-room building produced $46 \mathrm{~W} / \mathrm{m}^{2}$ of peak cooling which resulted in a $61.1 \%$ reduction in peak cooling load. The roof cooling system reduced the peak temperature by $8{ }^{\circ} \mathrm{C}$. By comparing the sustainable cooling alternatives, the 
roof cooling system showed to be the most effective in reducing the one-room building peak cooling load. Over a 24 hour period the roof cooling system reduced the net heat entry to the one-room building by $57.3 \%$.

In a further attempt to reduce the peak cooling load, the sustainable cooling alternatives were applied in combinations to the one-room building. The combination of night flushing and roof-spray reduced the peak cooling load by $36 \%$ while a combination of night flushing and active mass cooling reduced the peak cooling load by 55\%. Combining night flushing with the roof-pond also yielded a 55\% peak cooling load reduction. The combination of roofpond, active mass cooling and night flushing provided $51 \mathrm{~W} / \mathrm{m}^{2}$ of cooling which corresponded to a $68 \%$ reduction in peak cooling load. Utilising the sustainable cooling alternatives in a combination in the one-room building gave improved results when compared to the case where the sustainable cooling alternatives were employed as standalone systems.

It is illustrated by means of a sensitivity analysis that the ability of the roof cooling system to produce cool water is largely influenced by ambient conditions, droplet diameter and roofspray rate. Under clear sky conditions, an ambient temperature of $15^{\circ} \mathrm{C}$, relative humidity of $80 \%$, a roof-spray rate of $0.02 \mathrm{~kg} / \mathrm{sm}^{2}$ and a roof-pond water level of $100 \mathrm{~mm}$, water could be cooled at a rate of $113 \mathrm{~W} / \mathrm{m}^{2}$. The roof-spray energy contributed to $28 \mathrm{~W} / \mathrm{m}^{2}$ whilst the night sky radiation was responsible for $85 \mathrm{~W} / \mathrm{m}^{2}$ of the water cooling. It must however be noted that the water of the roof cooling system can never be reduced to a temperature that is lower than the ambient dew point temperature. 


\section{UITTREKSEL}

Die tesis is geïnisieer deur ' $n$ Raadgewende Ingenieurs Maatskappy (KV3) as a navorsingsprojek om verskeie opsies te ondersoek waarmee die effektiwiteit en energie verbruik van konvensionele lugversorgingstelsels verbeter kan word deur middel van alternatiewe en hernubare energie. Agt opsies is oorspronglik geïdentifiseer en deur middel van ' $n$ proses waarby die graad van kommersialisering van hierdie alternatiewe maniere bepaal is, kon die opsies verminder word tot drie. Hierdie opsies, ook verwys na as die volhoubare verkoelingsalternatiewe, sluit in aktiewe massa verkoeling, dakverkoeling en nagventilasie.

Die dakverkoelingstelsel bestaan uit dakwater, 'n dakspuit, 'n pomp en 'n stoortenk. Die dakverkoelingstelsel is wiskundig en eksperimenteel gemodelleer. Die dakverkoelingseksperiment is uitgevoer onder ' $\mathrm{n}$ verskeidenheid van weersomstandighede. Die dakwater asook die stoortenk se water temperatuur is voortdurend aangeteken. Dieselfde weer- en insetkondisies is gebruik vir die simulasie berekening en die temperature van die stoortenk se water en die dakwater is vergelyk met die temperatuurlesings van die eksperimentele werk. Die temperature van die eksperimentele lesings het goed vergelyk met die temperatuur simulasie berekeninge. Die grootste verskil tussen die simulasie en eksperimentele temperatuur was in die orde grootte van $1{ }^{\circ} \mathrm{C}$.

' $n$ Een-kamer gebou is aangeneem om as basis te dien waarop die volhoubare verkoelingsalternatiewe aangewend kon word vir teoretiese simulasie. Die een-kamer gebou het uit vier buite mure en ' $\mathrm{n}$ horisontale beton dak bestaan. Nag ventilasie, aktiewe massa verkoeling en die dakverkoelingstelsel is toegepas op die een-kamer gebou en die kamer se verkoelingslas asook die kamer se lugtempertuur is teoreties gesimuleer. Die teoretiese simulasies is ook herhaal vir die geval waar die dakwater and dakspuitstelsel apart aangewend is op die een-kamer gebou. Die teoretiese simulasie berekeninge is uitgevoer vir tipiese somer weersomstandighede vir Stellenbosch, Suid Afrika.

Onder basisgeval omstandighede, waar die een-kamer gebou gesimuleer is, sonder enige volhoubare verkoelingsalternatiewe en ' $\mathrm{n}$ termostaat verstelling van $22{ }^{\circ} \mathrm{C}$, is die piek verkoelingslas bereken as $74.73 \mathrm{~W} / \mathrm{m}^{2}$. Met die toepassing van nagventilasie tussen die ure 24:00 en 07:00 was die piekverkoelingslas van die kamer verminder met 5.2\% deur $3.9 \mathrm{~W} / \mathrm{m}^{2}$ se verkoeling te verskaf en die piekkamer temperatuur te verminder met $1.4{ }^{\circ} \mathrm{C}$. Aktiewe massa verkoeling is gesimuleer deur water teen ' $n$ konstante temperatuur van $15^{\circ} \mathrm{C}$ te verskaf aan ' $n$ pypnetwerk, geïnstalleer in the beton dak, van die een-kamer gebou. Geboue geleë aan die kus kan tipies seewater oorweeg as ' $\mathrm{n}$ bron van koue water. Aktiewe massa verkoeling het die piekverkoelingslas van die een-kamer gebou verminder met $50 \%$ deur $37.2 \mathrm{~W} / \mathrm{m}^{2}$ se verkoeling te verskaf en die piekkamer temperatuur te verminder met $6.7^{\circ} \mathrm{C}$.

Wanneer die dakspuit- en dakwaterstelsel aangewend is op die een-kamer gebou as enkel staande stelsels, is die piekverkoelingslas verminder met $30 \%$ en $51 \%$ onderskeidelik. Dit is ekwivalent aan $22.3 \mathrm{~W} / \mathrm{m}^{2}$ se verkoeling vir die dakspuitstelsel en $38 \mathrm{~W} / \mathrm{m}^{2}$ se verkoeling vir die dakwaterstelsel. Die dakspuitstelsel het die piekkamer temperatuur verminder met 
$3.71{ }^{\circ} \mathrm{C}$ terwyl die dakwaterstelsel ' $\mathrm{n} 5.9^{\circ} \mathrm{C}$ verlaging in piekkamer temperatuur tot gevolg gehad het.

Die dakverkoelingstelsel het $46 \mathrm{~W} / \mathrm{m}^{2}$ se piekverkoeling verskaf wat ' $\mathrm{n} 61.1 \%$ vermindering in piekverkoelingslas tot gevolg gehad het. Die ooreenstemmende piek temperatuur vermindering is $8{ }^{\circ} \mathrm{C}$. Deur die verskeie volhoubare verkoelingsalternatiewe met mekaar te vergelyk, word getoon dat die dakverkoelingstelsel die mees effektiefste manier is om die een- kamer se piekverkoelingslas te verminder. Oor 'n tydperk van 24 uur het die dakverkoelingstelsel die totale energievloei na die een-kamer gebou met $57.3 \%$ verminder.

In ' $n$ verdere poging om die piekverkoelingslas te verminder, is die volhoubare verkoelingsalternatiewe toegepas in kombinasies op die een-kamer gebou. Die kombinasie van nagventilasie met die dakspuitstelsel het die piekverkoelingslas met $36 \%$ verminder, terwyl ' $n$ kombinasie van nagventilasie en aktiewe massa verkoeling ' $n$ 55\% vermindering in piekverkoelingslas tot gevolg gehad het. Die kombinasie van dakwater en nagventilasie het ook ' $\mathrm{n}$ piekverkoelingslas vermindering van 55\% teweeggebring. Die kombinasie van dakwater, aktiewe massa verkoeling en nagventilasie het $51 \mathrm{~W} / \mathrm{m}^{2}$ se verkoeling veskaf, wat ooreenstem met ' $n$ 68\% vermindering in piekverkoelingslas. Deur die volhoubare verkoelingsalternatiewe in kombinasies toe te pas op die een-kamer gebou, kon beter resultate verkry word toe dit vergelyk is met die geval waar die volhoubare verkoelingsalternatiewe as enkelstaande stelsels toegepas is.

Dit is geïllustreer deur middel van 'n sensitiwiteitsanalise dat die vermoë van die dakverkoelingstelsel om koue water te produseer, beïnvloed word deur buitelug kondisies, waterdruppel deursnee en dakspuit massa vloeitempo. Onder die oop hemelruimteomstandighede, ' $\mathrm{n}$ buitelug temperatuur van $15{ }^{\circ} \mathrm{C}$, ' $\mathrm{n}$ relatiewe humiditeit van $80 \%$, ' $\mathrm{n}$ dakspuit massa vloeitempo van $0.02 \mathrm{~kg} / \mathrm{sm}^{2}$ en dakwatervlak van $100 \mathrm{~mm}$, kon water verkoel word teen 'n tempo van $113 \mathrm{~W} / \mathrm{m}^{2}$. Die dakspuit gedeelte het $28 \mathrm{~W} / \mathrm{m}^{2}$ bygedra terwyl die nagruim radiasie sowat $85 \mathrm{~W} / \mathrm{m}^{2}$ se verkoeling verskaf het. Daar moet egter kennis geneem word dat die water temperatuur van die dakverkoelingstelsel nooit verminder kan word tot onder die buitelug doupunttemperatuur nie. 


\section{ACKNOWLEDGEMENTS}

The following people are thanked for their contributions towards this project, without which the completion thereof would not have been possible:

Robert Dobson - Supervisor

Thank you for your guidance, advise, patience and enthusiasm throughout this project. Your input is greatly appreciated.

Cobus Zietsman - Laboratory technician

Thank you for your helpful suggestions and assistance with the experimental set-up.

Margaretha Vorster - My Wife

Thank you for your helpful suggestions and assistance in writing the thesis report. 
To my wife, family and friends.

Your support and understanding will always be treasured. 


\section{TABLE OF CONTENTS}

DECLARATION

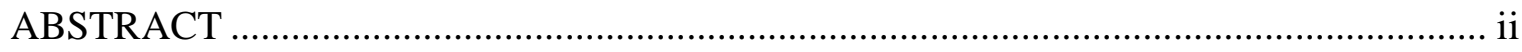

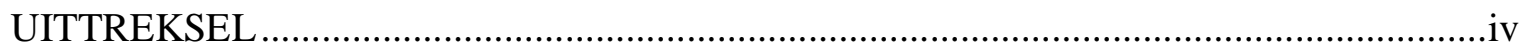

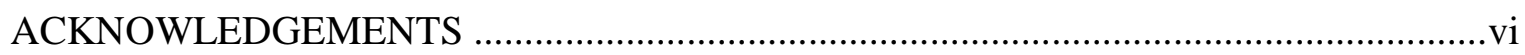

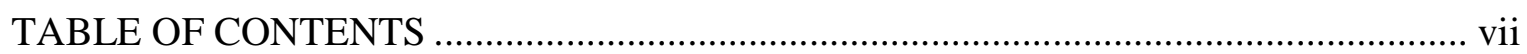

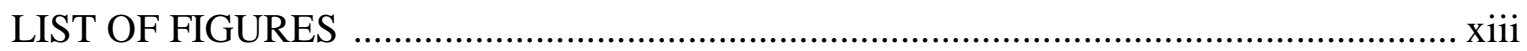

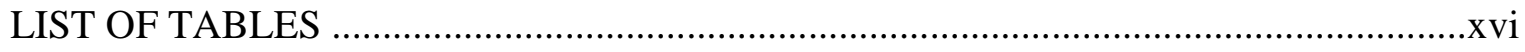

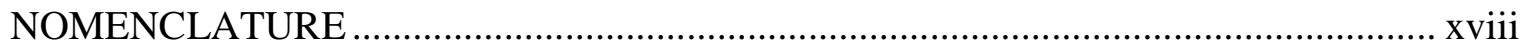

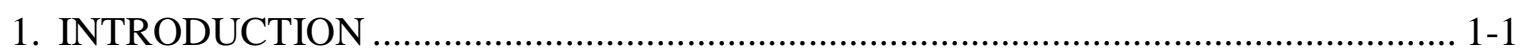

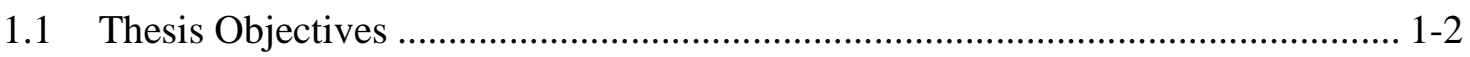

1.2 Sustainable Cooling Alternatives Identified......................................................... 1-2

2. COMMERCIALISATION OF COOLING ALTERNATIVES ................................... 2-1

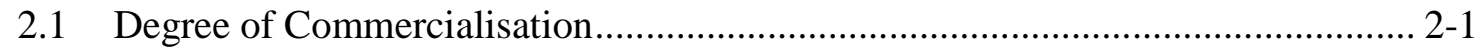

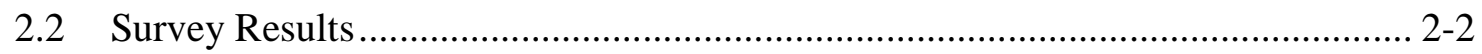

2.3 Sustainable Cooling Alternatives Selected......................................................... 2-3

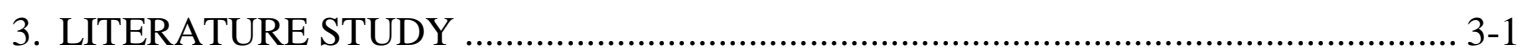

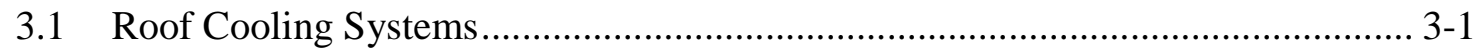

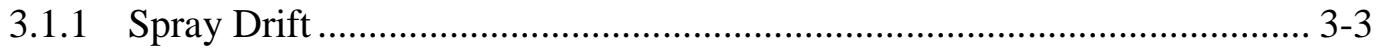

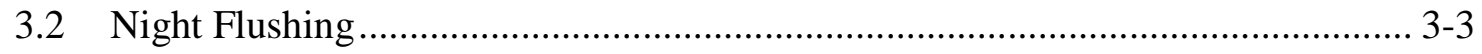

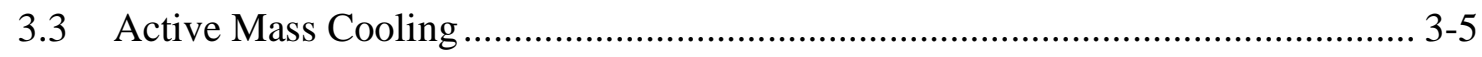

4. MATHEMATICAL MODELLING OF THE ROOF COOLING SYSTEM.................. 4-1

4.1 Control Volumes and Conservation Equations ................................................... 4-1

4.1.1 Assumptions ...................................................................................... 4-2

4.1.2 The Water Droplet Continuity and Momentum Equations ....................... 4-2 
4.1.3 The Water Droplet Energy Equation ..................................................... 4-4

4.1.4 The Roof-pond Control Volume and Energy Equation............................. 4-4

4.1.5 The Pump Control Volume ….............................................................. 4-5

4.1.6 The Storage Tank Volume.............................................................. 4-7

4.2 Droplet Size Distribution........................................................................... $4-8$

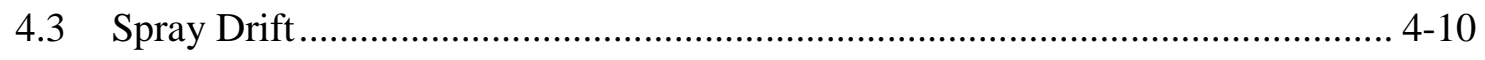

4.3.1 Modelling Spray Drift in Roof Cooling Systems ................................... 4-11

4.3.2 Trajectory of Water Droplets............................................................ 4-12

4.3.3 The Effect of Spray Drift on the Roof Cooling System ......................... 4-14

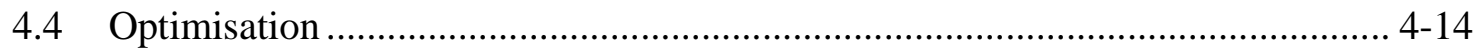

4.4.1 Roof-pond Optimisation................................................................ 4-14

4.4.2 Roof-spray Optimisation ........................................................... 4-16

4.4.3 Roof-spray Optimisation Procedure .......................................................... 4-18

4.5 Numerical Simulation Flowcharts ........................................................................ 4-20

4.5.1 The Droplet-Flowchart ............................................................... 4-20

4.5.2 The Roof Cooling Flowchart ............................................................ 4-22

5. MATHEMATICAL MODELLING OF THE ONE-ROOM BUILDING AND THE SUSTAINABLE COOLING ALTERNATIVES ......................................................... 5-1

5.1 One-Room Building Description and Modelling .............................................. 5-1

5.1.1 One-Room Building Heat and Cooling Load Mathematical Modelling .... 5-2

5.1.2 Heat Gain through Single Brick Walls ................................................. 5-4

5.1.3 Heat Gain through the Roof-slab....................................................... 5-8

5.1.4 Heat Gain through the Window..................................................... 5-10

5.1.5 Lighting Loads........................................................................ 5-13

5.1.6 Infiltration and Ventilation Heat Gains ..................................................... 5-13

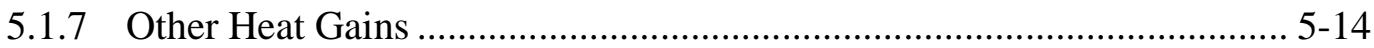


5.2 Mathematical Modelling with Night Flushing.....

5.3 Mathematical Modelling with Active Mass Cooling

5.4 Mathematical Modelling with Roof-spray Cooling

5.5 Mathematical Modelling with Roof-pond Cooling

5.6 One-Room Building Flowchart

6. EXPERIMENTAL WORK

6.1 Experimental Set-up 6-1

6.2 Experimental Procedure 6-2

6.3 Measurement Uncertainty 6-3

6.3.1 Uncertainty Analysis .... 6-3

6.4 Error Propagation 6-6

7. SIMULATION AND EXPERIMENTAL RESULTS 7-1

7.1 Experimental Results $7-1$

7.2 Comparison of Experimental Results with Theoretical Results $7-6$

7.3 Roof Cooling Experiment Heat Loss Mechanisms $7-9$

7.4 Roof Cooling Experiment Sensitivity Analysis ................................................. 7-10

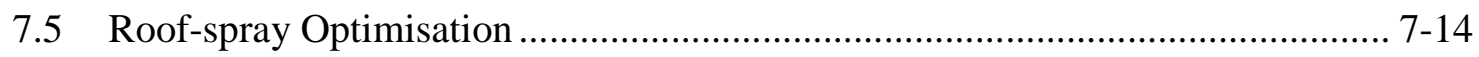

7.6 One-Room Building Instantaneous Heat Gain and Actual Cooling Load for Base Case Conditions....

7.7 Room Temperature and Cooling Load Profile of the One-Room Building with the Sustainable Cooling Methods Included Separately.

7.8 Room Temperature and Cooling Load Profile of the One-Room Building with the Sustainable Cooling Methods Applied in Combinations

7.9 Room Temperature and Cooling Load Profile of the One-Room Building with Night Flushing Under a Variety of Air Change Rates

7.10 Roof Temperature and Roof Heat Flux Profile of the One-Room Building with the Roof-pond of Varying Water Levels 
7.11 Water Heat Removal Rate from the Roof Cooling System.

8. CONCLUSION AND RECOMMENDATIONS FOR FUTURE WORK

8.1 Recommendations for Future Work

9. REFERENCES

APPENDIX A: COMMERCIALISATION CYCLES AND SURVEY QUESTIONNAIRE.

A.1 Industry Stakeholders in the Commercialisation Cycle

A.2 Stratified Random Sampling

A.3 Survey Design and Questions A-4

A.3.1 Survey Questions Explained A-4

A.4 Determination of the Degree of Commercialisation from the Survey Response ...A-5

A.5 Sample Questionnaire.

APPENDIX B: INPUT VARIABLES TO THE ONE-ROOM BUILDING SIMULATION

APPENDIX C: DERIVATION OF CONSERVATION EQUATIONS AND HEAT TRANSFER CORRELATIONS.

C.1 Derivation of Conservation Equations

C.1.1 Derivation of the Equation 4.2 to 4.4, the water droplet momentum equations

C.1.2 Derivation of Equation 4.5, the water droplet energy equation C-2

C.1.3 Derivation of Equation 4.7, the roof-pond energy equation C-4

C.2 Correlations for the Convection Heat Transfer Coefficients C-6

C.2.1 Water Droplet Heat and Mass Transfer Coefficient C-6

C.2.2 Roof-pond to Air Heat and Mass Transfer Coefficients C-7

C.2.2.1 Correlations for Nusselt and Sherwood Number Under Forced Convection C-8

C.2.2.2 Correlations for Nusselt and Sherwood Numbers under Natural Convection 
C.2.2.3 Combination of Natural and Forced Convection. C-10

C.2.3 Roof-pond Water to Roof Heat Transfer Coefficients. C-10

C.3 Correlations for Mass Transfer Rates C-11

C.3.1 Mass Transfer due to Evaporation C-11

C.3.2 Mass Transfer due to Condensation C-11

APPENDIX D: ORDER OF MAGNITUDE ANALYSIS ….......................................

APPENDIX E: INCIDENT SOLAR RADIATION CALCULATION .............................. E-1

E.1 Solar Radiation Components .................................................................................... E-1

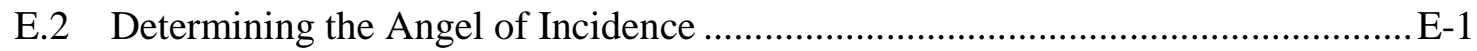

E.3 Determination of the Solar Radiation Components ............................................ E-3

\section{APPENDIX F: UNCERTAINTY ASSOCIATED WITH ENERGY LOSS}

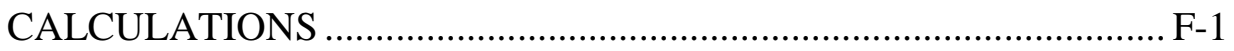

F.1 Uncertainty Associated with Convection Energy Loss Calculations ..................... F-1

F.2 Uncertainty Associated with Evaporation Energy Loss Calculations.................... F-2

F.3 Uncertainty Associated with Radiation Energy Loss Calculations....................... F-4

F.4 Uncertainty Values for the Experimental Tests .................................................... F-5

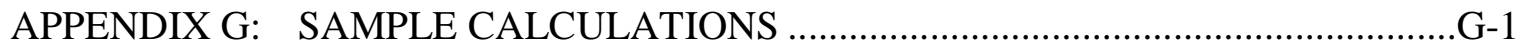

G.1 Sample Calculations for the Droplet-Flowchart as given in Figure 4.14 ................

G.2 Sample Calculations for the Roof Cooling Flowchart given by Figure 4.15 .........G-5

G.3 Sample Calculations for the One-Room Building Cooling load ............................

APPENDIX H: ADDITIONAL INFORMATION ON THE EXPERIMENTAL WORK.

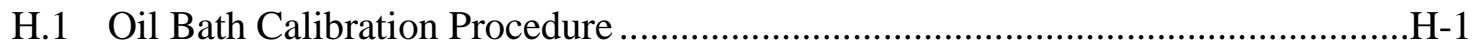

H.2 Procedure for Determining Experimental Variables ........................................

H.2.1 Procedure for Determining the Storage Tank Water Volume...................H-2

H.2.2 Procedure for Determining the Water Mass Flow Rate ...........................H-4 
H.2.3 Procedure for Determining the Volume Mean Diameter of the Spray

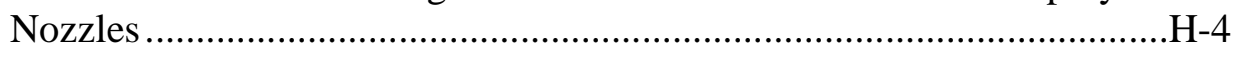

H.2.4 Procedure for Determining the Initial Droplet Discharge Velocity ..........H-5

H.3 Measured Humidity and Ambient Temperature Levels of the Experimental TestsH-6 


\section{LIST OF FIGURES}

Figure 2.1: Chart Depicting the Degree of Commercialisation of the Sustainable Cooling Alternative Methods Relative to Each Other.

Figure 4.1: Roof Cooling System with the Relevant Control Volumes.............................. 4-2

Figure 4.2: Velocity and Force Vectors Acting on the Water Droplet Control Volume ..... 4-3

Figure 4.3: Heat Transfer Mechanisms Applicable to the Water Droplet Control Volume 4-4

Figure 4.4: Control Volume of the Roof-pond................................................................... 4-5

Figure 4.5: Control Volume of the Centrifugal Pump ...................................................... 4-6

Figure 4.6: Storage Tank Energy Control Volume .......................................................... 4-7

Figure 4.7: Rosin Rammler Probability Density Function for the Six Defined Droplet

Categories of the ASAE Standard S-572 ...................................................... 4-9

Figure 4.8: Rosin Rammler Cumulative Distribution Function for the Six Defined Droplet Categories of the ASAE Standard S-572 ......................................... 4-10

Figure 4.9: Typical Water Droplet Trajectory ............................................................. 4-11

Figure 4.10: Trajectory of Water Droplets with Various VMD's .................................... 4-13

Figure 4.11: Fluid Power at the Spray Nozzle and Heat Transfer Mechanisms of the Water Droplets ............................................................................................. 4-16

Figure 4.12: Powell's Method for Zero-Order Multi Variable Optimisation .................... 4-19

Figure 4.13: Time Intervals in the Water Droplet Spray Path ........................................ 4-21

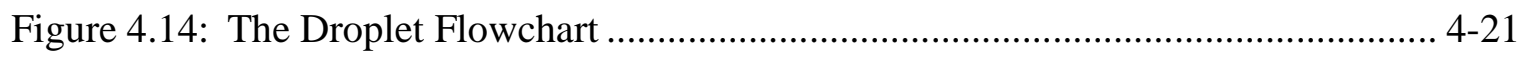

Figure 4.15: The Roof Cooling Flowchart........................................................... 4-23

Figure 5.1: The One-Room Building Layout and Dimensions (not to scale) ..................... 5-1

Figure 5.2: Control Volume of the One-Room Building Space Air .................................. 5-3

Figure 5.3: One-Building Room Wall Control Volumes .................................................. 5-4

Figure 5.4: Heat Transfer Mechanisms on the Inner and Outer Wall Control Surface........ 5-6

Figure 5.5: Roof-slab Control Volumes and Heat Transfer Mechanisms at Inner and Outer Surfaces 
Figure 5.6: Control Volume at the Centre of the Roof-slab with Embedded Pipes

Figure 5.7: Partitioning of the Roof-slab with Embedded Pipes.

Figure 5.8: Control Volume for the Water Flowing in the Embedded Pipes of the Roof-slab

Figure 5.9: Control Surface of the Wetted Roof

Figure 5.10: Control Surface of the Roof with a Roof-pond

Figure 5.11: The Three Main Sub Procedures for the One-Room Building Flowchart .... 5-24

Figure 5.12: The One-Room Building Flowchart.

Figure 6.1: Experimental Set-up of the Roof Cooling System 6-1

Figure 7.1: Roof Cooling Temperatures for (a) 25 May 2008, (b) 12 July 2008,

(c) 02 August 2008, (d) 03 May 2009 and (e) 04 May 2009 Experimental Tests

Figure 7.2: Computer Simulation and Experimental Test Result Comparison for the

(a) 25 May 2008, (b) 12 July 2008, (c) 02 August 2008, (d) 03 May 2009 and (e) 04 May 2009 Experimental Tests

Figure 7.3: Optimisation Graph for the Nozzle Spray Coefficient

Figure 7.4: Flowchart Illustrating the Difference between Instantaneous Heat Gain and Actual Cooling Load (ASHRAE Fundamentals, 2005)

Figure 7.5: (a) Instantaneous Heat Gain vs Actual Cooling Loads and (b) Individual Cooling Load Contributions of the Various Heat Gain Elements of the One-Room Building.

Figure 7.6: (a) Room Temperature and (b) Cooling Load Profile of the One-Room Building with the Sustainable Cooling Methods Included Separately

Figure 7.7: (a) Room Temperature and (b) Cooling Load Profile of the One-Room Building with the Sustainable Cooling Methods Applied in Combinations ... 7-19

Figure 7.8: Hourly Room Temperature Variation of the One-Room Building under a Variety of Night Flushing Air Change Rates

Figure 7.9: (a) Peak Cooling Load and (b) Percentage Reduction in Peak Cooling Load for Increasing Night Flushing Air Change Rates and Four Room Temperature Settings 
Figure 7.10: (a) Roof Heat Flux Profile and (b) Roof Temperature of the One-Room Building with Roof-spray and Roof-pond with Varying Roof-pond Water Levels

Figure 7.11: Rate of Heat Removal from the Water in the Roof Cooling System for Increasing Ambient Temperatures and $\dot{m}_{r c}=0.02 \mathrm{~kg} / \mathrm{sm}^{2}, V M D=1200 \mu \mathrm{m}$, $\phi_{a}=80 \%, u_{w}=3 \mathrm{~m} / \mathrm{s}, T_{r p}=15^{\circ} \mathrm{C}$ and $z_{r p}=100 \mathrm{~mm}$

Figure 7.12: Rate of Heat Removal from the Water in the Roof Cooling System for an Increasing Relative Humidity and $\dot{m}_{r c}=0.02 \mathrm{~kg} / \mathrm{sm}^{2}, V M D=1200 \mu \mathrm{m}$, $T_{a m b}=15.5{ }^{0} \mathrm{C}, u_{w}=3 \mathrm{~m} / \mathrm{s}, T_{r p}=15{ }^{\circ} \mathrm{C}$ and $z_{r p}=100 \mathrm{~mm}$

Figure A.1: Various Stages of the Commercialisation Cycle A-1

Figure A.2: Industry Stakeholders in the Commercialisation Cycle A-2

Figure A.3: Pie Chart Depicting the Weight Percentages of the Survey Questions to determine the Degree of Commercialisation

Figure B.1: (a) Ambient Temperature and (b) Relative Humidity for a Typical Summers Day in Stellenbosch, South Africa

Figure D.1: Location of Water Droplets in a Spray Cloud D-1

Figure E.1: Relevant Angles for Describing the Position of the Sun Relative to a Plane ....E-1

Figure G.1: Velocity Diagram of Water Droplet G-3

Figure G.2: Cross Section of Roof Slab that Depicts Ten Control Volumes and Temperature Nodes

Figure H.1: Set-up of Oil Bath with Thermocouples H-1

Figure H.2: Photograph Depicting the Set-up of the Oil Bath for the Calibration of the Thermocouples H-2

Figure H.3: Dimensions of the Water Storage Tank .H-3

Figure H.4: Pump Curve for a $0.75 \mathrm{~kW}$ Foras JA-100 pump H-4 


\section{LIST OF TABLES}

Table 4.1: Rosin Rammler Characteristics for ASAE Droplet Categories

Table 4.2: Sedimentation Velocities of Various Size Droplets as a Percentage of Wind

Velocity

Table 5.1: One-Room Building Properties

Table 5.2:Non-Solar Radiant Time Factors (RTF) for a Medium Weight Construction

Building with $10 \%$ Glass of a Total Surface Area and a Carpet

Table 6.1: Oil Bath Temperature Measurements ............................................................. 6-4

Table 6.2:Bias, Precision and Total Errors for the Oil Bath Measured Data Sets ............... 6-5

Table 7.1: Test Conditions for the Roof Cooling Experiments ........................................... 7-1

Table 7.2: Calculated Energy Loss and Gain for the Various Heat Transfer Mechanisms in the Experimental Tests over a Time Period of 1.5 hours.............................. 7-9

Table 7.3: Base Case Values for the Sensitivity Analysis ............................................... 7-11

Table 7.4: Influence of System Variables on the Performance Parameters ........................ 7-11

Table 7.5:Total Heat Energy and Peak Cooling Load of the One-Room Building with the Sustainable Cooling Alternatives Applied Separately

Table 7.6:Total Heat Energy and Peak Cooling Load of the One-Room Building with the Sustainable Cooling Alternatives Included as Combinations ...................... 7-20

Table A.1: Two Pair Force Decision Procedure …..........................................................

Table B.1: Input Parameters for the Base Case Simulation of the One-Room Building .... B-1

Table B.2:Design Parameters for the Sustainable Cooling Alternatives Applied to the

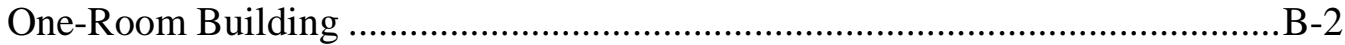

Table B.3: Solar Radiation for Stellenbosch on 03 March 2009........................................

Table E.1: Values for $A, B$ and $C$ for the 21st day of each Month of the Year (Values taken from ASHRAE Fundamentals, 2005, Chapter 31) ...................... E-3

Table F.1:Uncertainty Values for Convection, Evaporation and Radiation Energy Losses of the Experimental Tests.

Table G.1: Temperature Values for the Roof Cooling System. G-9

Table H.1: VMD from the Spray Nozzles Utilised in the Experimental Work. .H-5 
Table H.2: VMD from the Spray Nozzles Utilised in the Experimental Work. H-6

Table H.3: Ambient Temperature and Humidity Levels Measured at 6 Minute Interval During the Five Experiments...... 


\section{NOMENCLATURE}

\section{VARIABLES:}

$\begin{array}{ll}A & \text { Area }\left(\mathrm{m}^{2}\right) \text { or Apparent Solar } \\ & \text { Irradiation }\left(\mathrm{W} / \mathrm{m}^{2}\right) \\ B & \text { Atmospheric Extinction } \\ & \text { Coefficient }\end{array}$

C Constant Specific Heat (J/kgK), Coefficient or Coarse

$d A \quad$ Element Area $\left(\mathrm{m}^{2}\right)$

$d V \quad$ Element Volume $\left(\mathrm{m}^{3}\right)$

$D \quad$ Diameter (m)

$D_{A B} \quad$ Binary Mass Diffusion Coefficient $\left(\mathrm{m}^{2} / \mathrm{s}\right)$

$e \quad$ Energy per Unit Mass

E Energy (J)

ET Equation of Time

$F \quad$ Force (N), Forced or Fine

Fo $\quad$ Fourier Number

Fpo People Occupancy Factor

$\mathrm{Fu} \quad$ Usage Factor

$g \quad$ Gravitational Constant $\left(9.81 \mathrm{~m}^{2} / \mathrm{s}\right)$

Gr Grashof Number

$h \quad$ Heat Transfer Convection Coefficient $\left(\mathrm{W} / \mathrm{m}^{2} \mathrm{~K}\right)$, Enthalpy (J/kgK), Height (m) or Control Volume Thickness (m)

$h_{m} \quad$ Mass Transfer Coefficient $(\mathrm{m} / \mathrm{s})$

$H \quad$ Head (m) or Hour Angle (degrees)

$i \quad$ Integer denoting the internal nodes of a set of control volumes or the $\mathrm{i}^{\text {th }}$ test in the oil bath calibration procedure

ii Integer Value used in Powell's Algorithm for Optimisation
I Incident Solar Radiation $\left(\mathrm{W} / \mathrm{m}^{2}\right)$

$j \quad$ Integer to indicate the $\mathrm{j}^{\text {th }}$ thermocouple

$k \quad$ Thermal Conductivity (W/mK) or Shape Factor

$K \quad$ Nozzle Loss Coefficient

$l \quad$ Length (m)

$L \quad$ Latitude

$m \quad$ Mass $(\mathrm{kg})$ or the Order of the Polynomial Regression Fit

$\dot{m} \quad$ Mass Flow Rate $(\mathrm{kg} / \mathrm{s})$

$m v \quad$ Momentum $(\mathrm{kgm} / \mathrm{s})$

$M \quad$ Medium, Total Number of Control Volumes in the Wall, Total Number of Thermocouples or Water Molar Mass $(\mathrm{kg} / \mathrm{kmol})$

$n \quad$ Exponent or Integer for counting time increments or units

$\hat{n} \quad$ Scalar Value (-)

$N \quad$ Number of (\#) or Day of the Year

$\mathrm{Nu} \quad$ Nusselt Number

$p \quad$ Pressure $(\mathrm{Pa})$

$P \quad$ Power (Watt)

Pr Prandtl Number

$q \quad$ Integer used in Powell's Algorithm

$\dot{q} \quad$ Rate of Heat Transfer per Unit Area $\left(\mathrm{W} / \mathrm{m}^{2}\right)$

$Q \quad$ Heat Transfer (J)

$\dot{Q} \quad$ Rate of Heat Transfer (W)

$r \quad$ Radius (m) or Radiant Time Factor 
$R \quad$ Universal Gas Constant $(\mathrm{J} / \mathrm{kgK})$, Thermal Resistance (W/K) or Resistance Coefficient $\left(\mathrm{W} / \mathrm{m}^{2} \mathrm{~K}\right)$

$R a \quad$ Rayleigh Number

Re Reynolds Number

$s \quad$ Displacement (m)

$S \quad$ Matrix with Search Directions used in Powell's Algorithm for Optimisation, Standard Deviation or Distance (m)

Sc Schmidt Number

Sh Sherwood Number

$t \quad$ Time (s) or thickness (mm)

$T \quad$ Temperature $\left(\mathrm{K}\right.$ or $\left.{ }^{\circ} \mathrm{C}\right)$

$\bar{T} \quad$ Mean Temperature $\left(\mathrm{K}\right.$ or $\left.{ }^{\circ} \mathrm{C}\right)$

$u \quad$ Velocity $(\mathrm{m} / \mathrm{s})$, Internal Energy per Unit Mass $(\mathrm{J} / \mathrm{K})$ or Uncertainty

$\bar{u} \quad$ Average Velocity $(\mathrm{m} / \mathrm{s})$ or Velocity Vector
$U \quad$ Total Internal Energy (J) or Overall Heat Transfer Coefficient $\left(\mathrm{W} / \mathrm{m}^{2} \mathrm{~K}\right)$

Kinematic Viscosity $\left(\mathrm{m}^{2} / \mathrm{s}\right)$

$\dot{V} \quad$ Volume Flow Rate $\left(\mathrm{m}^{3} / \mathrm{s}\right)$

$V \quad$ Volume $\left(\mathrm{m}^{3}\right)$

$w \quad$ Width (m) or Probability

Density Fraction

$\dot{w} \quad$ Rate of Work done (W/kg)

$\dot{W} \quad$ Rate of Work done (W)

$x \quad \mathrm{x}$ Cartesian Coordinates or Distance (m)

$X \quad$ Vector Containing Design Variables used in Powell's Algorithm for Optimisation

y y Cartesian coordinates

$Y \quad$ Vector Containing Design Variables used in Powell's Algorithm for Optimisation or the Ratio of Sky to Diffuse Radiation

z Depth (m)

\section{GREEK SYMBOLS:}

$\alpha \quad$ Angle (degrees), Absorptivity or Thermal Diffusivity $\left(\mathrm{m}^{2} / \mathrm{s}\right)$

$\alpha^{*} \quad$ Scalar Value used in the Golden Section One Dimensional Procedure

$\beta \quad$ Angle (degrees), Solar Altitude or Coefficient of Thermal Expansion $\left(\mathrm{K}^{-1}\right)$

$\gamma \quad$ Specific Weight $\left(\mathrm{N} / \mathrm{m}^{3}\right)$ or Surface to Solar Azimuth

$\Delta \quad$ Differential

$\delta \quad$ Solar Declination

$\varepsilon \quad$ Emissivity

$\eta \quad$ Efficiency (\%)

$\theta \quad$ Angle (radians or degrees) or Sensitivity Index $\lambda$ Constant Characteristic of the Rosin Rammler Function

$\mu \quad$ Dynamic Viscosity $(\mathrm{kg} / \mathrm{ms})$

$v \quad$ Kinematic Viscosity $\left(\mathrm{m}^{2} / \mathrm{s}\right)$ or Degrees of Freedom

$\pi \quad$ Pi Constant (3.142857)

$\rho \quad$ Density $\left(\mathrm{kg} / \mathrm{m}^{3}\right)$ or Reflectivity

$\sigma \quad$ Stefan-Boltzmann constant $\left(5.67 \times 10^{-8} \mathrm{~W} / \mathrm{m}^{2} \mathrm{k}^{4}\right)$

$\Sigma \quad$ Tilt Angle (degrees)

$\tau \quad$ Transmissivity or Shear Stress $\left(\mathrm{N} / \mathrm{m}^{2}\right)$

$\phi \quad$ Humidity (\%) or Solar Azimuth

$\psi \quad$ Surface Azimuth

$\omega \quad$ Humidity Ratio

d Partial Derivative 
SUB- AND SUPERSCRIPTS:

\begin{tabular}{|c|c|c|c|}
\hline$a$ & Air & $\min$ & Minute \\
\hline$a c t$ & Actual & $m s d$ & Measured \\
\hline$a m b$ & Ambient & $M$ & Number of control volumes \\
\hline avg & Average & & in the wall \\
\hline$b$ & Beam & $n$ & Exponent or Integer for \\
\hline build & Building & & $\begin{array}{l}\text { counting time increments } \\
\text { or units }\end{array}$ \\
\hline$B$ & Bias & $\hat{n}$ & Scalar Value \\
\hline$c$ & Critical or Correlation & new & New \\
\hline$c l$ & Cooling Load & $n h$ & Nozzle Height \\
\hline cond & Condensation & $N$ & Natural or Northern \\
\hline $\operatorname{conv}$ & Convection & $o$ & Out, Outer or Overall \\
\hline$c s$ & Control Surface & old & Old \\
\hline$c v$ & Control Volume & $p$ & Projected, Pump, Pressure \\
\hline$d$ & Diffuse, Droplet or Drag & & or People \\
\hline$d p$ & Dew Point & $p k$ & Peak \\
\hline$D$ & Characteristic Diameter & $P$ & Precision \\
\hline$D N$ & Direct Normal & $r$ & Resultant or Reflectivity \\
\hline$e$ & Equipment & $\mathrm{rad}$ & Radiation \\
\hline evap & Evaporation & $r c$ & Roof cooling \\
\hline$E$ & Eastern or Energy & rel & Relative \\
\hline$f$ & Fluid or Film & $\mathrm{rm}$ & Room \\
\hline$f l$ & Floor & $r p$ & Roof-pond \\
\hline$F$ & Forced & $r s$ & Roof slab \\
\hline$g$ & Gas or Ground & $R R$ & Rosin Rammler \\
\hline grav & Gravity & $s$ & Surface or Slab \\
\hline$h$ & Heat or Hour & sat & Saturated \\
\hline$i$ & Node index, In, Inner or & $s b w$ & Single Brick Wall \\
\hline & Instantaneous & sed & Sedimentation \\
\hline if & Infiltration & shaft & Shaft \\
\hline$i i$ & Integer for counting the number & sky & Sky \\
\hline & $\begin{array}{l}\text { of droplets in the Rosin Rammler } \\
\text { distribution }\end{array}$ & sn & Spray Nozzle \\
\hline$i n i$ & Initial & solar & Solar \\
\hline$l$ & Length or Lighting & spray & Spray \\
\hline lost & Lost & $s t$ & Storage Tank \\
\hline$L$ & Characteristic Length & sur & Surrounding \\
\hline$m$ & Make-up or Mean & sys & System \\
\hline
\end{tabular}




$\begin{array}{ll}S & \text { Southern } \\ t & \text { temperature } \\ \text { tot } & \text { Total } \\ t r & \text { Transmission } \\ T & \text { Temperature } \\ v & \text { Volume or Degrees of } \\ & \text { Freedom } \\ v a p & \text { Vapour }\end{array}$

\section{ABBREVIATIONS:}

$A C H \quad$ Air Changes per Hour (\#)

$A C P D$ Air Changes per Day (\#)

$A M C$ Active Mass Cooling

AST Apparent Solar Time

$B C \quad$ Base Case

IAC Inside Shading Attenuation

Coefficient

LON Local Longitude

LSM Local Standard Meridian

LST Local Standard Time

$N F \quad$ Night Flushing

NSC Nozzle Spray Coefficient

$R P \quad$ Roof-pond

$R R \quad$ Rosin Rammler

$R S \quad$ Roof-spray

$R T F \quad$ Radiant Time Factor

SHGC Solar Heat Gain Coefficient

$V C \quad$ Very Coarse

$V F \quad$ Very Fine

$V M D \quad$ Volume Mean Diameter $(\mu \mathrm{m})$

$X C \quad$ Extra Coarse

$\begin{array}{ll}w & \text { Water or Wind } \\ w d & \text { Window } \\ w l & \text { Wall } \\ W & \text { Western } \\ x & \text { Reference to the Horizontal } \\ & \text { Axis } \\ y & \text { Reference to the Vertical Axis }\end{array}$

w Water or Wind

wd Window

$w l \quad$ Wall

$W \quad$ Western

Reference to the Vertical Axis 


\section{INTRODUCTION}

The worldwide movement to sustainability and renewable energy is fuelled by rising energy costs and the belief that the current levels of green house gas emissions are causing global warming and climate change. Climate change is widely considered the most critical humanmade environmental problem (Seed Urban, 2002). The Kyoto Protocol to the United Nations Framework Convention of Climate Change is an international agreement that sets binding targets for 27 industrialised countries for reducing greenhouse gas emissions (UNFCCC, 2009). Countries that ratified are obliged to reduce their green house gas emissions by at least 5\% below their 1990 levels in the time period 2008 to 2012. South Africa also ratified to this protocol.

In South Africa electricity usage is directly linked to $\mathrm{CO}_{2}$ production as almost all electricity is generated by coal-burning power stations. If the energy usage of a building is optimised, electricity usage is lowered resulting in reduced $\mathrm{CO}_{2}$ emissions at the power stations. This makes optimal usage of energy prevalent in the South African building sector. The Green Building Council of South Africa released the Green Star SA-Office rating tool in November 2008 (GBCSA, 2009). One of the objectives of the star rating is to promote integrated, whole-building design and raise awareness of green building benefits in South Africa.

It is estimated that a third of the world's energy is consumed in the production and operation of buildings (WBCSD, 2009). Air conditioning accounts for approximately $50 \%$ of the total energy consumed by buildings (Grobler, 2002). The energy consumption of air conditioning systems can directly be reduced by minimising the heat gains to buildings (Spoormaker and Kohler, 2002). In South Africa commercial buildings are not operating at their economic and environmental optimum (Grobler, 2002) and it was under this backdrop that the thesis originated.

The thesis was initiated by a consulting engineering company (KV3) as a research project on the subject of air conditioning for green buildings. The Green Building Council of South Africa defines a green building as a building which is energy efficient, resource efficient and environmentally responsible - such a building incorporates design, construction and operational practices that significantly reduce or eliminate its negative impact on the environment and its occupants.

As a consulting engineering company, KV3 Engineers are involved with building projects from the design phase to project completion and handover. In order to construct a green building, green solutions need to be incorporated during the design phase of a building. It is due to this reason that options must be explored in which the intensive usage of energy (by air conditioning systems) in buildings may be lowered. These options would have to reduce the heat gain to buildings and be implemented during design phase of the building's lifecycle. These options will be referred to as sustainable cooling alternatives in the thesis. 


\subsection{Thesis Objectives}

The thesis was initiated by KV3 Engineers with the following objectives;

i. To find and identify sustainable cooling alternatives for buildings. Sustainable cooling alternatives refer to alternative ways to conventional compressor operated air conditioning systems in which comfort levels in buildings may be achieved or building heat gains reduced.

ii. To select three sustainable cooling alternatives based on the level of commercialisation, practicality and suitability of implementation in buildings.

iii. To research the selected sustainable cooling alternatives by carrying out a literature review on each method.

iv. To mathematically model each of the selected sustainable cooling alternatives such that it may be employed in theoretical simulation calculations.

v. To carry out experimental work such that the validity of the mathematical model may be determined by comparing the results from the theoretical simulation calculations to the readings from the experimental work.

vi. To determine the typical peak cooling load reduction that may be achieved from each sustainable cooling alternative.

vii. To determine the sustainable cooling alternative that would reduce the heat gain to a typical building the greatest and provide the most cooling.

\subsection{Sustainable Cooling Alternatives Identified}

The first objective of the thesis is to identify a number of sustainable cooling alternatives to conventional air conditioning systems in buildings. The eight sustainable cooling alternatives identified are explained below. It must be emphasised that these alternatives generally lowers the cooling load of a building and increases comfort levels but does not maintain room temperature to a desired thermostat setting.

i. Active Mass Cooling: The technique, also known as concrete core conditioning or thermo active slabs, involves the cooling of the structural mass of a building such that it acts as a heat sink to reduce heat gains. Cooling of the building structure is achieved by circulating cool water through a pipe network embedded in the building structure (Esmore, 2005)

ii. Roof Cooling System: The technique, also referred as the night sky roof-spray system (Rumsey Engineers, 2001) or a night sky radiation system with a roof-spray, comprise water sprayed above and onto a pond located on the roof of a building. The roof-pond water is cooled by means of night sky radiation (Feustel et al. 1992) while the roof-spray water is primarily cooled through convection and evaporation. During diurnal hours heat gain to the building through the roof is lowered by means of the roof-spray and roof- 
pond system while these systems produce cool water during nocturnal hours. The roofpond and roof-spray systems may also be employed separately to act as a cooling system.

iii. Thermal Chimney for Natural Ventilation: Natural ventilation uses the principle of buoyancy whereby an air pressure difference is created between indoor and outdoor air to induce airflow into a building naturally. Such a pressure difference can be created by a chimney that has a vertical separation between its inlet and outlet (ASHRAE Fundamentals, 2005). Depending on the desired room air temperature, the heat gain may be reduced by the continuous fresh air admitted to building.

iv. Night Flushing: Night flushing is the process whereby a building is flushed with cool ambient air for several hours each night to remove the heat stored in the building mass. This allows the building structure to absorb more heat the following day which results in a reduced room temperature (Artmann et al. 2008).

v. Earth Heat Exchangers: Also referred to as ground couple heat exchanges comprise of a series of tubes laid underground through which air is circulated before being admitted to a building. The ground acts as a heat sink that precools the air (Van Wyk, 2009). The cold air supplied to the building reduces the cooling load on the air conditioning system.

vi. Phase Change Materials: The latent heat of phase change materials may be utilised to increase the thermal storage capacity of building materials. Phase change materials may typically be incorporated in a concrete mixture (Bentz and Turpin, 2007). At room temperature the phase change material would be in solid state. As the room temperature increases the phase change material liquefies while absorbing and storing heat (Toolbase, 2007). The opposite occurs when the temperature drops. The addition of phase change material to a building would flatten the heat gain profile resulting in a reduced air conditioning cooling load.

vii. Desiccant Adsorption Cooling: Adsorption cooling involves a thermo-chemical process of sorption (adsorption) whereby a liquid or gaseous substance is absorbed by a material such as silica gel when heat is added. The concept of adsorption cooling is to dry outside air by means of adsorption before evaporatively cooling the air entering the building (Feustel et al. 1992). The cooling effect of evaporative cooling depends largely on the moisture levels of the air being cooled. The drier the air the more cooling is attained.

viii. Evaporative Cooling with Chimney: A chimney-like cooling tower is attached to a building that scoops the upwind and channels it downwards through a set of evaporative pads. The evaporatively cooled air becomes denser and flows downwards into the building (Chakraborty and Fonseca, 2005). The admission of the cool air reduces the cooling load on the air conditioning system. 


\section{COMMERCIALISATION OF COOLING ALTERNATIVES}

Eight sustainable cooling alternatives have been identified in Chapter 1. The second objective of the thesis requires that three sustainable cooling alternatives be selected based on the level of commercialisation, practicality and suitability of implementation in buildings. Some of these methods have been known for centuries whilst others are fairly immature when it comes to the implementation of these alternatives in commercial buildings. This implies that each of these sustainable cooling alternatives lies on a different level of the commercialisation cycle ${ }^{1}$. The different stages of the commercialisation cycle are explained in Appendix A.

One way to definitely reduce the number of sustainable cooling alternatives is to utilise the degree of commercialisation of the sustainable cooling alternatives as an evaluation criterion. The degree of commercialisation refers to the level of the specific cooling alternative on the commercialisation cycle. In order to determine the degree of commercialisation, a survey was conducted in December 2008. The response of the survey was utilised to determine the degree of commercialisation of the sustainable cooling alternatives. The process of ascertaining the degree of commercialisation from the survey response is explained Appendix A.

\subsection{Degree of Commercialisation}

The degree of commercialisation of each sustainable cooling alternative is be regarded as a justifiable evaluation measure as it embodies the following information

i. The number of successful installations of each green building cooling alternative.

ii. The level of research done on each technology to date.

iii. The suitability of each sustainable cooling technology for building installation.

iv. How well-known the technology is.

The information above is directly related to the level in which the sustainable cooling alternatives are perceived by the industry stakeholders. This means that the more encounters a person has had with the particular sustainable cooling alternative, the higher the likelihood that the technology has been installed or researched.

The degree of commercialisation for the sustainable cooling alternatives was statistically determined in this thesis by surveying a sample population of people in a target population. The target population comprised people in the building industry including builders, architects, engineers, quantity surveyors, etc. Analysis of the sample population gave an estimate of the degree of commercialisation of the target population. Ideally, the best

\footnotetext{
${ }^{1}$ The commercialisation cycle refers to the various stages a product undergoes when developing from a basic concept stage to fully commercialised.
} 
sampling technique for this application is stratified random sampling ${ }^{2}$ but due to the relatively large sample population required simple random sampling ${ }^{3}$ was used.

The survey entailed a questionnaire randomly sent to industry stakeholders. Each question in the questionnaire was structured such that the corresponding answer disclosed clues regarding the position of the sustainable cooling alternative on the commercialisation cycle. The weighting of each question in the survey was determined by a two pair forced decision procedure so that a single value for the degree of commercialisation could be given. Further information on this procedure is given in Appendix A.

\subsection{Survey Results}

The outcome from the survey, shown in figure 2.1, gives the degree of commercialisation of each sustainable cooling alternative relative to the others. The degree of commercialisation of each sustainable cooling alternative is quantified as a percentage with the sum total of all sustainable cooling alternatives equal to $100 \%$.

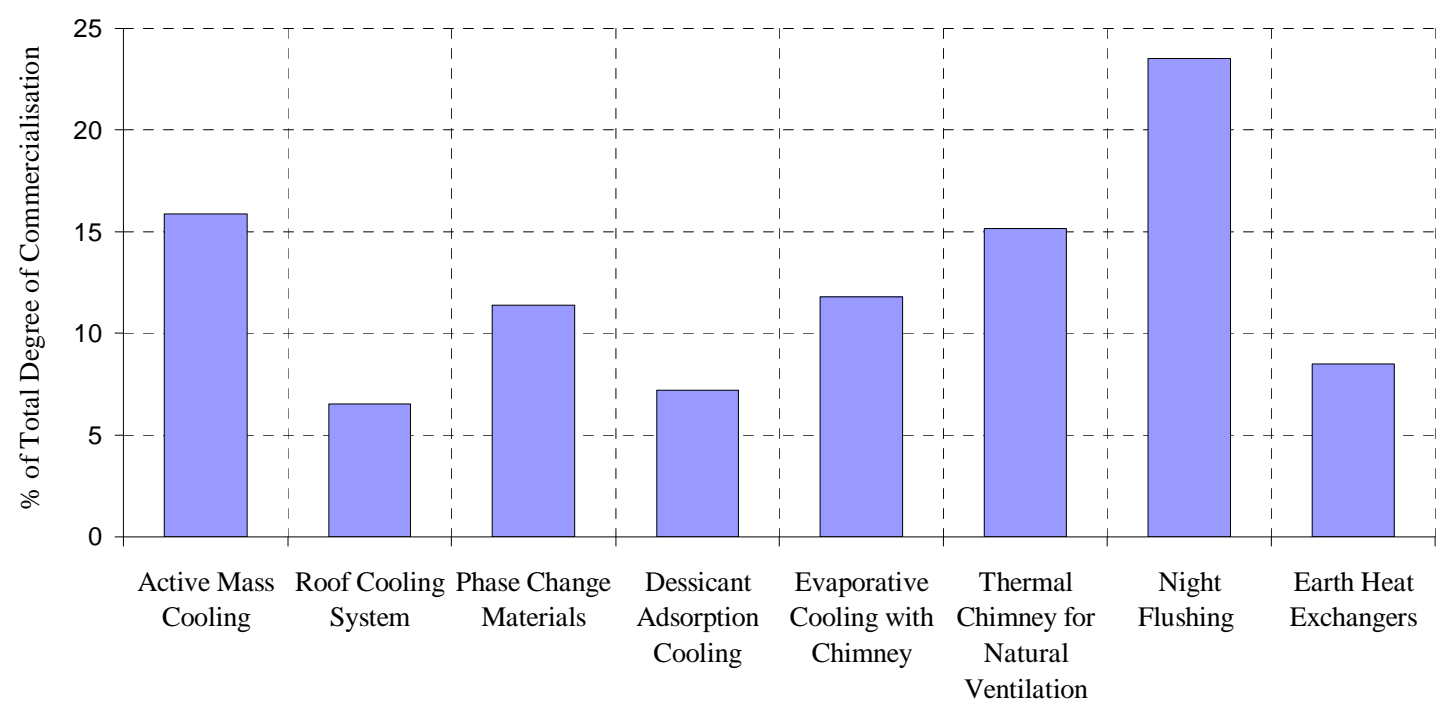

Figure 2.1: Chart Depicting the Degree of Commercialisation of the Sustainable Cooling Alternative Methods Relative to Each Other

The survey results may be explained as follows:

i. Figure 2.1 show that night flushing has the highest degree of commercialisation. This is expected as this technique of lowering the building heat load is widely celebrated in buildings for centuries (Kolokotroni et al. 1998)

\footnotetext{
${ }^{2}$ A stratified random sample is obtained by separating the population into separate category groups and then drawing simple random samples from each group.

${ }^{3}$ A simple random sample is a sample selected in such a way that every possible sample with the same number of observations is equally likely to be chosen.
} 
ii. Active mass cooling also has a relatively high degree of commercialisation with the technology used for several decades in various forms to assist in providing comfort to building occupants (Esmore, 2005)

iii. Many architects make use of natural ventilation to comply with South African Building Regulations 10400 (SABS, 1990). This alleviates the necessity of costly mechanical ventilation systems. Natural ventilation by means of a chimney is not widely utilised due to the large capital outlay of the chimney and building constraints. Survey respondents might have confused the chimney ventilation concept with conventional natural ventilation.

iv. Evaporative coolers are commercially available but employing the technology in an unconventional way with a natural downdraft chimney is not. The relatively high score in commercialisation of this technology can be attributed to respondents confusing the concept with evaporative coolers on the market.

v. The concept of incorporating phase change materials in building materials is welcomed by many respondents but with limited installation references the technology's degree of commercialisation is diminished.

vi. Desiccant adsorption cooling and earth cooling tubes are known by most respondents but the other sustainable cooling methods perceptionally enjoy priority over these.

vii. The roof cooling system that comprises night sky radiative cooling and a roof-spray pond has been installed successfully (Technology Installation Review, 2007). Scoring the lowest in Figure 2.1it seems the technology is commercially not well known.

\subsection{Sustainable Cooling Alternatives Selected}

Since night flushing and active mass cooling showed the highest degree of commercialisation they were selected for further research. The third sustainable cooling alternative selected was the roof cooling system even though it displayed the lowest degree of commercialisation. The roof cooling system was selected due to its promising ability to reduce building cooling load during daytime and produce cool water during the night time. Since the roof cooling system comprised a roof-pond and roof-spray it provided the additional opportunity to investigate the roof-pond and roof-spray system independently.

The three sustainable cooling alternatives selected namely active mass cooling, night flushing and roof cooling system may also be implemented in a building with existing equipment and technology. They also do not constrain a building with a chimney nor do they require expensive earth heat exchangers (Feustal, 1992). They are also suitable for implementation as a combination of systems.

The ability of the three selected sustainable cooling alternatives to provide cooling will be analysed in the thesis. The hypothesis that the combination of these alternatives would yield even better results will be tested. 


\section{LITERATURE STUDY}

In Chapter 2, the three sustainable cooling alternatives that were selected for further research were night flushing, active mass cooling and the roof cooling system. In this Chapter a literature review on these sustainable cooling alternatives is given. A literature review on spray drift is also included due to the essential role it plays on the cooling ability of the roof cooling system. The role of spray drift on the roof cooling system is explained in Chapter 4. Most research papers analyse night flushing, active mass cooling and roof cooling systems independently. In this thesis these sustainable cooling alternatives are not only analysed independently but also compared with each other.

\subsection{Roof Cooling Systems}

The roof cooling system comprises two major components namely the roof-pond and the roof-spray. The concept of a roof-spray and roof-pond system has been reported as an effective method of reducing the solar heat gain in industrial and commercial buildings (Feustel et al. 1992). The first roof-spray system was introduced in Washington, D.C. in 1934 where an irrigation engineer designed and installed a roof-spray system on the roof of a three story apartment building to reduce heat loads in summer months (Abernethy, 1984).

In 1939 the American Society of Heating \& Ventilating Engineers (forerunners of ASHRAE) conducted extensive tests on roof-spray systems. It was found that the roof-spray system could typically reduce peak roof heat load penetration by $87 \%$ and average heat gain penetration by $92 \%$ during the course of the day (Abernethy, 1984). In 1940, Houghten et al. conducted further tests on the cooling produced by a roof-pond and roof water spray system. Houghten et al. (1940) found that both a roof-pond and roof water spray system is highly effective in reducing heat gain to a building. Based on observations by Houghten et al. (1940) and the analysis of Mackey and Wright (1944) the American Society of Heating \& Ventilating Engineers published data in their 1958 Engineers Guide that indicates the effectiveness of reducing building heat flux by using an open pond and roof-spray system (Tiwari et al. 1981).

Jain and Rao (1974) experimentally investigated the effect of a roof-pond, roof-spray and wetted gunny bags on the temperature and heat flow at the ceiling surface of air conditioned and non air conditioned rooms. The experiments were carried out on four identical full sized $(3.5 \times 2.9 \times 3.2 \mathrm{~m})$ test rooms in hot sunny ambient conditions. The roof-spray proved to reduce the peak roof temperature from 55 to $28^{\circ} \mathrm{C}$ while the roof-pond could only reduce the peak roof temperature from 55 to $32^{\circ} \mathrm{C}$.

Jain (2006) presented thermal models for solar passive systems to lower the heat flux entering through the roof of a building. The bare roof, insulation beneath the roof, wetted roof surface and roof-pond with movable insulation were analysed for a typical summers day in India. The results from thermal models by Jain exhibited a peak roof temperature reduction from 63 to $30^{\circ} \mathrm{C}$ when the roof was continuously wetted with water. This gives good agreement with the peak roof temperature reduction found by Jain and Rao (1974). Sutton (1950) found similar roof temperature reductions. Sutton's observations show that the surface 
temperature can be reduced from 65.6 to $39.4^{\circ} \mathrm{C}$ by maintaining an open roof-pond depth of $150 \mathrm{~mm}$.

Chandra et al. (1985) conducted a periodic heat transfer analysis to predict the dynamic behaviour of a non-air-conditioned building with evaporative cooling systems over the roof. The three types of evaporative cooling systems considered were open roof-pond, a moving water layer over the roof and water spray over the roof. From the analysis it was found that the maximum cooling was achieved by the water spray system on the roof. This corresponds to what was found by Jain and Rao (1974) who concluded that the roof-spray would reduce roof temperature further.

Both Holder (1957) and Thappen (1943) pointed out that the air conditioning load can be reduced by $25 \%$ by the application of a roof-spray system. Sodha et al. (1980:1) theoretically analysed the reduction of the heat flux entering a room through a roof with an open water pond. It is claimed that the roof-pond reduces the peak heat flux entering a room by $48 \%$ compared to the $41 \%$ achieved by a water spray system for a relative humidity of $80 \%$. The disagreement to that found by Jain and Rao (1974) may be ascribed to the high relative humidity under which the calculations by Sodha et al (1980:1) were performed. A 48\% peak heat flux reduction would give a $24 \%$ air conditioning load reduction when considering that the roof contributes to $50 \%$ of the total building heat load (Jain, 2006). The reduction compares favourably with the $25 \%$ cooling load reduction as reported by Holder and Thappen.

Kharrufa and Adil (2006) gives a similar cooling load reduction, in the order of $30 \%$, to that found by Holder and Thappen. The experimental tests were performed on a 4 x 7 m single room building with a mechanical ventilated roof-pond and Styrofoam cover. When mechanically ventilated, the roof temperature dropped by approximately $10{ }^{\circ} \mathrm{C}$ and the interior room temperature by about $1{ }^{\circ} \mathrm{C}$.

Sodha et al. (1980:2) investigated the reduction of the heat flux caused by the flow of water over an insulated roof. It was concluded that flowing water was more effective than a roofpond system and to some extent more effective than a water film spray system. Dan and Chinappa (1989) conducted an experiment where preheated water at 35 to $40{ }^{\circ} \mathrm{C}$ was trickled over the cover glass of a solar collector exposed to the night sky. Measurements show that the water can be cooled down overnight within a couple of degrees of the diurnal minimum. The minimum temperature to which water can be cooled overnight will experimentally be tested and verified in this study.

Dobson (2005) analysed a night sky radiation system that cools water and stores the water in a tank for usage the following day. The stored water is used by a radiator panel to cool a room during daytime. The thermal model derived by Dobson was applied to a room situated in the Namib Desert, Gobabed, Namibia. The results from the analysis indicated that the room temperature could be kept below $25^{\circ} \mathrm{C}$.

In a design report by Rumsey Engineers Inc. (2001) the concept of using a combination of roof-spray and roof-pond systems to produce chilled water is described. The system cools water during nocturnal hours through night sky radiative and evaporative cooling. The cool 
water is stored for cooling application the following day. Further reference to the concept of cooling water during nocturnal hours by both roof-spray and roof-pond is made by Givoni (1991).

The roof temperature and building cooling load reduction reported in literature for the roof cooling system will be tested and verified in this study.

\subsubsection{Spray Drift}

As will be shown in Chapter 4, spray drift is detrimental to the performance of the roof cooling system. It is therefore imperative that spray drift be modelled as accurately as possible such that its effect may be properly accounted for. Most spray drift research work applies to the agricultural industry where spray drift causes pesticides from agricultural crop sprayers to be transported out of the target area by the action of wind forces. Nonetheless, the mechanism under which spray drift occurs remain the same when applied to the roof cooling system.

Miller (1993) discusses spray drift and the wide range of passive collection surfaces that have been used to collect samples of drifting spray droplets. Southcombe et al. (1997) introduces the concept of a drift potential factor as an additional category for measuring spray quality of spray nozzles. Holterman et al. (1997) describes the modelling of spray drift from boom sprayers and in 1998 developed a random-walk model, IDEFICS, to describe downwind spray deposits from conventional boom sprayers. Holterman et al. (1998) concludes that boom height, wind speed and nozzle type are the major factors affecting spray drift.

Experimental work by Van de Zande et al. (undated a) shows that nozzles from different manufacturers, alternative designs and construction materials have different drift performances despite having the same reference specification. Miller (2003) reviews the methods that may be followed to measure spray drift and the factors that influence the level of spray drift. Holterman (2003) provides a report that deals with the theory of both kinetic and evaporative aspects of in-flight water drops.

A number of spray drift models exist that can be employed to predict the movement of water droplets under the influence of wind forces (Southcombe et al. 1997). The United States Environmental Protection Agency and the United States Department of Agriculture have developed AgDrift ${ }^{\circledR}$ to estimate drift from spray applications (Hewitt, 2001). The model predicts pesticide movements and deposition by using spray parameters from the application and weather conditions. An important input variable to the model is the droplet size distribution spectrum. Another model, IDEFICS, developed in the Netherlands simulates spray drift by calculating the amount of pesticide or water deposition on a surface area situated downwind ${ }^{1}$ from the targeted crop area (Holterman et al. 1998).

\footnotetext{
${ }^{1}$ Downwind: The term downwind is used since water spray droplets drifts away from the target crop area coincident with the prevailing wind.
} 


\subsection{Night Flushing}

Geros et al. (1990) reported that the cooling efficiency of night flushing is mainly dependent on the air flow rate, the thermal capacity of the building structure and the efficient coupling of air flow and thermal mass. Pfafferott et al. (2003) also emphasized that air flow rate, heat transfer rates and heat storage are the crucial factors in modelling night ventilation efficiency.

Pfafferott et al. (2003), Geros et al. (1999) and Artmann et al. (2008) quantified the performance of the night flushing technique by calculating the number of hours certain indoor thermal comfort conditions exceed an acceptable operative room temperature. The acceptable operative temperature for people in typical summer months is in the temperature range 23 to $27{ }^{\circ} \mathrm{C}$ (ASHRAE Fundamentals, 2005). Artmann et al. (2008) reports that according to the German norm, it is acceptable to have an operative room temperature above $26^{\circ} \mathrm{C}$ for a maximum of $10 \%$ of the total working hours.

Pfafferott et al. (2004) evaluated monitored room data of 12 office rooms of a low energy office building in Germany, named the "DB Netz AG in Hamm". A detailed simulation, based on the monitored room data, of the building was performed to ascertain the possibility of improved ventilation strategies. Geros et al. (1999) showed through full scale experimental work on a full scale office building in Athens that the average overheating hours could be reduced from 1253 to 615 by the application of night ventilation at a rate of $30 \mathrm{ACH}^{2}$.

Artmann et al. (2008) quantified the performance of the night flushing technique by means of overheating degree hours. The overheating degree hours are defined as the number of hours during which the temperature exceeds $26{ }^{\circ} \mathrm{C}$, weighted by degrees by which $26{ }^{\circ} \mathrm{C}$ is exceeded. Artmann et al. (2008) simulated the operative room temperature of a typical office room for climatic conditions in Europe based on Meteonorm 10 year maximum data. The office room volume was $52 \mathrm{~m}^{3}$ with a high peak internal heat gain of $35 \mathrm{~W} / \mathrm{m}^{2}$ and a medium level thermal mass. The overheating degree hours above $26^{\circ} \mathrm{C}$ for Zurich, London and Paris were $79 \mathrm{Kh} / \mathrm{a}, 90 \mathrm{Kh} / \mathrm{a}$ and $434 \mathrm{Kh} / \mathrm{a}$ respectively when night ventilation was applied between $7 \mathrm{pm}$ and 7 am at 6 air changes per hour $(\mathrm{ACH})$.

Artmann et al. (2008) also evaluated the effect of the air change rate on the effectiveness of the night flushing technique. It was found that the average overheating hours above $26^{\circ} \mathrm{C}$ were reduced from $466 \mathrm{Kh} / \mathrm{a}$ to $138 \mathrm{Kh} / \mathrm{a}$ when the air change rate was increased from 2 to 8 $\mathrm{ACH}$ in a building with medium internal heat gains. For an office building with high heat gains and thermal mass the overheating hours were reduced from $419 \mathrm{Kh} / \mathrm{a}$ to $32 \mathrm{Kh} / \mathrm{a}$ for a 2 to $8 \mathrm{ACH}$ increase. This agrees with the analysis by Finn et al. (2007) who found that thermal comfort levels where significantly increased for air change rates of 4 to $10 \mathrm{ACH}$ with no significant improvement found beyond $10 \mathrm{ACH}$.

In Artmann's evaluation (2008) of air change rates it was found that the night ventilation air change rate had to be increased from 8 to $32 \mathrm{ACH}$ to yield a reduction of 100 overheating hours of a low-weight office with high internal heat gains. A further increase in the air change rate did not produce a significant heat load reduction. The light to medium weight building

\footnotetext{
${ }^{2}$ ACH: Air Changes per Hour
} 
Blondeau et al. (1997) showed through experimental and simulation models that night flushing can provide cooling up to $25 \mathrm{~W} / \mathrm{m}^{2}$ and that the cooling capacity for a setpoint of $26{ }^{\circ} \mathrm{C}$ could be halved. Geros et al. (1999) showed that the peak indoor temperature of an office building could be reduced by $3{ }^{\circ} \mathrm{C}$. In this thesis, the reduction in peak heat gain to a building as well as the peak room temperature will be evaluated. The effect of different air change rates will also be investigated.

\subsection{Active Mass Cooling}

In order to maintain thermal comfort and a constant temperature within a building it is necessary to offset heat gains immediately after heat entry or when generated. This leads to oversized cooling equipment resulting in additional energy costs (Corgnati and Kindinis, 2007). If the building mass can be activated to act as a heat sink, peak heat gains can be reduced and better and more uniform thermal comfort levels may be achieved.

Corgnati and Kindinis (2007) report that the mass structure plays an essential role in the thermal response of a building. Lehmann et al. (2007) reports that building elements such as structural floors and slabs serve as energy storage whose dynamic thermal behaviour can be exploited to provide either cooling or heating. The higher the thermal mass the smaller the indoor temperature swing and vice versa. The importance of building thermal mass is further highlighted by Givoni (1998) who noted that the effect of night ventilation is very effective for buildings with high thermal mass but not for those buildings with a low thermal mass. Lehmann et al. (2007) noted that the use of the building's thermal mass serves to flatten out peaks in energy demand.

Corgnati and Kindinis (2007) reports that one of the more profitable systems to activate building thermal mass is night cooling by means of natural, forced or hybrid ventilation. Ruud et al. (1990) showed that cooling energy supplied for an office building could be reduced by $18 \%$ by pre-cooling the building at night with forced ventilation and utilising the building's thermal storage as a heat sink. Another way to activate the thermal mass of the building is to make use of hollow core slab cooling in combination with night ventilation. With this concept ventilation air is first circulated through the hollow cores of the slab before entering the room (Corgnati and Kindinis, 2007)

The thermal surfaces of the building structure constantly absorb energy from the heat gained by the room and the thermal energy capacity of the building structure is increased. During night time the energy contained in the building structure may be removed and transferred to the night ventilation air by utilising the night flushing technique. As an alternative to night flushing both Lehmann et al. (2007) and Koschenz and Dorer (1999) utilises water as a medium to which building mass energy is rejected. The water flows through a pipe network embedded in the floor or roof slab of the building.

Tian and Love (2009) utilises the concept of embedded pipes installed in a slab as a radiant system to condition indoor space. ASHRAE, Systems and Applications, defines a radiant system as a system that provides $50 \%$ or more of the heat transfer through radiation. Tian and Love (2009) conclude in their paper that radiant slab cooling is well suited for building envelopes with low heat gains. Stetiu (1999) reports that humidity control is essential to 
avoid condensation on the radiant surface in buildings that are conditioned by radiant cooling systems. In Europe, cooling water at temperatures between 18 and $20{ }^{\circ} \mathrm{C}$ supplied to radiant system would not lead to condensation of moisture from air (Vangtook and Chirarattananon, 2007).

Another concept found in literature is that of chilled beams. Similar to the slab with embedded pipes, the chilled beam also has a set of embedded pipes that chills the beam. The chilled beam then provides cooling via displacement ventilation (Fredriksson and Sandberg, 2008). The chilled beam constitutes a small part of the building structural mass and is rather seen as a ceiling-mounted cooling device as described by Fredriksson and Sandberg.

In this study the active mass cooling concept of embedded pipes through which water flows will be further investigated. 


\section{MATHEMATICAL MODELLING OF THE ROOF COOLING SYSTEM}

The mathematical model required for the simulation of the roof cooling system is derived in this section. In addition to the conservation equation applied to the relevant control volumes, the model also incorporates the effect of spray drift as well as a drop size distribution function for the roof spray. An optimisation procedure is followed to ascertain the best possible input parameters for the maximum cooling effect under specified ambient and system conditions. A numerical simulation algorithm is also presented.

\subsection{Control Volumes and Conservation Equations}

Control volumes were created around the components in the roof cooling system where a noticeable change in internal energy occurs. These components are the roof-pond, the roofspray water droplet, the storage volume and the centrifugal pump. These control volumes are depicted in figure 4.1 .

Water is pumped from the storage tank to a set of spray nozzles on the roof to create the roofspray. The water is collected on the roof forming the pond and is gravity fed back to the storage tank. The storage tank is supplied with make-up water to compensate for water loss through evaporation and spray drift ${ }^{1}$.

During nocturnal hours, when the solar radiation incident on the roof-pond is zero, water is pumped from the storage tank through the spray nozzles to the roof-pond. With this scenario the water in the roof cooling system is cooled by means of night sky radiation as well as the evaporation and convection heat losses from both the sprayed droplets and roof-pond. At the start of the day the roof-pond and storage tank water is cooled down. As the intensity of the incident solar radiation increases the roof-pond water starts to heat up. To prevent the storage tank from also gaining heat, water is short circuited and the storage tank is bypassed. Water from the roof-pond is however still continuously sprayed under this situation such that evaporation cooling effect of the spray droplets can be taken into consideration. This concept is illustrated in figure 4.1

\footnotetext{
${ }^{1}$ Miller (2003) defines spray drift as that portion of the spray output that is deflected out of the target area by the action of wind and that spray drift loss may either be in the form of vapour or droplets.
} 


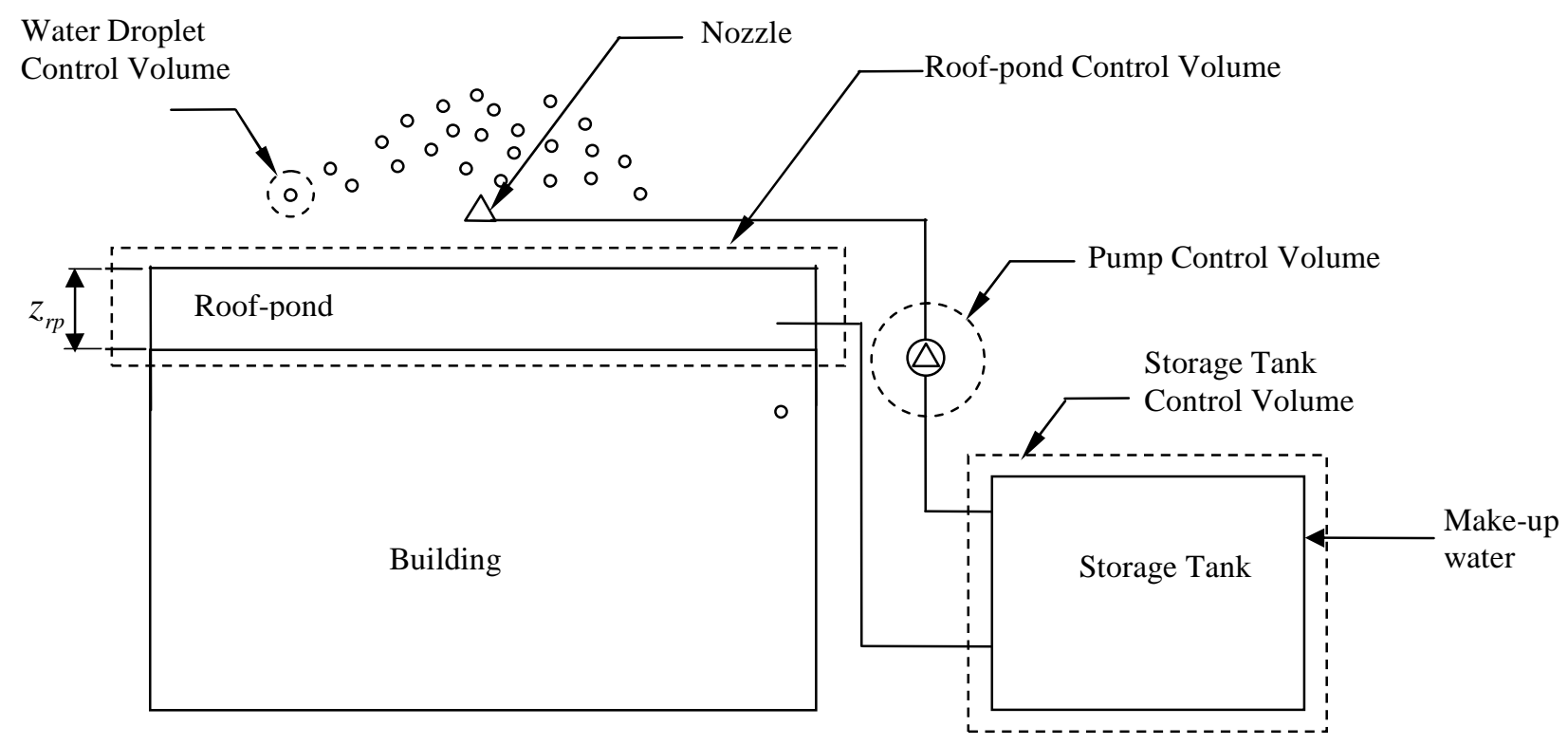

Figure 4.1: Roof Cooling System with the Relevant Control Volumes

\subsubsection{Assumptions}

The following assumptions are made in the derivation of the conservation equations:

i. The heat loss through the walls of the pipe work between the storage tank, centrifugal pump, roof-pond and spray nozzles is negligible.

ii. The variation in the water droplet size when sprayed from the spray nozzles may statistically be modelled with the Rosin Rammler (Weibull) distribution.

iii. The radiation heat exchange between the water droplets, sky and surrounding surface may be discarded. This is demonstrated to be acceptable by an order of magnitude analysis in Appendix D.

iv. The heat transfer to the fluid in the pump casing is assumed negligible.

v. The mathematical model is performed such that the storage tank casing insulated resulting in negligible heat loss or gain.

In the following sections the conservation energy, momentum and mass equations are applied to the control volumes defined in figure 4.1.

\subsubsection{The Water Droplet Continuity and Momentum Equations}

Figure 4.2 gives the control volume of a water droplet in the spray system. The control volume on the left gives the velocity vectors while the control volume on the right, the forces acting on the water droplet control volume. The wind velocity is denoted by $u_{w}$, the droplet 
velocity vector by $\bar{u}_{d}$ and the droplet velocity relative to the wind velocity by $\bar{u}_{d, \text { rel }}$. The figure on the right shows that the resultant drag force $F_{d}$ is in the opposite direction of $\bar{u}_{d, r e l}$. $F_{g}$ in figure 4.2 denotes the gravitational force acting on the water droplet.
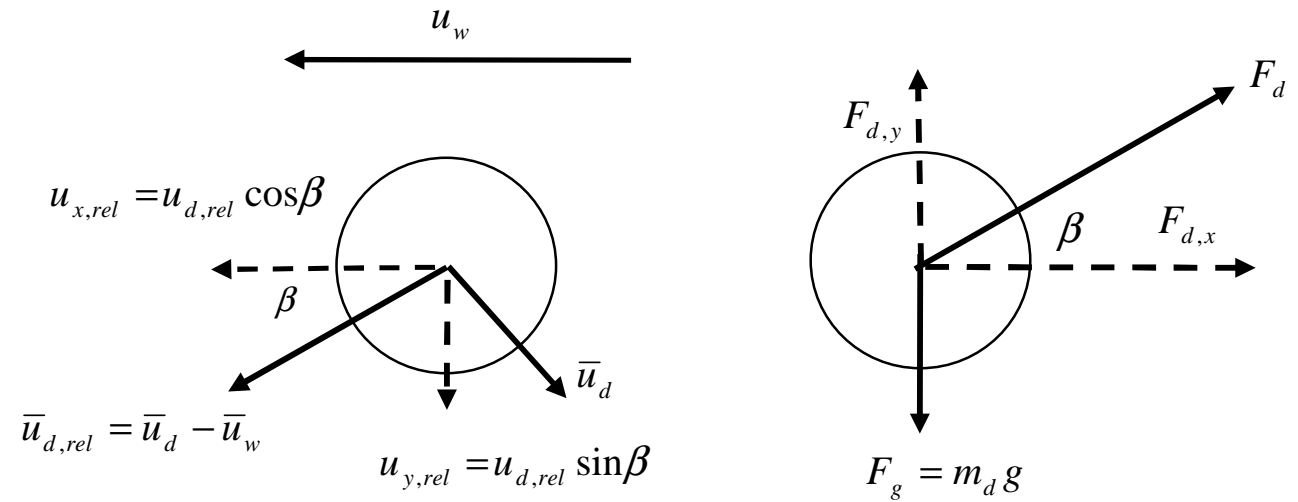

Figure 4.2: Velocity and Force Vectors Acting on the Water Droplet Control Volume

Applying the conservation of mass to the water droplet control volume depicted in figure 4.2 above, gives the continuity equation

$\frac{d m_{d}}{d t}=-\dot{m}_{d, \text { evap }}+\dot{m}_{d, \text { cond }}$

where $m_{d}$ denotes the mass of a single water droplet, $\dot{m}_{d, \text { evap }}$ the rate of water evaporation and $\dot{m}_{d, \text { cond }}$ the rate of condensation. It must be noted that evaporation and condensation will not occur simultaneously and one of the terms on the right hand side of equation 4.1 will be zero. Applying the conservation of momentum to the water droplet control volume gives

$\sum F=\frac{d\left(u_{d} m_{d}\right)}{d t}+\dot{m}_{\text {evap }} u_{o}-\dot{m}_{\text {cond }} u_{i}$

where the term on the left hand side denotes the sum of the forces acting on the water droplet, $u_{d}$ the water droplet velocity, $u_{o}$ the velocity of water evaporating from the droplet surface and $u_{i}$ the water condensation velocity at the droplet surface. Rewriting equation 4.2 in the horizontal plane gives

$\left(m_{d} u_{d, x}\right)^{\text {new }}=\left(m_{d} u_{d, x}\right)^{\text {old }}+\left(F_{d, x} \cos \beta-\dot{m}_{d, \text { evap }} u_{o, x}+\dot{m}_{d, \text { cond }} u_{i, x}\right) \Delta t$

Likewise, rewriting equation 4.2 in the vertical plane gives

$$
\left(m_{d} u_{d, y}\right)^{\text {new }}=\left(m_{d} u_{d, y}\right)^{o l d}+\left(F_{d, y} \sin \beta-F_{g}-\dot{m}_{d, \text { evap }} u_{o, x}+\dot{m}_{d, \text { cond }} u_{i, x}\right) \Delta t
$$


The derivation of equations 4.2 to 4.4 may be found in Appendix C. The calculation of $F_{d}$ is also presented in Appendix C.

\subsubsection{The Water Droplet Energy Equation}

The water droplet control volume with the various energy transfer terms is given in figure 4.3 below. The three applicable heat transfer mechanisms are convection, evaporation and condensation. Notice the absence of any radiation heat transfer terms. An order of magnitude analysis in Appendix D shows that radiation heat exchange between the water droplet, the sky and environment may be neglected.

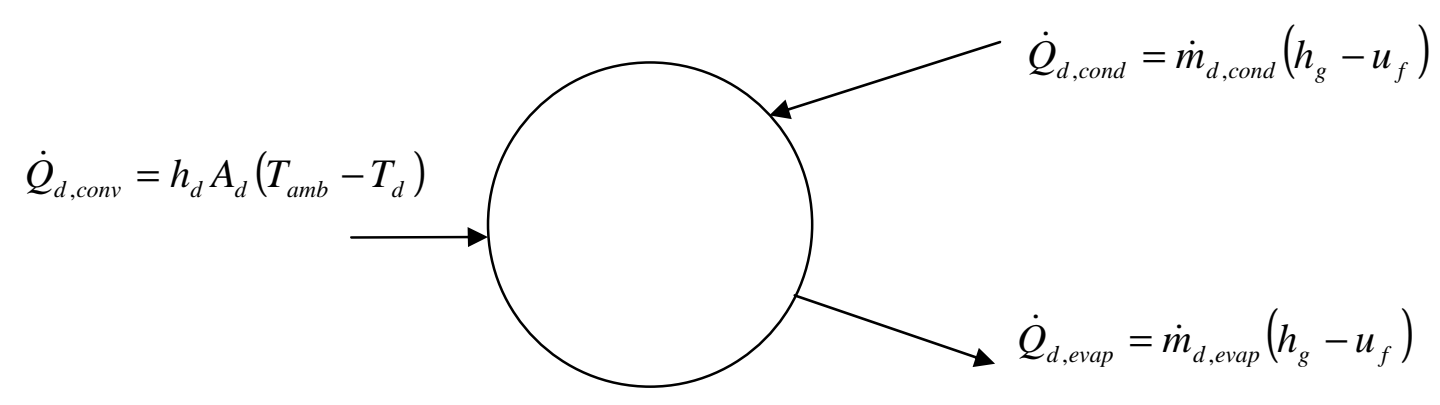

Figure 4.3: Heat Transfer Mechanisms Applicable to the Water Droplet Control Volume Applying the conservation of energy to the water droplet control volume gives

$m_{d} C_{p} \frac{\partial T_{d}}{\partial t}=h_{d} A_{d}\left(T_{a m b}-T_{d}\right)-\dot{m}_{d, \text { evap }}\left(h_{g}-u_{f}\right)+\dot{m}_{d, \text { cond }}\left(h_{g}-u_{f}\right)$

where $C_{p}$ denotes the constant pressure specific heat of water, $h_{d}$ the convection heat transfer coefficient between the droplet surface and ambient air, $T_{a m b}$ the ambient temperature, $T_{d}$ the droplet temperature, $h_{g}$ the enthalpy of water vapour in the ambient air and $u_{f}$ the internal energy of droplet water. The derivation of equation 4.5 is given in Appendix C. The procedure for calculating $h_{d}, \dot{m}_{d, \text { evap }}$ and $\dot{m}_{d, \text { cond }}$ are also given in Appendix C. Discretising the differential term in equation 4.5 and rewriting gives

$T_{d}^{\text {new }}=T_{d}^{\text {old }}+\frac{\Delta t}{m_{d} C_{p}}\left(h_{d} A_{d}\left(T_{a m b}-T_{d}\right)-\dot{m}_{d, \text { evap }}\left(h_{g}-u_{f}\right)+\dot{m}_{d, \text { cond }}\left(h_{g}-u_{f}\right)\right)$

\subsubsection{The Roof-pond Control Volume and Energy Equation}

Figure 4.4 depicts the roof-pond control volume with the various energy transfer modes and energy flows. 


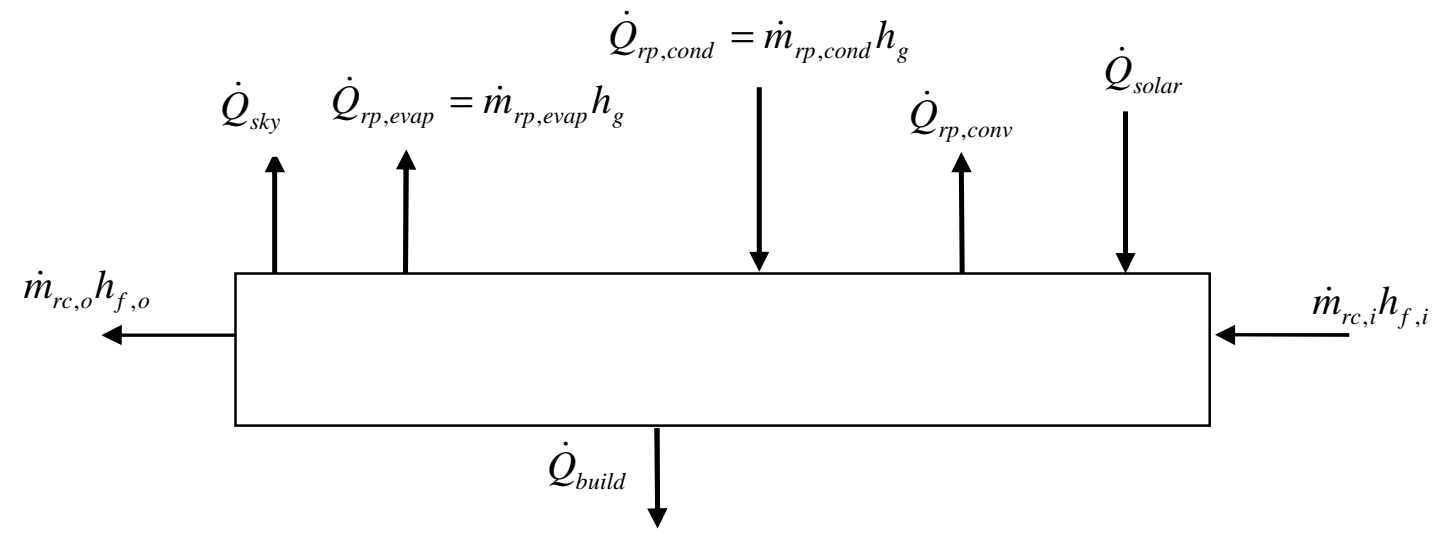

Figure 4.4: Control Volume of the Roof-pond

Applying the conservation of energy to the roof-pond control volume gives

$$
m_{r p} C_{p} \frac{\partial T_{r p}}{\partial t}=\dot{Q}_{s o l a r}-\dot{Q}_{s k y}-\dot{Q}_{b u i l d}-\dot{Q}_{r p, c o n v}+h_{f, i} \dot{m}_{r c, i}-h_{f, o} \dot{m}_{r c, o}+h_{g} \dot{m}_{r p, c o n d}-h_{g} \dot{m}_{r p, e v a p}
$$

where $m_{r p}$ denotes the mass of the water in the roof-pond, $\dot{Q}_{\text {solar }}$ denotes the incident solar radiation absorbed by the roof-pond, $\dot{Q}_{r p, c o n v}$ the convection heat transfer between the ambient air and the roof-pond, $\dot{Q}_{\text {build }}$ the heat transfer from the roof-pond to the roof slab of building below, $\dot{Q}_{s k y}$ the radiation heat exchange between the roof-pond and the sky, $h_{f, i}$ the enthalpy of the water entering the roof-pond, $h_{f, o}$ the enthalpy of the water flowing out of the roof-pond, $\dot{m}_{r c, i}$ the water mass flow rate flowing into the roof-pond, $\dot{m}_{r c, o}$ the water mass flow rate flowing out of the roof-pond, $h_{g}$ the enthalpy of the vapour in the ambient air, $\dot{m}_{r p, c o n d}$ the mass flow rate of water condensing on the roof-pond and $\dot{m}_{r p, e v a p}$ the mass flow rate of the water evaporating from the roof-pond surface. Discretising the differential term and rearranging gives

$T_{r p}^{\text {new }}=T_{r p}^{\text {old }}+\frac{\Delta t}{m_{d} C_{p}}\left(\dot{Q}_{\text {solar }}-\dot{Q}_{s k y}-\dot{Q}_{b u i l d}-\dot{Q}_{r p, c o n v}+h_{f, i} \dot{m}_{r c, i}-h_{f, o} \dot{m}_{r c, o}+h_{g} \dot{m}_{r p, c o n d}-h_{g} \dot{m}_{r p, e v a p}\right)$

The derivation of equation 4.6 and the calculation of the corresponding heat transfer mechanisms are given in Appendix C.

\subsubsection{The Pump Control Volume}

The water flowing through the pump undergoes shearing deformation since the fluid in contact with the solid surface does not slip. Shearing stresses are created and the temperature rises (Hughes et al. 1999). In order to calculate the temperature rise of the water in the pump 
the conservation of energy is applied to a control volume taken across the pump. Figure 4.5 depicts the control volume with the various energy transfer mechanisms.

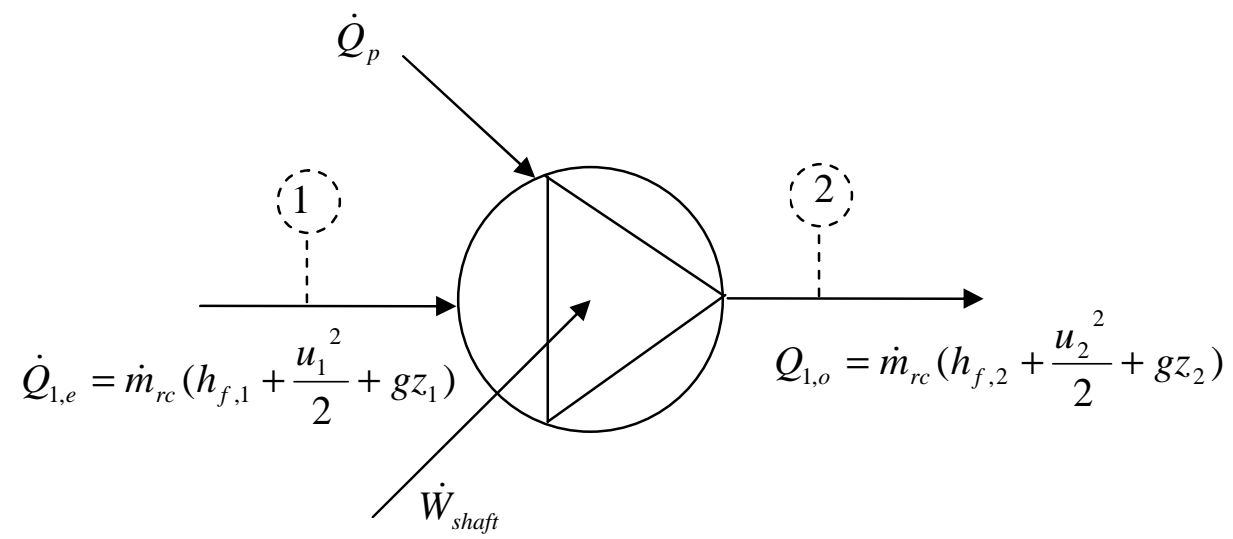

Figure 4.5: Control Volume of the Centrifugal Pump

Applying the conservation of energy to the pump control volume gives

$\frac{\dot{q}_{p}}{\dot{m}_{r c}}+\frac{\dot{w}_{\text {shaft }}}{\dot{m}_{r c}}=\left(h_{f, 2}-h_{f, 1}\right)+\frac{\left(u_{2}^{2}-u_{1}^{2}\right)}{2}+g\left(z_{2}-z_{1}\right)$

where $\dot{q}_{p}$ represents the heat transferred to the pump fluid per unit mass, $\dot{w}_{\text {shaft }}$ the shaft power of the pump, $h_{f, 1}$ the enthalpy of the water flowing into the pump, $h_{f, 2}$ the enthalpy of the water flowing out of the pump, $u_{1}$ the velocity of the water entering the pump, $u_{2}$ the velocity of the water leaving the pump, $z_{1}$ the suction depth and $z_{2}$ discharge depth relative to the same datum line. Since the suction and discharge velocities are approximately equal they are discarded from further simplifications. Similarly the height difference between the suction inlet and discharge outlet of the pump is negligible and this term is discarded. Enthalpy may be expressed as (Cengel \& Boles, 2002)

$$
h_{f}=u_{f}+\frac{p}{\rho_{f}}
$$

where $u_{f}$ denotes the internal energy of the fluid, $p$ the pressure of the fluid and $\rho_{f}$ the density of the fluid. Incorporating the enthalpy relation of equation 4.10 into equation 4.9 and rearranging gives

$\frac{\dot{w}_{\text {shaft }}}{\dot{m}_{r c}}=\left(u_{f, 2}-u_{f, 1}-\dot{q}_{p}\right)+\frac{\left(p_{2}-p_{1}\right)}{\rho_{f}}$

where the first term on the right hand side of equation 4.10 represents the conversion of mechanical energy to thermal energy. According to Sayers (1990) the shaft input power is 
related to the fluid power developed by the pump by means of the pump overall efficiency $\eta_{o}$

$$
\dot{w}_{\text {shaft }}=\frac{H \dot{V} \rho_{f} g}{\eta_{o}}
$$

where $H$ denotes the water head, $\dot{V}$ the water flow rate, $\rho_{f}$ the water density and $g$ the gravitational constant. Rewriting equation 4.12 in terms of pressure and shaft power

$$
\dot{w}_{\text {shaft }}=\frac{\left(p_{2}-p_{1}\right) \dot{m}_{r c}}{\rho_{f} \eta_{o}}
$$

Substituting equation 4.13 into equation 4.11 and rearranging gives

$$
\left(u_{f, 2}-u_{f, 1}-\dot{q}\right)=\frac{\left(1-\eta_{o}\right) \dot{w}_{\text {shaft }}}{\dot{m}_{r c}}
$$

Assuming the heat transfer from the pump casing to the fluid is zero, expressing the change in internal energy in terms of temperature and constant pressure specific heat and rearranging gives

$$
T_{f, 2}=T_{f, 1}+\frac{\left(1-\eta_{o}\right) \dot{w}_{\text {shaft }}}{\dot{m}_{r c} C_{p}}
$$

The temperature rise across the pump may now be calculated from equation 4.15.

\subsubsection{The Storage Tank Volume}

Figure 4.6 depicts the storage tank control volume with the corresponding energy terms

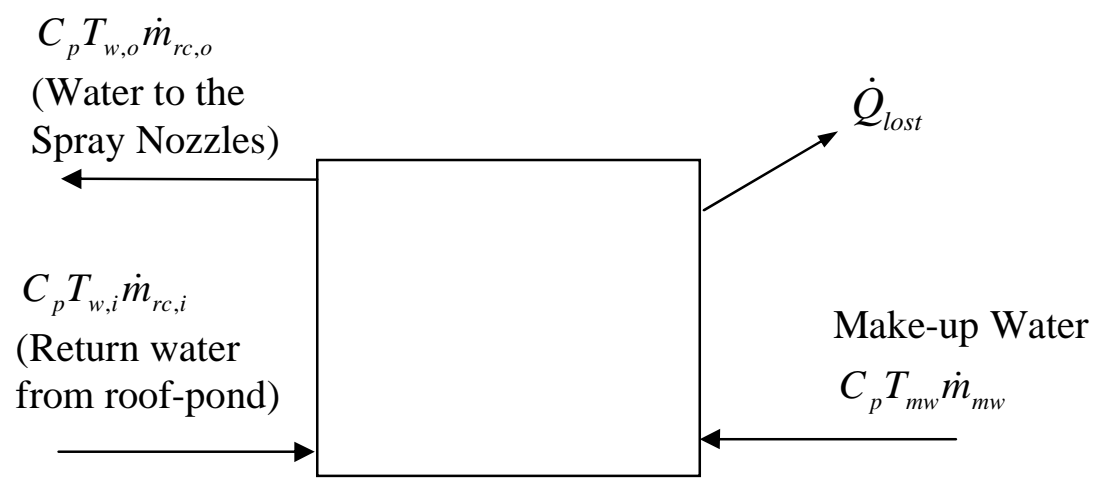

Figure 4.6: Storage Tank Energy Control Volume

The storage tank water volume remains constant as the water loss from spray drift and evaporation is replaced with make-up water. Applying the conservation of energy to the 
water control volume, neglecting the energy loss $\dot{Q}_{\text {lost }}$ through the tank walls and discretising gives the explicit numerical form of the energy equation

$T_{s t}^{\text {new }}=T_{s t}^{\text {old }}+\frac{\Delta t}{m_{s t}}\left(T_{w, i} \dot{m}_{r c, i}+T_{m w} \dot{m}_{m w}-T_{w, o} \dot{m}_{r c, o}\right)$

where $T_{s t}$ denotes the storage tank water temperature, $T_{w, i}$ the temperature of the water flowing into the roof-pond, $T_{m w}$ the temperature of the make-up water, $m_{s t}$ the mass of the water in storage tank, $\dot{m}_{r c, i}$ the mass flow rate of the water entering the tank, $\dot{m}_{m w}$ the mass flow rate of the make-up water and $\dot{m}_{r c, o}$ is the mass flow rate of the water pumped from the tank to the spray nozzles.

\subsection{Droplet Size Distribution}

The water sprayed from the nozzles in the roof-pond system comprises of water droplets of different sizes. The drop size distribution differs in accordance with the size of the nozzle orifice, the shape of the nozzle, the water pressure head and fluid viscosity (Van de Zande et al. undated a). From equation 4.6 it can be seen that the water droplet volume and surface area plays a dominant role in the heat transfer and evaporation rate. Hewitt (2001) reports that spray drift is vastly influenced by drop size since smaller droplets are more likely to be blown away by wind than bigger droplets. To perform an accurate simulation of the roof cooling system and to take the effect of spray drift into consideration, the roof-spray droplets have to be modelled as a size distribution function in lieu of modelling all the sprayed droplets with a single droplet size.

A common droplet classification is the volume median diameter or VMD (Hewitt, 2001). Fifty percent of the total volume or mass of the water sprayed is made up of water droplets with diameters smaller than the $V M D$ and fifty percent of the water droplets larger. Tanner and Knasiak (2003) reports that the $V M D$ cannot be used alone to accurately represent an entire spray distribution. A common droplet distribution function used to represent a spray distribution is the Rosin Rammler function (Schick, undated b) also known as the Weibull distribution. The probability density for this function is given by

$$
f(x, k, \lambda)=\frac{k}{\lambda}\left(\frac{x}{\lambda}\right)^{k-1} \exp ^{-(x / \lambda)^{k}}
$$

where $\lambda$ is constant characteristic of the function such that $63.2 \%$ of the spray droplets are smaller than the constant $\lambda, k$ the shape factor of the distribution and $x$ the value at which the distribution function is evaluated. The ASAE standard S-572 by the American Society of Agricultural Engineers has six categories in which water droplet sizes are classified (ASAE, 1999). The $V M D$, constant characteristic $\lambda$ and the shape factor $k$ for these categories are given in table 4.1 below. 
Table 4.1: Rosin Rammler Characteristics for ASAE Droplet Categories

\begin{tabular}{|l|c|c|c|}
\hline \multicolumn{1}{|c|}{ ASAE Standard Classification } & $\begin{array}{c}\text { VMD } \\
\text { (microns) }\end{array}$ & $\begin{array}{c}\text { Constant } \\
\text { Characteristic } \boldsymbol{\lambda}\end{array}$ & Shape Factor k \\
\hline Very Fine to Fine (VF to F) & 140 & 175 & 1.65 \\
\hline Fine to Medium (F to M) & 240 & 280 & 2.2 \\
\hline Medium to Coarse (M to C) & 340 & 415 & 2.25 \\
\hline Coarse to Very Coarse (C to VC) & 400 & 490 & 2 \\
\hline Very Coarse to Extra Coarse (VC to XC) & 500 & 590 & 2.35 \\
\hline
\end{tabular}

Figure 4.7 depicts the Rosin Rammler probability density function for the six defined droplet categories of the ASAE standard S-572. Figure 4.8 gives the cumulative spray volume for the six droplet categories.

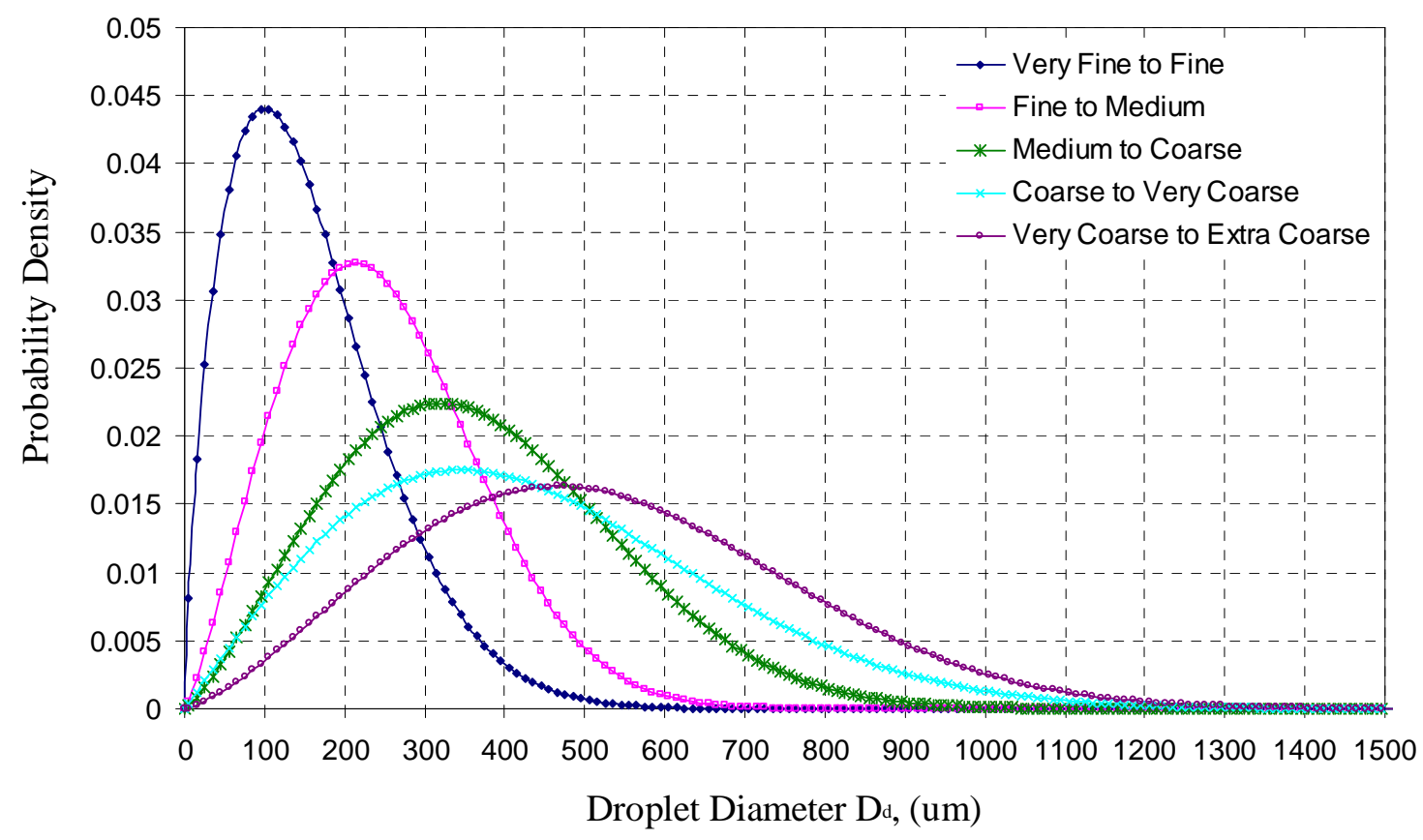

Figure 4.7: Rosin Rammler Probability Density Function for the Six Defined Droplet Categories of ASAE Standard S-572

From figure 4.7 it can be seen that the larger the $V M D$ of the water spray becomes, the closer the Rosin Rammler distribution resembles a normal distribution. For the roof cooling theoretical simulation calculations, droplets classified as extra coarse will be utilised. The matching droplet size distribution in figure 4.7 and the cumulative distribution function in figure 4.8 for extra coarse droplets will be used in the theoretical simulation calculations. 


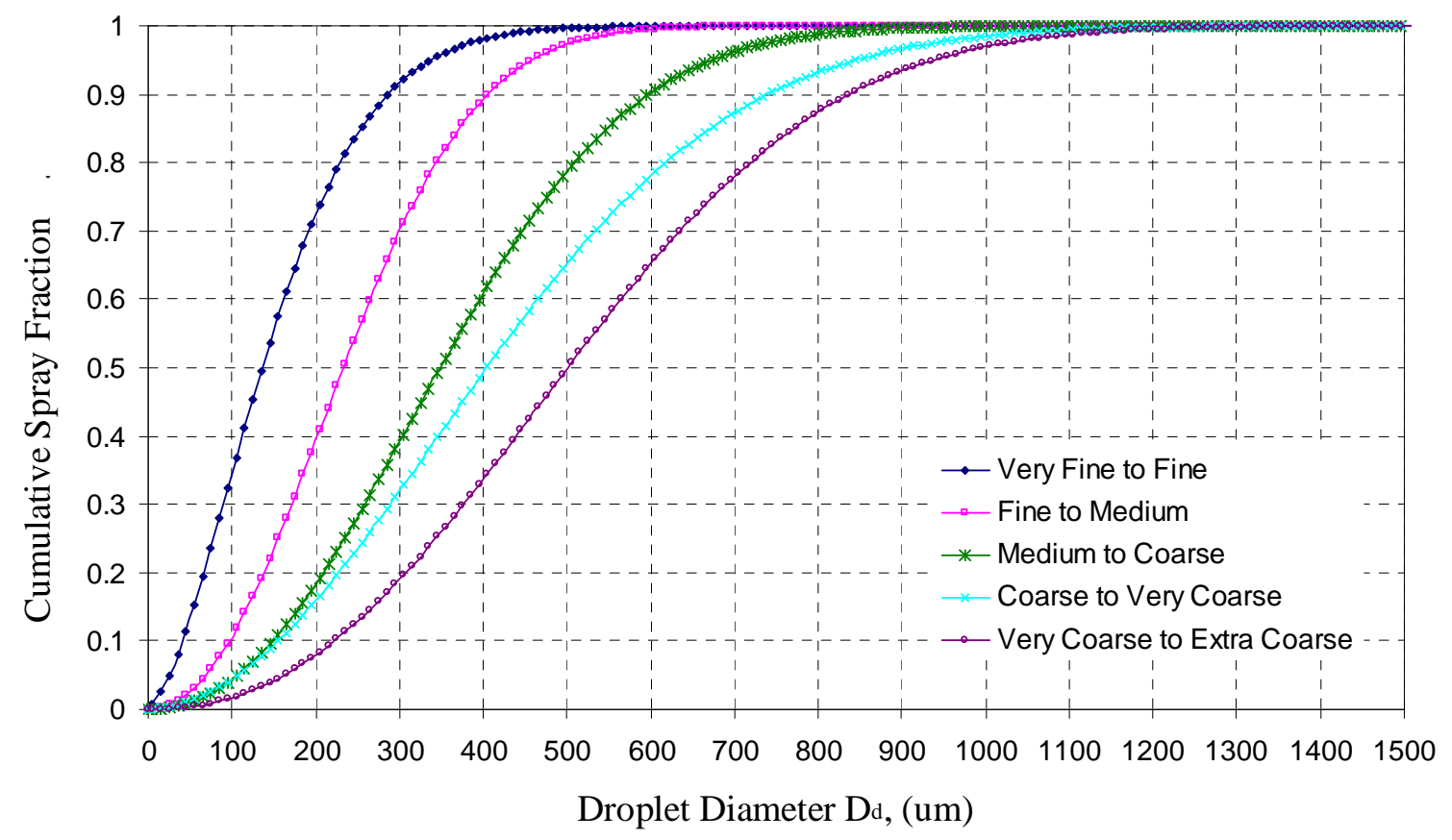

Figure 4.8: Rosin Rammler Cumulative Distribution Function for the Six Defined Droplet Categories of the ASAE Standard S-572

\subsection{Spray Drift}

The water in the roof cooling system is open to the atmosphere resulting in an inevitable water loss from the system to the environment. Sprayed water droplets may not always reach their intended target area due to external wind forces. Water mass is also transferred to the atmosphere through evaporation at the surface area of the water droplets and the roof-pond. Miller (2003) defines spray drift as that portion of the spray output that is deflected out of the target area by the action of wind and that spray drift loss may either be in the form of vapour or droplets.

The roof cooling system, see figure 4.1, has a make-up water tank that continuously replaces the water lost from the system. This means that the make-up water flow rate is equal to the spray drift rate. Generally, the spray drift water temperature would be lower than that of the make-up water which means additional energy is added to the system for every water droplet lost to spray drift. Thus, the less spray drift the more efficient the roof cooling system.

A literature review was conducted in Section 3.1.1 to identify the variables affecting spray drift. Based on the preceding research work and findings the following variables need to be considered in modelling spray drift: wind velocity, height of nozzle above the surface, type of nozzle, ambient air temperature, humidity, atmospheric pressure and droplet size. 


\subsubsection{Modelling Spray Drift in Roof Cooling Systems}

Spray drift may be quantified by measuring spray drift as a percentage of the nozzle output that is deposited or remains airborne at a defined distance downwind of the nozzle (Miller, 2003). In the case of the roof cooling system, any droplet that remains airborne and that is deposited outside the roof-pond surface area due to wind force is considered lost due to spray drift. Figure 4.9 illustrates the spray drift concept by displaying the typical trajectory of a water droplet after projected vertically from a spray nozzle in the presence of a moving air stream.

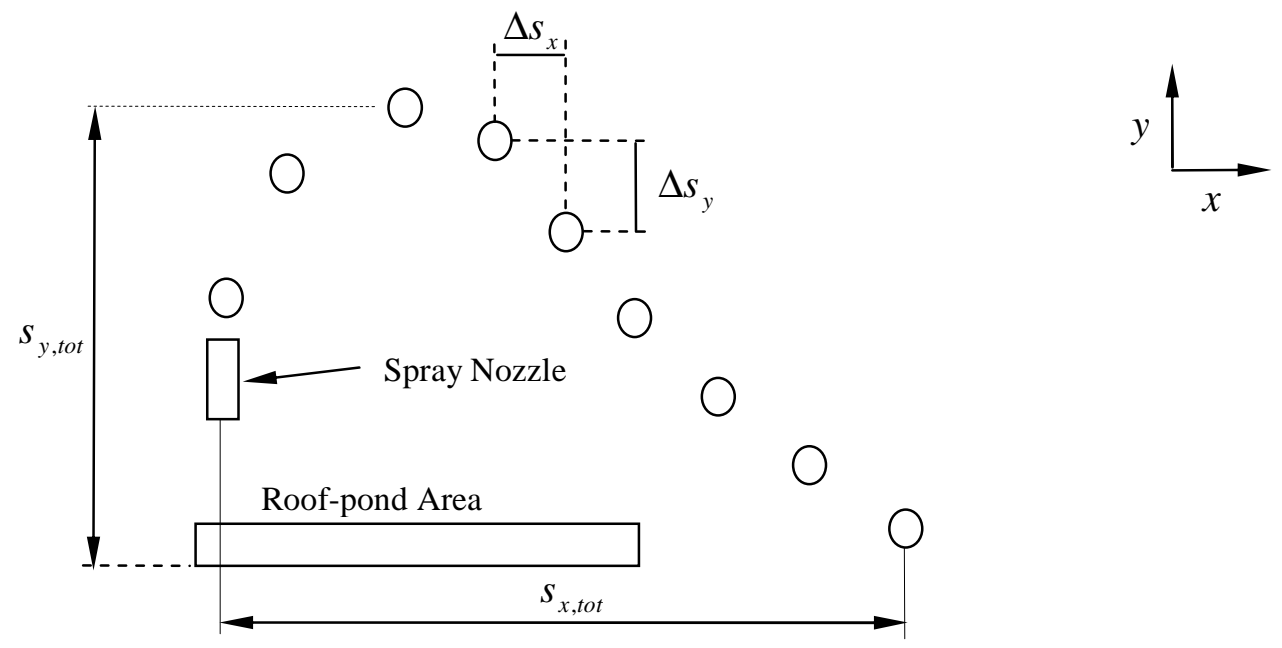

Figure 4.9: Typical Water Droplet Trajectory

Velocity is the time differential of displacement

$u=\frac{d s}{d t}$

where $d s$ denotes the water droplet displacement in the time increment $d t$. Discretising equation 4.18 for two subsequent points in space $\Delta s$ and increment time step $\Delta t$ gives

$\Delta s_{x}=u_{d, x} \Delta t$

and for the horizontal plane

$\Delta s_{y}=u_{d, y} \Delta t$

for the vertical plane. The horizontal and vertical velocity components for each time increment are obtained by dividing the water droplet momentum calculated from equations 4.3 and 4.4 by the droplet mass. The total horizontal displacement $s_{x, t o t}$ is calculated as the sum of the horizontal incremental displacements $\Delta s_{x}$ for the total time the droplet is airborne

$s_{x, t o t}=\sum_{t=0}^{t=t_{t o t}} \Delta s_{x}$ 
Likewise, the total vertical displacement $s_{y, t o t}$ is determined by the sum of the vertical incremental displacements, $\Delta s_{y}$, for the total time the droplet is airborne

$$
s_{y, t o t}=\sum_{t=0}^{t=t_{\text {tot }}} \Delta s_{y}
$$

Where $t_{\text {tot }}$ gives the total time required for the water droplet to travel from the nozzle to the roof-pond water. The total time is calculated by the summation of the vertical distances between the time increments until the distance between the nozzle and ground level is reached. The horizontal displacement $s_{x, t o t}$ reveals whether the droplet has reached targeted catchment area or not. If targeted catchment area is not reached, the droplet is treated as one that has drifted away due to wind forces.

\subsubsection{Trajectory of Water Droplets}

The trajectory of a water droplet denotes the path the droplet follows from the nozzle discharge point to the point where it is deposited on the target area. The trajectory gives the horizontal distance the droplet travels and reveals whether the droplet has reached its intended target area or not. Wind forces may drive droplets away from their intended target area and these droplets are considered lost to spray drift.

The two aspects that affect the trajectory of a water droplet is the stopping distance and sedimentation velocity. Holterman (2003) defines the stopping distance as a measure of the distance a droplet can penetrate into an air stream before its momentum is lost and it moves solely due to the influence of wind and gravity. Sedimentation velocity is that velocity where the stopping distance is reached and the droplet travels at a downward angle at the mercy of wind and gravity. Sedimentation velocity $u_{\text {sed }}$ may be calculated by the following relation (Holterman, 2003)

$$
u_{\text {sed }}=\sqrt{\frac{4 \rho_{d} g D_{d}}{3 \rho_{a m b} C_{d, s e d}}}
$$

where $\rho_{d}$ and $\rho_{a m b}$ are the density of the water droplet and the ambient air respectively, $D_{d}$ the droplet diameter, $g$ the gravitational acceleration constant and $C_{d, s e d}$ the drag coefficient of the droplet at the sedimentation velocity.

Figure 4.10 below illustrates the effect of spray trajectory of various size droplets projected into a horizontal air stream. The graphs in figure 4.10 were generated for droplets sprayed into a moving air stream of $4 \mathrm{~m} / \mathrm{s}$ and droplets with an initial spray velocity of $15 \mathrm{~m} / \mathrm{s}$. The ambient temperature and relative humidity were taken as $285 \mathrm{~K}$ and $58 \%$ respectively. 


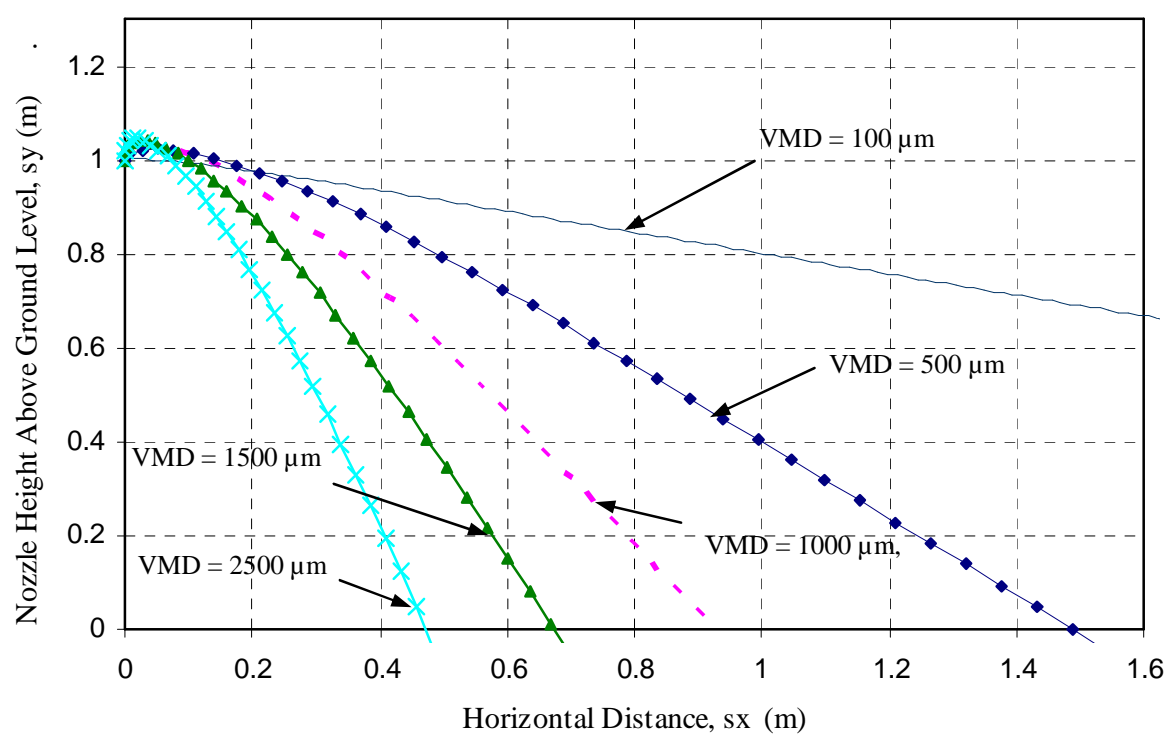

Figure 4.10: Trajectory of Water Droplets with Various VMD's

The following may be concluded from figure 4.10:

i. The larger the droplet size or $V M D$, the higher the vertical projection of the droplet. Since all the droplets in figure 4.10 were given the same initial velocity, the larger droplets had a greater initial momentum resulting in a larger vertical projection.

ii. The larger the droplet, the quicker the droplet turned around to descent. This may be ascribed to the increasing gravity and drag force that accompanies larger droplets.

iii. The smaller the droplet, the more likely the droplet is to float away under wind forces. In this situation the droplet drifts away and motion is only due to gravity and wind influence. This is illustrated by the droplets with a VMD of $500 \mu \mathrm{m}$ and smaller

Table 4.2 below gives the sedimentation velocity of the various droplets sizes. The sedimentation velocity as a percentage of the wind velocity $(4 \mathrm{~m} / \mathrm{s})$ is also presented.

Table 4.2: Sedimentation Velocities of Various Size Droplets as a Percentage of Wind Velocity

\begin{tabular}{|c|c|c|}
\hline $\begin{array}{c}\text { Volume Median } \\
\text { Diameter, VMD (microns) }\end{array}$ & $\begin{array}{c}\text { Sedimentation Velocity, } \\
u_{\text {sed }}(\mathrm{m} / \mathrm{s})\end{array}$ & $\begin{array}{c}\text { Sedimentation Velocity as a } \\
\text { Percentage of Wind Velocity (\%) }\end{array}$ \\
\hline 100 & 0.302 & $7.6 \%$ \\
\hline 150 & 0.68 & $17 \%$ \\
\hline 200 & 1.2 & 30.2 \\
\hline 500 & 7.55 & $188 \%$ \\
\hline 1000 & 30.2 & $755 \%$ \\
\hline
\end{tabular}


In the presence of a wind velocity of $4 \mathrm{~m} / \mathrm{s}$, droplet sizes from $150 \mu \mathrm{m}$ to $1000 \mu \mathrm{m}$ have a sedimentation-to-wind velocity ratio that exceeds $10 \%$. The trajectories of these droplets also show minimal horizontal deflection and drift. The $100 \mu \mathrm{m}$ droplet's sedimentation velocity is $3.3 \%$ of the wind velocity. Figure 4.10 also illustrates that the $100 \mu \mathrm{m}$ droplet drifted away from the target area. This finding corresponds to Holterman's rule of thumb that droplets with a sedimentation velocity in excess of $10 \%$ of the wind velocity are not likely to drift, and those within $10 \%$ are likely to drift away (Holterman, 2003).

To minimise the effect of spray drift on the roof cooling system, the spray droplets should at least have a diameter that produces sedimentation velocities that exceed $10 \%$ of the wind velocity.

\subsubsection{The Effect of Spray Drift on the Roof Cooling System}

Spray drift is detrimental to the cooling performance of the roof cooling system. This may be explained in the following ways:

i. Water droplets that were cooled down by evaporative cooling are lost from the system due to spray drift. This water is replaced by warmer make-up water that introduces additional energy that needs to be compensated for in the system.

ii. Water lost due to drift decreases the efficiency of the system since less cooling is obtained for the same amount of energy input to the system.

iii. Spray drift from a roof cooling system could result in undesirable water sedimentation on adjacent buildings. The roof cooling system may possibly be discarded as a viable green sustainable option.

iv. Spray drift increases the water consumption of the roof cooling system. The roof cooling system operates optimally in areas with a large diurnal temperature shift, e.g. dry arid areas. Such areas usually have water shortages making the implementation of the roof cooling system difficult.

\subsection{Optimisation}

Optimisation of the roof cooling system is required to give the optimum design parameters that would yield the best possible system efficiency. Heat in the roof cooling system is rejected to the environment via the roof-pond and the roof-spray system components. These two components are optimised independently in the following sections.

\subsubsection{Roof-pond Optimisation}

The roof-pond serves a dual purpose in the roof cooling system. Firstly, during daytime the roof-pond lowers the heat gain to the building through the roof, implying $\dot{Q}_{\text {build }}$ in equation 4.6 must be minimised. Secondly, during night time the roof-pond water is cooled such that it can be employed for cooling the following day. This implies that the heat loss $\dot{Q}_{r p, l o s s}$ from the roof-pond water needs to be minimised. Since $\dot{Q}_{r p, l o s s}$ comprise $\dot{Q}_{s k y}, \dot{Q}_{r p, \text { evap }}$ and $\dot{Q}_{b u i l d}$ 
the heat transfer to and from the roof-pond becomes function of the following variables

$\dot{Q}_{r p, t o t}=f\left(T_{r p}, T_{a m b}, T_{0}, T_{s k y}, I_{s o l a r}, A_{r p}, \alpha_{s, r p}, \alpha_{s k y}, \varepsilon_{r p}, z_{r p}, \phi_{a m b}, u_{w}\right)$

where the weather dependent variables are the ambient air temperature $T_{a m b}$, the sky temperature $T_{s k y}$, the incident solar irradiation flux $I_{\text {solar }}$, the ambient air humidity $\phi_{a m b}$, the sky absorbtivity $\alpha_{s k y}$, and the wind velocity $u_{w}$. The roof-pond solar absorptivity $\alpha_{s, r p}$ and the roof-pond emissivity $\varepsilon_{r p}$ are fixed water properties. The roof-slab temperature $T_{0}$ and the roof-pond temperature $T_{r p}$ are the performance parameters that are minimised when $\dot{Q}_{r p, t o t}$ and $\dot{Q}_{\text {build }}$ are minimised. The only two remaining variables that can be optimised are the roof-pond surface area $A_{r p}$ and the roof-pond water level $z_{r p}$.

When the roof-pond covers the full area of the building roof the heat transfer to the building $\dot{Q}_{\text {build }}$ is minimised since all the incident solar radiation is intercepted by the roof-pond water. The roof-pond water in turn is continuously cooled by means of the evaporative cooling effect of the roof-spray. During night time the available surface area of the roof-pond should also be as large as possible to maximise the roof-pond surface exposure to the night sky and to increase night sky radiation heat loss.

The larger the roof-pond water mass $m_{r p}$ the smaller the increase in $T_{r p}$ for the time interval $\Delta t$ (see equation 4.8). The lower the value of $T_{r p}$ the less energy is transferred to the roofslab $\dot{Q}_{\text {build }}$. The roof-pond mass is calculated as the product of water density $\rho_{f}$, roof-pond water level $z_{r p}$ and the roof-pond surface area $A_{r p}$. Theoretically it is therefore beneficial to have the roof-pond water level $z_{r p}$ as large as possible. This is however not always practical.

In contrast to what has been theoretically analysed above Houghten et al. (1940) found that the cooling produced by an open roof-pond does not significantly change when the roof pond water level is increased from 0.05 to $0.15 \mathrm{~m}$. In an investigation by Sutton (1950) it was found that a roof-pond with a thickness of $0.15 \mathrm{~m}$ reduced the roof surface temperature to $39.4{ }^{\circ} \mathrm{C}$ from $65.6{ }^{\circ} \mathrm{C}$ while a roof-pond with a thickness of $0.05 \mathrm{~m}$ only reduced the roof surface temperature to $42.2^{\circ} \mathrm{C}$.

In this study, the roof-pond water level will be varied and the roof heat flux and roof temperature monitored. The hypothesis that a change in roof-pond water level thickness has no significant effect on the cooling ability of the roof cooling system will be tested. 


\subsubsection{Roof-spray Optimisation}

The roof-spray system operates optimally when the cooling of the water droplets are maximised for the smallest amount of input fluid power to the spray nozzles. In optimising the roof-spray, the cooling obtained from the water droplets sprayed from a typical nozzle is compared to the fluid input power required to spray the droplets from the nozzle. The combination of input variables that give the largest ratio of droplet-cooling to fluid-input power is regarded as the optimal set of system design variables. The mechanisms of heat transfer at the water droplet surface are convection and evaporation. The relevant energy terms are depicted in figure 4.11 below.

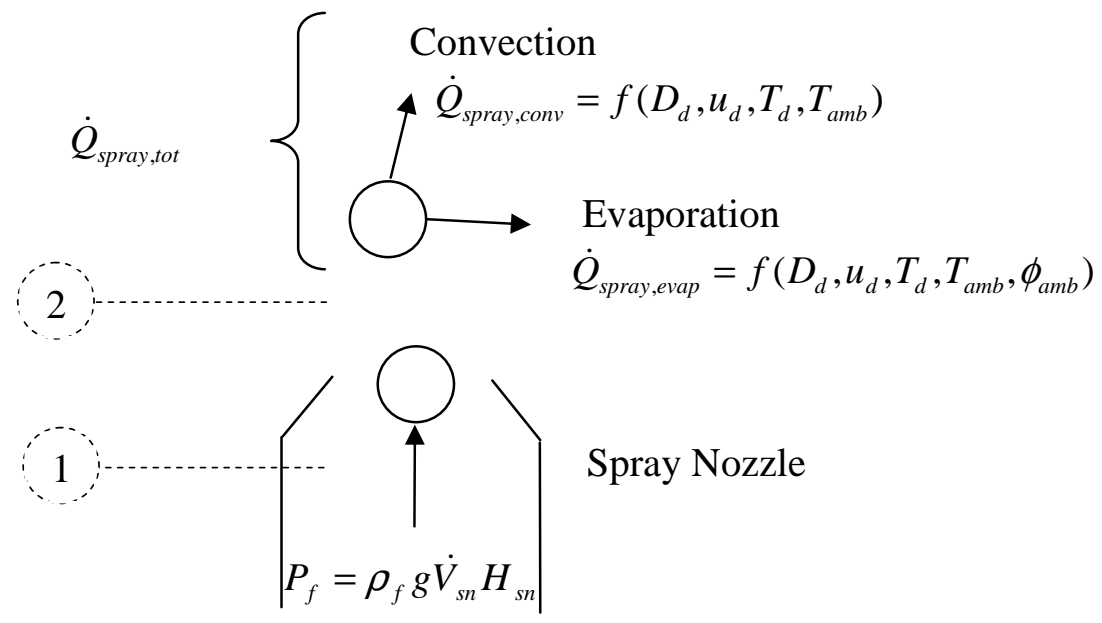

Figure 4.11: Fluid Power at the Spray Nozzle and Heat Transfer Mechanisms of the Water Droplets

$P_{f}$ in figure 4.11 denotes the fluid power required to spray the water from the nozzle and create water droplets, $\dot{Q}_{\text {spray,conv }}$ the convection heat transfer rate between the water droplet and the ambient air and $\dot{Q}_{\text {spray,evap }}$ the evaporation heat transfer rate. $\dot{Q}_{\text {spray,tot }}$ denotes the combined cooling effect of both convection and evaporation for all the water droplets in the water spray. The weather dependent variables are the wind velocity $u_{w}$, the ambient temperature $T_{a m b}$ and the relative humidity $\phi_{a m b}$.

If a new performance parameter namely the nozzle spray coefficient NSC is defined as the ratio of the total spray cooling $\dot{Q}_{\text {spray,tot }}$ to fluid power $\dot{P}_{f}$ then the nozzle input variables may be optimised with a multi-dimensional optimisation procedure to give a optimum NSC value; i.e.

$N S C=\frac{\dot{Q}_{\text {spray,tot }}}{\dot{P}_{f}}$ 
The fluid power is calculated by

$P_{f}=\rho_{f} g \dot{V}_{s n} H_{s n}$

where $H_{s n}$ denotes the pressure head of the water entering the spray nozzle and $\dot{V}_{s n}$ the water volume flow rate of the nozzle. Expressing the pressure head $H_{s n}$ in terms of a pressure differential between points 1 and 2 in figure 4.11, equation 4.26 becomes

$P_{f}=\frac{\rho_{f} g \dot{V}_{s n}\left(p_{1}-p_{2}\right)}{g \rho_{f}}=\dot{V}_{s n} P_{1}=f\left(\dot{V}_{s n}, p_{1}, p_{2}\right)$

where $p_{1}$ denotes the pressure upstream of the nozzle and $p_{2}$ the pressure outside the nozzle equal to atmospheric pressure. The total cooling for a single water droplet may be presented as the total change in internal energy the water droplet undergoes whilst being airborne

$\dot{Q}_{d, t o t}=m_{d} \frac{d U_{d}}{d t}=m_{d} T_{d} \frac{\partial C}{\partial t}+m_{d} C \frac{\partial T_{d}}{\partial t}$

where the first term on the right hand side is zero since the specific heat of water remains constant. For all the droplets in the spray distribution the total cooling is the sum of the individual contributions of each droplet

$$
\begin{aligned}
\dot{Q}_{\text {spray }, \text { tot }} & =\sum_{n=0}^{n=n_{\text {tot }, R R}} \dot{Q}_{d, \text { tot }} \\
& \approx \sum_{n=o}^{n=n_{\text {tot }, R R}} m_{d} C \frac{\Delta T_{d}}{\Delta t} \\
& =\dot{m}_{s n} C \sum_{n=o}^{n=n_{\text {tot }, R R}} \frac{m_{d}}{\dot{m}_{s n}} \frac{\Delta T_{d}}{\Delta t} \\
& =\rho \dot{V}_{s n} C \sum_{n=o}^{n=n_{\text {tot }, R R}} \frac{\dot{m}_{d}}{\dot{m}_{s n}} \Delta T_{d} \\
& =\rho \dot{V}_{s n} C \sum_{n=o}^{n=n_{\text {tot }, R R}} w_{i i} \Delta T_{d}
\end{aligned}
$$

where $n_{t o t, R R}$ gives the total number of droplet sizes in the Rosin Rammler distribution and $w_{i i}$ the probability density fraction for the $i i^{\text {th }}$ droplet size. From equation 4.29 the cooling of the water droplets are dependent on the spray volume flow rate $\dot{V}_{s n}$ and the temperature drop $\Delta T_{d}$ of the water droplets in the time increment $\Delta t$. It can further been seen from the respective heat transfer mechanisms that the water droplet cooling is also a function of ambient air temperature $T_{a m b}$, droplet diameter $D_{d}$, droplet discharge velocity $u_{d}$, and the ambient relative humidity $\phi_{a m b}$. 
$\dot{Q}_{s p r a y, t o t}=f\left(\dot{V}_{s n,} D_{d}, u_{d}, T_{d}, T_{a m b}, \phi_{a m b}\right)$

where the ambient temperature $T_{a m b}$ and relative humidity $\phi_{a m b}$ are weather permitting parameters. Substituting equations 4.30 and 4.27 into equation 4.25 gives

$N S C=\frac{\dot{Q}_{\text {spray,tot }}}{P_{f}}=f\left(\dot{V}_{r c}, D_{d}, u_{d}, T_{d}, T_{a m b}, \phi_{a m b}, p_{1}, p_{2}\right)$

The initial water droplet spray velocity $u_{d}$ is related to the nozzle pressure $p_{1}$ by means of the energy equation, i.e.

$u_{d}=\sqrt{\frac{u_{1}^{2}+2\left(p_{1}-p_{2}\right) / \rho}{K+1}}$

where $u_{1}$ denotes the water velocity at a point upstream of the spray nozzle $p_{1}$ the water pressure applied to the spray nozzle, $p_{2}$ the ambient air pressure and $K$ the spray nozzle loss coefficient. $u_{1}$ is calculated by dividing the volume flow rate $\dot{V}_{s n}$ by the water flow area $A_{s n}$. The spray pressure is related to the volume flow rate in the following way (Stewart et al. 1995)

$K=\frac{\dot{V}_{s n}}{p_{1}^{n}}$

where $n$ is the pressure exponent of the specific nozzle type. The pressure exponent $n$ and the nozzle loss coefficient $K$ vary with nozzle type. Since the volume flow rate $\dot{V}_{s n}$ and the initial water droplet spray velocity $u_{d}$ is a function of the spray pressure $p_{1}$, the remaining design variables to optimise are the droplet diameter $D_{d}$ and the spray pressure $p_{1}$.

\subsubsection{Roof-spray Optimisation Procedure}

In the previous section it was illustrated that the two design variables to optimise to give an optimum $N S C$ value, were the spray pressure, $p_{1}$, and the droplet diameter, $D_{d}$. For any optimisation procedure an objective function is required, in this case it is the nozzle spray coefficient calculated by

$$
N S C=\frac{\dot{Q}_{\text {spray,tot }}}{P_{f}}
$$

A zero-order optimisation procedure is followed to optimise NSC. A suitable zero order optimisation method is Powell's method (Vanderplaats, 2005). Powell's method uses subsequent conjugate directions to search for the optimum value of the objective function. The algorithm for Powell's method is illustrated in figure 4.12 


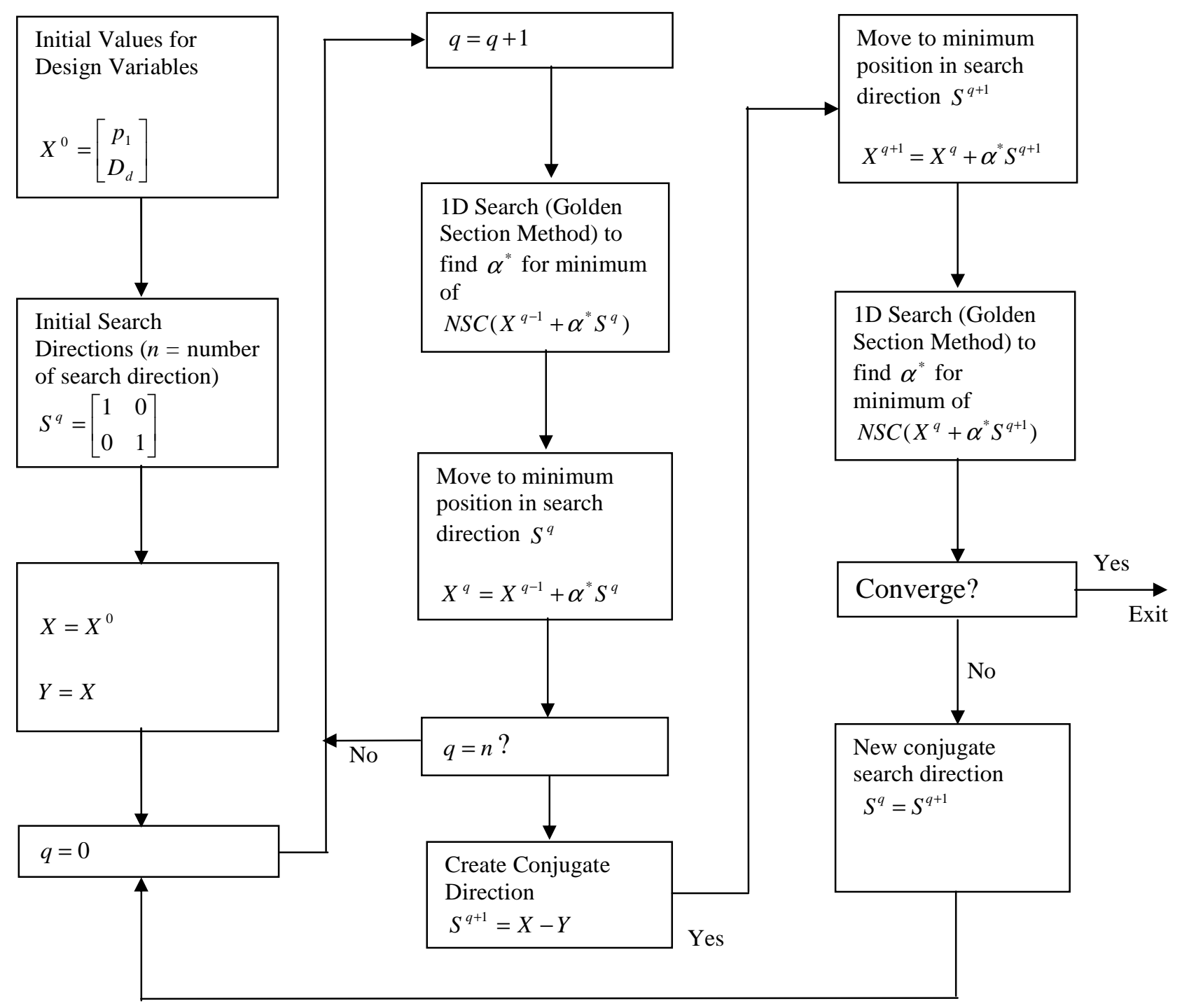

Figure 4.12: Powell's Method for Zero-Order Multi Variable Optimisation

The basic concept of Powell's method (Vanderplaats, 2005) is to initially start searching for the optimum NSC value in $n$ orthogonal directions. The optimum design parameters, $p_{1}$ and $D_{d}$ contained in the $X$-vector, are updated after an optimum has been found in a particular search direction. After completion of the $n$ unidirectional searches a new $n+1$ search direction is created by connecting the first and the last design points. The process is repeated until convergence is achieved.

The Golden section method (Vanderplaats, 2005) may be used as the one dimensional search method for the optimisation of NSC in a specific search direction. More information on Powell's method of optimization, the Golden section method, may be found in Vanderplaats (2005). 


\subsection{Numerical Simulation Flowcharts}

The conservation equations derived in section 4.1 serve as the basis for the computer simulation program. The roof cooling system is simulated numerically to allow the following

i. The solving of the continuity, momentum and energy conservation equations pertaining to a water droplet in subsequent time intervals.

ii. The calculation of drift and trajectory of a droplet as it travels from the spray nozzle to the roof-pond.

iii. The solving of the continuity, momentum and energy conservation equations pertaining to the roof-pond, pump and storage tank in subsequent time intervals.

iv. The simulation of the roof cooling system under ever changing ambient and weather conditions.

v. The simulation of the roof cooling system for a variety of system design parameters, e.g. nozzle height, roof-pond size, water flow rate etc.

vi. The implementation of an optimisation procedure to determine optimum design variables that would yield an optimum nozzle spray coefficient, NSC.

The computer simulation program was written in Visual Basic for Applications with an Excel workbook serving as the user interface. The numerical simulation flowchart comprises two main flowcharts, i.e. the droplet flowchart and the roof cooling flowchart.

The droplet flowchart simulates the water droplet as it travels from the spray nozzle to the roof-pond. The continuity, momentum and energy equations are solved at subsequent time intervals. The drift and droplet trajectory are also calculated and incorporated in the logic of the flowchart. The droplet flowchart calculations are repeated for the variation in droplet sizes that corresponds to the characteristic Rosin Rammler distribution of the spray nozzle.

The roof cooling flowchart solves the continuity, momentum and energy equations of the roof-pond, pump and storage volume control volumes for subsequent time intervals. The droplet flowchart is also employed in the calculations of the roof cooling flowchart.

\subsubsection{The Droplet-Flowchart}

The path a water droplet follows from the spray nozzle to the roof-pond is illustrated in figure 4.13. This path is divided into several intervals spaced apart such that the water droplet in each interval takes time $\Delta t$ to move through it. The water droplet mass, velocity and energy transfer is calculated for each time interval with the calculation procedure as set out in the droplet-flowchart. 


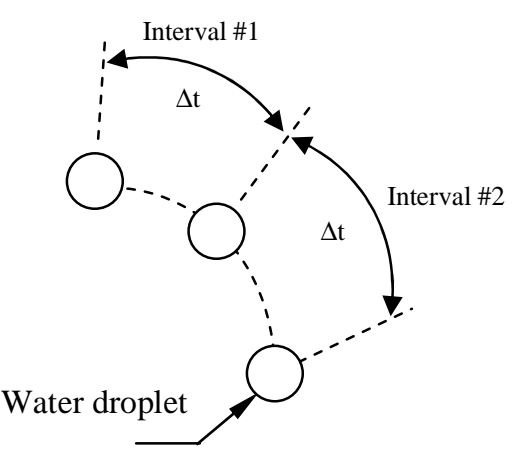

Figure 4.13: Time Intervals in the Water Droplet Spray Path
The droplet-flowchart is given in figure 4.14. The droplet-flowchart starts off with the ambient dependant variables, system variables and system constant design parameters fed to the computer program (see figure 4.14). This is followed by a calculation loop where the energy, the continuity and the momentum equations are performed. The droplet velocity and displacement are also calculated. The calculation loop is repeated for each time intervals depicted in figure 4.13 until the water droplet has reached the roof-pond, i.e. when $s_{y, t o t}<=0$.

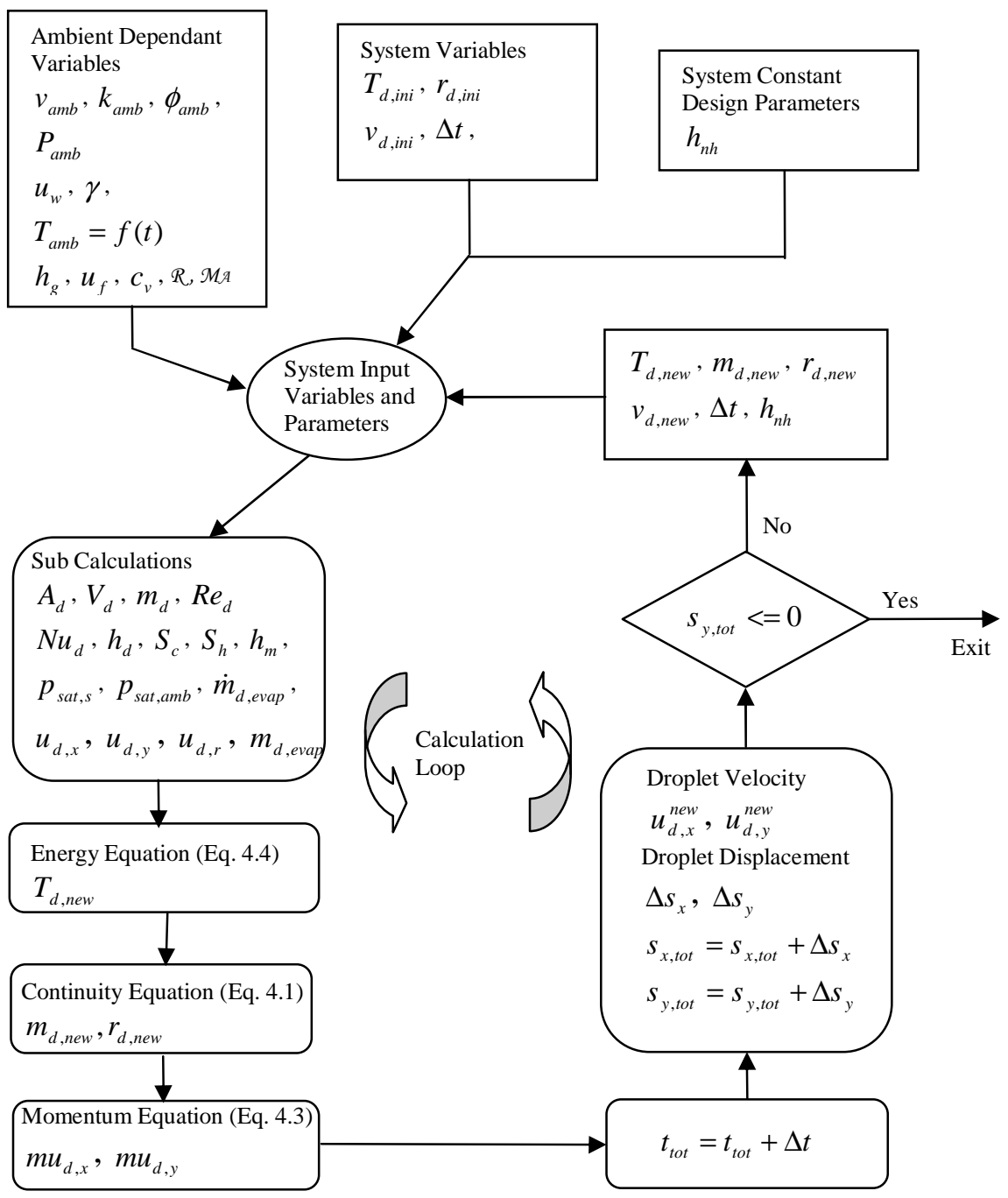

Figure 4.14: The Droplet Flowchart 


\subsubsection{The Roof Cooling Flowchart}

The roof cooling flowchart incorporates the modelling of the centrifugal pump, storage volume and roof-pond. The roof cooling flowchart is given in figure 4.15. Where a symbol is given in the flowchart, it means that the corresponding property or variable is calculated at the specific step of the flowchart. The roof cooling flowchart may be explained as follows

i. Firstly, the ambient dependant variables, system design parameters, system constants and initial system variables are fed to the simulation program (refer to figure 4.15)

ii. The outlet water temperature from the pump $T_{p, o}$ is calculated by means of the pump energy equation. The calculation uses the initial storage tank temperature $T_{s t, i n i}$ and the pump inlet temperature $T_{p, i}$.

iii. The droplet algorithm is performed for a range of droplet sizes that corresponds with the specific nozzle Rosin Rammler distribution function and the mean droplet diameter. A representative droplet temperature $T_{d, o}$ is calculated from the temperatures of all water droplet sizes in the spray distribution weighed in accordance with Rosin Rammler probability density function. The total number of droplet sizes in the distribution is given by $n_{t o t, R R}$ and the probability density fraction by $w_{i i}$ for the $i i^{\text {th }}$ droplet size. $T_{d, o}$ is carried over as the inlet temperature to the roof-pond $T_{r p, i n i}$.

iv. A droplet is considered lost to spray drift when it's calculated landing position is beyond the catchment area of the spray. The temperature contribution of such a droplet is zero however in the flowchart this drift will be modelled as if the drifted droplet is replaced with another droplet at a temperature equal to the initial spray temperature

v. The necessary sub-calculations are performed to allow the calculation of the roof-pond temperature from the conservation of energy equation. The new roof-pond temperature, $T_{r p, o}$, is set equal to the temperature of the water flowing into the storage tank, $T_{s t, i}$. The make-up water flow rate $\dot{m}_{m w}$ is set equal to the amount of water evaporated from the roof cooling system, $\dot{m}_{d, \text { evap }}+\dot{m}_{r p, \text { evap }}$.

vi. The time increment $\Delta t$ is added to the accumulative time variable $t_{t o t, n}$.

vii. The accumulative time variable $t_{t o t, n}$ is compared to the total running time $t_{t o t}$. The calculation is repeated until the total running time has been reached.

The roof cooling algorithm combines the cooling effect of the water spray and roof-pond. The simulation results are presented in Section 7. 


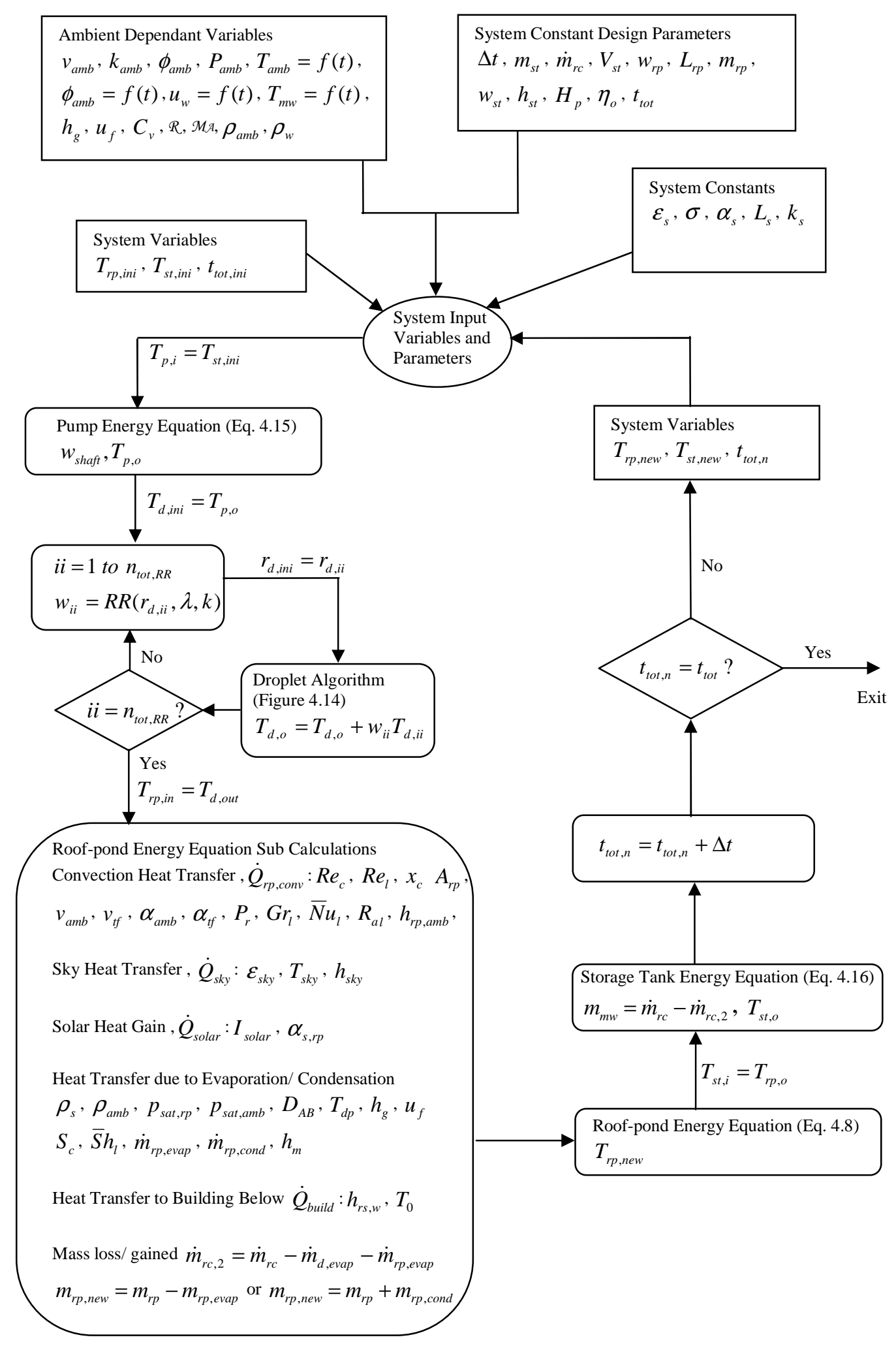

Figure 4.15: The Roof Cooling Flowchart 


\section{MATHEMATICAL MODELLING OF THE ONE-ROOM BUILDING AND THE SUSTAINABLE COOLING ALTERNATIVES}

In Chapter 2 active mass cooling, night flushing and the roof cooling system were selected as the sustainable cooling alternatives that would be further investigated in detail. These sustainable cooling alternatives are complex and difficult to analyse if a simulation model is not utilised. In this chapter a one-room building is assumed to serve as a simulation model to which the sustainable cooling alternatives may be applied to. The mathematical model for the one-room building required for cooling load calculations as well as the calculation of hourly room temperatures are presented in this chapter. The mathematical model and simulation of the one-room building for the scenario where no sustainable cooling alternatives are applied will hereafter be referred to as the base case.

The mathematical model required for the roof cooling system, active mass cooling and night flushing are also presented. The mathematical model also addresses the scenario where the roof cooling components, namely the roof-pond and roof-spray are employed as standalone systems on the one-room building. A flowchart is also presented to show the procedure in which the simulation calculations may be performed.

\subsection{One-Room Building Description and Modelling}

A one-room building is assumed to serve as a basis from which a mathematical model for the calculation of cooling load and room temperatures may be derived. The one-room building comprises four single brick walls, a roof-slab, a north facing window with venetian blinds and a door on the southern end. The window has an aluminium frame with uncoated single glazing. The layout and building dimensions of the one-room building are presented in figure 5.1.

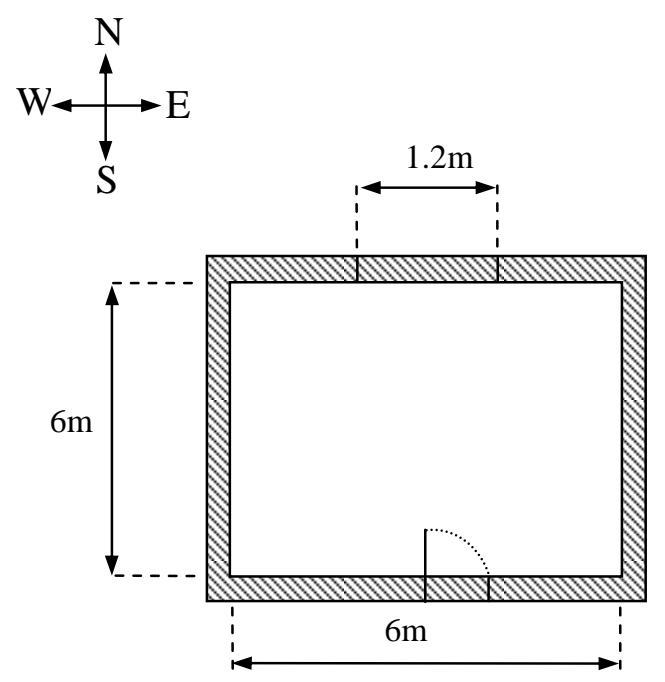

Plan View

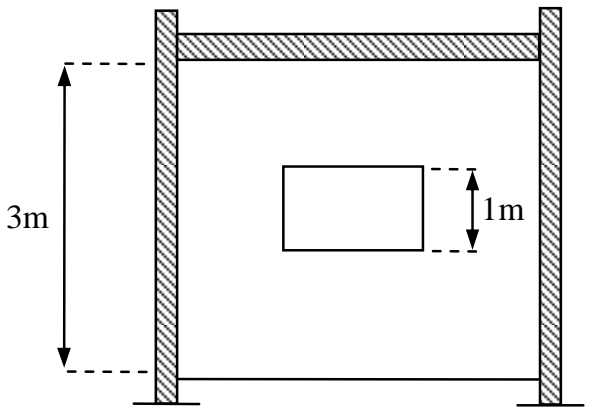

North Elevation

Figure 5.1: The One-Room Building Layout and Dimensions (not to scale) 
The properties of the wall, slab and window of the one-room building are given in the table 5.1 .

Table 5.1: One-Room Building Properties

\begin{tabular}{|l|l|l|c|}
\hline \multicolumn{1}{|c|}{ Description } & Symbol & \multicolumn{1}{c|}{ Units } & Value \\
\hline Building Envelope & & & 6 \\
\hline Width & $w_{\text {build }}$ & $\mathrm{m}$ & 6 \\
\hline Length & $l_{\text {build }}$ & $\mathrm{m}$ & 3 \\
\hline Height & $h_{\text {build }}$ & $\mathrm{m}$ & 230 \\
\hline Single Brick Wall Thickness & $t_{w l}$ & $\mathrm{~mm}$ & 0.8 \\
\hline Brick Wall Thermal conductivity & $k_{s b w}$ & $\mathrm{~W} / \mathrm{mK}$ & 1000 \\
\hline Brick Wall Density & $\rho_{s b w}$ & $\mathrm{~kg} / \mathrm{m}^{2}$ & 835 \\
\hline Brick Wall Specific Heat & $C_{s b w}$ & $\mathrm{~J} / \mathrm{kgK}$ & 200 \\
\hline Roof Slab Thickness & $t_{s}$ & $\mathrm{~mm}$ & 1.2 \\
\hline Window (North Facing) & & & 1 \\
\hline Window Width & $w_{w d}$ & $\mathrm{~m}$ & 0.006 \\
\hline Window Height & $h_{w d}$ & $\mathrm{~m}$ & \\
\hline Window Glazing Thickness & $t_{w d}$ & $\mathrm{~m}$ & \\
\hline
\end{tabular}

For the purpose of mathematically modelling the cooling load of the one-room building it is assumed that the building is occupied by one person performing normal office work from 07:00 to 19:00. It is further assumed that the office equipment release heat at a rate of 5 Watts and the natural air changes per day for the one-room building is 6 ACPD $^{1}$.

\subsubsection{One-Room Building Heat and Cooling Load Mathematical Modelling}

The mathematical model for the calculation of the cooling load comprises a set of energy conservation equations applied to those components of the one-room building that influences room temperature (e.g. walls, roof-slab etc.). Heat enters or escapes the building through the walls, roof-slab, floor and window. Electrical appliances, lighting, people and infiltration also contributes to the building heat gain. All these components are included in the mathematical model to simulate the cooling load and the room temperature profile.

A distinction must be made between the instantaneous heat gain and the actual space cooling load. The instantaneous heat gain refers to the rate at which heat enters into and/or is generated within a space (ASHRAE Fundamentals, 2005). ASHRAE ${ }^{2}$ defines the actual space cooling load as the rate at which heat must be removed to maintain a constant space air temperature. The instantaneous heat gain is not necessarily equal to the actual cooling load.

\footnotetext{
${ }^{1}$ ACPD: Air Changes Per Day

${ }^{2}$ ASHRAE: American Society of Heating Refrigeration and Air Conditioning Engineers
} 
A large portion of heat from sources such as lights and solar radiation is radiant which means the radiant energy must strike and be absorbed by a solid surface within the space. This radiant energy only becomes an actual cooling load when some of this energy is released to the space air through convection.

The time delay between the instantaneous heat gain and the actual space cooling load must be taken into account when performing cooling load calculations (ASHRAE Fundamentals, 2005). Heat entry at the outside wall surface does not result in an immediate heat entry of the same quantity to the room air. Similarly, radiation heat from lights and window solar loads only becomes an actual cooling load to the space air sometime after the initial application. To account for this time delay effect, the solar heat gain through the window and the lighting loads are simulated with the radiant time series procedure as recommended by ASHRAE.

To account for the heat transfer time delay through the building structure, the walls and the roof-slab of the one-room building are treated as a transient conduction problem. The walls and roof-slab are broken up into a set of control volumes. The partial differential equation pertaining to each control volume in the walls and roof-slab is the so called Heat Equation solved with finite difference methods. Figure 5.2 below gives the space air control volume of the one-room building with the corresponding heat gain mechanisms.

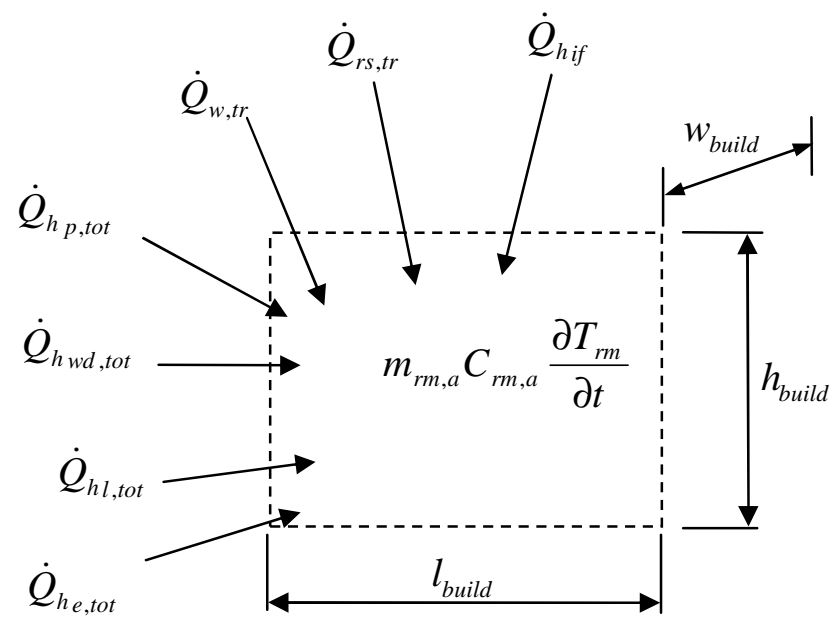

Figure 5.2: Control Volume of the One-Room Building Space Air

Applying the conservation of energy to the room air control volume depicted in figure 5.2 gives

$m_{r m, a} C_{r m, a} \frac{\partial T_{r m}}{\partial t}=\dot{Q}_{h i f}+\dot{Q}_{r s, t r}+\dot{Q}_{w l, t r}+\dot{Q}_{h p, t o t}+\dot{Q}_{h w d, t o t}+\dot{Q}_{h l, t o t}+\dot{Q}_{h e, t o t}$

where $m_{r m, a}$ denotes the room air mass, $C_{r m, a}$ the constant pressure specific heat of the room air, $T_{r m}$ the room temperature, $t$ time, $\dot{Q}_{h i f}$ the infiltration energy gain, $\dot{Q}_{r s, t r}$ the roof-slab heat gain, $\dot{Q}_{w l, t r}$ the wall heat gain, $\dot{Q}_{h p, t o t}$ the heat gain from the people in the building, 
$\dot{Q}_{h_{w d, t o t}}$ the heat gain through the window, $\dot{Q}_{h l, t o t}$ the heat gain from the lighting and the heat gain from the room equipment, $\dot{Q}_{h e, t o t}$.

Note that all the heat gains as they appear in equation 5.1 are modelled as actual cooling loads that influence room temperature and should not be confused with the instantaneous heat gain. The conversion of instantaneous heat gain to actual cooling load is accounted for in the calculation of each respective cooling load in the remaining sections of this chapter. Expressing the derivative term on the left hand side of equation 5.1 in terms a finite difference approximation gives

$m_{r m, a} C_{r m, a} \frac{\partial T_{r m}}{\partial t}=m_{r m, a} C_{r m, a} \frac{T_{r m}^{n+1}-T_{r m}^{n}}{\Delta t}$

where $\Delta t$ gives the time increment such that $N \Delta t=t_{\text {tot }}$ and $n=0,1, \ldots N$. Substituting equation 5.2 into equation 5.1 and rearranging gives

$T_{r m}^{n+1}=T_{r m}^{n}+\frac{\Delta t}{m_{r m, a} C_{r m, a}}\left(\dot{Q}_{h i f}+\dot{Q}_{r s, t r}+\dot{Q}_{w l, t r}+\dot{Q}_{h p, t o t}+\dot{Q}_{h w d, t o t}+\dot{Q}_{h l, t o t}+\dot{Q}_{h e, t o t}\right)$

\subsubsection{Heat Gain through Single Brick Walls}

The energy absorbed by the walls of the one-room building only contributes to the space cooling load after a time lag. Some energy is stored in the walls and only released by means of convection to the space some time later. In order to take this effect into account each wall is broken up into a set of control volumes as depicted in the figure 5.3.

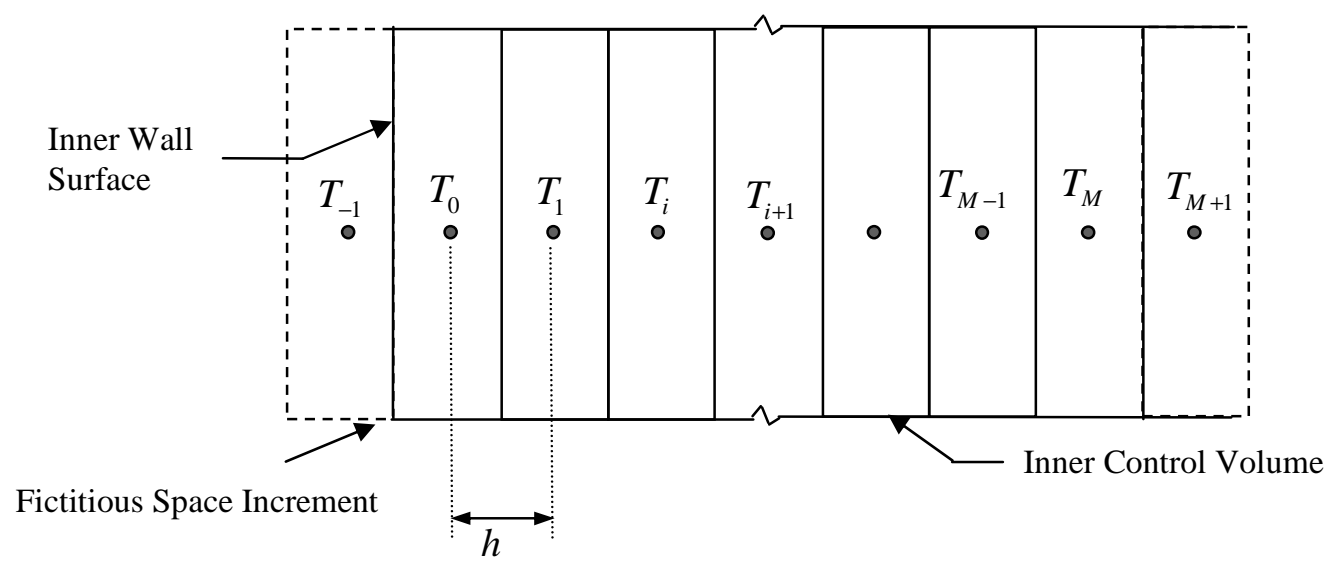

Figure 5.3: One-Room Building Wall Control Volumes

The control volume thickness is $h$ with internal node $i$ such that $h M=t_{w l}$ and $i=0,1, \ldots M$. Node 0 is located on the outer surface of the wall and the node $M$ on the inner surface of the wall. 


\section{Temperature Nodes of the Internal Control Volumes}

The heat flow in the walls is assumed one dimensional which implies that energy only flows in a direction perpendicular to the wall surface. This allows the application of the one dimensional heat equation for each control volume. The derivation of the heat equation in one dimensional Cartesian coordinates may be found in Mills (2000). The heat equation is given by

$$
\frac{\partial T}{\partial t}=\alpha_{s b w} \frac{\partial^{2} T}{\partial x^{2}}
$$

where $\alpha_{s b w}$ denotes the thermal diffusivity calculated as the thermal conductivity $k_{s b w}$ divided by the product of density $\rho_{s b w}$ and specific heat $C_{s b w}$. Using a the simple explicit method as a finite difference scheme, the heat equation in equation 5.4 may be approximated by

$T_{i}^{n+1}=F o\left(T_{i-1}^{n}\right)+(1-2 F o) T_{i}^{n}+F o T_{i+1}^{n}$

where $n$ denotes the $n^{\text {th }}$ point in time, $i$ the $i^{\text {th }}$ control volume and Fo the Fourier number. The application of the simple explicit difference scheme to the heat equation to give equation 5.5 may be found in Mills (2000). The Fourier number $F o$ in equation 5.5 is calculated by

$$
F o=\frac{\alpha_{s b w} \Delta t}{h^{2}}
$$

where $\Delta t$ in equation 5.6 gives the time increment such that $N \Delta t=t_{t o t}$ and $n=0 \ldots N$. A major drawback of the simple explicit method is that the coefficient of $T_{i}^{n}$ in equation 5.5 must be positive for the scheme to be convergent and to avoid divergent oscillations. That is

$\left(1-2 F_{o}\right) \geq 0$

Such that

$$
F o \leq \frac{1}{2}
$$

Substituting equation 5.6 into equation 5.8 gives

$$
\Delta t \leq \frac{h^{2}}{2 \alpha_{s b w}}
$$

\section{Boundary Condition - Temperature Node at the Outer Wall Surface}

At the outer wall surface, or at node 0 , short wave solar energy strikes the wall during daytime, energy is radiated to the environment and heat is gained by means of convection. Figure 5.4 depicts both the inner and outer wall control surface with the corresponding heat transfer mechanisms. 


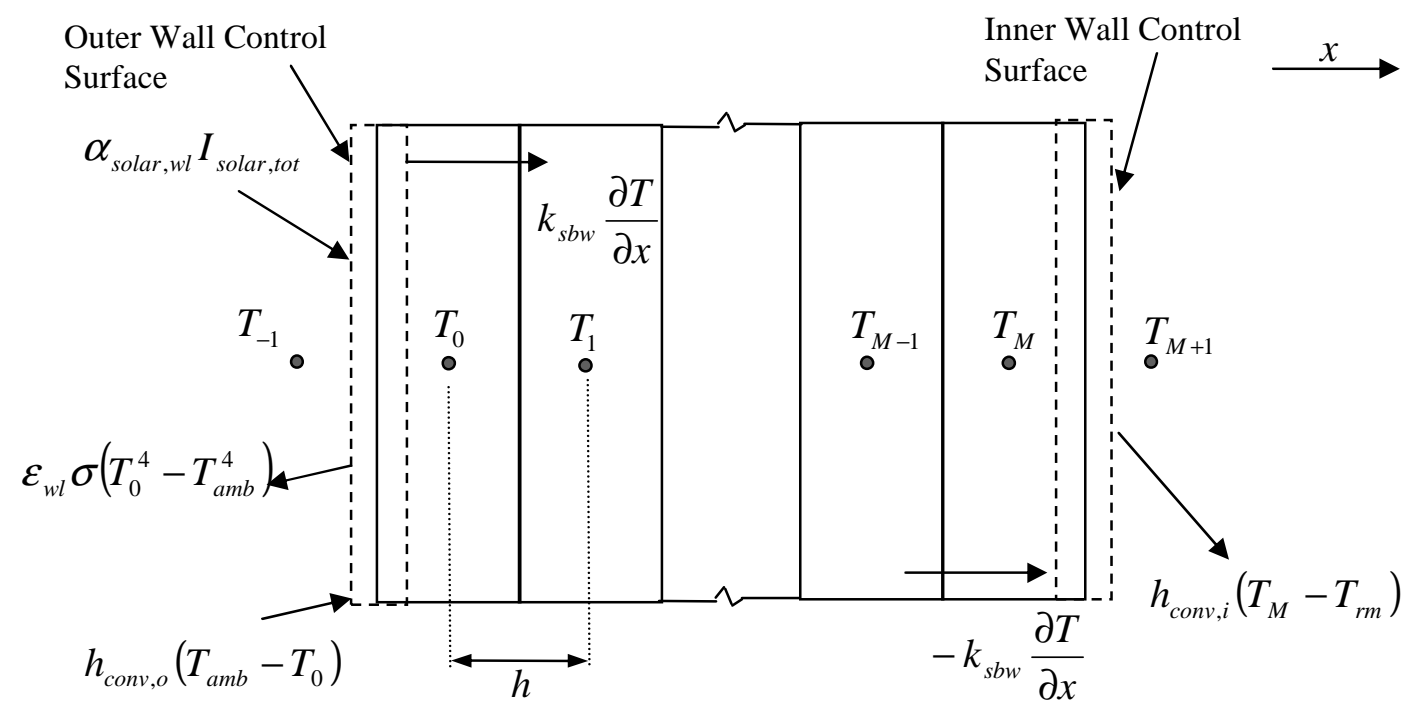

Figure 5.4: Heat Transfer Mechanisms on the Inner and Outer Wall Control Surface

Performing an energy balance per unit area on the outer wall control surface gives

$\alpha_{\text {solar }, w l} I_{\text {solar }, \text { tot }}+h_{c o n v, o}\left(T_{a m b}-T_{0}\right)+k_{s b w} \frac{\partial T}{\partial x}-\varepsilon_{w l} \sigma\left(T_{0}^{4}-T_{a m b}^{4}\right)=0$

Where $\alpha_{\text {solar,wl }}$ is the wall solar absorbtivity, $I_{\text {solar,tot }}$ the total solar radiation comprising reflected, diffuse and beam components, $h_{\text {conv,o }}$ the heat transfer convection coefficient between the outer wall surface and the ambient air, $T_{a m b}$ the ambient temperature and $\varepsilon_{w l}$ the wall emissivity. The solar radiation is specific for longitude, latitude, time of day, day of year and surface orientation. The calculation procedure for the incident solar radiation is explained in Appendix E.

An average ambient air velocity of $2 \mathrm{~m} / \mathrm{s}$ is assumed to give forced convection at the outside wall surface of the one-room building. The corresponding heat transfer coefficient $h_{\text {conv, }}$, is calculated from equation C.45 in Appendix C. The correlations for the calculation of the Nusselt number in equation C. 45 depend on whether the air flow is laminar, turbulent or a combination thereof. Under laminar flow conditions equation C. 48 is utilised to calculate the Nusselt number, under turbulent flow equation C.50 and under combined flow conditions equation C.52 is used. Applying the simple explicit finite difference scheme to the differential term in equation 5.10 gives

$-k_{s b w} \frac{\partial T}{\partial x}=k_{s b w} \frac{T_{-1}-T_{1}}{2 h}$

where $T_{-1}$ is an fictitious node located distance $h$ from the outer surface temperature node $T_{0}$. Substituting equation 5.11 into equation 5.10 and rearranging gives 
$T_{-1}=T_{1}+\frac{2 h \alpha_{\text {solar }, w l} I_{\text {solar }, \text { tot }}}{k_{s b w}}+\frac{2 h h_{c o n v, o}\left(T_{a m b}-T_{0}\right)}{k_{s b w}}-\frac{2 h \varepsilon_{w l} \sigma\left(T_{0}^{4}-T_{a m b}^{4}\right)}{k_{s b w}}$

Applying the simple explicit difference scheme as given in equation 5.5 to node 0 gives

$$
T_{0}^{n+1}=F o T_{-1}^{n}+\left(1-2 F_{o}\right) T_{0}^{n}+F o T_{1}^{n}
$$

Substituting equation 5.12 into equation 5.13 for time step $n$ and rearranging gives

$$
\begin{array}{rl}
T_{0}^{n+1}=2 & F o T_{1}^{n}+\left(1-2 F o-\frac{2 h F o \varepsilon_{w l} \sigma T_{0}^{n^{3}}}{k_{s b w}}-\frac{2 h F o h_{c o n v, o}}{k_{s b w}}\right) T_{0}^{n} \\
& +\left(\frac{2 h F o h_{c o n v, o}}{k_{s b w}}+\frac{2 h F o \varepsilon_{w l} \sigma T_{a m b}^{3}}{k_{s b w}}\right) T_{a m b}+\frac{2 h F o \alpha_{s o l a r, w l} I_{\text {solar }, \text { tot }}}{k_{s b w}}
\end{array}
$$

In the derivation of equation 5.14 the assumption was made that the outer walls only radiates to the ambient environment and not the sky.

\section{Boundary Condition - Temperature Node at the Inner Wall Surface}

At the inner wall surface, or node $M$, heat is continuously removed from the wall by means convection (refer to figure 5.4). The radiation heat exchange between the walls is assumed negligible due the small temperature difference of the different inside wall surfaces. Applying the conservation of energy per unit area to the inner wall control surface gives

$-k_{s b w} \frac{\partial T}{\partial x}=h_{c o n v, i}\left(T_{M}-T_{r m}\right)$

where $h_{c o n v, i}$ denotes the inner wall surface convection coefficient and $T_{r m}$ the space room temperature. As will be shown in Section 5.2 natural convection is the prevailing heat transfer mechanism between the inside wall surface and the room air. The inside surface heat transfer coefficient $h_{\text {conv }, i}$ is calculated from natural convection correlations presented in Section 5.2 of this chapter. Applying the finite difference scheme to the differential term in equation 5.15 gives

$-k_{s b w} \frac{\partial T}{\partial x}=k_{s b w} \frac{T_{M-1}-T_{M+1}}{2 h}$

where the node $M+1$ represents a fictitious node. Substituting equation 5.16 into equation 5.15 and rearranging gives

$T_{M+1}=T_{M-1}-\frac{2 h h_{c o n v, i}}{k_{s b w}}\left(T_{M}-T_{r m}\right)$

Applying the simple explicit difference scheme as given in equation 5.5 to node $M$ gives 
$T_{M}^{n+1}=F o T_{M-1}^{n}+\left(1-2 F_{O}\right) T_{M}^{n}+F o T_{M+1}^{n}$

Substituting equation 5.17 into equation 5.18 for time step $n$ and rearranging gives

$T_{M}^{n+1}=2 F o T_{M-1}^{n}+\left(1-2 F o-\frac{2 h F o h_{c o n v, i}}{k_{s b w}}\right) T_{M}^{n}+\frac{2 h F o h_{c o n v, i}}{k_{s b w}} T_{r m}$

The heat transmitted through the walls and transferred to the room space air via convection can now be calculated as

$\dot{Q}_{w l, t r}=h_{c o n v, i} A_{w l}\left(T_{M_{s}}-T_{r m}\right)$

Equation 5.19 and 5.20 applies to all the walls of the one-room building.

\subsubsection{Heat Gain through the Roof-slab}

Similar to the one-room building walls the instantaneous energy absorbed by the roof-slab only emerges as a space cooling load after a time lag. The mass of the roof-slab stores some of the energy absorbed and only releases this energy sometime later by means of convection heat transfer. The roof-slab is broken up into a set of control volumes as depicted in figure 5.5 and the heat equation is applied to each control volume. The heat transfer mechanisms at both the inner and outer surface of the roof-slab are also given in figure 5.5.

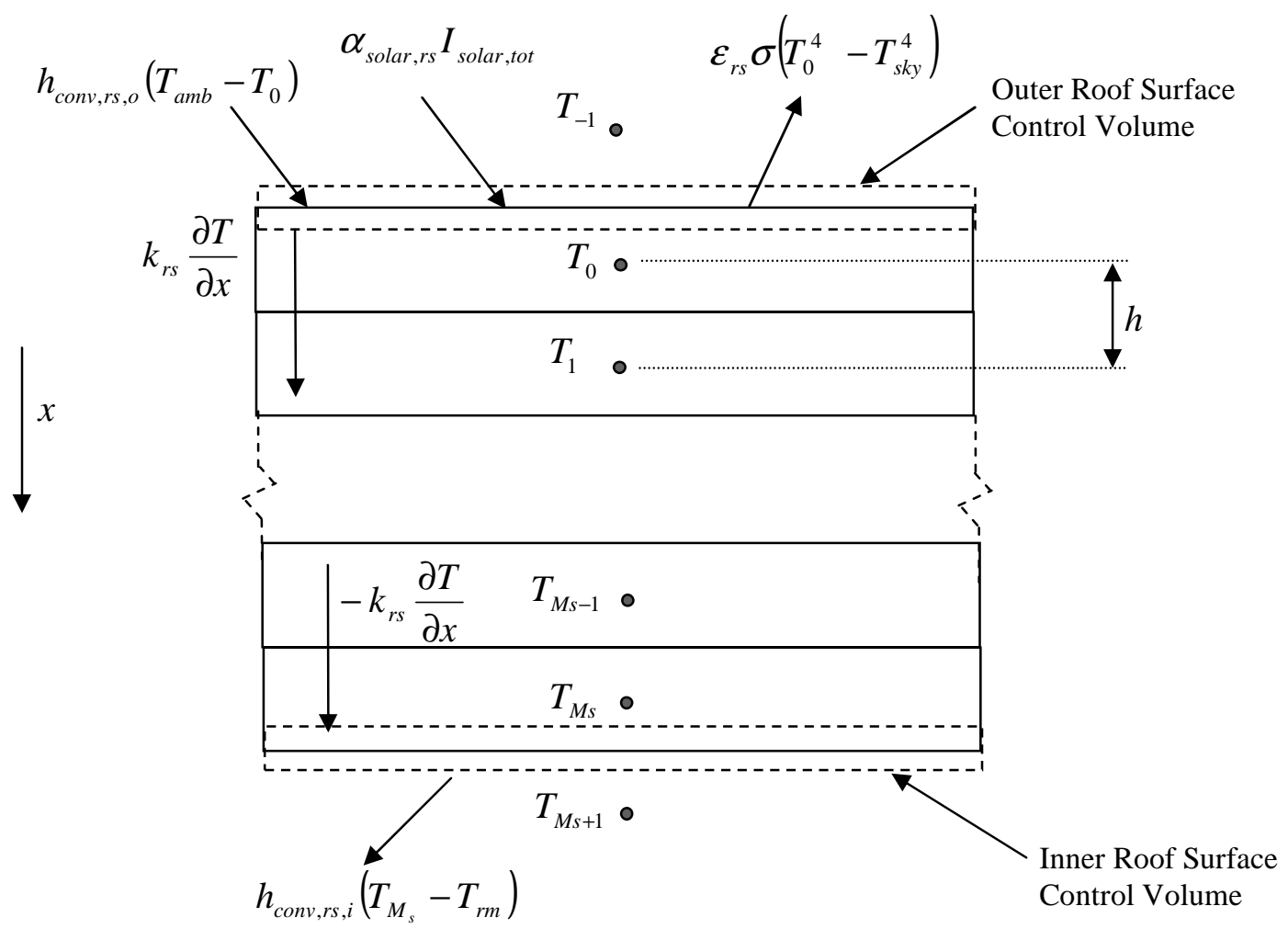

Figure 5.5: Roof-slab Control Volumes and Heat Transfer Mechanisms at Inner and Outer Surfaces 
Similar to the control volumes of the one room building walls, the heat equation given in equation 5.4 also applies to the control volumes of the roof-slab. The finite difference scheme as given in equation 5.5 for the internal control volumes of the roof-slab therefore also applies.

\section{Boundary Condition - Temperature Node at the Outer Roof-slab Surface}

Performing an energy balance on the outer roof surface control volume in figure 5.6 gives

$\alpha_{\text {solar }, r s} I_{s o l a r, t o t}+h_{c o n v, r s, o}\left(T_{a m b}-T_{0}\right)+k_{r s} \frac{\partial T}{\partial x}-\varepsilon_{r s} \sigma\left(T_{0}^{4}-T_{s k y}^{4}\right)=0$

where $h_{c o n v, r s, o}$ denotes the outer roof-slab convection coefficient, $\alpha_{\text {solar, rs }}$ the solar absorbtivity of the roof-slab, $\varepsilon_{r s}$ the roof-slab emissivity and $T_{s k y}$ the sky temperature. The last term on the left hand side of equation 5.21 gives the radiation heat exchange between the roof and the sky. The radiation heat exchange between the roof surface and sky may be combined when $\varepsilon_{r s} \approx \alpha_{s k y}$. The latter is a reasonable assumption considering that the sky radiation is concentrated in approximately the same spectral region as the roof surface emission (Incropera and DeWitt, 2002).

Similar the outside wall convection coefficient, the outer roof-slab convection coefficient $h_{\text {conv, } r s, o}$ is calculated from equation C.45 in Appendix C and the Nusselt number from either equation C.48, equation C.50 or equation C.52 depending on whether the flow is turbulent or laminar.

The temperature distribution in the concrete roof is governed by the heat conduction equation as given by equation 5.4 (Tiwari et al. 1981). Analogous to the wall outer surface control volume, the finite difference scheme for the conduction heat transfer term in equation 5.21 becomes

$-k_{r s} \frac{\partial T}{\partial x}=k_{r s} \frac{\left(T_{-1}-T_{1}\right)}{2 h}$

Substituting equation 5.22 into equation 5.21 gives

$T_{-1}=T_{1}+\frac{2 h \alpha_{\text {solar }, r s} I_{\text {solar }, \text { tot }}}{k_{r s}}+\frac{2 h h_{c o n v, r s, o}\left(T_{a m b}-T_{0}\right)}{k_{r s}}-\frac{2 h \varepsilon_{r s} \sigma\left(T_{0}^{4}-T_{s k y}^{4}\right)}{k_{r s}}$

At the node 0 the simple explicit finite difference scheme takes the form

$T_{0}^{n+1}=F o T_{-1}^{n}+(1-2 F o) T_{0}^{n}+F o T_{1}^{n}$

Substituting equation 5.23 into equation 5.24 and rearranging gives 


$$
\begin{aligned}
T_{0}^{n+1}= & 2 F o T_{1}^{n}+\left(1-2 F o-\frac{2 h F o \varepsilon_{r s} \sigma T_{0}^{n^{3}}}{k_{r s}}-\frac{2 h F o h_{c o n v, r s, o}}{k_{r s}}\right) T_{0}^{n}+\frac{2 h F o h_{c o n v, r s, o}}{k_{r s}} T_{a m b} \\
& +\frac{2 h F o \alpha_{\text {solar }, r s} I_{\text {solar }, t o t}}{k_{r s}}+\frac{2 h F o \varepsilon_{r s} \sigma T_{s k y}^{4}}{k_{r s}}
\end{aligned}
$$

\section{Boundary Condition - Temperature Node at the Inner Roof-slab Surface}

The finite difference equation for the temperature $T_{M s}$ at the node $M_{s}$ in the roof-slab is analogous to the derivation of the temperature equation for $T_{M}$ at the node $M$ for the inner wall surface. Similar to the derivation of equation 5.19, the finite difference equation for temperature $T_{M}$ at node $M$ for the wall inner surface, the temperature equation for $T_{M s}$ becomes

$T_{M s}^{n+1}=2 F o T_{M s-1}^{n}+\left(1-2 F o-\frac{2 h F o h_{c o n v, r s, i}}{k_{r s}}\right) T_{M s}^{n}+\frac{2 h F o h_{c o n v, r s, i}}{k_{r s}} T_{r m}$

where $h_{c o n v, r s, i}$ gives the convection heat transfer between the roof-slab surface and the room air. As will be shown in Section 5.2, the heat transfer mechanism between the slab soffit and the room air is natural convection. Correlations for natural convection as presented in Section 5.2 applies for the calculation of $h_{c o n v, r s, i}$. The heat transmitted through the slab and transferred to the air via convection is given by

$\dot{Q}_{r s, t r}=h_{c o n, r s, i} A_{r s}\left(T_{M s}-T_{r m}\right)$

\subsubsection{Heat Gain through the Window}

The heat gain through the window comprises conductive, convective and radiation heat transfer components. The conductive and convective heat transfer through the window is caused by the temperature difference between the indoor and outdoor air. The radiation heat transfer comprises shortwave solar radiation and long wave radiation heat exchange between the window and the environment. The instantaneous heat gain through the window for hour $h$ is calculated by

$\dot{Q}_{h_{w d, i}}=\dot{Q}_{h_{w d, b}}+\dot{Q}_{h_{w d, d}}+\dot{Q}_{h_{w d, c o n d}}$

where $\dot{Q}_{h_{w d, i}}$ is the total instantaneous window heat gain to the one-room building for hour $h$, $\dot{Q}_{h_{w d, b}}$ the direct beam solar heat gain, $\dot{Q}_{h_{w d, d}}$ the diffuse solar heat gain and $\dot{Q}_{h_{w d, c o n d}}$ the conductive and convective heat gain to the air space. The direct beam solar heat gain is calculated by (ASHRAE Fundamentals, 2005)

$\dot{Q}_{h_{w d, b}}=A_{w d} I_{\text {solar }, b} \operatorname{SHGC}\left(\theta_{\text {solar }}\right) I A C$ 
where $A_{w d}$ is the window area, $I_{\text {solar, } b}$ the direct beam solar radiation incident on the window, $\operatorname{SHGC}\left(\theta_{\text {solar }}\right)$ the direct solar heat gain coefficient at the solar incident angle $\theta_{\text {solar }}$ and $I A C$ the inside shading attenuation coefficient. Appendix E outlines a procedure that may be followed for the calculation of solar radiation. ASHRAE defines the IAC as the fraction of the heat flow that enters the room with some energy having been excluded by the shading devices. The IAC for a variety of internal shade type devices may be found in ASHRAE Fundamentals 2005 (Chapter 31, Table 19).

The solar heat gain coefficient SHGC combines the effect of the window glazing solar transmittance and the fraction of energy transferred to the space due to the absorbed radiation of the window glazing. Since the absorptance and transmittance are window optical properties that varies with solar incident angle, $\theta_{\text {solar }}$ the $S H G C$ also becomes a function of the solar incidence angle. The $S H G C$ for a variety of window types and solar incidence angles can be found in ASHRAE Fundamentals 2005 (Chapter 31 Table 13). Note that up to approximately 40 degrees the window optical properties remain approximately constant and a constant value for $S H G C$ is assumed. The solar diffuse heat gain is calculated by

$$
\dot{Q}_{h_{w d, d}}=A_{w d}\left(I_{\text {solar }, d}+I_{\text {solar }, r}\right) \operatorname{SHGC}(d) I A C
$$

where $I_{\text {solar }, d}$ denotes the diffuse solar radiation, $I_{\text {solar, } r}$ the ground reflected solar radiation and $\operatorname{SHGC}(d)$ is the hemispherical average solar heat gain coefficient. The conductive and convective heat gain through the window is calculated by

$$
\dot{Q}_{h w d, c o n d}=U_{w d} A_{w d}\left(T_{a m b}-T_{r m}\right)
$$

where $U_{w d}$ is the overall heat transfer coefficient that combines the center-of-glass $U$-factor, the edge-of-glass $U$-factor and the frame $U$-factor. $U_{w d}$ incorporates the convective heat transfer between the air and the window as well as the conductive heat transfer through the window itself. ASHRAE Fundamentals 2005 (Chapter 31, Table 4) gives $U$-factors for various window and frame products. These $U$-factors where initially determined for winter conditions but it is reported that they can also be applied for summer peak cooling load calculations since conductive heat gain through a window is usually a small portion of the total window heat gain. In the one-room building the window type is single with an aluminium frame and thermal breaks. ASHRAE Fundamentals 2005 (Chapter 31, Table 4) gives an overall $U$-factor of $5.43 \mathrm{~W} / \mathrm{m}^{2} \mathrm{~K}$ for the aforementioned window type.

Only a fraction of the heat gain through the window converts an actual cooling load that results in an almost immediate change in the space air temperature. A large part of the window heat gain is radiant that only becomes a cooling load some time later. To take this time delay effect into account, ASHRAE recommends the use of a Radiant Time Series (RTS) procedure that utilises radiant time factors. The radiant time factors reflect the heat gain of earlier hours that becomes a cooling load in the current hour of operation. 
The RTS procedure calculates cooling load based on the 24 hour heat gain profile of the specific heat source. The heat gain for each hour is split into radiant and convective parts. The convective part becomes an actual cooling load. Radiant time factors are applied to the radiant part to account for the time delay from instantaneous heat gain to actual cooling load conversion.

ASHRAE Fundamentals 2005 (Chapter 30, Table 16) gives the convective portion of heat gain through a window with inside shade as $37 \%$. The remaining $63 \%$ of the heat gain is radiant that would only become an actual cooling load sometime later. Thus

$\dot{Q}_{h_{w d, c o n v}}=0.37 \dot{Q}_{h_{w d, i}}$

and

$\dot{Q}_{h w d, r a d, i}=0.63 \dot{Q}_{h w d, i}$

where $\dot{Q}_{h_{w d}, r a d, i}$ is the instantaneous radiant portion of the total window heat gain and $\dot{Q}_{h_{w d, c o n v}}$ the convective portion of the total window heat gain. The radiant time factors for non-solar heat gains for a building with medium weight construction, $10 \%$ glass and a carpet are given in table 5.2.

Table 5.2: Non-Solar Radiant Time Factors (RTF) for a Medium Weight Construction Building with $10 \%$ Glass of a Total Surface Area and a Carpet

\begin{tabular}{|c|c|c|c|c|c|}
\hline Hour & RTF $(\%)$ & Hour & RTF $(\%)$ & Hour & RTF (\%) \\
\hline 0 & 46 & 8 & 1 & 16 & 1 \\
\hline 1 & 18 & 9 & 1 & 17 & 1 \\
\hline 2 & 10 & 10 & 1 & 18 & 1 \\
\hline 3 & 6 & 11 & 1 & 19 & 0 \\
\hline 4 & 4 & 12 & 1 & 20 & 0 \\
\hline 5 & 2 & 13 & 1 & 21 & 0 \\
\hline 6 & 2 & 14 & 1 & 22 & 0 \\
\hline 7 & 1 & 15 & 1 & 23 & 0 \\
\hline
\end{tabular}

If $r_{h}$ denotes the radiant time factor for the $h^{\text {th }}$ hour then the actual cooling load of the radiant portion of the window heat gain for the $h^{\text {th }}$ hour becomes

$\dot{Q}_{h_{w d, r a d}}=r_{0} \dot{Q}_{h_{w d, r a d, i}}+r_{1} \dot{Q}_{h-1 w d, r a d, i}+r_{2} \dot{Q}_{h-2 w d, r a d, i}+r_{3} \dot{Q}_{h-3 w d, r a d, i}+\ldots+r_{23} \dot{Q}_{h-23 w d, r a d, i}$

The actual window cooling load on the one-room building for hour $h$ is the sum of the radiant and convective portions

$\dot{Q}_{h_{w d, t o t}}=\dot{Q}_{h_{w d, r a d}}+\dot{Q}_{h_{w d, c o n v}}$ 


\subsubsection{Lighting Loads}

Similar to the heat gain from windows, the heat gain from lighting is also divided into a convective and radiant portion. For the one-room building it is assumed that the lighting comprises fluorescent lights, suspended and unvented with a wattage of $5 \mathrm{~W} / \mathrm{m}^{2}$. The lighting usage extends from 07:00 to 19:00 daily. The instantaneous lighting heat gain is calculated by

$\dot{Q}_{h l, i}=\dot{q}_{l} A_{f l} F u_{l}$

where $\dot{q}_{l}$ is the lighting load per floor area, $A_{f l}$ the floor area and $F u_{l}$ the lighting usage factor. ASHRAE Fundamentals 2005 (Chapter 30, Table 16) gives the convective portion of heat gain from lighting as $33 \%$ and the radiant portion as $67 \%$. The convective portion is an actual cooling load on the space calculated by

$\dot{Q}_{h l, c o n v}=0.33 \dot{Q}_{h l, i}$

The instantaneous radiant portion of the lighting heat gain for the $h^{\text {th }}$ hour is the remaining $67 \%$, i.e.

$\dot{Q}_{h l, r a d, i}=0.67 \dot{Q}_{h l, i}$

Similar to the window loads, the radiant portion of the lighting heat gain only becomes an actual cooling load after some delayed time period. To take the time delay effect into account the RTS procedure is followed. The radiant portion from the lighting heat gain that becomes an actual cooling load is calculated by the application of the radiant time factors, i.e.

$$
\dot{Q}_{h l, r a d}=r_{0} \dot{Q}_{h l, r a d, i}+r_{1} \dot{Q}_{h-1 l, \text { rad }, i}+r_{2} \dot{Q}_{h-2 l, r a d, i}+r_{3} \dot{Q}_{h-3 l, r a d, i}+\ldots+r_{23} \dot{Q}_{h-23 l, \text { rad }, i}
$$

where $\dot{Q}_{h l \text {,rad }}$ is the radiant portion that becomes an actual cooling load for the current hour, $\dot{Q}_{h l, r a d, i}$ to $\dot{Q}_{h-23 l, r a d, i}$ the instantaneous lighting loads for the previous hours and $r_{0}$ to $r_{23}$ the radiant time factors for non-solar radiation in the one-room building. The actual cooling load on the space for lighting is the sum of the convective and radiant portion

$\dot{Q}_{h l, t o t}=\dot{Q}_{h l, r a d}+\dot{Q}_{h l, c o n v}$

\subsubsection{Infiltration and Ventilation Energy Gains}

The infiltration and ventilation energy gain accounts for outdoor air infiltrating the one-room building through the door and window. The infiltration energy gain is an actual cooling load that immediately influences the space air temperature. From the conservation of mass the quantity of air entering the one-room building equals the quantity of air leaving the building. The infiltration load $\dot{Q}_{h i f}$ can therefore be seen as the difference in energy between the air entering the building and the air leaving the building 
$\dot{Q}_{h i f}=\rho_{a} \dot{V} \Delta h$

where $\rho_{a}$ is the average air density between the outdoor and indoor air, $\dot{V}$ the infiltration or ventilation volume flow rate and $\Delta h$ the difference in enthalpy between the indoor and outdoor air. The difference in enthalpy may be approximated as (Cengel and Boles, 2002)

$\Delta h=\left(C_{p, a}+\omega C_{p, v a p}\right) \Delta T$

where $C_{p, a}$ is the constant pressure specific heat of dry air, $\omega$ the humidity ratio, $C_{p, v a p}$ the constant pressure specific heat of water vapour and $\Delta T$ the temperature difference between the indoor and outdoor air. Substituting equation 5.42 into equation 5.41 gives

$\dot{Q}_{h i f}=\rho_{a} \dot{V}\left(C_{p, a}+\omega C_{p, v a p}\right) \Delta T$

The infiltration heat gain as given in equation 5.43 is also applies when the one-room building is mechanically ventilated.

\subsubsection{Other Heat Gains}

The remaining heat gains to the one-room building are that of people, equipment and heat transmission through the floor. It is assumed that the one-room building has one person performing office work from 07:00 to 19:00. From ASHRAE Fundamentals 2005 (Chapter 30 , Table 1) the instantaneous sensible heat for an average adult male performing moderately active office work is $75 \mathrm{~W}$ of which $58 \%$ is radiant and $42 \%$ convective. The actual cooling load of people occupying the one-room building is therefore calculated as

$\dot{Q}_{h p, t o t}=\dot{Q}_{h p, r a d}+\dot{Q}_{h p, c o n v}$

where $\dot{Q}_{h_{p, t o t}}$ is the total actual cooling load of people for the $h^{\text {th }}$ hour, $\dot{Q}_{h p, r a d}$ the radiant portion of the cooling load and $\dot{Q}_{h p, \text { conv }}$ the convective portion of the people load. From ASHRAE Fundamentals 2005 (Chapter 30, Table 1) the radiant portion of the heat gain from a person performing moderate office work is $58 \%$ and the convective portion is $42 \%$. The convective portion is calculated by

$\dot{Q}_{h p, c o n v}=0.42 \dot{Q}_{h p, t o t}=0.42 N_{p} F_{p o o} \dot{q}_{p, i}$

where $N_{p}$ is the number of people in the one-room building, Fpo the people occupancy factor and $\dot{q}_{p, i}$ the instantaneous sensible heat gain from a person performing office work. Since the radiant heat from people only becomes a load some time later the RTS procedure, as described earlier applies. The portion of the radiant load for time $h$ that becomes an actual cooling load is calculated by

$\dot{Q}_{h p, r a d}=r_{0} \dot{Q}_{h_{p, r a d}, i}+r_{1} \dot{Q}_{h-1 p, r a d, i}+r_{2} \dot{Q}_{h-2 p, r a d, i}+r_{3} \dot{Q}_{h-3 p, r a d, i}+\ldots+r_{23} \dot{Q}_{h-23 p, r a d, i}$ 
where $\dot{Q}_{h, \text { rad }}$ is the radiant portion of the cooling load for the current hour, $\dot{Q}_{h_{p, r a d, i}}$ to $\dot{Q}_{h-23 p, r a d, i}$ the instantaneous radiant heat gains for the current and previous hours and $r_{0}$ to $r_{23}$ the radiant time factors for non-solar radiation in the one-room building. The instantaneous radiant load from people is calculated as $58 \%$ of the total cooling load from people

$\dot{Q}_{h, r a d, i}=0.58 N_{p} F p o \dot{q}_{p, i}$

The office equipment in the one-building room comprises a computer and accompanying monitor. The heat gain from a typical computer and monitor may be obtained from ASHRAE Fundamentals 2005 (Chapter 30, Table 8). For the one-room building example the sensible actual heat gain is assumed $5 \mathrm{~W}$.

According to ASHRAE Fundamentals (2005), the heat gain through the floor may be regarded as negligible when cooling load calculations are performed. The heat gain through the floor of the one-room building is assumed zero and is therefore not included in the mathematical model.

\subsection{Mathematical Modelling with Night Flushing}

When night flushing is applied to the one-room building, the equations for the base case cooling load as derived in Section 5.1 applies. The major difference with night flushing when compared to that of the base case is the high volume at which ambient air is flushed through the building at night time. When cold ambient air is admitted to the one-room building, the infiltration load given by $\dot{Q}_{h i f}$ in equation 5.42 reduces to a negative value. From equation 5.3 it can be seen that the greater the negative value of $\dot{Q}_{h i f}$, the greater the offset in room temperature.

Night flushing not only cools the air in the room, it also removes stored energy from the walls and roof slab. The rate at which energy is removed from the building structure depends greatly on the convective heat transfer coefficient. Pfafferott et al. (2003) reports that accurate modelling of the convective heat transfer coefficients is essential in simulating the effect of night flushing of a building. This notion is further supported by Artmann et al. (2008) as well as Blondeau et al. (1997). According to Dascalaki et al. (1994) both natural and forced convection are the primary mechanisms of heat transfer inside buildings. Both natural and forced convection effects are comparable when (Cengel and Boles, 2002)

$\frac{G r_{L}}{R e_{L}^{2}} \approx 1$

where $G r_{L}$ is the Grashof number and $R e_{L}$ the Reynolds number. When the term on the left of equation 5.48 is significantly smaller than 1, free convection is negligible and when significantly larger than 1 , forced convection becomes negligible. The Grashof number is calculated by 
$G r_{L}=\frac{g \beta\left(T_{s}-T_{r m}\right) L^{3}}{v^{2}}$

where $g$ is the gravitational constant, $\beta$ the volumetric thermal expansion coefficient, $T_{s}$ the surface temperature, $T_{r m}$ the room temperature, $L$ the surface length and $v$ the kinematic viscosity. The Reynolds number is calculated by

$R e_{L}=\frac{u_{a} L}{v}$

where $u_{a}$ is the air flow velocity. If equation 5.50 and equation 5.49 are substituted into equation 5.48 and the result set equal to unity, then

$$
\frac{g \beta\left(T_{s}-T_{r m}\right) L}{u_{0}^{2}}=1.0
$$

Substituting a typical wall temperature of $21{ }^{\circ} \mathrm{C}$, a room air temperature of $12{ }^{\circ} \mathrm{C}$ and a wall length of $3 \mathrm{~m}$ into equation 5.51 gives

$$
\frac{1.015}{u_{0}^{2}}=1.0
$$

From equation 5.52 the air flow velocity must be in the order of $1 \mathrm{~m} / \mathrm{s}$ for forced convection to be comparable with natural ventilation. The average air velocity through the one-room building may be approximated by

$$
u_{0}=\frac{V_{\text {build }} A C H}{10800}\left(\frac{1}{w_{\text {build }} h_{\text {build }}}+\frac{1}{l_{\text {build }} w_{\text {build }}}+\frac{1}{h_{\text {build }} l_{\text {build }}}\right)
$$

If an air velocity of $1 \mathrm{~m} / \mathrm{s}$ and the building dimensions of table 5.1 are inserted in equation 5.53, the air changes per hour in equation 5.53 comes to 720 for forced convection to be significant. As pointed out in the literature review of this study, both Artmann et al. (2008) and Geros et al. (1999) found that increasing the air changes per hour beyond $32 \mathrm{ACH}$ does not significantly decrease the peak room temperature the following day. Since these air changes per hour are significantly less than the $720 \mathrm{ACH}$ required for forced convection to take place, the heat transfer coefficient for the inside wall surfaces when the building is flushed will be calculated from natural convection correlations.

Dascalaki et al. (1994) reviews the correlations available in the literature for estimating the natural convection heat transfer coefficient in buildings. Chandra and Kerestecioglu (1984) proposed that the internal convection heat transfer coefficient be double while Clark (1989) proposed that the convective heat transfer coefficient be quadrupled when a room is highly ventilated. As an alternative, Artmann et al. (2008) used a convective heat transfer coefficient of $2.5 \mathrm{~W} / \mathrm{m}^{2} \mathrm{~K}$ for vertical surfaces, $5 \mathrm{~W} / \mathrm{m}^{2} \mathrm{~K}$ for a horizontal surface facing upwards and 0.7 $\mathrm{W} / \mathrm{m}^{2} \mathrm{~K}$ for a horizontal surface facing downward 
Blondeau et al. (1997) did not notice any significant difference in predicted indoor air temperatures and consequently made the assumption of still air values for the heat transfer convective coefficients. Pfafferott et al. (2003) utilised natural ventilation correlations by Alamdari and Hammond as well as Khalifa and Marshall to determine the convective heat transfer coefficients. These heat transfer coefficients can be found in Dascalaki et al. (1994). In this study the Churchill and Chu natural convection correlations are used for the vertical surfaces of the walls

$$
\bar{N} u_{L}=\frac{h_{\text {conv }, i} L}{k_{r m, a}}=\left[0.825+\frac{0.387 R a_{L}^{1 / 6}}{\left[1+(0.492 / P r)^{9 / 16}\right]^{8 / 27}}\right]^{2}
$$

where $R a_{L}$ is the Rayleigh number calculated by

$$
R a_{L}=G r_{L} \operatorname{Pr}
$$

Equation 5.54 has no restrictions and is valid for $0<R a_{L}<\infty$. The correlation proposed by Incorpera and DeWitt (2002) for the lower surface of a cooled plate is used to determine the natural convection coefficient between the roof-slab and the air, i.e.

$$
\bar{N} u_{L}=\frac{h_{\text {conv }, i} L}{k_{r m, a}}=0.15 R a_{L}^{1 / 3}
$$

\subsection{Mathematical Modelling with Active Mass Cooling}

From the literature study it was seen that the thermal mass of a building cooled may be achieved by circulating water in a pipe network embedded within the roof slab. The layout geometry of the water pipes, the spacing between the pipes and the dimensions of the concrete slab are essential design parameters for this type of system (Koschenz et al. 1996)

\section{One Dimensional Heat Transfer in the Roof-slab}

Figure 5.6 depicts three control volumes located in the centre of the roof slab of the one-room building

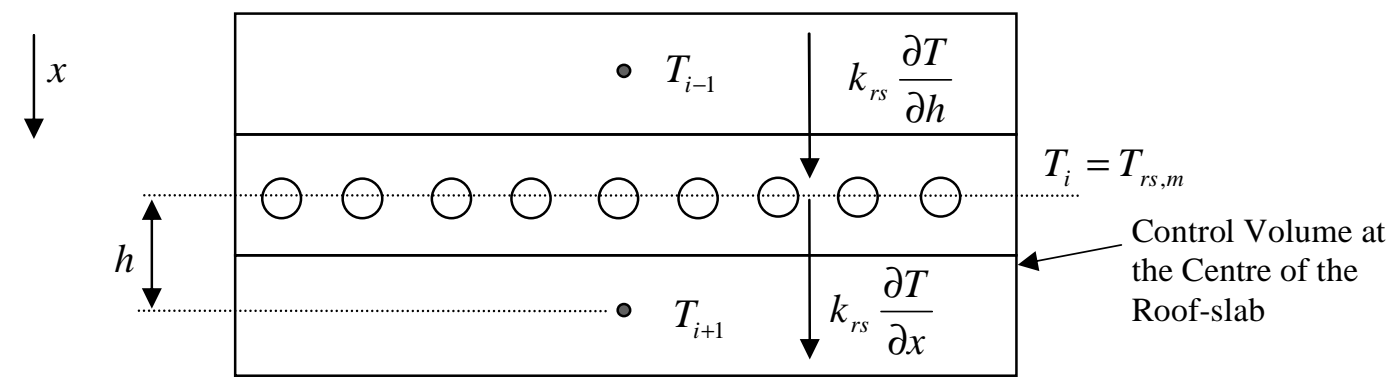

Figure 5.6: Control Volume at the Centre of the Roof-slab with Embedded Pipes 
According to Koschenz and Dorer (1999) it is reasonable to assume a mean temperature within the slab at the pipe level with a resistance coefficient $R_{w, r s}$ that exists between the water temperature $T_{w}$ and the mean slab temperature $T_{r s, m}$. The heat transfer coefficient $R_{w, r s}$ is dependent on the diameter of the pipes and the spacing of the pipe. Values for $R_{w, r s}$ may be found in Koschenz and Dorer (1999).

The heat transfer in the slab may also be assumed one dimensional (Koschenz and Dorer, 1999) and the heat equation as given in equation 5.4 applies. The equations for calculating the temperatures at the outer and inner surfaces of the roof-slab are the same as the base case and equation 5.25 and equation 5.26 applies. Performing an energy balance per unit volume at the $i^{\text {th }}$ control volume located in the centre of the slab (see figure 5.6) gives

$$
\rho_{r s} C_{r s} \frac{\partial T}{\partial t}=k_{r s} \frac{\partial^{2} T}{\partial x^{2}}+\frac{\dot{q}_{w}}{h}
$$

where $\dot{q}_{w}$ denotes the heat transfer from the slab to the water that flows through the tubes calculated by

$$
\dot{q}_{w}=\frac{T_{w}-T_{s, m}}{R_{w, r s}}
$$

where $R_{w, r s}$ is the resistance coefficient between the water temperature in the tubes and the mean roof slab temperature $T_{r s, m}$ at a plane located at the centre of the embedded pipes. Substituting equation 5.58 into equation 5.57 and dividing by $\rho_{r s} C_{r s}$ gives

$$
\frac{\partial T}{\partial t}=\frac{k_{r s}}{\rho_{r s} C_{r s}} \frac{\partial^{2} T}{\partial x^{2}}+\frac{\left(T_{w}-T_{r s, m}\right)}{h R_{w, r s} \rho_{r s} C_{r s}}
$$

Applying the simple explicit method as a finite difference scheme to equation 5.59 and realising that the thermal diffusivity $\alpha_{r s}$ is calculated by $k_{r s} / \rho_{r s} C_{r s}$ gives

$$
\frac{T_{r s, m}^{n+1}-T_{r s, m}}{\Delta t}=\alpha_{r s} \frac{T_{i+1}-2 T_{r s, m}+T_{i-1}}{h^{2}}+\frac{\left(T_{w}-T_{r s, m}\right)}{h R_{w, r s} \rho_{r s} C_{r s}}
$$

Multiplying equation 5.60 with $\Delta t$, substituting equation 5.6 for the Fourier number and rearranging gives $T_{s, m}$ for the time step $n+1$ gives

$$
T_{s, m}^{n+1}=F o T_{i+1}^{n}+\left(1-2 F o-\frac{\Delta t}{h R_{w, r s} \rho_{s} C_{s}}\right) T_{s, m}^{n}+F o T_{i-1}^{n}+\frac{\Delta t T_{w}}{h R_{w, r s} \rho_{s} C_{s}}
$$


For the remaining nodes 1 to $i-1$ and $i+1$ to $M_{s}-1$ equation 5.5, the simple explicit finite difference scheme for the one dimensional heat equation, applies.

\section{Water Temperature Simulation}

Another consideration is the variation in water temperature as it flows through the embedded pipes of the roof slab. Koschenz and Dorer (1999) propose that a single average water temperature in the pipes be used and that this temperature be approximated by using a logarithmic average. As an alternative, partitioning the slab in the $z$-direction is also proposed. In this study the variation in water temperature will be modelled by partitioning the slab into control volumes along the route of the embedded pipes. Figure 5.7 illustrates this concept.

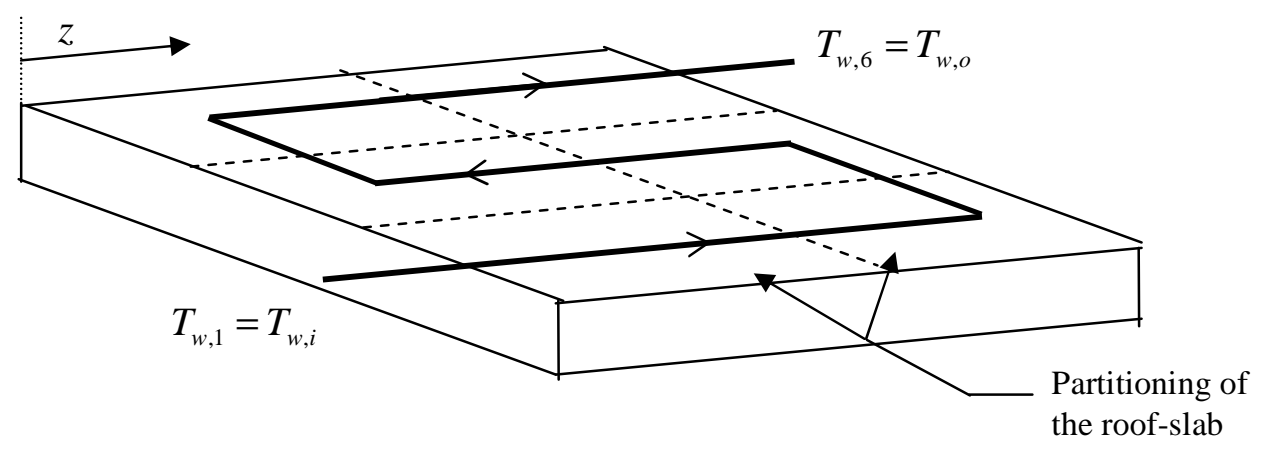

Figure 5.7: Partitioning of the Roof-slab with Embedded Pipes

Figure 5.8 depicts the typical control volume for the water flowing in the pipe.

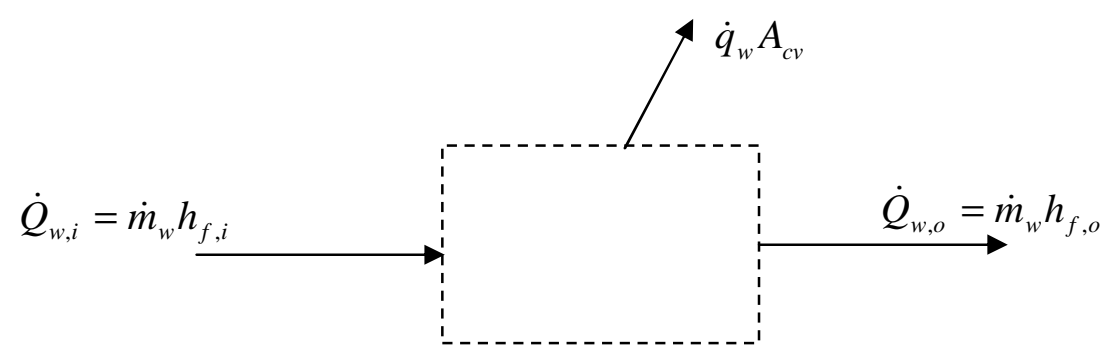

Figure 5.8: Control Volume for the Water Flowing in the Embedded Pipes of the Roof-slab

Applying the conservation of energy to the water control volume in figure 5.8 gives

$\dot{Q}_{w, i}=\dot{Q}_{w, o}+\dot{q}_{w} A_{c v}$

where $\dot{Q}_{w, i}$ and $\dot{Q}_{w, o}$ are the rate at which energy flows in and out of the control volume, $\dot{q}_{w}$ the rate of heat transfer to the water from the roof-slab and $A_{c v}$ the control volume surface area of slab where the pipes are embedded. Substituting equation 5.58 into equation 5.62 for 
$\dot{q}_{w}$ and expanding the first two terms in terms of water mass flow rate $\dot{m}_{w}$ and enthalpy $h_{f}$ gives

$$
-\dot{m}_{w}(\Delta h)=\frac{\left(T_{w, i}-T_{r s, m}\right) A_{c v}}{R_{w, r s}}
$$

Substituting $\Delta h=C_{p}\left(T_{w, o}-T_{w, i}\right)$ into equation 5.63 and rearranging gives

$$
T_{w, o}=\frac{T_{w, i}\left(R_{w, r s} \dot{m}_{w} C_{p}-A_{c v}\right)+A_{c v} T_{s, m}}{R_{w, r s} \dot{m}_{w} C_{p}}
$$

Equation 5.64 may now be applied to each control volume in the z-direction of the roof slab such that the variation in water temperature may be accounted for.

\subsection{Mathematical Modelling with Roof-spray Cooling}

The basic concept of roof-spray cooling is to continuously wet the roof surface by cooling it down with sprayed water (Carrasco et al. 1987). With a wetted roof surface more heat from the roof surface is lost to the atmosphere due to evaporation resulting in a reduction in roof temperature and heat entry to the building (Jain, 2006). Figure 5.9 gives the roof control surface when a roof spray is applied to the one-room building.

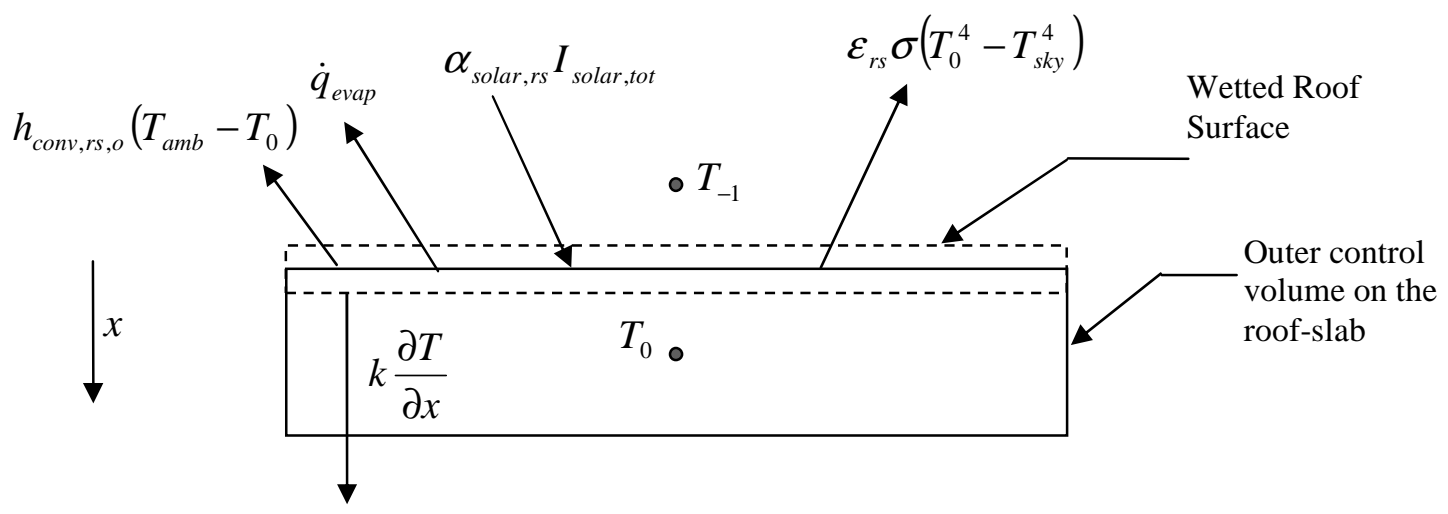

Figure 5.9: Control Surface of the Wetted Roof

In the derivation of the mathematical model of the roof spray system Jain (2006), Clements and Sherif (1998) as well as Carrasco et al. (1987) assumes a negligible thickness of the wetted water layer on the roof surface. The reasoning behind this was that the sprayed water on the roof adds a constant evaporative heat flux to the roof control surface without affecting the convective heat transfer (Carrasco et al. 1987). Applying the conservation of energy to the roof surface in figure 5.9 gives

$$
\alpha_{\text {solar }, r s} I_{\text {solar }, \text { tot }}+h_{c o n v, r s, o}\left(T_{a m b}-T_{0}\right)+k_{r s} \frac{\partial T}{\partial x}-\varepsilon_{r s} \sigma\left(T_{0}^{4}-T_{s k y}^{4}\right)-\dot{q}_{\text {evap }}=0
$$


The only difference between the energy balance of a bare roof surface (equation 5.21) and that of a wetted roof (equation 5.65) is the evaporative heat flux term $\dot{q}_{\text {evap }}$. At the wetted surface water vapour diffuses into the ambient air as a result of Fick's law of diffusion. Tiwari et al. (1981) presents this evaporative heat flux as

$$
\dot{q}_{\text {evap }}=0.013 h_{\text {evap }}\left(p_{\text {vap }, r s}-\phi_{\text {amb }} p_{\text {vap }, \text { amb }}\right)
$$

where $h_{\text {evap }}$ is the evaporative heat transfer coefficient from the water surface to the ambient, $\phi_{a m b}$ the air relative humidity, $p_{v a p, r s}$ the partial pressure of the water vapour evaluated at the wetted roof surface temperature and $p_{\text {vap,amb }}$ the partial vapour pressure of the ambient air. The partial vapour pressure has an exponential relationship as a function of temperature and may be calculated by (Jain, 2006)

$$
p_{\text {vap }}(T)=\exp \left[25.317-\frac{5144}{T+273.15}\right]
$$

Substituting equation 5.66 into equation 5.65 and incorporating the finite difference scheme for the conduction heat transfer term (equation 5.22) gives

$$
\begin{aligned}
T_{-1}= & T_{1}+\frac{2 h \alpha_{\text {solar }, r s} I_{\text {solar }, \text { tot }}}{k_{r s}}+\frac{2 h h_{\text {conv }, r s, o}\left(T_{a m b}-T_{0}\right)}{k_{r s}}-\frac{2 h \varepsilon_{r s} \sigma\left(T_{0}^{4}-T_{s k y}^{4}\right)}{k_{r s}} \\
& -\frac{0.026 h h_{\text {evap }}\left(p_{\text {vap }, r s}-\phi p_{\text {vap }, a m b}\right)}{k_{r s}}
\end{aligned}
$$

Substituting equation 5.68 into the simple explicit finite difference scheme at node 0 ,equation 5.24, gives

$$
\begin{aligned}
T_{0}^{n+1}= & 2 F o T_{1}^{n}+\left(1-2 F o-\frac{2 h F o \varepsilon_{r s} \sigma T_{0}^{n^{3}}}{k_{r s}}-\frac{2 h F o h_{c o n v, r s, o}}{k_{r s}}\right) T_{0}^{n}+\frac{2 h F o h_{c o n v, r s, o}}{k_{r s}} T_{a m b} \\
& +\frac{2 h F o \alpha_{\text {solar }, r s} I_{\text {solar }, \text { tot }}}{k_{r s}}+\frac{2 h F o \varepsilon_{r s} \sigma T_{s k y}^{4}}{k_{r s}}-\frac{0.026 h F o h_{\text {evap }}\left(p_{w}-\phi p_{a}\right)}{k_{r s}}
\end{aligned}
$$

\subsection{Mathematical Modelling with Roof-pond Cooling}

The roof cooling system as modelled in Chapter 4 utilises a roof-pond and roof-spray system to cool water during nocturnal hours. During the diurnal hours the roof-pond serves to reduce the heat flux entering the one-room building through the roof. Tiwari et al. (1981) reports that an open roof-pond reduces the roof heat flux up to $66 \%$ while Sodha et al. (1980:2) found a reduction of $48 \%$. Figure 5.10 depicts the roof with the roof-pond.

In Chapter 4 the conservation of energy was applied to the roof-pond control volume and roof-pond water temperature may therefore be calculated from equation 4.8. 


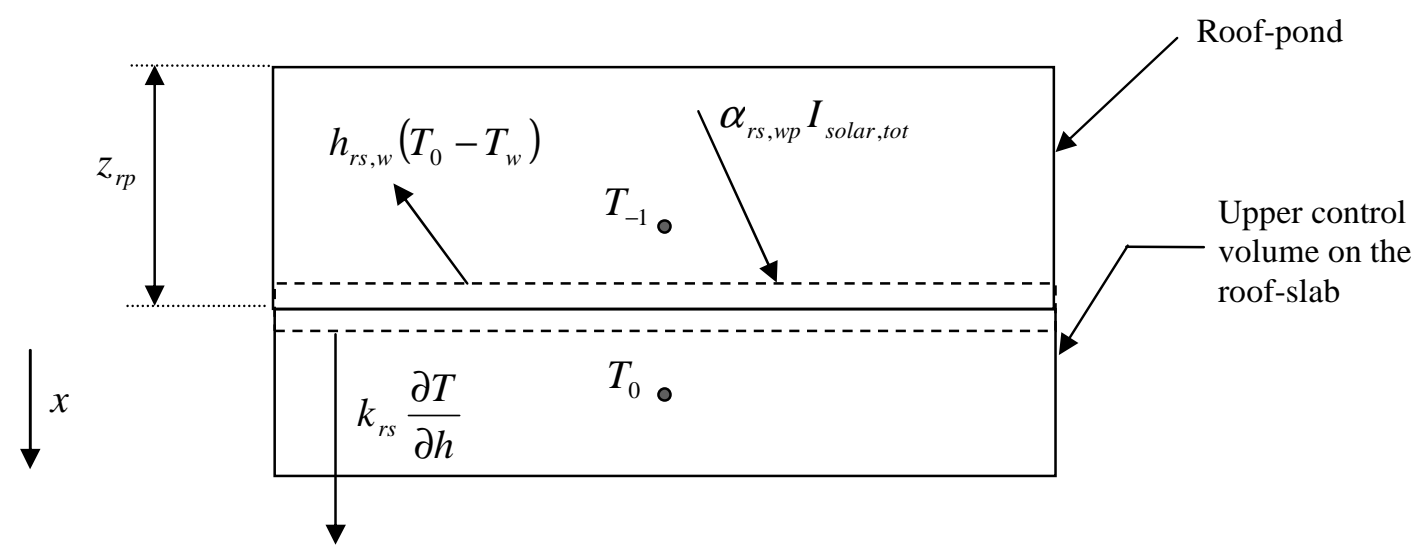

Figure 5.10: Control Surface of the Roof with a Roof-pond

Applying the conservation of energy to the roof surface control volume in figure 5.10 gives

$$
I_{s o l a r, t o t} \alpha_{r s, r p}-h_{r s, w}\left(T_{0}-T_{w}\right)=-k_{r s} \frac{\partial T}{\partial x}
$$

where $I_{\text {solar,tot }}$ is the incident solar shortwave radiation on the roof surface, $\alpha_{r s, r p}$ the portion of solar radiation absorbed by the roof-slab and $h_{r s, w}$ the convective heat transfer coefficient between the roof surface and the roof-pond. The solar radiation absorbed by the roof surface is a function of the roof reflectivity $\rho_{r, r s}$, the water reflectivity $\rho_{r, w}$, the water transmissivity, $\tau_{w}$, and the roof surface solar absorbtivity $\alpha_{r s}$. It can be shown that $\alpha_{r s, r p}$ may be calculated by

$$
\alpha_{r s, r p}=\frac{\tau_{w} \alpha_{r s}}{1-\rho_{r, r s} \rho_{r, w}}
$$

Both Sodha et al. (1980:2) and Jain (2006) uses a value of $135 \mathrm{~W} / \mathrm{m}^{2} \mathrm{~K}$ for the heat transfer coefficient $h_{r s, w}$ between the roof surface and the roof-pond. For stagnant conditions, flow is established by buoyancy forces caused by the temperature difference between the roof-pond water and roof surface. The calculation of the natural convection coefficient depends on whether the roof surface is warmer than the roof-pond water or not. For a scenario where the roof-pond water is warmer than the roof surface the heat transfer coefficient may be calculated from the Nusselt number given by equation C.54. When the roof surface is warmer than that of the roof-pond the Nusselt number given by equation C.51 is used.

Incorporating the finite difference scheme for the conduction heat transfer term (equation 5.22) in equation 5.70 and rearranging gives

$T_{-1}=T_{1}+\frac{2 h I_{\text {solar }, t o t} \alpha_{r s, r p}}{k}-\frac{2 h h_{r s, w}}{k}\left(T_{0}-T_{w}\right)$ 
Substituting equation 5.71 into the simple explicit finite difference scheme at node 0 (equation 5.24) gives

$$
T_{0}^{n+1}=2 F o T_{1}^{n}+\left(1-2 F o-\frac{2 h F o h_{r s, w}}{k}\right) T_{0}^{n}+\frac{2 h F o I_{s o l a r, t o t} \alpha_{r s, r p}}{k}+\frac{2 h F o h_{r s, w}}{k} T_{w}
$$

\subsection{One-Room Building Flowchart}

The one-room building flowchart (figure 5.12) shows the computer program logic for the cooling load and room temperature simulations. The three main sub procedures for the oneroom building flowchart are presented in figure 5.11. The one-room building flowchart includes built-in options that allow the selection of the sustainable cooling alternatives, i.e. either the base case, night flushing, roof-pond, roof-spray, active mass cooling or a practical combination thereof.

From figure 5.12 the one-room building flowchart comprise three main loops namely Loop3_min, Loop2_hrs and Loop1_day that utilise three main sub procedures called Initial conditions, Instant Calculations and Building Properties. Figure 5.11 gives each of the main sub procedures with the corresponding variables that are calculated when the specific procedure is implemented. The Initial conditions procedure feeds the program with initial temperatures of the walls, slab, room and ambient. All building related properties are fed to the program by means of the Building Properties procedure.

The Instant Calculations procedure calculates the various cooling loads of the one-room building for a predetermined time interval. In order to execute the Instant Calculations procedure, numerous sub-calculations such as the heat transfer coefficients, solar radiation etc. needs to be calculated. Where ambient properties (e.g. $T_{a m b} T_{d p}, T_{s k y}, \varepsilon_{s k y}, \phi_{a m b}$ ) and the solar irradiation is assumed constant for a specific hour of a day these may be incorporated in Loop2_hr before Loop3_min is performed. The procedure starts off by calculating general instantaneous properties followed by the calculation of variables that pertain to the specified sustainable cooling alternative method. Once all the sub-calculations have been performed, the cooling loads are calculated and the new room air temperature is determined.

The three main procedures described above are incorporated into Loop3_min,Loop2_hr and Loop1_day such that the cooling loads may be calculated every minute, for every hour of subsequent days. The concept of calculating the cooling load and room temperature at minute, hourly and daily intervals are illustrated in the one-room building flowchart (refer to figure 5.12). 


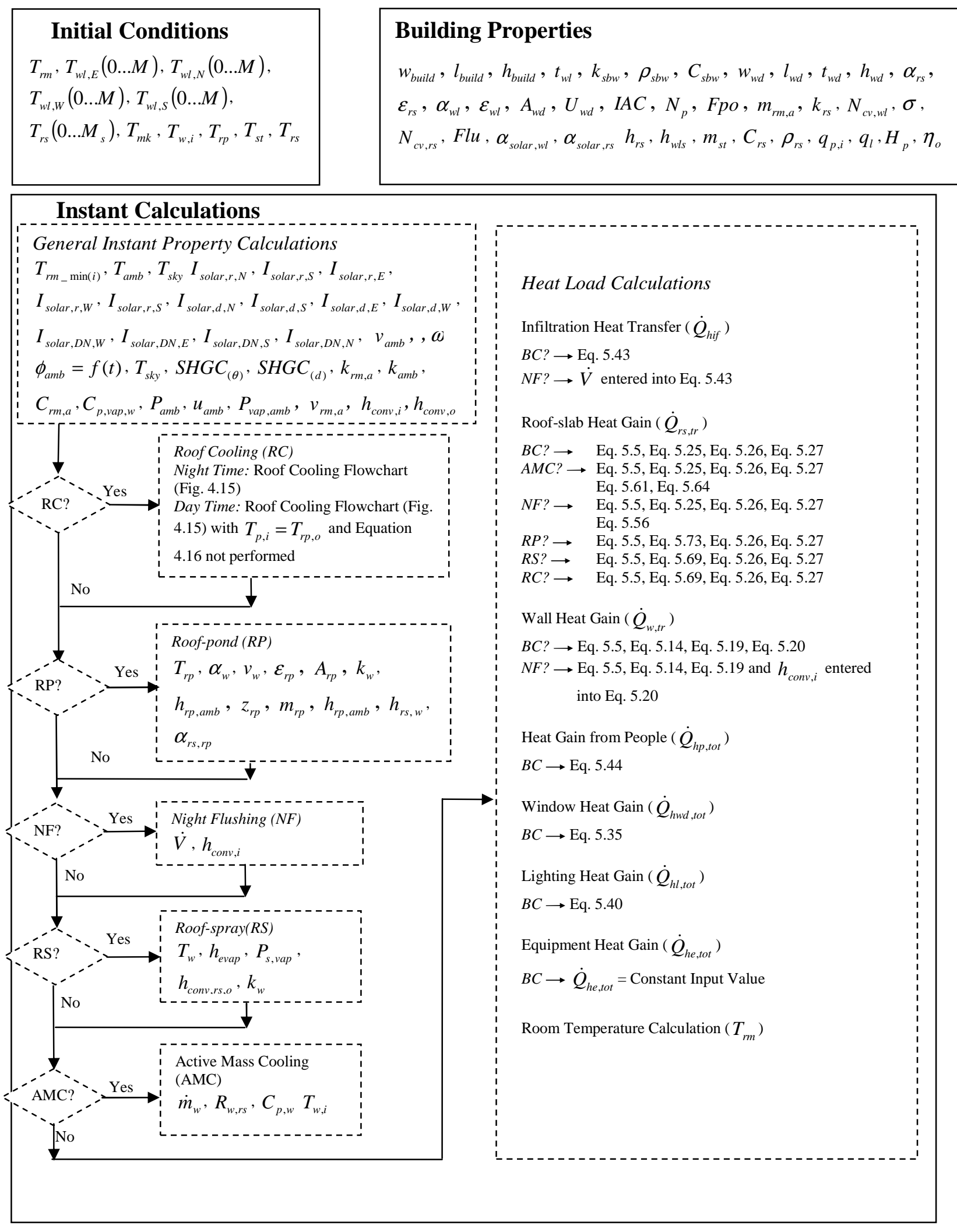

Figure 5.11: The Three Main Sub Procedures for the One-Room Building Flowchart 
Loop3_min

$n=0, i=0$,

$T_{r m_{-} \min }(i)=T_{r m_{-} h}(i i-1)$

$i i>0$ or $i i i>0$ ? $\longrightarrow$ Set

$T_{w l, E}(0 \ldots M), T_{w l, N}(0 \ldots M)$,

$T_{w l, W}(0 \ldots M), T_{w l, S}(0 \ldots M)$,

$T_{r s}\left(0 \ldots M_{s}\right), T_{r p}(0)$ and $T_{s t}(0)$ equal

to the value of the previous hour

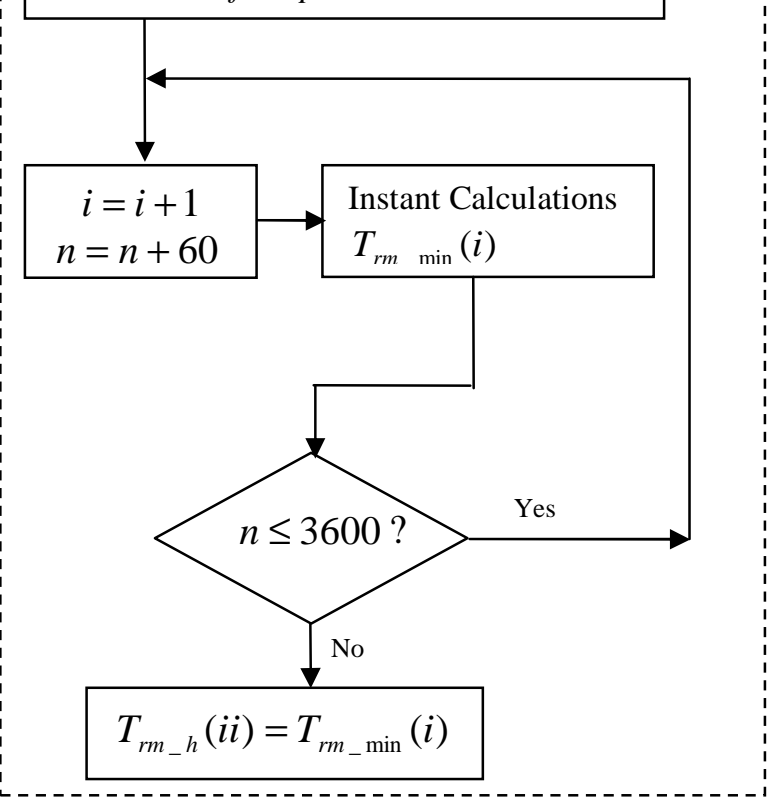

Loop2_hr

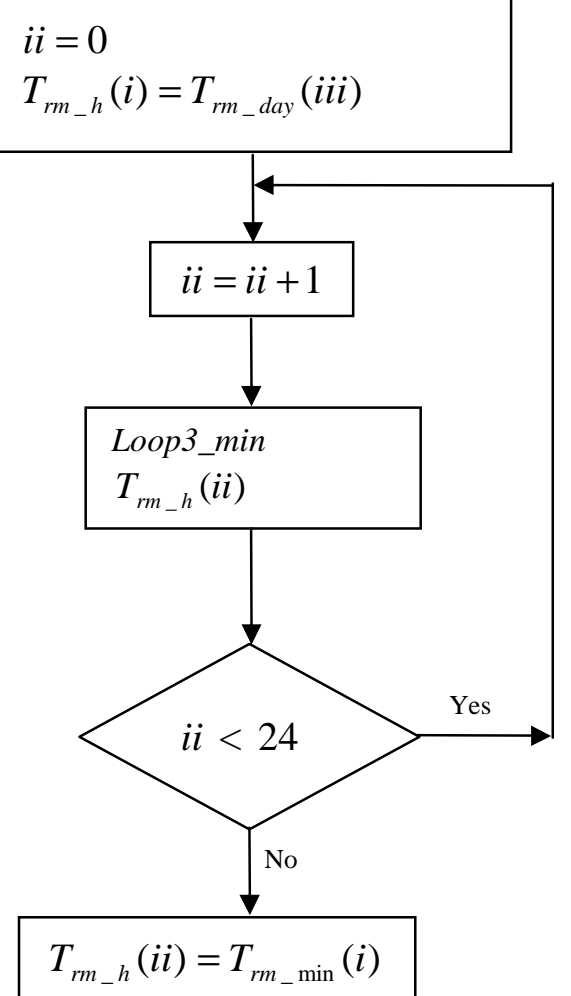

Loop1_day

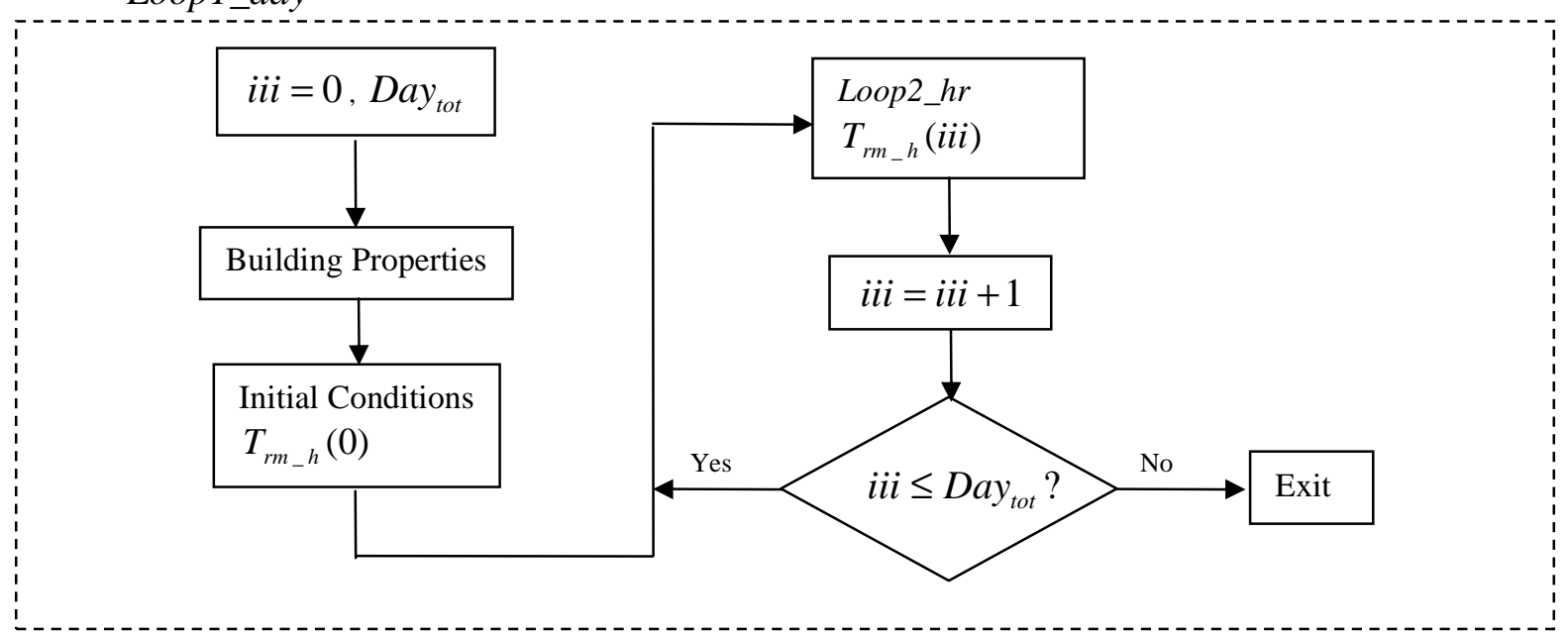

Figure 5.12: The One-Room Building Flowchart 


\section{EXPERIMENTAL WORK}

Experimental work was performed to provide a means of validating the mathematical model and computer simulation calculations of the roof cooling system. A roof cooling experiment was performed at the solar laboratory of the Mechanical Engineering Faculty, University of Stellenbosch, South Africa (Latitude: -33.93, Longitude: 18.85, Altitude: 250m). Nocturnal experimental readings were taken in the winter months of 2008 and 2009. The roof cooling experiment was performed under a variety of meteorological conditions.

\subsection{Experimental Set-up}

The experiment was set-up such that the cooling effect of both the sprayed water droplets and the roof-pond could be taken into account. The spray part of the roof cooling system was modelled by a set of spray nozzles and the roof-pond part by a galvanised tray filled with water exposed to the night sky. The galvanised tray was left uninsulated at the bottom and sides. Figure 6.1 schematically illustrates of the experimental set-up.

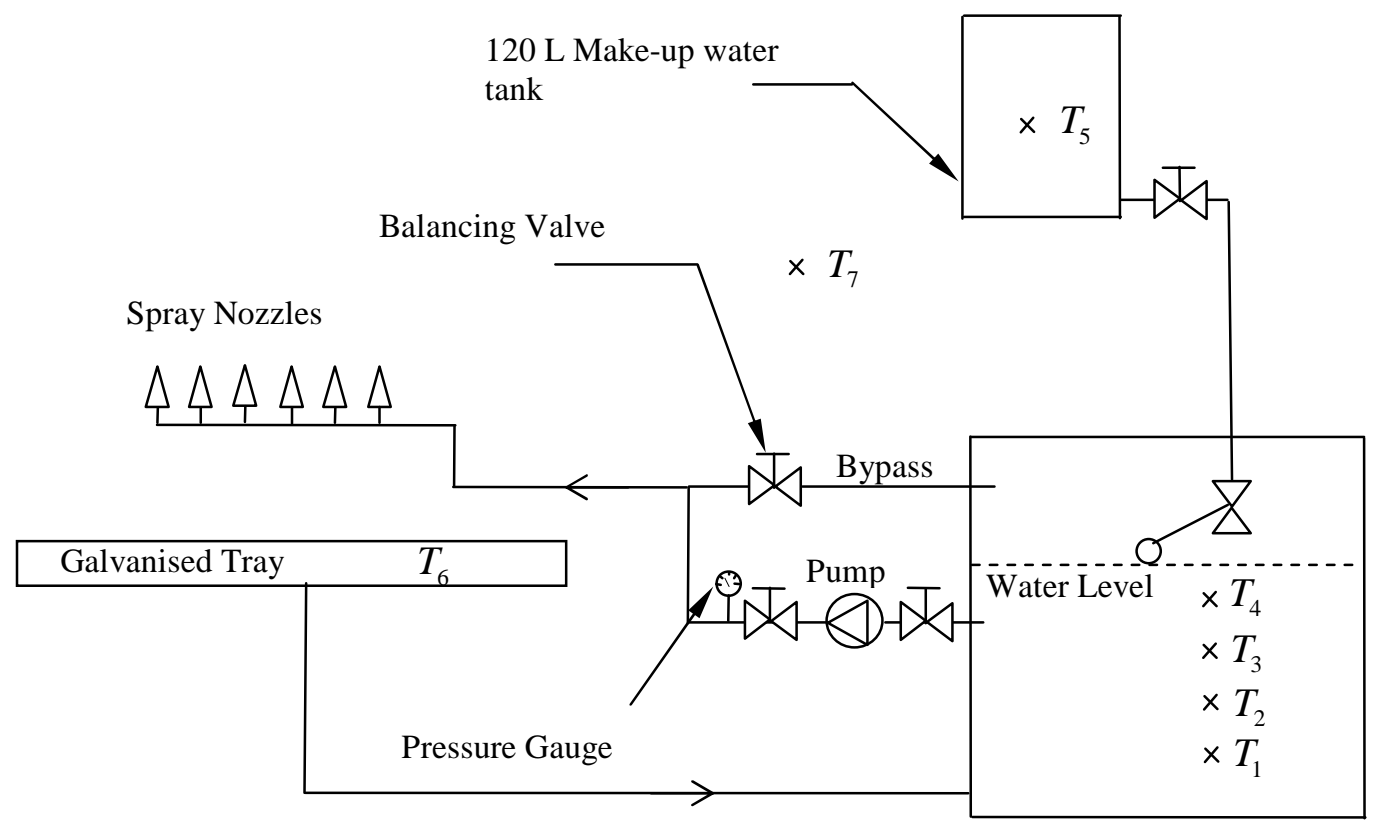

200 L Storage Tank

Figure 6.1: Experimental Set-up of the Roof Cooling System

A 200 litre u-PVC storage tank was used as a storage volume. The storage tank was intentionally left uninsulated to increase the heat loss from the roof cooling system during nocturnal hours. Water from the storage tank was pumped by a $0.75 \mathrm{~kW}$ Foras centrifugal pump to a set of six spray nozzles. The spray nozzles were of the Hunter manufacture (6Q and $2 \mathrm{H}$ type with a spray angle of approximately $90^{\circ}$ and $180^{\circ}$ respectively), producing droplet sizes classified as "extra coarse". The nozzles were orientated such that the maximum number of sprayed droplets would reach the tray and spray drift minimised. The galvanised tray was $2060 \mathrm{~mm}$ wide by $2090 \mathrm{~mm}$ long with a water holding capacity of 300 litres. Water from the galvanised tray was gravity fed back to the 228 litre storage tank. A 120 litre make- 
up water tank and float valve situated in the 228 litre storage tank maintained the water volume at 204 litres. The purpose of the make-up water tank was to replace the water lost to evaporation and spray drift.

Water feeding the spray nozzles was taken from the top of the 228 litre storage tank and the return water from the tray was fed back to the tank at the bottom. This was done to introduce a temperature gradient within the tank.

Seven type- $T$ thermocouples were employed in the experiment. Four thermocouples, designated as $T_{1}, T_{2}, T_{3}$ and $T_{4}$, were placed at increasing heights in the 228 litre storage tank, one thermocouple $T_{6}$ was placed in the water accumulated in the galvanised tray (hereafter referred to as the roof-pond water), another $T_{5}$ was placed in the make-up water storage tank, and the last thermocouple $T_{7}$ was placed in the ambient air whilst being shielded from the night sky with a galvanised steel plate. Refer to figure 6.1 for the location of the thermocouples.

The spray pressure was measured with a dial pressure gauge placed in the supply pipe between the pump and nozzles. The ambient temperature, wind velocity and humidity were measured by means of the calibrated weather station at the Solar Laboratory, University of Stellenbosch, South Africa

\subsection{Experimental Procedure}

At the onset of the experiment the galvanised tray, make-up water tank and the storage tank were filled with water. The water volume of the storage tank and galvanised tray were determined by the procedure outlined in Appendix H. The procedure followed to determine the characteristic VMD of all the nozzles as well as the droplet initial discharge velocity are also given in Appendix $\mathrm{H}$.

The flow to the nozzles was set not to cause an excessive water spray but to rather have the sprayed water droplets reach the intended catchment area of the galvanised tray. The balancing of the flow to the spray nozzles was done via the balancing valve in the bypass line (see figure 6.1). The nozzle discharge angles were set so as to minimise water loss and to have maximum water collection on the galvanised tray.

The water flow rate to the spray nozzles was determined by inserting the nozzles into a separate 200 litre tank and measuring the quantity of water that was sprayed in the tank during a given time period. For example, it was measured that 5.6 litres of water was sprayed in the tank in 30 seconds resulting in an average flow rate of $0.1867 \mathrm{l} / \mathrm{s}$. The water flow rate were also in some instances estimated from the pump duty curve of the Foras pump, refer to Appendix $\mathrm{H}$.

The temperatures from all the thermocouples were measured continuously and logged via the data acquisition system. In all experiments, the ambient relative humidity, air pressure, wind velocity and dry bulb temperature were measured at $5 \mathrm{~min}$ intervals. The cloud cover was also observed for the duration of all the experiments. The roof cooling experiment was 
repeated for a variety of initial and ambient conditions. The test conditions and results of the experiments are given in Chapter 7.

\subsection{Measurement Uncertainty}

Figliola and Beasley (2000) define measurement error as the difference between the true value and the value assigned by the measurement. An estimate of the probable error in the measurement refers to the uncertainty of the measurement. The uncertainty defines an interval about the measured value within which the true value is expected to fall (Figliola and Beasley, 2000). Measurement errors can be categorised as either calibration errors, data acquisition errors or data reduction errors. A calibration error in a measurement arises due to bias and precision errors that occur during the calibration process. Data acquisition errors are those errors that occur in the actual act of measurement. Data reduction errors emerge in data processing during curve and correlation fits, truncation or any procedure required to make the measured data presentable.

The National Institute for Science and Technology (NIST) in the United States provides specifications for the materials and construction of standard thermocouple circuits for temperature measurement. A thermocouple manufactured to NIST standards has a temperature measurement accuracy that is within the NIST specified tolerance limits and does therefore not require calibration (Figliola and Beasley, 2000). The type T thermocouple is manufactured to NIST standards from a material combination of copper and constantan and has a temperature measurement accuracy of $\pm 1.0^{\circ} \mathrm{C}$ according to NIST standard.

According to Figliola and Beasley (2000), the total error contained in a set of measurements may be described by an average bias error and statistical estimate of the precision errors in the measurement. The total error would encompass calibration, data acquisition and data reduction errors. In order to determine the total error for the roof cooling experiment and oil bath calibration procedure was followed.

\subsubsection{Uncertainty Analysis}

An oil bath calibration procedure was followed such that the uncertainty associated with the experiments could be determined. The oil bath calibration procedure is given in Appendix $\mathrm{H}$.

The temperatures measured with the thermocouples of the oil bath procedure are given in table 6.1. The mean temperature of each measurement is calculated by

$\bar{T}_{i}=\frac{1}{M} \sum_{j=1}^{M} T_{j}$

where $j$ denotes the $j^{\text {th }}$ thermocouple, $i$ the $i^{\text {th }}$ test number or data set, $T$ the thermocouple temperature reading and $M$ the total number of thermocouples. The mean temperature of each data set is given in the column on the right of table 6.1 . 
Table 6.1: Oil Bath Temperature Measurements

\begin{tabular}{|c|c|c|c|c|c|c|c|c|c|}
\hline & & \multicolumn{7}{|c|}{ Thermocouple Number } & \\
\hline $\begin{array}{c}\text { Data Set } \\
\text { Number }\end{array}$ & $\begin{array}{c}T_{i, a c t} \\
\text { (measured with } \\
\text { the PRT) }\end{array}$ & $T_{1, i}$ & $T_{2, i}$ & $T_{3, i}$ & $T_{4, i}$ & $T_{5, i}$ & $T_{6, i}$ & $T_{7, i}$ & $\begin{array}{c}\bar{T}_{i} \text { (Mean } \\
\text { Temperature) }\end{array}$ \\
\hline 1 & 0.04 & -0.20 & -0.21 & -0.25 & -0.23 & -0.25 & -0.25 & -0.27 & -0.237 \\
\hline 2 & 20.72 & 20.78 & 20.77 & 20.76 & 20.76 & 20.77 & 20.76 & 20.74 & 20.76 \\
\hline 3 & 30.48 & 30.46 & 30.39 & 30.38 & 30.42 & 30.50 & 30.38 & 30.34 & 30.41 \\
\hline 4 & 40.88 & 40.86 & 40.80 & 40.77 & 40.81 & 40.71 & 40.77 & 40.78 & 40.78 \\
\hline 5 & 47.35 & 47.16 & 47.08 & 47.02 & 47.10 & 47.36 & 47.04 & 46.76 & 47.07 \\
\hline
\end{tabular}

The manufacturer of the platinum resistance thermometer gives a maximum calibration error of $0.015^{\circ} \mathrm{C}$. This value will be treated as a bias error $u_{B, 1}$ in the uncertainty analysis. Where the true temperature value is known, the bias error of a measurement may be estimated as the difference between the true temperature and the mean measured temperature (Figliola and Beasley 2000). With the oil bath calibration procedure this bias error becomes

$u_{B, 2}=T_{i, a c t}-\bar{T}_{i}$

where $u_{B, 2}$ denotes the second bias error. If it is assumed that the data acquisition errors associated with resistance recording of the ohm meter is negligible, the total bias error for each measurement may be calculated by the sum of squares of the all the bias errors (Figliola and Beasley, 2000), i.e.

$u_{B, t o t}=\sqrt{u_{B, 1}^{2}+u_{B, 2}^{2}}$

The precision error gives a measure of the random variation found during each measurement. The precision error for finite data sets may be estimated by the standard deviation of the means (Figliola and Beasley 2000)

$S_{\bar{T}}=\frac{S_{T}}{\sqrt{M}}$

where $S_{\bar{T}}$ denotes the standard deviation of the means, $S_{T}$ the standard deviation of each respective measured data set and $M$ the sample size. The standard deviation of the $i^{\text {th }}$ data set is calculated by

$S_{\bar{T}, i}=\sqrt{\frac{\sum_{i=1}^{N}\left(T_{i}-\bar{T}_{i}\right)^{2}}{(M-1)}}$ 
The precision error $u_{P}$ of each measured data set is estimated as the product of the $t$ weighting function for finite data sets and the standard deviation of the mean temperatures

$$
u_{P}=t_{v, 95} S_{\bar{T}}
$$

where $t_{v, 95}$ is the weighting function at $95 \%$ probability and $v$ the degrees of freedom. The total measurement uncertainty associated with data acquisition and data reduction system of the $i^{\text {th }}$ data set is calculated by the sum of the squares of the bias and precision errors (Figliola and Beasley, 2000)

$$
u_{t o t, i}=\sqrt{u_{B, t o t, i}^{2}+u_{P, i}^{2}}
$$

A representative measurement uncertainty may be calculated for all the measured data sets given in table 6.1. This representative measurement uncertainty is calculated by

$$
\bar{u}_{t o t}=\frac{1}{N} \sum_{i=1}^{N} u_{t o t, i}
$$

where $N$ is the number of data sets. Table 6.2 gives the bias, precision and total errors of the measured data sets.

Table 6.2: Bias, Precision and Total Errors for the Oil Bath Measured Data Sets

\begin{tabular}{|c|c|c|c|c|c|c|c|}
\hline $\begin{array}{c}\text { Data Set } \\
\text { Number }\end{array}$ & $u_{B, 1}$ & $u_{B, 2}$ & $u_{B, t o t, i}$ & $S_{T}$ & $S_{\bar{T}, i}$ & $u_{P, i}$ & $u_{t o t, i}$ \\
\hline 1 & $0.015^{\circ} \mathrm{C}$ & $0.27^{\circ} \mathrm{C}$ & $0.279^{\circ} \mathrm{C}$ & $0.025^{\circ} \mathrm{C}$ & 0.0094 & 0.018 & 0.279 \\
\hline 2 & $0.015^{\circ} \mathrm{C}$ & $-0.046^{\circ} \mathrm{C}$ & $0.049^{\circ} \mathrm{C}$ & $0.015^{\circ} \mathrm{C}$ & 0.006 & 0.011 & 0.049 \\
\hline 3 & $0.015^{\circ} \mathrm{C}$ & $0.071^{\circ} \mathrm{C}$ & $0.073^{\circ} \mathrm{C}$ & $0.053^{\circ} \mathrm{C}$ & 0.02 & 0.039 & 0.083 \\
\hline 4 & $0.015^{\circ} \mathrm{C}$ & $0.098^{\circ} \mathrm{C}$ & $0.099^{\circ} \mathrm{C}$ & $0.047^{\circ} \mathrm{C}$ & 0.017 & 0.035 & 0.105 \\
\hline 5 & $0.015^{\circ} \mathrm{C}$ & $0.272^{\circ} \mathrm{C}$ & $0.272^{\circ} \mathrm{C}$ & $0.18^{\circ} \mathrm{C}$ & 0.068 & 0.133 & 0.302 \\
\hline
\end{tabular}

\section{Temperature Uncertainty}

To illustrate the procedure of calculating the uncertainty of the thermocouples a sample calculation will be presented here. From the second test, the average temperature measured by the thermocouples (refer to table 6.1) is calculated from equation 6.1

$\bar{T}_{2}=\frac{1}{M} \sum_{j=1}^{M} T_{j}=\frac{1}{7}(20.78+20.77+20.76+20.76+20.77+20.76+20.74)=20.76^{\circ} \mathrm{C}$

The calibration uncertainty of $u_{B, 1}$ for the platinum resistance thermometer is $0.015^{\circ} \mathrm{C}$. The second bias error $u_{B, 2}$ is calculated from equation 6.2, i.e.

$u_{B, 2}=T_{i, a c t}-\bar{T}_{i}=20.716-20.76=-0.048^{\circ} \mathrm{C}$ 
The total bias for the second data set is calculated from the sum of the squares of all the bias errors, i.e.

$u_{B, t o t, 2}=\sqrt{u_{B, 1}^{2}+u_{B, 2}^{2}}=\sqrt{0.048^{2}+0.015^{2}}=0.0485^{\circ} \mathrm{C}$

The standard deviation is calculated from equation 6.5

$S_{T, 2}=\sqrt{\frac{\sum_{i=1}^{N}\left(T_{i}-\bar{T}_{i}\right)^{2}}{(M-1)}}=0.0152^{\circ} \mathrm{C}$

The standard deviation of the means is calculated from equation 6.4

$S_{\bar{T}}=\frac{S_{T}}{\sqrt{M}}=\frac{0.0152}{\sqrt{7}}=0.0057^{\circ} \mathrm{C}$

The value of the $t$-distribution at $95 \%$ probability and 6 degrees of freedom is 1.943 (Figliola and Beasley, 2000). The precision error associated with the measurement becomes

$u_{P, 2}=t_{v, 95} S_{\bar{T}, 2}=1.943 \times 0.0057=0.011^{\circ} \mathrm{C}$

The total measurement uncertainty for the second measure data set is calculated from equation 6.7

$u_{t o t, 2}=\sqrt{u_{B, t o t, 2}^{2}+u_{P, 2}^{2}}=\sqrt{0.0485^{2}+0.0111^{2}}=0.049^{\circ} \mathrm{C}$

The above calculation is repeated for the remaining measure data sets. Their total uncertainties may be found in table 6.2. The uncertainties of all the data sets are averaged in equation 6.8 to give a representative uncertainty value for the temperature measurement of the experimental tests, i.e.

$\bar{u}_{t o t}=\frac{1}{N} \sum_{i=1}^{N} u_{t o t, i}=0.164^{\circ} \mathrm{C}$

\subsection{Error Propagation}

Measurement uncertainty propagates to an error in the result of a calculation when the measured value utilised has an associated measurement uncertainty. The energy loss from the storage tank $E_{\text {lost }}$ represents the cooling ability of the roof cooling system and is calculated by

$$
E_{\text {lost }}=m_{s t} C_{v, w}\left(T_{s t, i n i}-T_{s t, 1}\right)
$$


where $m_{s t}$ is the storage tank water mass, $C_{v}$ the constant volume specific heat of water, $T_{s t, i n i}$ the initial storage tank temperature and $T_{s t, 1}$ the storage tank temperature measured at time 1 . If $\left(T_{s t, i n i}-T_{s t, 1}\right)$ is presented by $\alpha_{s t}$ then equation 6.9 becomes

$$
E_{\text {lost }}=m_{s t} C_{v} \alpha_{s t}
$$

The maximum measurement error is given by $2 u_{T, t o t}$ as shown in the equation 6.11 below

$$
\alpha_{s t}+u_{\alpha}=\left(T_{0}-u_{T, t o t}\right)-\left(T_{s}+u_{T, t o t}\right)=T_{0}-T_{s}-2 u_{T, t o t}
$$

where $u_{\alpha}$ is the uncertainty associated with $\alpha_{s t}$. The propagation of uncertainty in the variables $m_{s t}$ and $C_{v}$ to an error in the storage volume heat loss $E_{l o s t}$ is given by (Figliola and Beasley, 2000)

$$
u_{E}= \pm \sqrt{\left(\theta_{\alpha} 2 u_{T, t o t}\right)^{2}+\left(\theta_{m} u_{m}\right)^{2}+\left(\theta_{C_{v}} u_{C_{v}}\right)^{2}}
$$

where $\theta$ is the sensitivity index that results from the Taylor series expansion and $u$ the uncertainty of the specific variable. The sensitivity index for $m_{s t}, C_{v}$ and $\alpha_{s t}$ is calculated by the partial derivative of $E_{\text {lost }}$ with respect to that specific variable. That is

$$
\begin{aligned}
& \theta_{\alpha}=\frac{\partial E_{\text {lost }}}{\partial \alpha_{s t}}=m_{s t} C_{v} \\
& \theta_{m}=\frac{\partial E_{\text {lost }}}{\partial m_{s t}}=C_{v} \alpha_{s t} \\
& \theta_{m}=\frac{\partial E_{\text {lost }}}{\partial C_{v}}=m_{s t} \alpha_{s t}
\end{aligned}
$$

The uncertainty associated with storage volume mass $m_{s t}$ is zero as the volume in the tank remains constant throughout the experiment. The constant volume specific heat is a constant and its partial derivative is zero.

$$
u_{m}=u_{c_{v}}=0
$$

Substituting equation $6.13,6.14,6.15$ and 6.16 into equation 6.12 gives the uncertainty associated with the energy loss calculation $u_{E}$

$$
u_{E}= \pm \sqrt{\left(m_{s t} C_{v} 2 u_{T, t o t}\right)^{2}+\left(C_{v} \alpha_{s t} u_{m}\right)^{2}+\left(m_{s t} \alpha_{s t} u_{C_{v}}\right)^{2}}=\sqrt{\left(m_{s t} C_{v} 2 u_{T, t o t}\right)^{2}}=2 m_{s t} C_{v} u_{T, t o t}
$$


For illustration purposes, the storage tank energy loss uncertainty will be calculated for the 02 August 2009 test. From Section 6.3 the uncertainty associated with the temperature measurement is $u_{T, t o t}=0.164{ }^{\circ} \mathrm{C}$. The storage tank water mass is $m_{s t}=200 \mathrm{~kg}$ and the constant volume specific heat of water at $17^{\circ} \mathrm{C}$ is $4187 \mathrm{~J} / \mathrm{kgK}$. Substituting these values into equation 6.17 gives the total error associated with the energy loss from the storage tank

$u_{E}=2 m_{s t} C_{v, w} u_{T, t o t}=275 \mathrm{~kJ}$

As will be shown in Chapter 7, the total energy loss from the storage tank in the 02 August test was $2909.2 \mathrm{~kJ}$. The uncertainty calculated above is approximately $10 \%$ of the total storage tank water energy loss. The measurement uncertainty associated with water temperature, ambient temperature and water flow rate propagates in an uncertainty in the energy loss calculation of the water droplets and the roof-pond. In Appendix F, the uncertainty related to the convection, evaporation and radiation energy transfer of both the water droplets and roof-pond is calculated by means of sequential perturbation ${ }^{1}$.

\footnotetext{
${ }^{1}$ Sequential perturbation is the numerical approach to estimate the propagation of uncertainty through to a result. (Figliola et al. 2000)
} 


\section{SIMULATION AND EXPERIMENTAL RESULTS}

The results of the roof cooling system experiment are discussed in this chapter. The experimental results are also compared to the roof cooling theoretical simulation results. This is followed by the discussion of the results obtained from the roof-spray optimisation procedure and a sensitivity analysis on the roof cooling system.

The theoretical simulation results for the one-room building cooling load and room temperature are presented for the base case as well as the case where night flushing, roofpond, roof-spray, roof cooling system and active mass cooling are applied to the building. The results for the scenario where the sustainable cooling alternatives are applied in combination to the one-room building are also discussed. The influence of the night flushing technique's air change rate on the one-room building cooling load is investigated. Similarly, the influence of the roof-pond water level on the cooling load of the one-room building is explored. The ability of the roof cooling system to produce cool water is presented for typical weather conditions.

\subsection{Experimental Results}

A benefit of the roof cooling system is its ability to produce cool water during night time. Experimental work was performed to test this ability and to verify that the temperatures predicted by the theoretical simulation calculations coincide with the experimental readings. The experimental set-up given in figure 6.1 has thermocouples $T_{1}$ to $T_{4}$ recording the storage tank temperatures, thermocouple $T_{5}$ the make-up water temperature, thermocouple $T_{6}$ the roof-pond temperature and thermocouple $T_{7}$ the ambient air temperature.

Five experimental tests were performed on five different days of which the ambient conditions differed. The test conditions for the experimental tests are given table 7.1. The ambient air temperature $T_{a m b}$, humidity $\phi_{a m b}$ and ambient air pressure, $p_{a m b}$ given in table 7.1 were initial values measured at the onset of the experiments. Values for the nozzle discharge angle, nozzle discharge velocity, nozzle characteristic volume, mean diameter, roof-pond surface area, roof-pond water volume, pump duty and pump efficiency were taken as shown in Table 7.1. Even though a precise value for these variables could not be determined were they nonetheless used as if they were known without any uncertainty. As shown in Appendix $\mathrm{H}$, a variation of these variable within an expected tolerance limits did not have a noteworthy influence on the end result. The remaining parameters were taken as shown in Table 7.1 below.

Table 7.1: Test Conditions for the Roof Cooling Experiments

\begin{tabular}{|c|c|c|c|c|c|c|}
\hline Experimental Test & & $\begin{array}{c}25 \text { May } \\
2008\end{array}$ & $\begin{array}{c}12 \text { July } \\
2008\end{array}$ & $\begin{array}{c}02 \text { August } \\
2008\end{array}$ & $\begin{array}{c}03 \text { May } \\
2009\end{array}$ & $\begin{array}{c}04 \text { May } \\
2009\end{array}$ \\
\hline & Symbol & & & & & \\
\hline Ambient Air Temperature & $T_{a m b}$ & $14.5^{\circ} \mathrm{C}$ & $4.3^{\circ} \mathrm{C}$ & $9.57^{\circ} \mathrm{C}$ & $16.1^{\circ} \mathrm{C}$ & $11.55^{\circ} \mathrm{C}$ \\
\hline
\end{tabular}




\begin{tabular}{|c|c|c|c|c|c|c|}
\hline Experimental Test & & $\begin{array}{l}25 \text { May } \\
2008\end{array}$ & $\begin{array}{l}12 \text { July } \\
2008\end{array}$ & $\begin{array}{l}02 \text { August } \\
2008\end{array}$ & $\begin{array}{c}03 \text { May } \\
2009\end{array}$ & $\begin{array}{c}04 \text { May } \\
2009\end{array}$ \\
\hline & Symbol & & & & & \\
\hline Ambient Relative Humidity & $\phi_{a m b}$ & $85 \%$ & $78 \%$ & $60 \%$ & $77 \%$ & $82 \%$ \\
\hline Ambient Air Pressure & $p_{a m b}$ & $100210 \mathrm{~Pa}$ & $102300 \mathrm{~Pa}$ & $-\mathrm{Pa}$ & $101250 \mathrm{~Pa}$ & $101040 \mathrm{~Pa}$ \\
\hline Maximum Wind Velocity & $u_{w}$ & $0.0 \mathrm{~m} / \mathrm{s}$ & $0.0 \mathrm{~m} / \mathrm{s}$ & $1.0 \mathrm{~m} / \mathrm{s}$ & $3.2 \mathrm{~m} / \mathrm{s}$ & $1.6 \mathrm{~m} / \mathrm{s}$ \\
\hline Nozzle Discharge Angle & $\alpha$ & $-35^{\circ}$ & $-35^{\circ}$ & $-35^{\circ}$ & $-35^{\circ}$ & $-35^{\circ}$ \\
\hline Nozzle Discharge Velocity & $u_{d}$ & $2.3 \mathrm{~m} / \mathrm{s}$ & $2.3 \mathrm{~m} / \mathrm{s}$ & $2.3 \mathrm{~m} / \mathrm{s}$ & $2.3 \mathrm{~m} / \mathrm{s}$ & $2.3 \mathrm{~m} / \mathrm{s}$ \\
\hline $\begin{array}{l}\text { Nozzle Characteristic } \\
\text { Volume Mean Diameter }\end{array}$ & $V M D$ & $1700 \mu \mathrm{m}$ & $1700 \mu \mathrm{m}$ & $1700 \mu \mathrm{m}$ & $1700 \mu \mathrm{m}$ & $1700 \mu \mathrm{m}$ \\
\hline $\begin{array}{l}\text { Initial Storage Tank Water } \\
\text { Temperature }\end{array}$ & $T_{s t, i n i}$ & $17.32^{\circ} \mathrm{C}$ & $8.27^{\circ} \mathrm{C}$ & $12.67^{\circ} \mathrm{C}$ & $17.41^{\circ} \mathrm{C}$ & $13^{\circ} \mathrm{C}$ \\
\hline $\begin{array}{l}\text { Initial Make Up Water } \\
\text { Temperature }\end{array}$ & $T_{m w, i n i}$ & - & $9.97^{\circ} \mathrm{C}$ & $12.55^{\circ} \mathrm{C}$ & $18.18^{\circ} \mathrm{C}$ & $12.17^{\circ} \mathrm{C}$ \\
\hline $\begin{array}{l}\text { Initial Roof-pond Water } \\
\text { Temperature }\end{array}$ & $T_{r p, i n i}$ & $14.85^{\circ} \mathrm{C}$ & $3^{\circ} \mathrm{C}$ & $9.07{ }^{\circ} \mathrm{C}$ & $18^{\circ} \mathrm{C}$ & $9.4^{\circ} \mathrm{C}$ \\
\hline $\begin{array}{l}\text { The Roof-pond Surface } \\
\text { Area }\end{array}$ & $A_{r p}$ & $4 \mathrm{~m}^{2}$ & $4 \mathrm{~m}^{2}$ & $4 \mathrm{~m}^{2}$ & $4 \mathrm{~m}^{2}$ & $4 \mathrm{~m}^{2}$ \\
\hline $\begin{array}{l}\text { The Roof-pond Water } \\
\text { Volume }\end{array}$ & $V_{r p}$ & 107 litre & 107 litre & 107 litre & 107 litre & 107 litre \\
\hline The Pump Duty & - & $\begin{array}{l}0.251 / \mathrm{s} @ \\
420 \mathrm{kPa}\end{array}$ & $\begin{array}{c}0.251 / \mathrm{s} @ \\
420 \mathrm{kPa}\end{array}$ & $\begin{array}{c}0.251 / \mathrm{s} @ \\
420 \mathrm{kPa}\end{array}$ & $\begin{array}{c}0.185 \mathrm{l} / \mathrm{s} \\
\text { @ } 270 \mathrm{kPa}\end{array}$ & $\begin{array}{c}0.185 \mathrm{l} / \mathrm{s} \\
\text { @ } 270 \mathrm{kPa}\end{array}$ \\
\hline The Pump Efficiency & $\eta$ & $70 \%$ & $70 \%$ & $70 \%$ & $70 \%$ & $70 \%$ \\
\hline Simulation Duration & $\Delta t$ & $90 \mathrm{~min}$ & $110 \mathrm{~min}$ & $90 \mathrm{~min}$ & $90 \mathrm{~min}$ & $65 \min$ \\
\hline Cloud Cover & - & $\begin{array}{l}\text { Misty } \\
\text { Night }\end{array}$ & $\begin{array}{l}\text { Partly } \\
\text { Cloudy }\end{array}$ & Clear Sky & Clear Sky & Clear Sky \\
\hline
\end{tabular}

All the experimental tests were performed during night time to avert solar radiation and to attain maximum water cooling. The experimental tests of 25 May 2008, 02 August 2008 and 03 May 2009 were conducted after sunset. The experimental tests 12 July 2008 and 04 May 2009 were conducted in the early morning hours of the day before sunrise. The experimentally measured temperatures by the thermocouples are presented in figure 7.1a to figure 7.1e. 


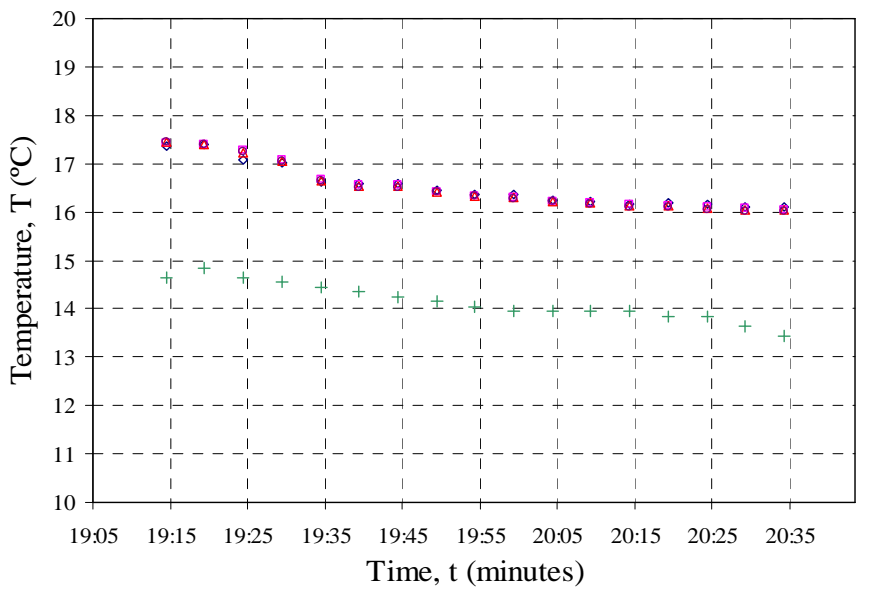

(a): 25 May 2008

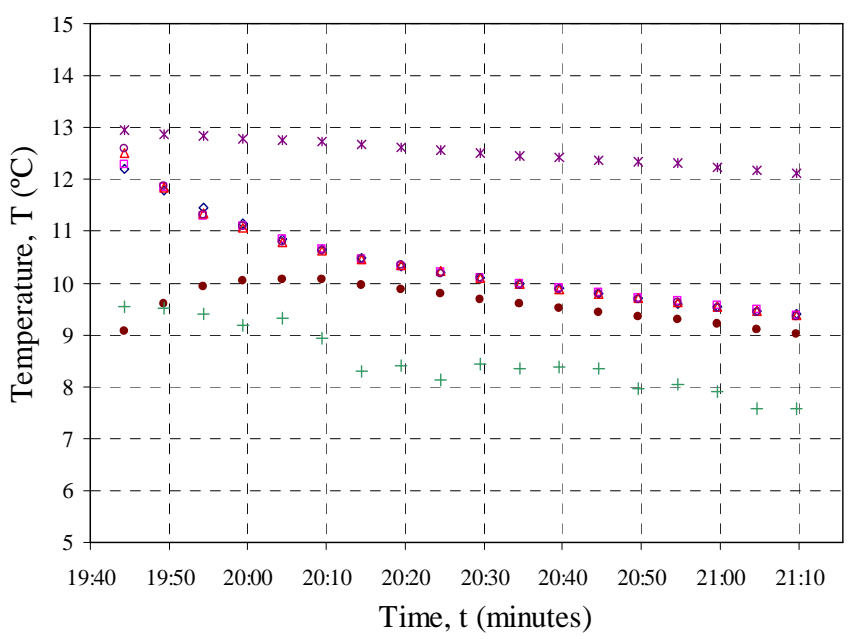

(c): 02 August 2008

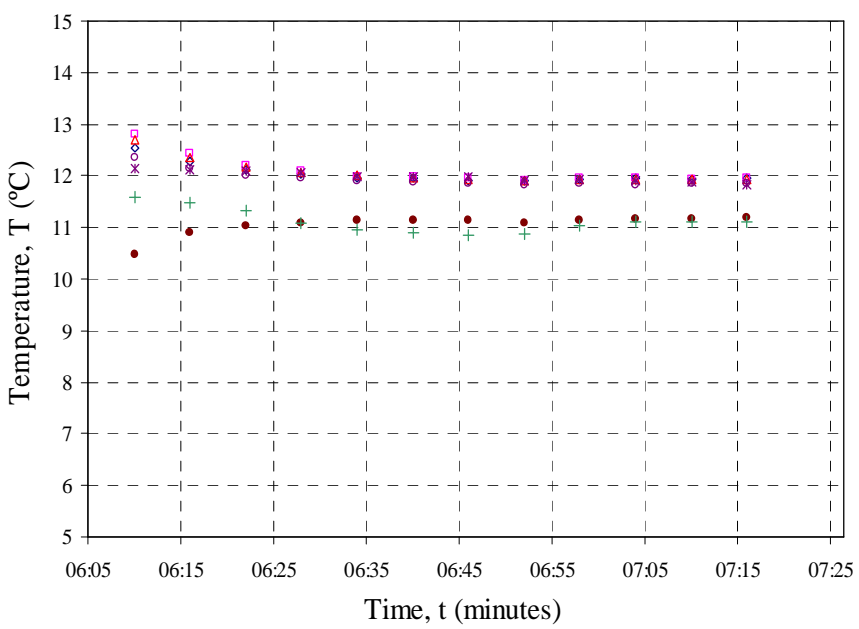

(e): 04 May 2009

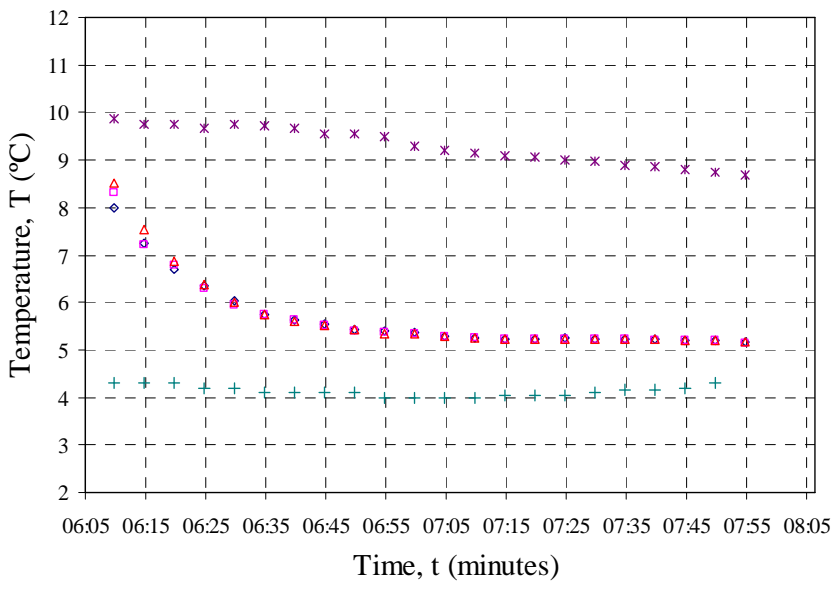

(b): 12 July 2008

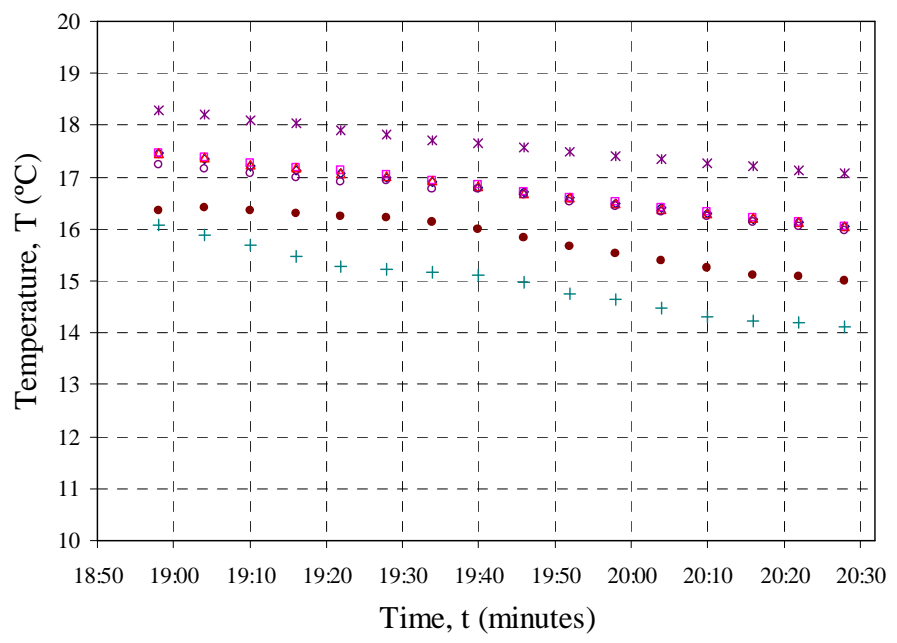

(d): 03 May 2009

- $T_{1}$ Storage tank temperature

$T_{2}$ Storage tank temperature

$T_{3}$ Storage tank temperature

$T_{4}$ Storage tank temperature

$T_{5}$ Make up water tank

- $T_{6}$ Roof-pond water temperature

$T_{7}$ Ambient air temperature

Figure 7.1: Roof Cooling Temperatures for (a) 25 May 2008, (b) 12 July 2008, (c) 02 August 2008, (d) 03 May 2009 and (e) 04 May 2009 Experimental Tests 
The following observations can be made from the roof cooling experimental temperatures depicted in figure 7.1:

\section{Observation 1}

Observation: The initial temperature decrease of the storage tank of the early morning tests differs from the tests conducted in the evening. The storage tank water temperature of the 12 July 2008 test showed a temperature drop of approximately $0.06{ }^{\circ} \mathrm{C} / \mathrm{min}\left(3^{\circ} \mathrm{C}\right.$ within $\left.50 \mathrm{~min}\right)$ while the storage tank of evening tests showed a gradual temperature decrease.

Explanation: The initial rapid temperature decrease of the storage tank temperature may be ascribed to a lower roof-pond water temperature that existed at the onset of the 12 July 2008 test. The roof-pond temperature was lower than the storage tank temperature due to the energy removed from the roof-pond by means of sky radiation, convection and evaporation during the night time hours before the experiment commenced. As the water was circulated through the system, the cool water of the roof-pond mixed with the water of the storage tank, causing the storage tank water to cool down rapidly. This effect is also visible in the 04 May 2009 test but to a lesser extent.

\section{Observation 2}

Observation: After the initial rapid cool down rate of the storage tank water temperature, the rate of temperature decrease for the morning tests reduced to almost zero. This can be seen from 07:15 onwards for the 12 July 2008 test and from 06:35 onwards for the 04 May 2009 test.

Explanation: The initial rapid cool down rate of the storage tank water temperature is explained in observation 1. After this initial cool down rate, the decrease in storage tank water temperature reduced to almost zero due to rising ambient temperatures at the onset of dawn. The increased ambient temperature resulted in a higher sky temperature which in turn reduced the radiation heat loss from the roof-pond.

\section{Observation 3}

Observation: In all the experimental tests performed the storage tank temperature could not be decreased beyond the dewpoint temperature of the ambient air. For the $25^{\text {th }}$ May 2008 test the storage tank temperature could only be lowered within $5.8{ }^{\circ} \mathrm{C}$ of the dewpoint temperature while for the $04^{\text {th }}$ May 2009 test the storage tank temperature could be lowered within $4.1^{\circ} \mathrm{C}$ of the dewpoint temperature.

Explanation: The storage tank and the roof-pond water can never be cooled down to a temperature lower than the dew-point temperature. When the ambient air, in contact with water surface, is cooled down to the dewpoint temperature the air becomes saturated and some water vapour condenses out (Cengel, 2002). During the process of condensation energy is released to the water which in turn increase the water temperature. The cycle of the ambient air cooling and condensation repeats itself and equilibrium is reached. For the $04^{\text {th }}$ May 2009 test this equilibrium was reached within $4.1^{\circ} \mathrm{C}$ of the dewpoint temperature while for the 12 July 2008 the equilibrium state was reached $4.9{ }^{\circ} \mathrm{C}$ above the dewpoint temperature. 


\section{Observation 4}

Observation: For the initial part of the 02 August 2008 and the 04 May 2009 tests the roofpond temperature increased rapidly at an inverted rate at which the storage tank temperature decreased. The rate of roof-pond temperature increase is higher than the rate of temperature decrease of the storage tank.

Explanation: According to the first law of thermodynamics energy can never be created or destroyed; it can only change forms (Cengel, 2002). In the case of the experimental test energy was transferred from the storage tank to the roof-pond as water circulated through the system. The roof-pond energy therefore increased at an inverted rate at which the storage tank energy decreased in order to conserve the energy contained in the system.

\section{Observation 5}

Observation: The roof-pond temperature cools down at a rate equal to that of the storage tank water but at a temperature offset that ranges from $0.4{ }^{\circ} \mathrm{C}$ for the 02 August 2008 test and $1{ }^{\circ} \mathrm{C}$ for the 03 May 2009 and 04 May 2009 tests.

Explanation: The first law of thermodynamics also states that the net change in the total energy of the system during a process is equal to the difference between the total energy entering and the total energy leaving the system during that process (Cengel, 2002). Thus, the net change of both the roof-pond and storage tank internal energy equals the difference between the total energy entering and the total energy leaving each control volume. If heat transfer and work effects are ignored the rate of energy increase by the roof-pond should equal the rate of decrease by the storage tank. The difference in temperature may be ascribed to the different thermal capacities of the roof-pond and the storage tank. The offset in temperature is caused by the difference in heat loss from the two systems.

\section{Observation 6}

Observation: All the tests were conducted under a clear night sky except for the 25 May 2008 test that was conducted in misty conditions and the 12 July 2008 test conducted in partly cloudy conditions. The 25 May 2008 test showed a temperature decrease of $0.019{ }^{\circ} \mathrm{C} / \mathrm{min}$ $\left(1.5^{\circ} \mathrm{C}\right.$ in $\left.80 \mathrm{~min}\right)$ whereas the 02 August 2008 test, performed under clear sky conditions, showed a temperature decrease of $0.038^{\circ} \mathrm{C} / \mathrm{min}\left(3^{\circ} \mathrm{C}\right.$ in $\left.80 \mathrm{~min}\right)$

Explanation: Under a clear night sky the rate of roof-pond temperature decrease is higher than that of a misty or cloudy night. When clear sky conditions prevail, heat is lost via convection, evaporation and radiation. Under cloudy conditions night sky radiation is limited and the prevailing energy loss mechanisms are convection and evaporation. Cloudy conditions results in lower energy removal rates compared to that of clear night sky conditions.

\section{Observation 7}

Observation: The storage tank temperatures measured by thermocouples $T_{1}$ to $T_{4}$ show that at the onset of experimental test 02 August 2008, the temperature at the bottom of the tank is approximately $0.6{ }^{\circ} \mathrm{C}$ lower than the temperature at the top. As time progressed, the temperatures at the top and bottom of the tank came within $0.1^{\circ} \mathrm{C}$ of each other. 
Explanation: Water density increases with decreasing temperatures. Denser water will also sag to the bottom of the tank while the less dense, warmer water will rise to the top. This was the case with the storage tank temperature at the onset of the experiment. As the experiment progressed, the bypass and make-up water flow as well as the suction action of the pump induced sufficient mixing of storage tank water such that a uniform temperature is measured at all levels of the tank.

\subsection{Comparison of Experimental Results with Theoretical Results}

The roof cooling system was simulated for the experimental test conditions given in table 7.1. Figure 7.2 compares the experimentally measured storage tank temperatures with those generated from the theoretical simulation calculations. The various times given in figure 7.2(a) to 7.2(e) denote the local time of the actual measurements. 


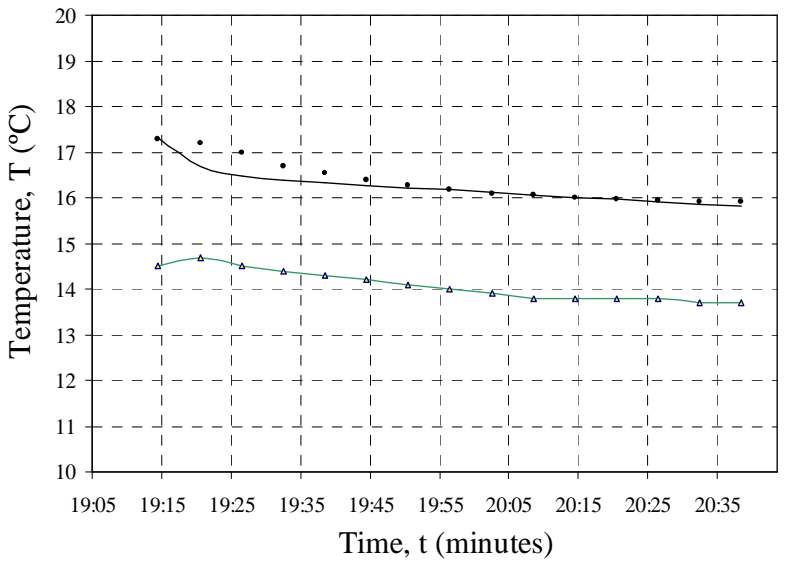

(a): 25 May 2008

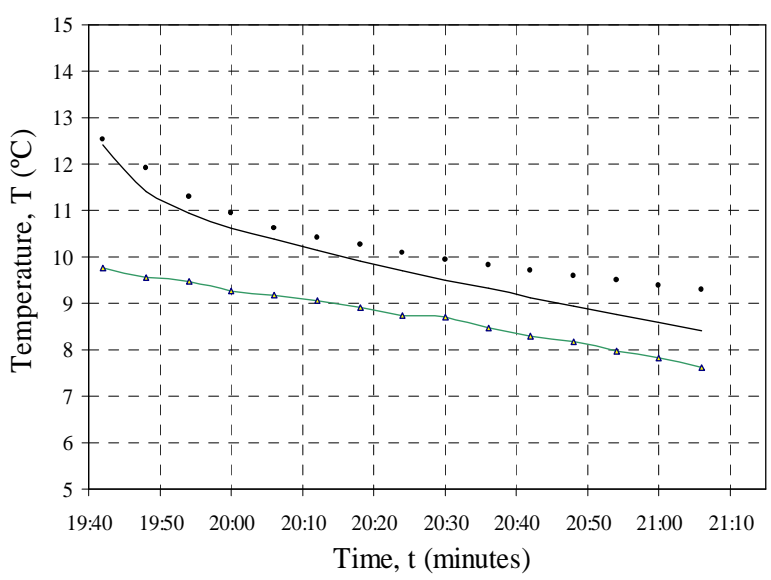

(c ): 02 August 2008

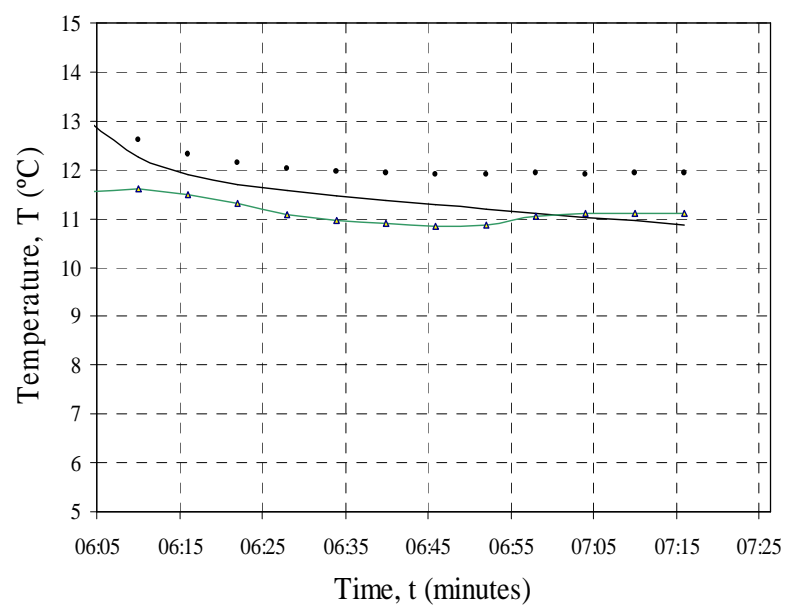

(e): 04 May 2009

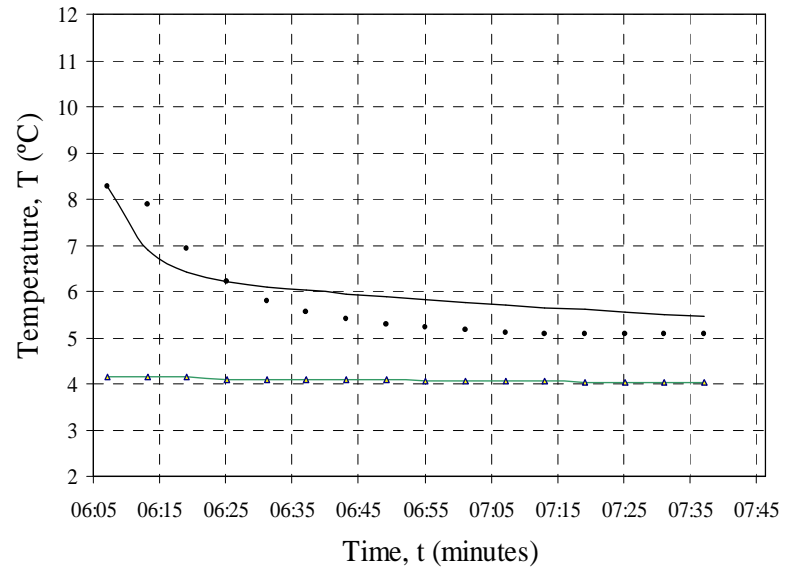

(b): 12 July 2008

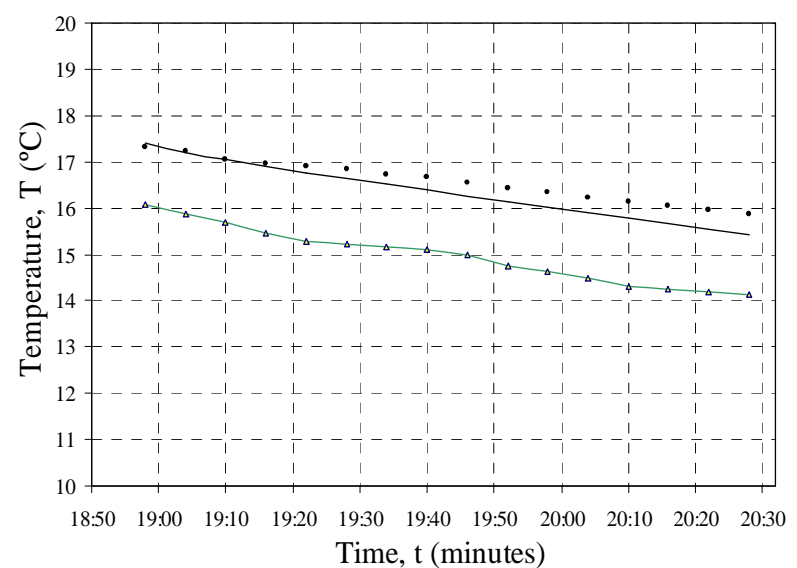

(d): 03 May 2009

- $\quad T_{s t}$ Calculated storage temperature

$$
\bar{T}_{s t, m}=\frac{1}{4} \sum_{i=1}^{4} T_{i}
$$

Average storage tank temperature

$\rightarrow T_{a m b}$ Measured ambient temperature

Figure 7.2: Computer Simulation and Experimental Test Result Comparison for the (a) 25 May 2008, (b) 12 July 2008, (c) 02 August 2008, (d) 03 May 2009 and (e) 04 May 2009 Experimental Tests 
The following observations can be made when the computer simulation is compared with the experimental test results depicted in figure 7.2:

\section{Observation 1}

Observation: The calculation simulations predicted the final storage tank temperature reasonably well. The largest discrepancy was found to be in the order of $1{ }^{\circ} \mathrm{C}$ for 02 August 2008 and the 04 May 2009 tests. The discrepancy may largely be ascribed to an over prediction in heat removal rate by the computer simulation program.

Explanation: The difference in the simulated storage tank temperature and those measured may be attributed to measurement uncertainty. In Chapter 6 it was shown that the measurement uncertainty associated with the experiment temperature readings is $0.164{ }^{\circ} \mathrm{C}$ with a $95 \%$ level of confidence. This uncertainty encompasses measurement, data acquisition and data processing errors. The following uncertainties and assumptions also attributed to the difference between the measured and simulated temperature

i. The uncertainty associated with the measurement of the roof cooling water flow rate, storage tank water volume, roof-pond water volume, humidity, pump efficiency and nozzle characteristic VMD.

ii. The assumption that the view factor between the roof-pond and the sky is unity. The radiation exchange between the roof-pond and sky could have partially been intercepted by nearby buildings. This would have influenced the energy loss by night sky radiation. The influence of the storage tank temperature to a change in night sky radiation is investigated in the sensitivity analysis, Section 7.4.

iii. The assumption that the sprayed droplets follow a Rosin Rammler distribution.

\section{Observation 2}

Observation: The computer simulation program over predicted the rate in which the storage tank temperature decreased. On the 03 May 2009 test the experimentally measured temperature decrease was $0.048^{\circ} \mathrm{C} / \mathrm{min}$ while the computer simulation program predicted a temperature decrease of $0.066^{\circ} \mathrm{C} / \mathrm{min}$ (refer to figure 7.2 (d)). Similar results can be seen for the 04 May 2009 test.

Explanation: The larger heat removal rates of the computer simulation may be ascribed to an over prediction of the evaporation and radiation heat transfer rates. Where a humidity level is measured too low, the calculated rate of evaporation would be higher than the actual measurement. An inaccurate measurement of humidity would propagate to calculation errors in both the dew-point and sky temperature. A dew-point and sky temperature calculated too low will lead to an over prediction in the sky radiation heat loss. The influence of humidity and sky temperature on the cooling ability of the roof cooling system is quantified by the sensitivity analysis in Section 7.4. Another influence on the heat removal rate is the thermal capacitance of the galvanised tray and tank that was not taken into account. 
The computer simulation of the storage tank temperatures provided good agreement with the experimentally measured temperatures despite the possible sources of error as outlined above. The simulated storage tank temperatures were within $0.45^{\circ} \mathrm{C}$ of the experimental temperatures.

\subsection{Roof Cooling Experiment Heat Loss Mechanisms}

The roof cooling system loses heat in the roof-pond and roof-spray by means of convection, evaporation and radiation. Heat is gained by the addition of make-up water and pump energy. Table 7.2 gives the energy removed and gained by the water through each respective heat transfer mechanism in the experimental tests. The values in table 7.2 were generated by the computer simulation of each experimental test. The percentage contribution of each heat transfer mechanism to the total water energy loss is given in brackets. A negative value or positive percentage denotes heat removal while the opposite is true for heat gain.

Table 7.2: Calculated Energy Loss and Gain for the Various Heat Transfer Mechanisms in the Experimental Tests over a Time Period of 1.5 hours

\begin{tabular}{|c|c|c|c|c|c|}
\hline Experimental Test & $\begin{array}{l}25 \text { May } \\
2008\end{array}$ & $\begin{array}{l}12 \text { July } \\
2008\end{array}$ & $\begin{array}{l}02 \text { August } \\
2008\end{array}$ & $\begin{array}{l}03 \text { May } \\
2009\end{array}$ & $\begin{array}{l}\text { 04 May } \\
2009\end{array}$ \\
\hline \multicolumn{6}{|l|}{ Energy Removed } \\
\hline $\begin{array}{l}\text { Roof-spray Convection Energy } \\
\text { Loss, } \dot{Q}_{r s, \text { conv }} d t\end{array}$ & $\begin{array}{l}-319.9 \mathrm{~kJ} \\
(33.69 \%)\end{array}$ & $\begin{array}{r}-376.91 \mathrm{~kJ} \\
(29.85 \%) \\
\end{array}$ & $\begin{array}{c}-218.09 \mathrm{~kJ} \\
(5.38 \%)\end{array}$ & $\begin{array}{c}-114.83 \mathrm{~kJ} \\
(4.79 \%)\end{array}$ & $\begin{array}{l}34.75 \mathrm{~kJ} \\
(-2.68 \%)\end{array}$ \\
\hline $\begin{array}{l}\text { Roof-spray Evaporation or } \\
\text { Condensation Energy Loss, } \\
\dot{Q}_{r s, \text { evap }} d t \text { or } \dot{Q}_{r s, \text { cond }} d t\end{array}$ & $\begin{array}{c}-645.81 \mathrm{~kJ} \\
(68.01 \%)\end{array}$ & $\begin{array}{l}-1095.14 \mathrm{~kJ} \\
(86.74 \%)\end{array}$ & $\begin{array}{l}-2063.95 \mathrm{~kJ} \\
(50.92 \%)\end{array}$ & $\begin{array}{c}-644.29 \mathrm{~kJ} \\
(26.90 \%)\end{array}$ & $\begin{array}{c}-465.77 \mathrm{~kJ} \\
(35.89 \%)\end{array}$ \\
\hline Roof-pond Heat Loss, $\dot{Q}_{r p, b u i l d} d t$ & $\begin{array}{c}-42.04 \mathrm{~kJ} \\
(4.43 \%)\end{array}$ & $\begin{array}{l}-9.39 \mathrm{~kJ} \\
(0.74 \%)\end{array}$ & $\begin{array}{l}-7.2 \mathrm{~kJ} \\
(0.18 \%)\end{array}$ & $\begin{array}{c}-18.86 \mathrm{~kJ} \\
(0.79 \%)\end{array}$ & $\begin{array}{l}16.95 \mathrm{~kJ} \\
(-1.31 \%)\end{array}$ \\
\hline $\begin{array}{l}\text { Roof-pond Sky Heat Loss, } \\
\dot{Q}_{r p, s k y} d t\end{array}$ & $\begin{array}{l}-210.58 \mathrm{~kJ} \\
(22.17 \%)\end{array}$ & $\begin{array}{c}-68.21 \mathrm{~kJ} \\
(5.4 \%)\end{array}$ & $\begin{array}{c}-1939.14 \mathrm{~kJ} \\
(47.84 \%)\end{array}$ & $\begin{array}{c}-2089.01 \mathrm{~kJ} \\
(87.22 \%)\end{array}$ & $\begin{array}{l}1491.80 \mathrm{~kJ} \\
(114.95 \%)\end{array}$ \\
\hline $\begin{array}{l}\text { Roof-pond Convection Heat Loss, } \\
\dot{Q}_{r p, c o n v} d t\end{array}$ & $\begin{array}{c}-11.63 \mathrm{~kJ} \\
(1.22 \%)\end{array}$ & $\begin{array}{l}-4.21 \mathrm{~kJ} \\
(0.33 \%)\end{array}$ & $\begin{array}{l}-2.90 \mathrm{~kJ} \\
(0.07 \%)\end{array}$ & $\begin{array}{l}-6.17 \mathrm{~kJ} \\
(0.26 \%)\end{array}$ & $\begin{array}{l}12.15 \mathrm{~kJ} \\
(-0.94 \%)\end{array}$ \\
\hline $\begin{array}{l}\text { Roof-pond Evaporation or } \\
\text { Condensation Energy Loss, } \\
\dot{Q}_{r p, \text { evap }} d t \text { or } \dot{Q}_{r p, \text { cond }} d t\end{array}$ & $\begin{array}{l}-37.60 \mathrm{~kJ} \\
(3.96 \%)\end{array}$ & $\begin{array}{l}-26.69 \mathrm{~kJ} \\
(2.11 \%)\end{array}$ & $\begin{array}{l}-141.02 \mathrm{~kJ} \\
(3.48 \%)\end{array}$ & $\begin{array}{l}-45.09 \mathrm{~kJ} \\
(1.88 \%)\end{array}$ & $\begin{array}{c}-56.49 \mathrm{~kJ} \\
(4.35 \%)\end{array}$ \\
\hline $\begin{array}{l}\text { Energy Gain from by-pass water } \\
\dot{Q}_{b p} d t\end{array}$ & $\begin{array}{l}79.52 \mathrm{~kJ} \\
(-8.37 \%)\end{array}$ & $\begin{array}{l}79.62 \mathrm{~kJ} \\
(-6.31 \%)\end{array}$ & $\begin{array}{l}80.24 \mathrm{~kJ} \\
(-1.98 \%)\end{array}$ & $\begin{array}{l}409.21 \mathrm{~kJ} \\
(-17.09 \%)\end{array}$ & $\begin{array}{l}509.78 \mathrm{~kJ} \\
(-39.28 \%)\end{array}$ \\
\hline Total Heat Loss, $E_{r p, l o s t}(\mathrm{~kJ})$ & $\begin{array}{l}-949.63 \mathrm{~kJ} \\
(100 \%)\end{array}$ & $\begin{array}{c}-1262.54 \mathrm{~kJ} \\
(100 \%)\end{array}$ & $\begin{array}{l}-4053.64 \mathrm{~kJ} \\
(100 \%)\end{array}$ & $\begin{array}{c}-2394.99 \mathrm{~kJ} \\
(100 \%)\end{array}$ & $\begin{array}{c}-1297.77 \mathrm{~kJ} \\
(100 \%)\end{array}$ \\
\hline \multicolumn{6}{|l|}{ Energy Gained } \\
\hline Heat gain from pump $\dot{Q}_{\text {pump }} d t$ & $\begin{array}{l}238.38 \mathrm{~kJ} \\
(-25.1 \%)\end{array}$ & $\begin{array}{l}238.38 \mathrm{~kJ} \\
(-18.88 \%)\end{array}$ & $\begin{array}{l}238.38 \mathrm{~kJ} \\
(-5.88 \%)\end{array}$ & $\begin{array}{l}114.02 \mathrm{~kJ} \\
(-4.76 \%)\end{array}$ & $\begin{array}{l}142.65 \mathrm{~kJ} \\
(-39.28 \%)\end{array}$ \\
\hline Make-up water heat gain $\dot{Q}_{m w} d t$ & $0.03 \mathrm{~kJ}$ & $0.02 \mathrm{~kJ}$ & $0.03 \mathrm{~kJ}$ & $0.03 \mathrm{~kJ}$ & $0.02 \mathrm{~kJ}$ \\
\hline
\end{tabular}


The energy removed and gained by the water through each respective heat transfer mechanism differs with each experimental test. This may be ascribed to the different meteorological conditions under which the experimental tests were performed. The experimental test conditions of 25 May 2008 and 12 July 2008 were such that night sky radiation was affected by mist and cloud cover. The night sky radiation energy removal for these two tests only contributed to approximately $10 \%$ of the total cooling. The lower night sky radiation may be ascribed to the higher sky temperature under which these tests were performed. When there is a low cloud cover the sky temperature may be assumed equal to the ambient temperature (Mills, 2000). In both the 25 May 2008 and 12 July 2008 tests, the energy removed by roof-spray evaporation contributed to between $50 \%$ and $70 \%$ of the total cooling.

The 02 August 2008 and 03 May 2009 tests were conducted under clear sky conditions which resulted in large night sky radiation heat removal rates. For the 02 August 2008 test, the night sky radiation energy loss contributed to almost $45 \%$ of the total cooling while the 03 May 2009 test showed that night sky radiation was responsible for approximately 80\% of the cooling. The remainder of the energy removed or gained due to the heat transfer rates by $\dot{Q}_{r p, b u i l d}, \dot{Q}_{r p, e v a p}, \dot{Q}_{r s, \text { cond }}$ and $\dot{Q}_{r p, \text { conv }}$ had no significant influence on the cooling of the water.

The following may be concluded from the above observations

i. Under clear sky conditions approximately $50 \%$ or more of the energy removal rate would be through night sky radiation $\dot{Q}_{r p, s y}$. The remainder of the energy removal would predominantly be by means of the roof-spray evaporation energy loss $\dot{Q}_{r s, e v a p}$. The roofspray evaporation would typical vary between $20 \%$ and $50 \%$ depending on the ambient temperature and humidity levels.

ii. When the sky temperature is higher and closer to the ambient temperature the convection $\dot{Q}_{r s, c o n v}$ and evaporation $\dot{Q}_{r s, \text { evap }}$ energy loss from roof-spray would contribute from $75 \%$ up to $90 \%$ of the cooling. The roof-spray cooling therefore plays a significant role in the cooling of the water under conditions where the night sky temperature approaches the ambient temperature.

\subsection{Roof Cooling Experiment Sensitivity Analysis}

The sensitivity of the roof cooling system performance parameters to a variation in design and weather dependent variables is quantitatively analysed by means of a sensitivity analysis. In the previous section it was shown that $\dot{Q}_{r p, s k y}, \dot{Q}_{r s, \text { conv }}$ and $\dot{Q}_{r s, e v a p}$ were the prevailing energy transfer mechanisms for the cooling of water. Another two important performance parameters are the storage tank energy loss, $E_{s t, l o s t}$ and the storage tank temperature relative to the ambient temperature, $T_{s t}-T_{a m b}$.

The sensitivity analysis is based on the experimental test conditions of 02 August 2008 test The design and weather dependent variables comprise the sky temperature $T_{s k y}$, the ambient 
air temperature $T_{a m b}$, the wind velocity $u_{w}$, the droplet mean diameter $V M D$, the water flow rate $\dot{m}_{r c}$, the ambient humidity $\phi_{a m b}$, the initial roof-pond temperature $T_{r p, i n i}$, and the roofpond surface area $A_{r p}$. The base case for these values for the 02 August 2008 experimental test is given in table 7.3

Table 7.3: Base Case Values for the Sensitivity Analysis

\begin{tabular}{|c|c|c|c|c|c|c|c|c|}
\hline & $T_{s k y}$ & $T_{a m b}$ & $u_{w}$ & $\dot{m}_{r c}$ & $V M D$ & $\phi_{a m b}$ & $T_{r p_{-} i n i}$ & $A_{r p}$ \\
\hline $\begin{array}{c}\text { Base Case } \\
\text { Values }\end{array}$ & $-12.12^{\circ} \mathrm{C}$ & $7.6^{\circ} \mathrm{C}$ & $0 \mathrm{~m} / \mathrm{s}$ & $0.25 \mathrm{~kg} / \mathrm{s}$ & $1600 \mu \mathrm{m}$ & $60 \%$ & $9.07^{\circ} \mathrm{C}$ & $4 \mathrm{~m}^{2}$ \\
\hline
\end{tabular}

Table 7.4 gives the values of the performance parameters for a corresponding change in design and weather dependent variables. Notice that the heat transfer mechanisms $\dot{Q}_{r p, s k y}$, $\dot{Q}_{r s, c o n v}$ and $\dot{Q}_{r s, e v a p}$ are multiplied with the time duration $d t$ of the experiment such that a total energy loss or gain may be presented. The design and weather dependent variables are altered by $10 \%$ from the base case values given in table 7.3. The percentage variations are given in brackets.

Table 7.4: Influence of System Variables on the Performance Parameters

\begin{tabular}{|c|c|c|c|c|c|c|}
\hline Variable & Value & $E_{s t, l o s t}$ & $T_{s t}-T_{a m b}$ & $\dot{Q}_{r p, s k y} d t$ & $\dot{Q}_{r s, c o n v} d t$ & $\dot{Q}_{r s, \text { evap }} d t$ \\
\hline \multicolumn{2}{|c|}{ Base Case Values } & $--3569 \mathrm{~kJ}$ & $0.8^{\circ} \mathrm{C}$ & $-1939.14 \mathrm{~kJ}$ & $-218.1 \mathrm{~kJ}$ & $-2063.95 \mathrm{~kJ}$ \\
\hline $0.9 T_{s k y}$ & $-11.55^{\circ} \mathrm{C}$ & $\begin{array}{c}-3521.4 \mathrm{~kJ} \\
(-1.33 \%)\end{array}$ & $\begin{array}{l}0.85^{\circ} \mathrm{C} \\
(6.55 \%) \\
\end{array}$ & $\begin{array}{c}-1848.67 \mathrm{~kJ} \\
(-4.7 \%) \\
\end{array}$ & $\begin{array}{c}-229.53 \mathrm{~kJ} \\
(5.25 \%)\end{array}$ & $\begin{array}{c}-2067.4 \mathrm{~kJ} \\
(0.17 \%)\end{array}$ \\
\hline $1.1 T_{s k y}$ & $-10.2^{\circ} \mathrm{C}$ & $\begin{array}{l}-3616 \mathrm{~kJ} \\
(1.32 \%) \\
\end{array}$ & $\begin{array}{c}0.75^{\circ} \mathrm{C} \\
(-6.47 \%)\end{array}$ & $\begin{array}{c}-2028.49 \mathrm{~kJ} \\
(4.61 \%)\end{array}$ & $\begin{array}{l}-206.7 \mathrm{~kJ} \\
(-5.22 \%)\end{array}$ & $\begin{array}{c}-2060.64 \mathrm{~kJ} \\
(-0.16 \%)\end{array}$ \\
\hline $0.9 T_{a m b}$ & $6.84{ }^{\circ} \mathrm{C}$ & $\begin{array}{c}-3821.2 \mathrm{~kJ} \\
(7.1 \%)\end{array}$ & $\begin{array}{c}0.52^{\circ} \mathrm{C} \\
(-35.2 \%)\end{array}$ & $\begin{array}{c}-1997.3 \mathrm{~kJ} \\
(3 \%)\end{array}$ & $\begin{array}{c}-518.12 \mathrm{~kJ} \\
(137.6 \%)\end{array}$ & $\begin{array}{c}-2078.78 \mathrm{~kJ} \\
(0.72 \%)\end{array}$ \\
\hline $1.1 T_{a m b}$ & $8.36^{\circ} \mathrm{C}$ & $\begin{array}{c}--3315.5 \mathrm{~kJ} \\
(-7.1 \%) \\
\end{array}$ & $\begin{array}{c}1.08^{\circ} \mathrm{C} \\
(35.37 \%) \\
\end{array}$ & $\begin{array}{c}-1880.27 \mathrm{~kJ} \\
(-3.04 \%) \\
\end{array}$ & $\begin{array}{c}-118.74 \mathrm{~kJ} \\
(-154.45 \%)\end{array}$ & $\begin{array}{c}-2083.4 \mathrm{~kJ} \\
(0.94 \%)\end{array}$ \\
\hline$u_{w}=1 \mathrm{~m} / \mathrm{s}$ & $1 \mathrm{~m} / \mathrm{s}$ & $\begin{array}{c}-4208.7 \mathrm{~kJ} \\
(17.92 \%)\end{array}$ & $\begin{array}{c}0.08^{\circ} \mathrm{C} \\
(-89.57 \%)\end{array}$ & $\begin{array}{l}-1891 \mathrm{~kJ} \\
(-2.48 \%)\end{array}$ & $\begin{array}{c}-27.37 \mathrm{~kJ} \\
(-87.45 \%)\end{array}$ & $\begin{array}{c}-2082.75 \mathrm{~kJ} \\
(0.91 \%)\end{array}$ \\
\hline$u_{w}=4 \mathrm{~m} / \mathrm{s}$ & $4 \mathrm{~m} / \mathrm{s}$ & $\begin{array}{c}-5049.9 \mathrm{~kJ} \\
(41.5 \%)\end{array}$ & $\begin{array}{c}-0.86^{\circ} \mathrm{C} \\
(-208.2 \%)\end{array}$ & $\begin{array}{c}-1826.12 \mathrm{~kJ} \\
(-5.83 \%)\end{array}$ & $\begin{array}{l}-355.55 \mathrm{~kJ} \\
(-263.03 \%)\end{array}$ & $\begin{array}{c}-2027.65 \mathrm{~kJ} \\
(-1.76 \%)\end{array}$ \\
\hline $0.9 \dot{m}_{r c}$ & $0.23 \mathrm{~kg} / \mathrm{s}$ & $\begin{array}{c}-3456.2 \mathrm{~kJ} \\
(-3.16 \%)\end{array}$ & $\begin{array}{c}0.93^{\circ} \mathrm{C} \\
(16.06 \%) \\
\end{array}$ & $\begin{array}{c}-1942.84 \mathrm{~kJ} \\
(0.19 \%) \\
\end{array}$ & $\begin{array}{c}-230.43 \mathrm{~kJ} \\
(5.66 \%) \\
\end{array}$ & $\begin{array}{c}-1868.71 \mathrm{~kJ} \\
(-9.46 \%) \\
\end{array}$ \\
\hline $1.1 \dot{m}_{r c}$ & $0.28 \mathrm{~kg} / \mathrm{s}$ & $\begin{array}{c}-3675.2 \mathrm{~kJ} \\
(2.97 \%)\end{array}$ & $\begin{array}{c}2.69^{\circ} \mathrm{C} \\
(237.4 \%)\end{array}$ & $\begin{array}{c}-1935.12 \mathrm{~kJ} \\
(-0.21 \%) \\
\end{array}$ & $\begin{array}{c}-199.74 \mathrm{~kJ} \\
(-8.42 \%)\end{array}$ & $\begin{array}{c}-2258.23 \mathrm{~kJ} \\
(9.41 \%)\end{array}$ \\
\hline $0.9 V M D$ & $1530 \mu \mathrm{m}$ & $\begin{array}{c}-3686.4 \mathrm{~kJ} \\
(3.3 \%)\end{array}$ & $\begin{array}{c}2.71{ }^{\circ} \mathrm{C} \\
(238.9 \%)\end{array}$ & $\begin{array}{c}-1929.4 \mathrm{~kJ} \\
(-0.5 \%)\end{array}$ & $\begin{array}{l}-185.79 \mathrm{~kJ} \\
(-14.81 \%)\end{array}$ & $\begin{array}{c}-2290.8 \mathrm{~kJ} \\
(11 \%)\end{array}$ \\
\hline $1.1 V M D$ & $1870 \mu \mathrm{m}$ & $\begin{array}{c}-3421.8 \mathrm{~kJ} \\
(-4.13 \%)\end{array}$ & $\begin{array}{c}2.83^{\circ} \mathrm{C} \\
(254.81 \%) \\
\end{array}$ & $\begin{array}{c}-1951.2 \mathrm{~kJ} \\
(0.62 \%)\end{array}$ & $\begin{array}{c}-242.67 \mathrm{~kJ} \\
(11.27 \%) \\
\end{array}$ & $\begin{array}{c}-1795.15 \mathrm{~kJ} \\
(-13.02 \%) \\
\end{array}$ \\
\hline $0.9 \phi_{a m b}$ & $55 \%$ & $\begin{array}{c}-3752.2 \mathrm{~kJ} \\
(5.13 \%)\end{array}$ & $\begin{array}{c}2.7^{\circ} \mathrm{C} \\
(238.57 \%)\end{array}$ & $\begin{array}{c}-1938.2 \mathrm{~kJ} \\
(-0.05 \%)\end{array}$ & $\begin{array}{l}-124.17 \mathrm{~kJ} \\
(-43.06 \%)\end{array}$ & $\begin{array}{c}-2449.13 \mathrm{~kJ} \\
(18.66 \%)\end{array}$ \\
\hline $1.1 \phi_{a m b}$ & $67 \%$ & $\begin{array}{c}-3386.2 \mathrm{~kJ} \\
(-5.12 \%)\end{array}$ & $\begin{array}{c}2.82{ }^{\circ} \mathrm{C} \\
(253.65 \%)\end{array}$ & $\begin{array}{c}-1940.33 \mathrm{~kJ} \\
(-0.06 \%)\end{array}$ & $\begin{array}{c}--305.58 \mathrm{~kJ} \\
(40.12 \%)\end{array}$ & $\begin{array}{c}-1685.36 \mathrm{~kJ} \\
(-18.34 \%)\end{array}$ \\
\hline
\end{tabular}




\section{Influence of Wind Velocity}

The third column in table 7.4 shows that $E_{s t, l o s t}$ is influenced the greatest by a variation in $u_{w}$. Increasing $u_{w}$ to 1 and $4 \mathrm{~m} / \mathrm{s}$ increased $E_{s t, l o s t}$ by $18 \%$ and $42 \%$ respectively. Under stagnant conditions the heat transfer between the roof-pond and ambient is driven by natural convection. However, with an air movement of 1 and $4 \mathrm{~m} / \mathrm{s}$, the convection heat transfer becomes forced producing increased convection- and evaporation energy transfer rates between the roof-pond and the ambient air. These larger heat transfer rates brought the final storage tank temperature closer to the ambient air temperature. The difference in $T_{s t}$ and $T_{a m b}$ was brought down from $0.8{ }^{\circ} \mathrm{C}$ to $0.08{ }^{\circ} \mathrm{C}$ for $u_{w}=1 \mathrm{~m} / \mathrm{s}$ and $-0.86{ }^{\circ} \mathrm{C}$ below $T_{a m b}$ for $u_{w}=4 \mathrm{~m} / \mathrm{s}$ respectively.

The roof-spray convection and evaporation heat loss is expected to decrease with increasing wind velocities. Two factors contribute to this; i) increased spray drift and ii) a lower initial droplet temperature. As explained in Chapter 4, the size of the sprayed droplets is assumed to follow a Rosin Rammler distribution which means that droplets down to a size of $100 \mu \mathrm{m}$ are formed. It was illustrated in section 4.3.2 that droplets with a sedimentation-to-wind velocity ratio less than $10 \%$ are prone to spray drift. It was further illustrated that under increased wind velocities, the quantity of droplets prone to spray drift also increased. As explained in Section 4.3.3, the effect of spray drift is detrimental to the cooling performance of the roof cooling system since the drifted droplets are continuously replaced by warmer make-up water.

\section{Influence of Droplet Diameter and Mass Flow Rate}

A smaller characteristic nozzle $V M D$ gives rise to a greater quantity of droplets sprayed since the size of the sprayed droplets follow a Rosin Rammler distribution. The more water droplets are sprayed at a time the greater the exposed surface area and the larger $\dot{Q}_{r s, c o n v}$ and $\dot{Q}_{r s, \text { evap }}$ should become. Table 7.4 shows that $\dot{Q}_{r s, \text { conv }}$ decreased by $14.81 \%$ and $\dot{Q}_{r s, \text { evap }}$ increased by $11 \%$. This occurred since smaller droplets cool down much faster than larger droplets and for an increased value of $\dot{Q}_{r s, e v a p}, \dot{Q}_{r s, c o n v}$ would have to decrease since $\left(T_{d}-T_{a m b}\right)$ is lower. It must also be remembered that a smaller characteristic VMD gives rise to a greater quantity of droplets with a sedimentation-to-wind velocity ratio less than $10 \%$. These droplets would be prone to spray drift which is detrimental to the performance of the roof cooling system.

If the mass flow rate $\dot{m}_{r c}$, is increased, more droplets are sprayed at a time resulting in a larger quantity of droplets exposed to the ambient air. More droplets in the spray means a greater surface area exposed to the ambient air and consequently an increase in both $\dot{Q}_{r s, c o n v}$ and $\dot{Q}_{r s, e v a p}$. From the sensitivity analysis a $10 \%$ increase in $\dot{m}_{r c}$ resulted in a $9.41 \%$ increase in $\dot{Q}_{r s, e v a p}$ and a $8.42 \%$ decrease in $\dot{Q}_{r s, c o n v}$. The decrease in $\dot{Q}_{r s, c o n v}$ may be ascribed to a decreased $\left(T_{d}-T_{a m b}\right)$ value which resulted due to an increased $\dot{Q}_{r s, e v a p}$ value 


\section{Influence of Sky Temperature}

The night sky radiation $\dot{Q}_{r p, s k y}$ is influenced by $T_{s k y}$. In addition to the sensitivity analysis the influence may also be quantified by looking at the derivative of $\dot{Q}_{r p, s k y}$ with respect to $T_{s k y}$. In Appendix C it is shown that $\dot{Q}_{r p, s k y}$ may be calculated by

$\dot{Q}_{r p, s k y}=\varepsilon_{r p} \sigma A_{r p}\left(T_{r p}^{4}-T_{s k y}^{4}\right)$

Differentiating equation 7.1 with respect to $T_{s k y}$ gives the change in $\dot{Q}_{r p, s k y}$ per degree change in $T_{s k y}$

$$
\frac{\partial \dot{Q}_{r p, s k y}}{\partial T_{s k y}}=-4 \varepsilon_{r p} \sigma A_{r p} T_{s k y}^{3}
$$

Discretising the differential term and inserting the experimental properties as well as the base case value for $T_{s k y}$ gives

$$
\frac{\partial \dot{Q}_{s k y}}{\partial T_{s k y}} \approx \frac{\Delta \dot{Q}_{s k y}}{\Delta T_{s k y}}=-14.52 \mathrm{~W} /{ }^{\circ} \mathrm{C}
$$

Inserting a value of $1.21{ }^{\circ} \mathrm{C}$ for $\Delta T_{s k y}$ into equation 7.3 gives a value of $17.57 \mathrm{~W}$ for $\Delta \dot{Q}_{s k y}$. Over a 90 min period the corresponding energy removed $\dot{Q}_{s k y} d t$ becomes $94.88 \mathrm{~kJ}$. Table 7.4 shows that $\dot{Q}_{s k y} d t$ increased by only $90.5 \mathrm{~kJ}$ when $T_{s k y}$ was altered by $1.21{ }^{\circ} \mathrm{C}$. The discrepancy between the predicted value of $94.88 \mathrm{~kJ}$ and the actual energy loss of $90.5 \mathrm{~kJ}$ in the sensitivity analysis may be ascribed to the assumption of a constant $T_{s k y}$ value. In the actual experiment $T_{s k y}$ continuously changed.

\section{Influence of Ambient Temperature and Humidity}

A $10 \%$ reduction in $T_{a m b}$ and $\phi_{a m b}$ increased $E_{s t, l o s t}$ by $7 \%$ and $5.2 \%$ respectively. A $10 \%$ increase in $T_{a m b}$ reduced $\dot{Q}_{r s, c o n v}$ by $138 \%$ whilst $\dot{Q}_{r p, s k y}$ and $\dot{Q}_{r s, \text { eva }}$ each decreased by $4.6 \%$ and $0.8 \%$ respectively. The night sky radiation heat loss decreased due to the larger calculated sky temperature that resulted from the larger $T_{a m b}$ value. Reducing $\phi_{a m b}$ by $10 \%$ increased the evaporation heat loss, $\dot{Q}_{r s, \text { evap }}$, by $18.7 \%$. The smaller $\phi_{a m b}$ becomes, the less the partial vapour density of the ambient air and the greater the partial vapour pressure difference between the droplet surface and the ambient air. This results in a greater water vapour mass flux between the droplet surface and the ambient air. 


\subsection{Roof-spray Optimisation}

In Chapter 4 a procedure was derived whereby the droplet diameter $D_{d}$, and spray pressure $p_{1}$, for a specific spray nozzle could be optimised such that an optimum value for the nozzle spray coefficient NSC could be obtained. NSC gives the ratio of total spray cooling $\dot{Q}_{\text {spray,tot }}$ to the power of the fluid entering the spray nozzle $P_{f}$. The optimisation procedure was performed for full cone spray nozzles with a pressure exponent of 0.47 and a nozzle loss coefficient $\mathrm{K}$ of 0.5 . The optimisation was performed for ambient conditions of the 02 August 2008 experimental test and a constant wind velocity of $1 \mathrm{~m} / \mathrm{s}$.

The droplet sizes were limited between $200 \mu \mathrm{m}$ and $5000 \mu \mathrm{m}$. The lower limit of $200 \mu \mathrm{m}$ was specifically chosen to limit potential spray drift. The spray pressure $p_{1}$ was limited to a range of $30 \mathrm{kPa}$ and $600 \mathrm{kPa}$. Figure 7.3 gives the graph of $N S C$ for a variation in droplet diameter $D_{d}$ and nozzle spray pressure $p_{1}$. From figure 7.3 a minimum value of NSC is seen to exist. The optimum NSC value of -828 occurred at the lower boundaries of the optimisation search, i.e. a droplet diameter $D_{d}=200 \mu \mathrm{m}$ and a nozzle spray pressure $p_{1}=30 \mathrm{kPa}$.

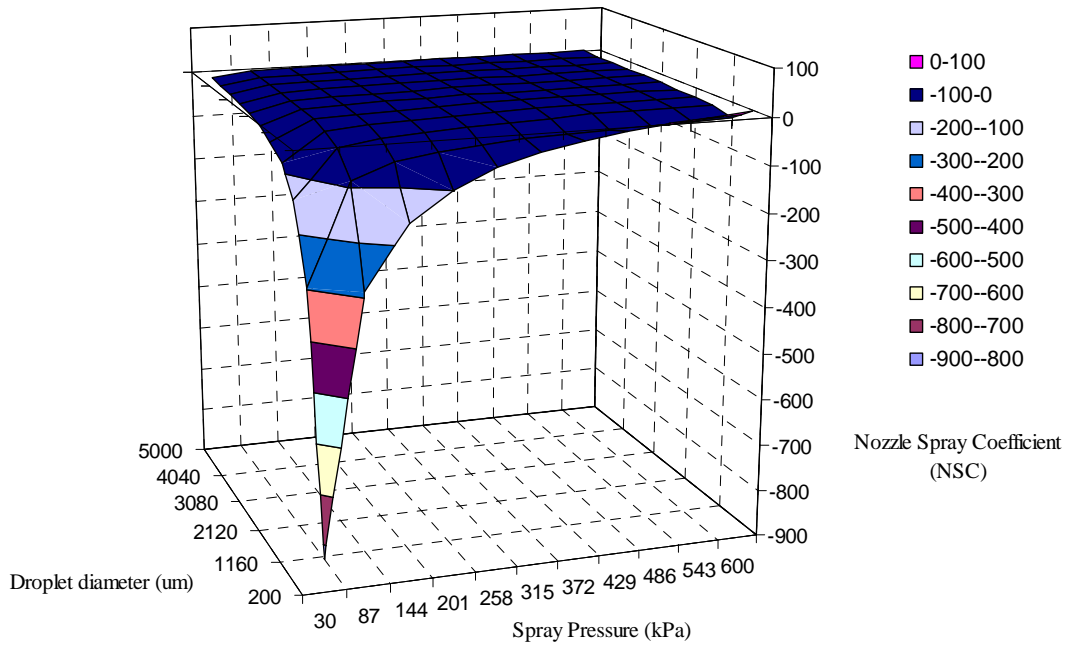

Figure 7.3: Optimisation Graph for the Nozzle Spray Coefficient

From figure 7.3 it can be concluded that a spray nozzle for a roof-spray system would have to be selected such that the nozzle gives the smallest possible droplet diameter for the lowest input pressure. The droplet diameter must however be chosen such that the droplet sedimentation velocity is at least $10 \%$ of the wind velocity to minimise the effect of spray drift. 


\subsection{One-Room Building Instantaneous Heat Gain and Actual Cooling Load for Base Case Conditions}

To investigate the effectiveness of the sustainable cooling alternatives, the cooling load and room temperature of a one-room building were considered. The dimensions and thermal properties of the one-room building are given in Appendix B. The simulation calculations were based on typical weather conditions for Stellenbosch, South Africa. The hourly variation of the solar radiation, ambient air temperature and humidity are given in Appendix B. Sample calculations for the calculation of the cooling load and room temperature of the one-room building presented in Appendix G. The flowchart in figure 7.4 illustrates the difference between the instantaneous heat gain and the actual cooling load.

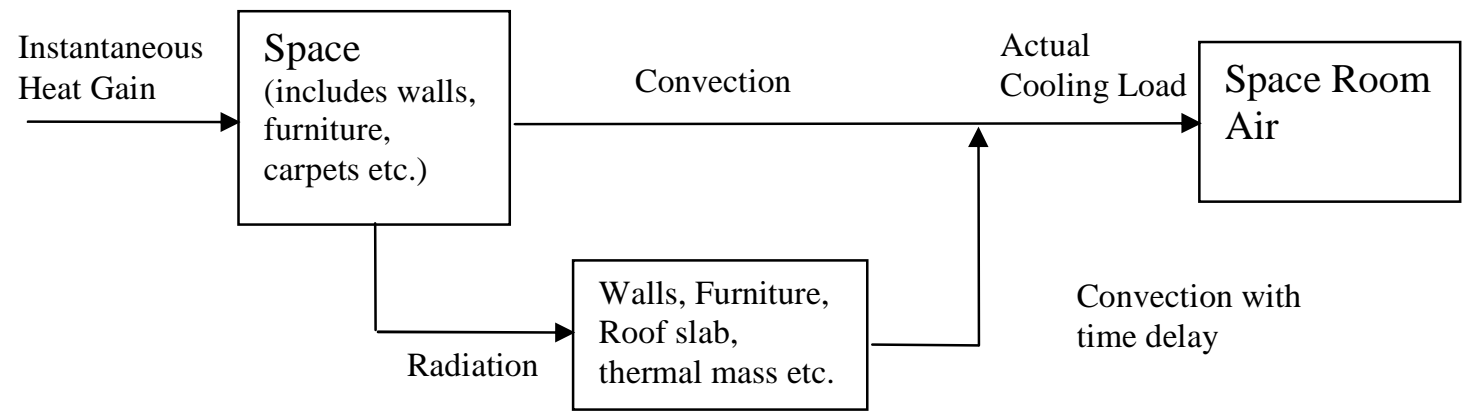

Figure 7.4: Flowchart Illustrating the Difference Between Instantaneous Heat Gain and Actual Cooling Load (ASHRAE Fundamentals, 2005)

Figure 7.5(a) gives both the instantaneous heat gain and hourly cooling load of the one-room building for the base case values and $22{ }^{\circ} \mathrm{C}$ temperature setting. The hourly cooling load of the one-room building as simulated with the Carrier Hourly Heat Analysis Program, hereafter referred to as the Carrier cooling load, is also presented in figure 7.5 (a).

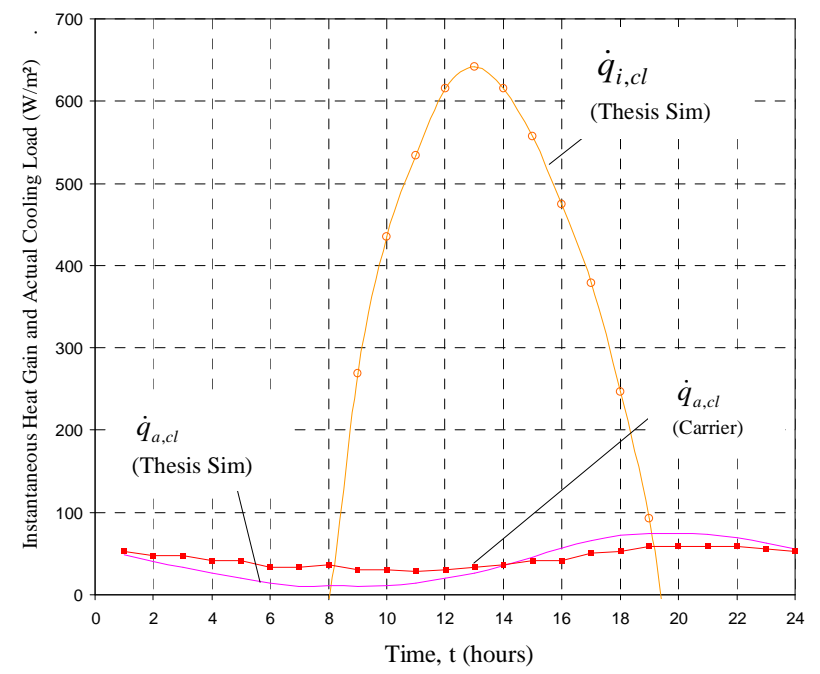

(a)

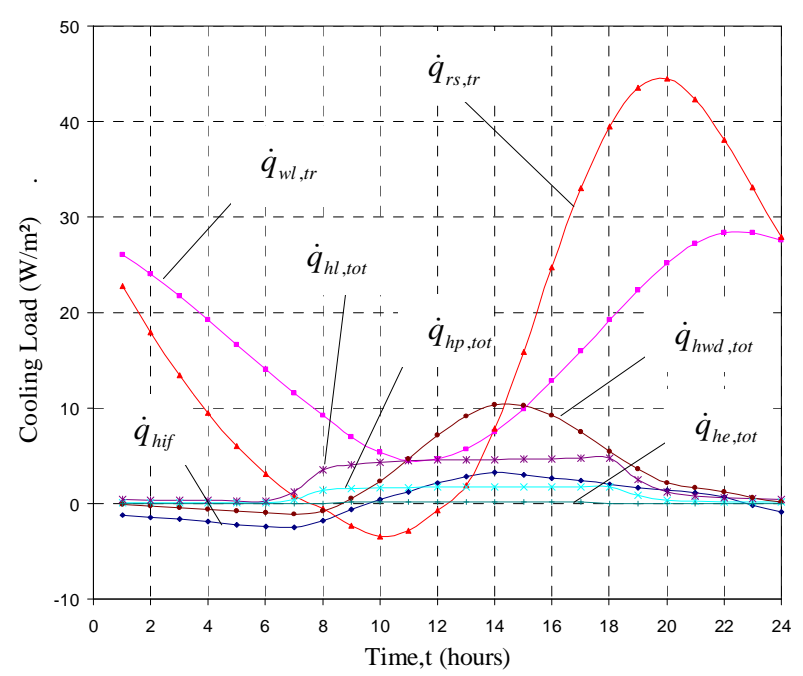

(b)

Figure 7.5: (a) Instantaneous Heat Gain vs Actual Cooling Loads and (b) Individual Cooling Load Contributions of the Various Heat Gain Elements of the One-Room Building 
Figure 7.5 (a) shows that the cooling load profile generated from the thesis simulation calculations is in phase with the Carrier cooling load profile. However, the minimum Carrier cooling load is $25 \mathrm{~W} / \mathrm{m}^{2}$ higher than that of the thesis simulation. At the peak cooling load hour the Carrier cooling load is $16.4 \mathrm{~W} / \mathrm{m}^{2}$ lower than the thesis simulation model. The mean difference between the Carrier cooling load and the thesis simulated cooling load over the 24 hour period is $-3.35 \mathrm{~W} / \mathrm{m}^{2}$ which is approximately $4 \%$ that of the peak cooling load. The disagreement in values may be ascribed to the different heat transfer coefficients these models used. The thesis simulations had a larger swing in cooling load and the heat transfer coefficient must consequently have been higher.

Mull (1998) reports that the thermal mass of a building directly affects the time lag between the peak instantaneous heat gain and the peak cooling load. The greater the thermal mass of the building, the larger the time lag and the lower the peak cooling load (Mull, 1998). Since the one-room building has a high thermal mass (building weight above $1000 \mathrm{~kg} / \mathrm{m}^{2}$ ) it is understandable that the peak cooling load is significantly less than the instantaneous peak heat gain (see figure 7.5(a)) and that it lags the peak heat gain by 6 hours.

Figure 7.5(b) depicts the hourly variations of the infiltration load $\dot{q}_{h i f}$, the roof slab heat transmission $\dot{q}_{r s, t r}$, the wall heat transmission $\dot{q}_{w l, t r}$, the heat gain from people $\dot{q}_{h p, t o t}$, the heat gain through the window $\dot{q}_{h_{w d}, t o t}$, the heat gain from lighting $\dot{q}_{h l, t o t}$ and the equipment heat gain $\dot{q}_{h e, t o t}$. It is evident from figure 7.5(b) that the greatest portion of the cooling load originates from the wall heat transmission $\dot{q}_{w l, t r}$ and the roof slab heat transmission $\dot{q}_{r s, t r}$. The large value of $\dot{q}_{w l, t r}$ is due to the large façade area $\left(72 \mathrm{~m}^{2}\right)$ of the one-room building. The roof slab transmission $\dot{q}_{r s, t r}$ is large due to the roof slab's exposure to solar radiation for the majority of the day. The roof slab transmission $\dot{q}_{r s, t r}$, contributes to between 50 and $60 \%$ of the peak cooling load (see figure 7.5).

\subsection{Room Temperature and Cooling Load Profile of the One-Room Building with the Sustainable Cooling Methods Included Separately}

The room temperature and cooling load profile of the one-room building for the base case, night flushing, roof-spray, roof cooling, roof-pond and active mass cooling are depicted in figure 7.6. The cooling load profile was generated for a room thermostat setting of $22^{\circ} \mathrm{C}$. The night flushing option was activated during nocturnal hours between 24:00 and 07:00 at a rate of $32 \mathrm{ACH}^{1}$. For the roof-pond simulation, the roof-pond water level was set equal to 100 $\mathrm{mm}$. With the active mass cooling option, water was continuously circulated through a pipe network embedded in the roof slab at a rate of $1 \mathrm{~kg} / \mathrm{s}$ and a constant temperature of $15^{\circ} \mathrm{C}$.

The roof cooling system comprised a storage tank, circulation pump, roof-pond and spray nozzles as depicted in figure 4.1. The spray nozzles in the simulation were assumed to be installed at a height of $300 \mathrm{~mm}$ spraying at an angle of $-10^{\circ}$ downwards form the horizontal plane. During nocturnal hours (from 21:00 to 06:00), water was pumped from a 1000 litre

\footnotetext{
${ }^{1}$ ACH: Air Changes per Hour
} 
storage tank to the spray nozzle and roof-pond at a rate of $1 \mathrm{~kg} / \mathrm{s}$. Water from the roof-pond was gravity fed back to the storage tank. During daytime hours (from 06:00 to 21:00), the storage tank was bypassed and the water from the roof-pond was directly routed to the spray nozzles.

Figure 7.6(a) shows that the room temperature profile coincides well with the cooling load profile depicted in figure 7.6(b) since the peaks and valleys occurs at the same point in time. From figure 7.6(b) the peak room temperature is $1.22{ }^{\circ} \mathrm{C}$ lower than the peak ambient temperature and occurs at approximately 7 hours. All the sustainable cooling alternatives show a similar profile with the minimum temperature occurring at 07:00 and the maximum between 18:00 and 20:00. However, during the hours where night flushing was activated the room temperature was closer to the ambient temperature.
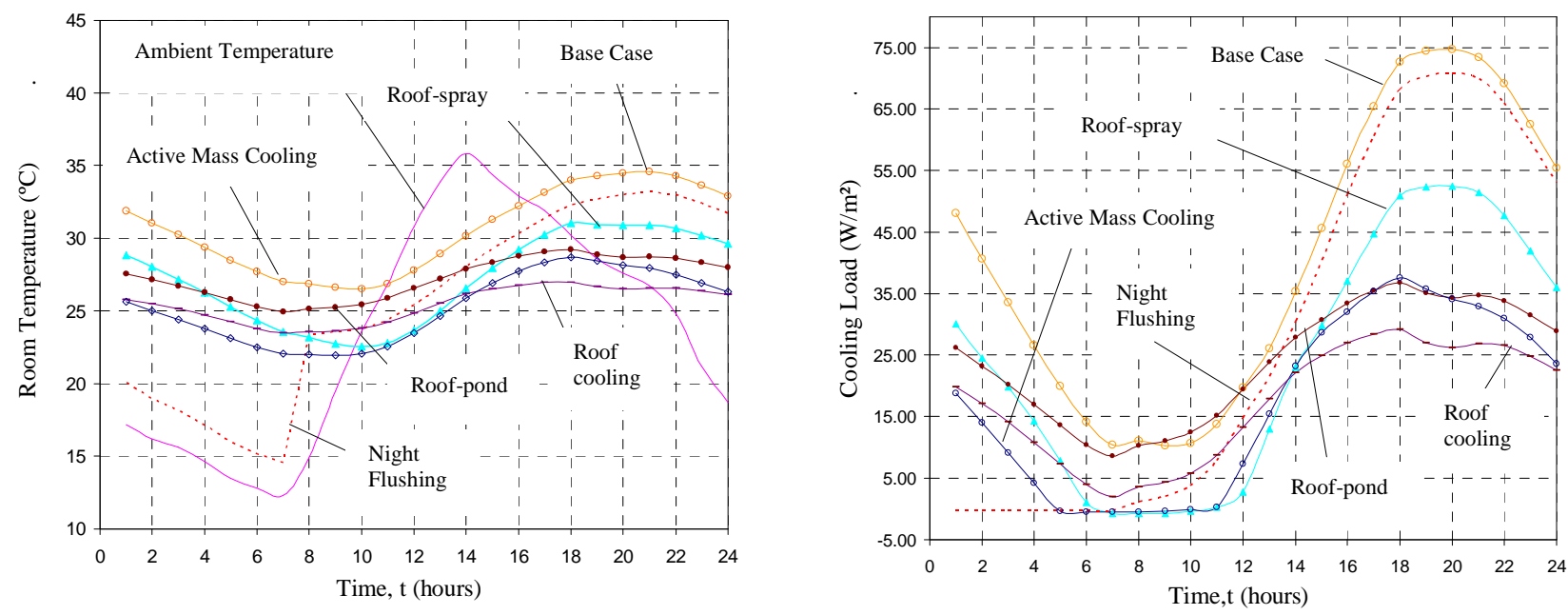

Figure 7.6: (a) Room Temperature and (b) Cooling Load Profile of the One-Room Building with the Sustainable Cooling Methods Included Separately

The peak room temperature reduction of $1.4^{\circ} \mathrm{C}$ by the night flushing technique agrees well with the temperature reductions of 1 to $3{ }^{\circ} \mathrm{C}$ found by Kolokotroni et al. 1998. Both Artmann et al. (2008) and Kolokotroni et al. (1998) pointed out that the room temperature reduction provided by night flushing is highly dependent on the air change rate, the thermal mass of the building, heat gains and meteorological conditions. The influence of air change rate will be evaluated in the Section 7.9.

The application of the roof-spray showed a peak room temperature reduction of $3.71{ }^{\circ} \mathrm{C}$ while active mass cooling produced a peak room temperature reduction of $6.7^{\circ} \mathrm{C}$ (refer figure 7.6 a). Both the roof-spray and active mass cooling showed a temperature profile similar to that of the base case but at an average offset of $3.5^{\circ} \mathrm{C}$ for the roof-spray and $5.4^{\circ} \mathrm{C}$ for active mass cooling. The roof-pond reduced the peak room temperature by $5.9^{\circ} \mathrm{C}$ with an average temperature reduction of $3.4^{\circ} \mathrm{C}$ over the 24 hour time period. Carrasco et al, 1997 analysed the performance of the roof-spray system by evaluating the roof surface temperature and the roof heat flux. Sodha et al (1980:1) and Jain (2006) did the same for the roof-pond. In Section 7.10 the roof surface temperature and heat flux will theoretically be investigated for 
the scenario where the roof-spray and roof-pond with varying water levels are applied to the one-room building.

Figure 7.6(a) shows that the roof cooling system produced the greatest peak room temperature reduction. The peak room temperature was reduced by $8{ }^{\circ} \mathrm{C}$ and the average room temperature by $5.16^{\circ} \mathrm{C}$ over the 24 hour simulation period. The roof cooling system combines the roof-pond and roof-spray system and the additional benefit of adding a roofspray to a roof-pond may be quantified by comparing the roof cooling peak room temperature and cooling load to that of the roof-pond. In this simulation, the additional benefit of adding a roof-spray to the roof-pond was $2.16^{\circ} \mathrm{C}$ for the peak room temperature and $7.7 \mathrm{~W} / \mathrm{m}^{2}$ for the peak cooling load.

Table 7.5 gives the total heat energy transferred (based on a $22{ }^{\circ} \mathrm{C}$ thermostat setting) to the one-room building over a 24 hour period, $E_{r m, t o t}$, and the peak cooling load, $\dot{q}_{p k, t o t}$, of the one-room building for the base case, roof-spray, roof-pond, active mass cooling, night flushing and roof cooling. The percentage reduction of the total heat energy transferred to the one-room building over a 24 hour and the peak cooling load is also presented.

Table 7.5: Total Heat Energy and Peak Cooling Load of the One-Room Building with the Sustainable Cooling Alternatives Applied Separately

\begin{tabular}{|l|c|c|c|c|}
\hline $\begin{array}{l}\text { Sustainable Cooling } \\
\text { Alternative }\end{array}$ & $E_{r m, t o t}\left(\mathrm{~kJ} / \mathrm{m}^{2}\right)$ & $\%$ Reduction in $E_{r m, t o t}$ & $\dot{q}_{p k, t o t}\left(\mathrm{~W} / \mathrm{m}^{2}\right)$ & $\%$ Reduction in $\dot{q}_{p k, t o t}$ \\
\hline Base Case & 3490.53 & $0.00 \%$ & 74.73 & $0.00 \%$ \\
\hline Roof-spray & 2081.70 & $40.36 \%$ & 52.44 & $29.83 \%$ \\
\hline Roof-pond & 2066.84 & $40.79 \%$ & 36.79 & $50.78 \%$ \\
\hline Active Mass Cooling & 1471.66 & $57.84 \%$ & 37.53 & $49.78 \%$ \\
\hline Night Flushing & 2483.16 & $28.86 \%$ & 70.88 & $5.16 \%$ \\
\hline Roof Cooling & 1490.46 & $57.30 \%$ & 29.09 & $61.07 \%$ \\
\hline
\end{tabular}

Under base case conditions the peak room cooling load to the one-room building is 74.7 $\mathrm{W} / \mathrm{m}^{2}$. Night flushing and roof-spray reduced the peak cooling load to $70.88 \mathrm{~W} / \mathrm{m}^{2}$ and 52.44 $\mathrm{W} / \mathrm{m}^{2}$ by providing $3.9 \mathrm{~W} / \mathrm{m}^{2}$ and $22.3 \mathrm{~W} / \mathrm{m}^{2}$ of peak cooling respectively. Active mass cooling provided $37.2 \mathrm{~W} / \mathrm{m}^{2}$ cooling while the roof-pond produced $37.94 \mathrm{~W} / \mathrm{m}^{2}$ cooling. The roof cooling system proved to be the most effective system by producing $45.64 \mathrm{~W} / \mathrm{m}^{2}$ of peak cooling and reducing the peak cooling load to $29.09 \mathrm{~W} / \mathrm{m}^{2}$.

Comparing the peak cooling load reduction of the various sustainable cooling alternatives it can be seen that the roof cooling system reduced the peak cooling load the most, i.e. by $61.1 \%$. The roof-pond came second with a reduction of $51 \%$ which is only $21 \%$ more than the $30 \%$ reported by Kharrufa and Adil (2006) and 25\% more than the 25\% cooling load reduction reported by Holder (1957) and Thappen (1943). The discrepancy in cooling load reduction may be ascribed to the $26{ }^{\circ} \mathrm{C}$ temperature setting Kharrufa and Adil used in their 
calculations. The largest reduction in total energy transfer to the one-room building over the 24 hour period was obtained by the active mass cooling system that reduced the total heat energy transfer to the room air by $58 \%$.

7.8 Room Temperature and Cooling Load Profile of the One-Room Building with the Sustainable Cooling Methods Applied in Combinations

Figure 7.7 gives the room temperature and cooling load profile of the one-room building for the following combinations of the sustainable cooling alternatives

i. Roof-spray and Night Flushing

ii. Roof-pond and Night Flushing

iii. Active Mass Cooling and Night Flushing

iv. Active Mass Cooling, Roof-pond and Night Flushing

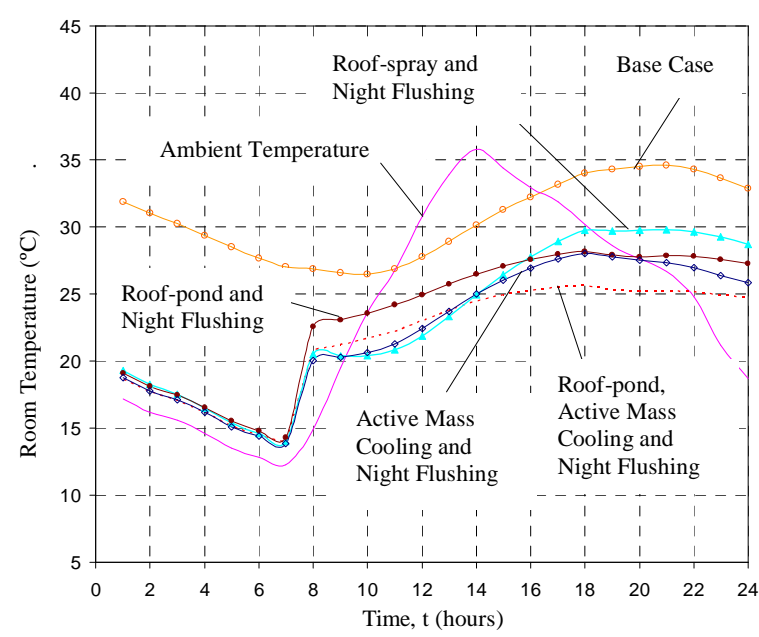

(a)

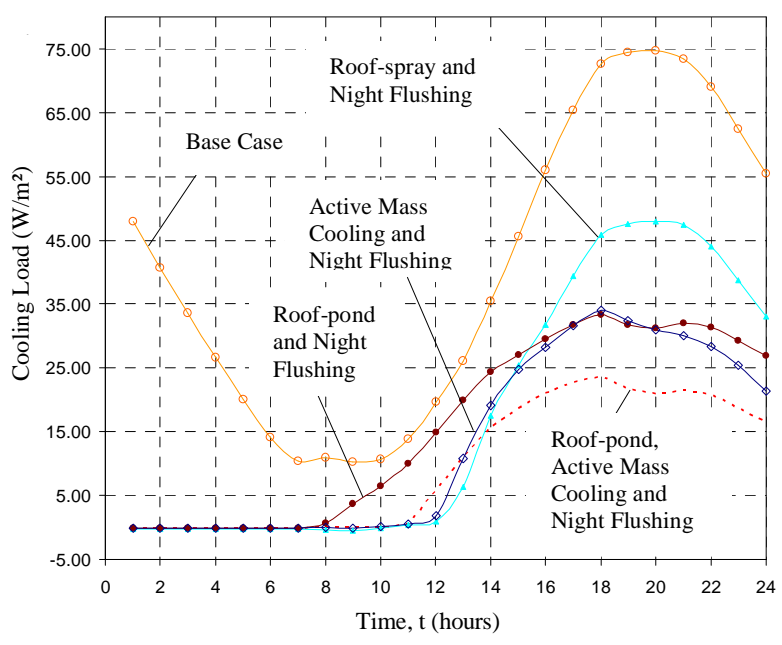

(b)

Figure 7.7: (a) Room Temperature and (b) Cooling Load Profile of the One-Room Building with the Sustainable Cooling Methods Applied in Combinations

Figure 7.7(a) shows that the combination of roof-spray and night flushing reduced the peak room temperature from the base case by $4.8^{\circ} \mathrm{C}$. The combination of roof-pond and night flushing gave a $6.7^{\circ} \mathrm{C}$ peak room temperature reduction while the combination of active mass cooling and night flushing yielded a $7.2{ }^{\circ} \mathrm{C}$ peak room temperature reduction. This compares favourably to the case where the roof-spray, roof-pond and active mass cooling systems were employed as standalone systems since the addition of night flushing to the roof-pond, roof-spray and active mass cooling systems produced an additional temperature reduction of $0.9^{\circ} \mathrm{C}, 1.1{ }^{\circ} \mathrm{C}$ and $0.6^{\circ} \mathrm{C}$ respectively. The combination of active mass cooling, night flushing and roof-pond showed the most promising results by reducing the peak room temperature $9.3{ }^{\circ} \mathrm{C}$. 
The total energy transferred (based on a $22{ }^{\circ} \mathrm{C}$ thermostat setting) to the one-room building over the 24 hour period $E_{r m, t o t}$ and the peak cooling loads $\dot{q}_{p k, t o t}$ for the above mentioned combination of the sustainable cooling alternatives are presented in table 7.6.

Table 7.6: Total Heat Energy and Peak Cooling Load of the One-Room Building with the Sustainable Cooling Alternatives Included as Combinations

\begin{tabular}{|l|c|c|c|c|}
\hline $\begin{array}{l}\text { Sustainable Cooling } \\
\text { Alternative Combination }\end{array}$ & $E_{r m, t o t}\left(\mathrm{~kJ} / \mathrm{m}^{2}\right)$ & $\%$ Reduction in $E_{r m, t o t}$ & $\begin{array}{c}\dot{q}_{p k, t o t} \\
\left(\mathrm{~W} / \mathrm{m}^{2}\right)\end{array}$ & $\begin{array}{c}\% \text { Reduction in } \\
\dot{q}_{p k, t o t}\end{array}$ \\
\hline Base Case & 3490.53 & $0.00 \%$ & 74.73 & $0.00 \%$ \\
\hline $\begin{array}{l}\text { Roof-spray \& Night } \\
\text { Flushing }\end{array}$ & 1526.39 & $56.27 \%$ & 48.02 & $35.74 \%$ \\
\hline $\begin{array}{l}\text { Roof-pond \& Night } \\
\text { Flushing }\end{array}$ & 1379.78 & $60.47 \%$ & 33.30 & $55.45 \%$ \\
\hline $\begin{array}{l}\text { Active Mass Cooling \& } \\
\text { Night Flushing }\end{array}$ & 1146.79 & $67.15 \%$ & 33.99 & $54.52 \%$ \\
\hline $\begin{array}{l}\text { Active Mass Cooling, } \\
\text { Roof-pond and Night } \\
\text { Flushing }\end{array}$ & 860.04 & $75.36 \%$ & 23.75 & $68.22 \%$ \\
\hline
\end{tabular}

Table 7.6 shows that the combination of roof-spray and night flushing reduced the peak cooling load from the base case value to $48 \mathrm{~W} / \mathrm{m}^{2}$. The combination of roof-pond and night flushing reduced the peak cooling load to $33.3 \mathrm{~W} / \mathrm{m}^{2}$ while the combination of active mass cooling and night flushing reduced the peak cooling load to $34 \mathrm{~W} / \mathrm{m}^{2}$. The addition of night flushing to the roof-pond produced and additional reduction in peak cooling load of $4.7 \%$, an additional reduction of 5.9\% for the roof-spray and an additional reduction of $4.72 \%$ for the active mass cooling system when compared to the case where these systems were used as stand alone systems. The most favourable results were obtained for a combination of the roof-pond, active mass cooling and night flushing. The one-room building peak cooling load was lowered from $74.73 \mathrm{~W} / \mathrm{m}^{2}$ to $23.75 \mathrm{~W} / \mathrm{m}^{2}$ which corresponds to a $68.22 \%$ reduction in peak cooling load.

The total energy transferred to the one-room building air in the 24 hour period was also significantly decreased by the addition of night flushing to the roof-pond, roof-spray and active mass cooling systems. In all cases the total energy transferred to the one-room building air could be reduced by more than 55\% from the base case value. The greatest reduction was found by the combination of active mass cooling, roof-pond and night flushing where the total energy transferred to the one-room building was reduced to $75.36 \%$.

It can be concluded that the large temperature and cooling load reduction produced by the combination of night flushing with a roof pond and the combination of the roof-pond with active mass cooling and night flushing should be sufficient to maintain temperature below 22 ${ }^{\circ} \mathrm{C}$ for a building where the cooling load does not exceed $25 \mathrm{~W} / \mathrm{m}^{2}$. 


\subsection{Room Temperature and Cooling Load Profile of the One-Room Building with Night Flushing Under a Variety of Air Change Rates}

Figure 7.8 shows the room temperature of the one-room building for air change rates varying from 2 to $40 \mathrm{ACH}$.

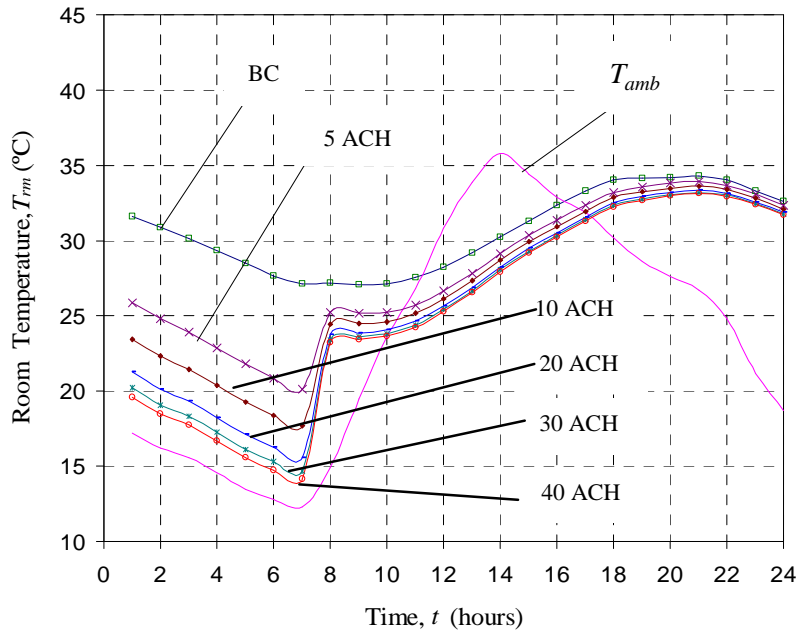

Figure 7.8: Hourly Room Temperature Variation of the One-Room Building under a Variety of Night Flushing Air Change Rates

From figure 7.8 it is illustrated that the peak room temperature may be reduced by $0.36{ }^{\circ} \mathrm{C}, 0.66{ }^{\circ} \mathrm{C}, 0.94{ }^{\circ} \mathrm{C}, 1.1{ }^{\circ} \mathrm{C}$ and $1.15^{\circ} \mathrm{C}$ when night flushing at a rate of 5 , $10,20,30$ and $40 \mathrm{ACH}$ are respectively applied to the one-room building.

From this result it can be seen that no significant improvement in peak room temperature is obtained when the air change rate is increased beyond $30 \mathrm{ACH}$. This agrees with the findings by Artmann (2008) who found that with night flushing a critical air change is reached. The critical air change rate reported by Artmann was $20 \mathrm{ACH}$.

The variation in the peak cooling load of the one-room building for a variety of night flushing air flow rates is presented in figure 7.9(a). Figure 7.9(b) gives the percentage by which the peak cooling load is reduced for increasing night flushing air change rates and four room temperature settings.

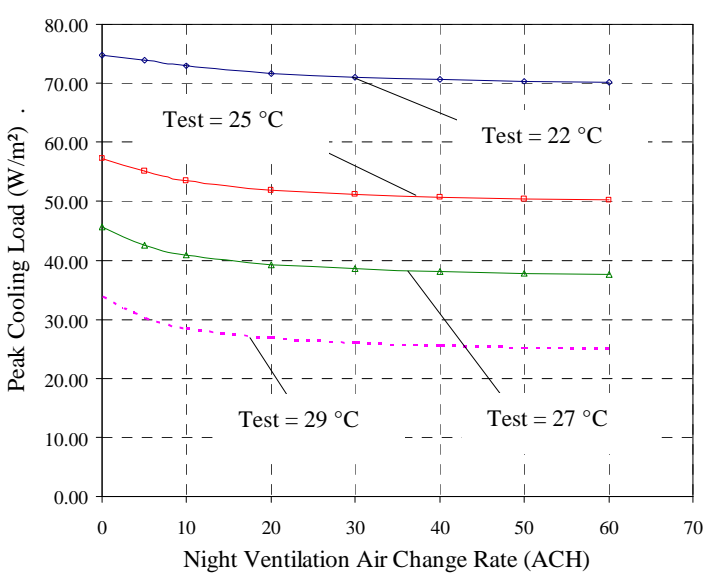

(a)

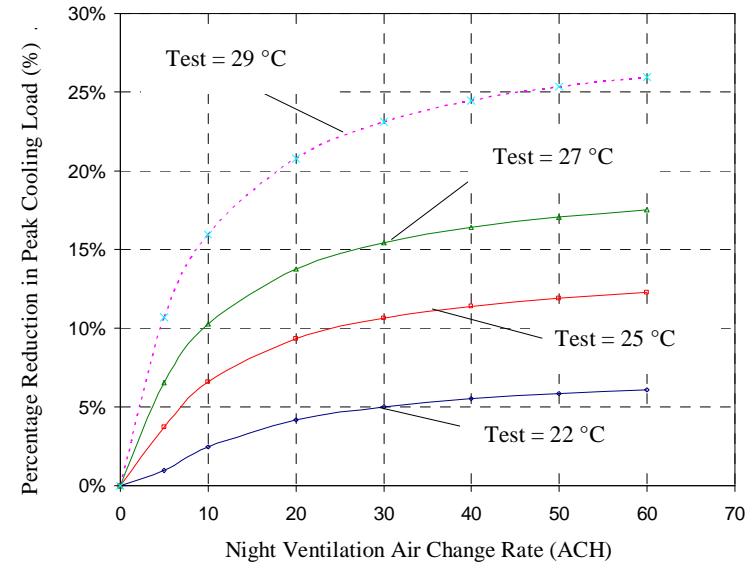

(b)

Figure 7.9: (a) Peak Cooling Load and (b) Percentage Reduction in Peak Cooling Load for Increasing Night Flushing Air Change Rates and Four Room Temperature Settings

From figure 7.9(a) it can be seen that the peak cooling load of the one-room building decreases as the night flushing air change rate increase. The peak cooling load shows a quick 
decline for night flushing rates from 0 to $10 \mathrm{ACH}$. From 10 to $30 \mathrm{ACH}$ the rate at which the cooling load decreases diminishes and from $40 \mathrm{ACH}$ onwards, the reduction in peak cooling load becomes insignificant. The sudden drop in peak heat loads between 0 and $10 \mathrm{ACH}$ corresponds with the findings of Blondeau et al. (1997), Agas et al. (1991) and Finn et al. (2007). However, in contrast with these authors a significant decrease is visible in the region from $10 \mathrm{ACH}$ to $30 \mathrm{ACH}$.

Figure 7.9(b) shows that for a night ventilation air change rate of $30 \mathrm{ACH}$ and a room temperature setting of $22{ }^{\circ} \mathrm{C}, 25^{\circ} \mathrm{C}, 27^{\circ} \mathrm{C}$ and $29^{\circ} \mathrm{C}$ the peak cooling load can be reduced by $5.04 \%, 10.65 \%, 15.43 \%$ and $23.11 \%$ respectively. Geros et al. (1999) reported a peak cooling load reduction of $56.2 \%, 79.1 \%$ and $93.7 \%$ for air change rates of 10, 20 and $30 \mathrm{ACH}$ respectively. The discrepancy between the thesis simulated results and those reported by Geros et al. may be ascribed to a different building configuration and meteorological conditions.

\subsection{Roof Temperature and Roof Heat Flux Profile of the One-Room Building with the Roof-pond of Varying Water Levels}

The hourly variation of the heat flux through the roof slab $\dot{q}_{r s, t r}$ for the base case, for the roof-spray and for the roof-pond with water levels of $50 \mathrm{~mm}, 100 \mathrm{~mm}$ and $150 \mathrm{~mm}$ are depicted in figure 7.10(a). Figure 7.10(b) gives the outer roof surface temperature for the base case, the roof-spray and roof-pond with water levels of $50 \mathrm{~mm}, 100 \mathrm{~mm}$ and $150 \mathrm{~mm}$.

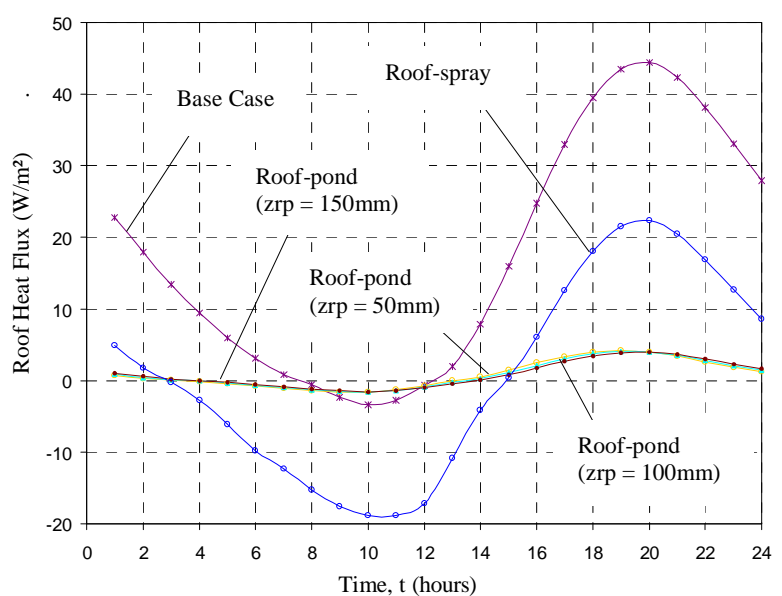

(a)

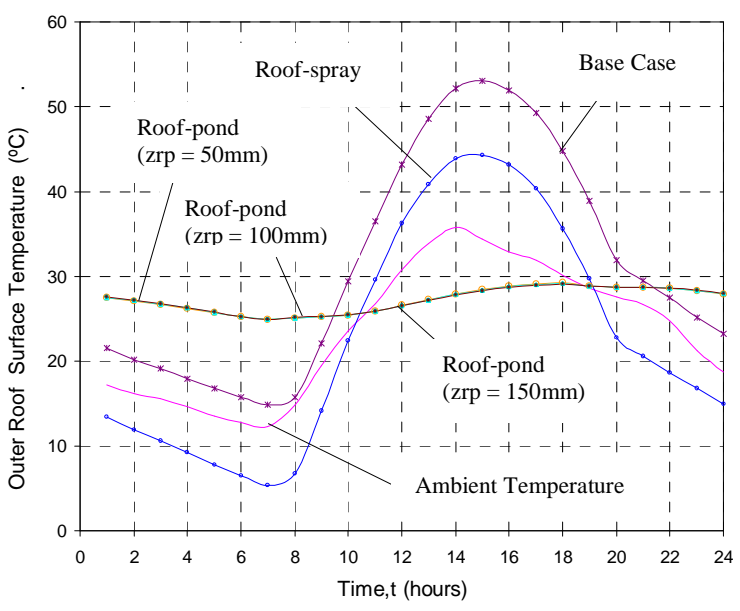

(b)

Figure 7.10: (a) Roof Heat Flux Profile and (b) Roof Temperature of the One-Room Building with Roof-spray and Roof-pond with Varying Roof-pond Water Levels

From figure 7.10 (b) the roof-spray system reduced the peak roof heat flux by $49.7 \%$ from $44.46 \mathrm{~W} / \mathrm{m}^{2}$ to $22.38 \mathrm{~W} / \mathrm{m}^{2}$. This reduction in peak roof flux compares favourably to the $56 \%$ reduction obtained by Clements and Sherif (1998) and the 41\% reduction reported by Sodha et al. (1980:1). The thermal analysis by Clements and Sherif (1998) was conducted for a heat flux through an insulated roof for a building in Bryan, Texas, where a reduction from 17 $\mathrm{W} / \mathrm{m}^{2}$ to $7 \mathrm{~W} / \mathrm{m}^{2}$ was found with the application of a roof-spray. 
Figure 7.10(a) demonstrates that the roof-pond with water levels of $50 \mathrm{~mm}, 100 \mathrm{~mm}$ and 150 $\mathrm{mm}$ reduced the roof heat flux by $91 \%\left(44.40 \mathrm{~W} / \mathrm{m}^{2}\right.$ to $\left.4 \mathrm{~W} / \mathrm{m}^{2}\right)$. The peak outer roof surface temperature for roof-pond water levels of $50 \mathrm{~mm}, 100 \mathrm{~mm}$, and $150 \mathrm{~mm}$ were approximately $29^{\circ} \mathrm{C}$. This result agrees with what has been found by Jain (2006) and Houghten et al. (1940). Jain (2006) showed in his thermal analysis of a roof in the arid region of Rajasthan, India, that there is no benefit to the reduction of roof temperature by increasing the water level of a roof-pond.

An increased roof-pond water level gives a larger roof-pond water mass, $m_{r p}$ and consequently a larger thermal storage. Equation 4.7 shows the conservation of energy applied to the roof-pond. The sum of the terms on the right hand side gives the net energy gain or loss from the roof-pond. When energy is gained the roof-pond increases in temperature (see equation 4.8) and the opposite is true when energy is lost. The amount by which the roofpond water temperature increases depend on $m_{r p}$ and $C_{p}$. Since $C_{p}$ remains constant $m_{r p}$ would influence the roof-pond water temperature. An increased $m_{r p}$ would theoretically give a lower roof-pond temperature. It must however be remembered that a lower roof-pond water temperature in turn increases $\dot{Q}_{b u i l d}$ and $\dot{Q}_{r p, c o n v}$ during daytime hours. This has the opposite effect on the roof-pond temperature resulting in an increases. It can therefore be concluded that even though an increase in roof-pond water mass would seems to be beneficial would the heat loss transfer mechanism be negatively influences which counters the benefit. The result is that a varying roof-pond water level as a negligible influence on the room temperature.

\subsection{Water Heat Removal Rate from the Roof Cooling System}

As illustrated by the discussion of the experimental results in section 7.1, the roof cooling system has the ability to produce cool water. Water is cooled through convection and evaporation in the roof-spray and through night sky radiation at the roof-pond. As shown in the sensitivity analysis of Section 7.4, the rate at which the water is cooled is dependent on weather parameters such as $T_{s k y}, T_{a}, u_{w}$ and $\phi_{a}$ as well as design variables such as VMD, $\dot{m}_{r c}, A_{r p}$ and $z_{r p}$.

When a roof cooling system is designed for a building the design variables and weather parameters need to be known in order for the designer to evaluate the cooling ability of the system. To illustrate this variation in performance the design parameters are fixed and the ambient temperature and humidity varied. Figure 7.11 gives the cooling ability of the roof cooling system for a fixed humidity and varying temperature while in figure 7.12 the ambient temperature is kept constant while the humidity is varied. The graphs in figure 7.11 and figure 7.12 were generated for $\dot{m}_{r c}=0.02 \mathrm{~kg} / \mathrm{sm}^{2}, V M D=1200 \mu \mathrm{m}, \phi_{a}=80 \%, u_{w}=3 \mathrm{~m} / \mathrm{s}$, $T_{r p}=15.5^{\circ} \mathrm{C}$ and $z_{r p}=100 \mathrm{~mm}$. 


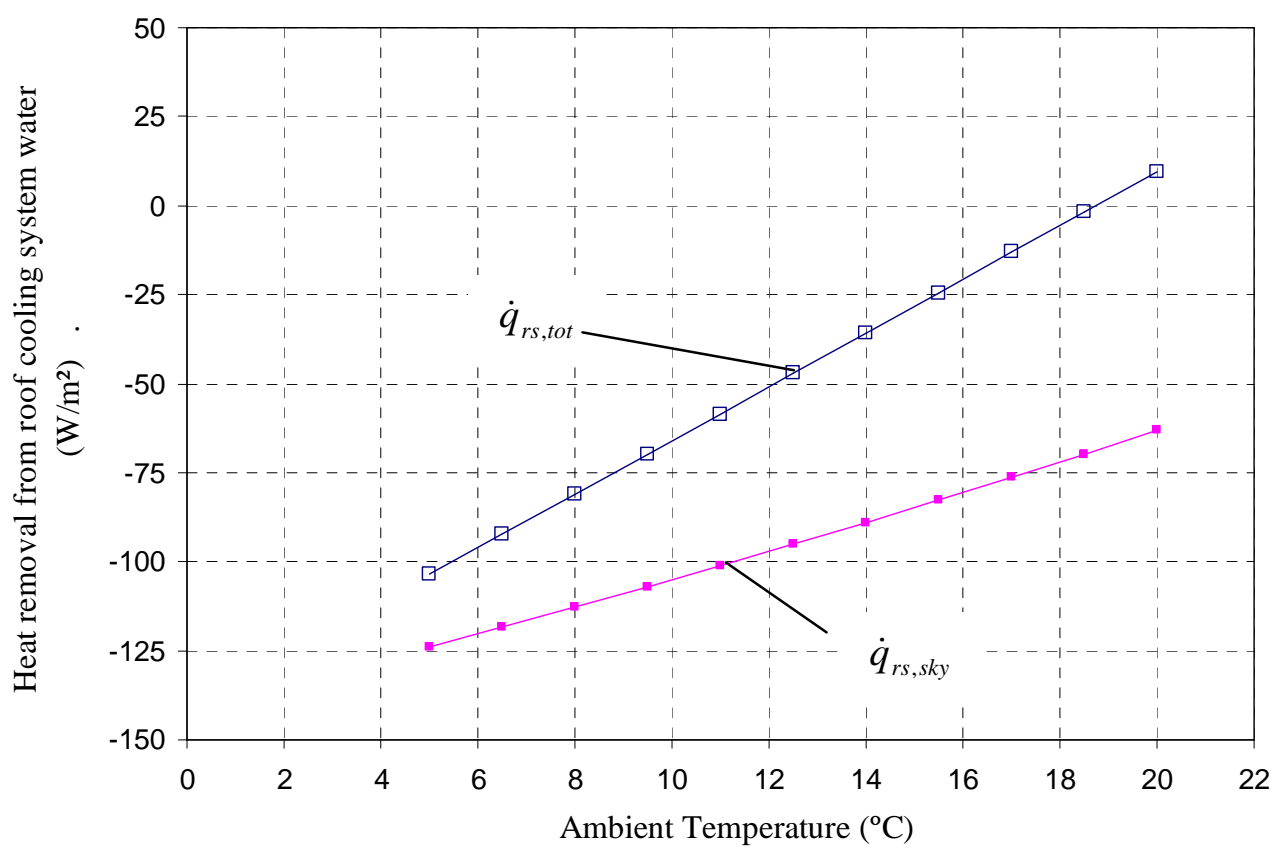

Figure 7.11: Rate of Heat Removal from the Water in the Roof Cooling System for Increasing Ambient Temperatures and $\dot{m}_{r c}=0.02 \mathrm{~kg} / \mathrm{sm}^{2}, V M D=1200 \mu \mathrm{m}$,

$$
\phi_{a}=80 \%, u_{w}=3 \mathrm{~m} / \mathrm{s}, T_{r p}=15.5{ }^{\circ} \mathrm{C} \text { and } z_{r p}=100 \mathrm{~mm}
$$

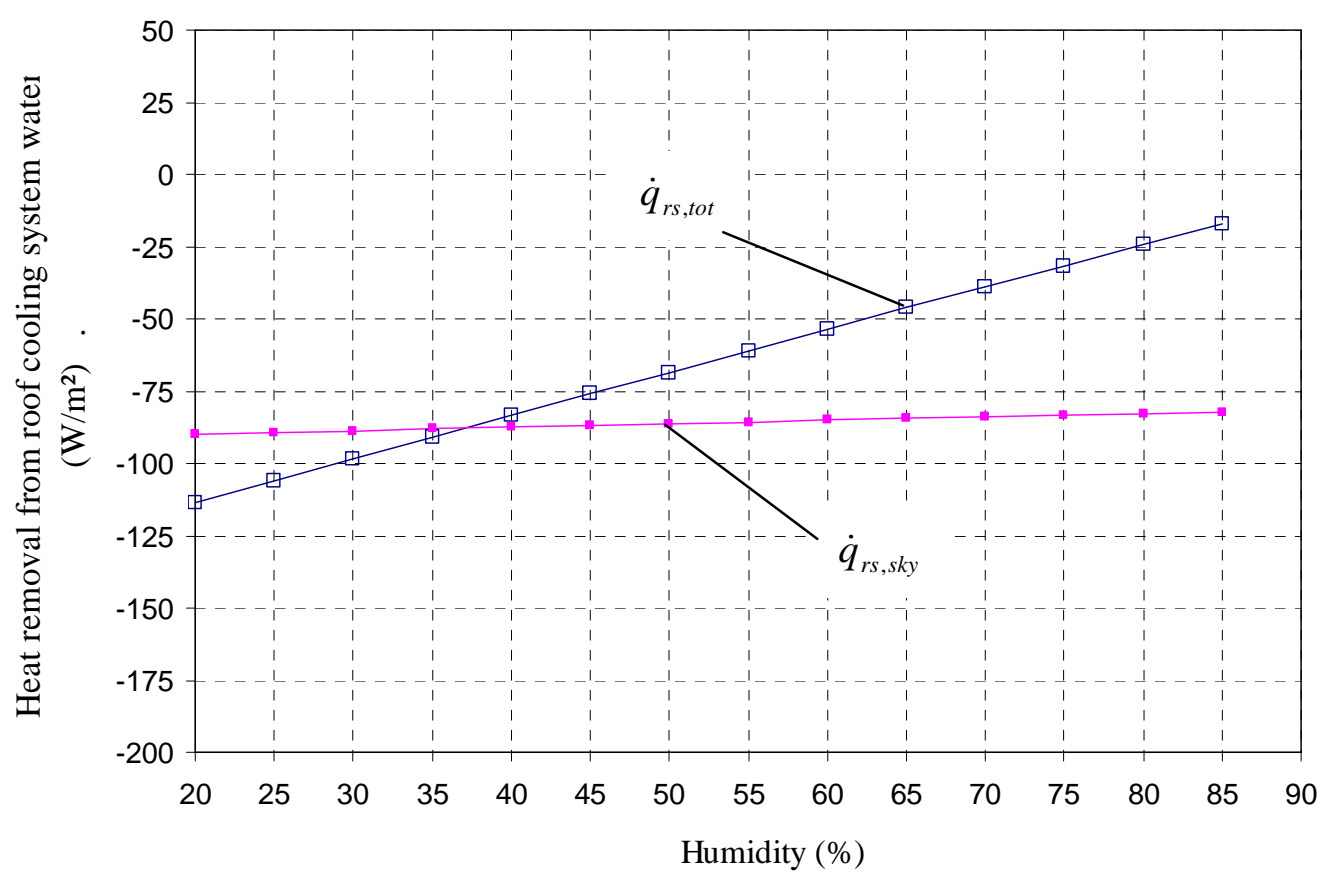

Figure 7.12: Rate of Heat Removal from the Water in the Roof Cooling System for an Increasing Relative Humidity and $\dot{m}_{r c}=0.02 \mathrm{~kg} / \mathrm{sm}^{2}, V M D=1200 \mu \mathrm{m}, T_{a m b}=15.5^{\circ} \mathrm{C}$,

$$
u_{w}=3 \mathrm{~m} / \mathrm{s}, T_{r p}=15 \quad{ }^{\circ} \mathrm{C} \text { and } z_{r p}=100 \mathrm{~mm} \text {. }
$$


Figure 7.11 shows at a constant humidity the sky energy loss $\dot{q}_{r s, s k y}$ changes at a rate of 4 $\mathrm{W} / \mathrm{m}^{2 \circ} \mathrm{C}$ while the energy loss from the roof-spray $\dot{q}_{r s, t o t}$ varies at rate of $7.54 \mathrm{~W} / \mathrm{m}^{2 \circ} \mathrm{C}$. The variation in $\dot{q}_{r s, s k y}$ may be ascribed to a change in sky temperature $T_{s k y}$ that varies with ambient temperature. The variation of $\dot{q}_{r s, t o t}$ results from the change in convection heat transfer and mass transfer at the surface of the water droplets. From figure 7.11 the sky radiation radiation heat loss, $\dot{q}_{r p s k y}$, is $82 \mathrm{~W} / \mathrm{m}^{2}$ at an ambient temperature of $15.5^{\circ} \mathrm{C}$ and the corresponding heat loss from the roof-spray water, $\dot{q}_{r s, t o t}$, is $24.4 \mathrm{~W} / \mathrm{m}^{2}$. The sky radiation heat removal rate compares favourably with the $80 \mathrm{~W} / \mathrm{m}^{2}$ reported by Erell and Etzion (1996).

Figure 7.12 shows at a constant ambient temperature the change in $\dot{q}_{r s, s k y}$ is barely visible while the change in $\dot{q}_{r s, t o t}$ occurs at a rate of $1.5 \mathrm{~W} / \mathrm{m}^{2}$ per \% change in relative humidity. The variation in $\dot{q}_{r s, t o t}$ may be ascribed to an increased evaporation rate. The change in $\dot{q}_{r p, s k y}$ is small since $T_{s k y}$ only varies $0.03{ }^{\circ} \mathrm{C}$ per $\%$ change in relative humidity."

It must further be noted that the above heat removal rates pertain to clear sky conditions. As pointed out in the discussion of the experimental results, cloudy conditions would decrease the night sky radiation heat removal rate since the sky temperature would be warmer. Also, the roof cooling system's ability to produce cool water is limited by the ambient dewpoint temperature. Under cloudy conditions when water evaporation is the main mechanism of cooling water can not be cooled lower than the wetbulb temperature. Under clear sky conditions the roof-pond water is cooled by means of night sky radiation at a constant pressure and can consequently be lowered to the dewpoint temperature. Take for example the scenario where $\phi_{a}=80 \%$ and $T_{a m b}=15^{\circ} \mathrm{C}$. The corresponding dewpoint temperature is $T_{d p}=11^{\circ} \mathrm{C}$. In this case the roof cooling system water cannot be cooled down lower than 11 ${ }^{\circ} \mathrm{C}$. 


\section{CONCLUSION AND RECOMMENDATIONS FOR FUTURE WORK}

The outcome of a structured survey questionnaire showed that of all the sustainable cooling alternatives identified, night flushing and active mass cooling had the highest degree of commercialisation since they are most likely to be specified by a client or consultant alike. A roof cooling system comprising a roof-pond and a roof-spray had the lowest potential of being specified but offered the ability to reduce building heat gains and produce cool water. From a literature study it is seen that although much research has been done on these sustainable cooling alternatives very little has been done to compare the efficacy of the various sustainable cooling alternative options with each other.

The different areas in the world and hence the different weather conditions under which the various options were investigated in the literature study made an accurate comparison of the various options impossible. To overcome this difficulty and to quantitatively establish the relative performance of the sustainable cooling alternatives a one-room building was assumed. From the one-room building simulations all the sustainable cooling alternative options proved to decrease the cooling load required to maintain the room at a constant temperature for the 24 hour operation period. However, the amount by which the cooling load could be reduced with each sustainable cooling alternative depended on variables such as the building structure, the orientation, location etc. The most important reduction occurred at the peak cooling load as this not only constitutes a saving in the energy consumed by a conventional air conditioner but also decreased the required size of the air conditioner.

Active mass cooling, roof-spray and night flushing are viable solutions that may be employed with confidence to lower the heat gains of buildings. When the roof spray were applied to the one-room building configuration a peak cooling load reduction in the order of $30 \%$ were achieved. A peak cooling load reduction in the order of $50 \%$ was obtained in the one-room building when the roof-pond and active mass cooling system were applied independently. Night flushing as a standalone system was not that effective and only yielded a peak cooling load reduction in the order of 5\%. For the given peak cooling load of $74.73 \mathrm{~W} / \mathrm{m}^{2}$ and the high ambient temperatures under which the simulations were performed, the active mass cooling and roof-spray system was able to lower the room temperature below $26^{\circ} \mathrm{C}$ for the morning hours of the day. However, around the afternoon hours the room temperature with the roof-spray applied raised to approximately $30{ }^{\circ} \mathrm{C}$ and for the active mass cooling to $29 .{ }^{\circ} \mathrm{C}$.

The roof cooling system on the other hand showed a significant improvement in peak cooling load reduction over the other sustainable cooling alternatives. The base case cooling load simulation peaked at $74.73 \mathrm{~W} / \mathrm{m}^{2}$ and since the roof-cooling option produced $46 \mathrm{~W} / \mathrm{m}^{2}$ of peak cooling it proved to be the most effective option off all the options considered. The large reduction in peak cooling load were possible due to the roof cooling system's ability to effectively eliminate the large base case roof heat gain which contributes to approximately 50 to $60 \%$ of the peak cooling load. The result for the 
roof cooling system is favourable in the sense that in milder climate conditions the necessity of a conventional air conditioner may be averted.

In order to boost the cooling ability of the sustainable cooling alternatives they were employed in combination with the night flushing technique. By doing this an additional reduction in the order of 5 to $6 \%$ in the peak cooling load could be achieved. The most effective combination was that of the roof-pond, active mass cooling and night flushing where the peak cooling load could be reduced by $68.22 \%$ from the base case. This combination showed a large improvement over the $61.1 \%$ reduction the roof cooling system provided.

The cooling ability of the night flushing technique was also investigated for varying air change rates. It was found that for air change rates greater than $30 \mathrm{ACH}$ no significant reduction in peak room temperature and cooling load could be obtained. This compares favourably with the findings reported by Geros et al. (1999) and Artmann et al. (2008). The effect of varying roof-pond water levels on the outer roof slab temperature as well as the roof heat flux was also investigated. The one-room building simulation calculations were repeated for roof-pond water levels of $50 \mathrm{~mm}, 100 \mathrm{~m}$ and $150 \mathrm{~mm}$. The cooling load through the roof and the outer roof slab temperature did not show any significant change for varying roof-pond water levels. This finding agrees to what has been reported by Houghten et al. (1940).

In addition to the cooling load reduction provided by the roof cooling system, cool water is also produced during nocturnal hours where the heat removal rate highly depends on the weather conditions. When the ambient temperature is $15^{\circ} \mathrm{C}$, the relative humidity is $80 \%$, the roof cooling water flow rate is $0.02 \mathrm{~kg} / \mathrm{sm}^{2}$ and the pond water level is $100 \mathrm{~mm}$ water may be cooled at a rate of $113 \mathrm{~W} / \mathrm{m}^{2}$. The roof-spray part constitutes to $28 \mathrm{~W} / \mathrm{m}^{2}$ of the cooling while the night sky radiation is responsible for $85 \mathrm{~W} / \mathrm{m}^{2}$ of the cooling. The theoretical results of a roof cooling simulation showed good agreement when compared to the results of a mock-up roof cooling experiment. It can therefore be concluded that the roof cooling mathematical model and computer program as derived in this thesis may be used with confidence as a design tool for the implementation of the roof cooling system in buildings.

A useful tool has been developed in the thesis by which the impact of the active mass cooling, roof-pond, night flushing, roof-spray and roof cooling on the hourly cooling loads of buildings can accurately be modelled. It must however be mentioned that the installation of any of the sustainable cooling alternatives would only be possible if the building design permits it without any physical constraints such as water availability, building thermal mass or an insufficient area on which a roof cooling system may be applied to.

\subsection{Recommendations for Future Work}

The sustainable cooling alternatives were analysed by applying them to a building comprising of four façade walls and a flat roof slab. It is recommended that the sustainable cooling alternatives be analysed experimentally by applying them to a full 
scale building of which the room temperature is continuously monitored. The theoretically determined cooling load and room temperature of the building can then be compared with the experimental results to provide further insight on the validity of the mathematical model as derived in this thesis. The mathematical model of the roof cooling system have been verified by comparing the theoretical results with those obtained from a limited number of daily test results.

The influence of the building thermal mass on the performance of the sustainable cooling alternatives requires further investigation. The literature review found that the thermal mass influenced the cooling ability of the night flushing technique. It is therefore anticipated that the building thermal mass would also influence the performance of active mass cooling, roof-pond, roof-spray and roof cooling systems. It is recommended that the cooling ability of the sustainable cooling alternatives be analysed for a buildings with varying thermal masses. Another possibility would be to insulate the walls and roof of the building and investigate the effect on the building cooling load and room temperature.

Similar to what has been done in literature for night flushing, it is recommended that the performance of each sustainable cooling alternative be quantified by calculating the number of hours that the indoor thermal comfort conditions exceed an acceptable operative room temperature. This would require that the calculation simulation be repeated for all the days in a year with actual measured temperatures of a specific location. Should it be found that the number of hours where the operative room temperature exceeds an acceptable limit by less than $10 \%$ of the total working hours in that year, it would be acceptable to omit the conventional AC system completely under German norms (Artmann et al. 2008).It is also recommended that a full scale one-room building be constructed to study the long term results of each of the sustainable cooling alternatives.

Even though the roof-pond and roof-spray system proved to be viable options that may be used to reduce the cooling load of buildings do these systems consume large quantities of water. Water may be regarded as a sustainable resource (WBCSD, 2009) that should be used sparingly in any green building design. It is therefore recommended that the typical water consumption of the roof-pond and roof-spray system be evaluated and quantified. It is further recommended that additional options be investigated in which the water consumption from the roof-pond and roof-spray can be reduced. 


\section{REFERENCES}

Abernethy, D., 1984, Evaporative roof cooling: A simple solution to cut cooling costs, Proceedings of the Second Symposium on Improving Building Systems in Hot and Humid Climates, College Station, Texas, 24-26 September, pp. 98-102.

Agas, G., Matsaggos, T., Santamouris, M., Argyriou, A., 1991, The use of the atmospheric heat sinks for heat dissipation, Energy and Buildings, Vol. 17, pp. 321-329.

Artmann, N., Manz, H. \& Heiselberg, P., 2008, Parameter study on performance of building cooling by night-time ventilation, Renewable Energy, Vol. 33, pp. 2589-2598.

ASAE, 1999, Spray nozzle classification by droplet spectra, American Society of Agricultural Engineers, ASAE S572 AUG99, St. Joseph, p. 3.

ASHRAE, 2003, ASHRAE Handbook - HVAC Applications, American Society of Heating, Refrigerating and Air-conditioning Engineers, Atlanta, Georgia.

ASHRAE, 2005, ASHRAE Handbook - Fundamentals, American Society of Heating, Refrigerating and Air-conditioning Engineers, Atlanta, Georgia.

Blondeau, P., Sperandio, M. \& Allard, F., 1997, Night ventilation for building cooling in summer, Solar Energy, Vol. 61, pp. 327-335.

Bentz, D.P. and Turpin, R., 2007, Potential applications of phase change materials in concrete technology, Cement \& Concrete Composites, Vol. 29, pp. 527-532.

Carrasco, A., Pittard, R., Kondepundi, S.N., \& Somasundaram, S., 1987, Evaluation of a direct evaporative roof-spray cooling system, Proceedings of the Fourth Symposium on Improving Building Systems in Hot and Humid Climates, College Station, Texas, 15-16 September, pp. 94-101.

Cengel, Y.A. and Boles, M.A., 2002, Thermodynamics: An Engineering Approach, $4^{\text {th }}$ Edition, New York, McGraw Hill.

Chakraborty, J. and Fonseca, E., 2005, Analysis and evaluation of a passive evaporative cool tower in conjunction with a solar chimney, The $22^{\text {nd }}$ Conference on Passive and Low Energy Architecture, Lebanon.

Chandra, S. and Kerestecioglu, A.A., 1984, Heat transfer in naturally ventilated rooms: Data from full-scale measurements, ASHRAE Transactions, Vol. 90, Issue 1B, pp. 211-225.

Chandra, S., Kaushik, S.C. \& Bansal, P.K., 1985, Thermal performance of a non airconditioned building for passive solar air-conditioning: Evaluation of roof cooling systems, Energy and Buildings, Vol. 8, Issue 1, pp. 51-69.

Clark, G., 1989, Passive cooling systems, Passive Cooling, Cook J. (Ed.), MIT Press, Cambridge, MA, pp.347-538. 
Clements, J.A. and Sherif, S.A., 1998, Thermal analysis of roof-spray cooling, International Journal of Energy Research, Vol. 22, Issue 1, pp. 1337-1350.

Commercialisation, Wikipedia Encyclopedia, [Online]. Available: http://www.wikipedia.com/commercialization. [2008, August 30]

Corgnati, S.P. and Kindinis, A., 2007, Thermal mass activation by a hollow core slab coupled with night ventilation to reduce summer cooling loads, Building and Environment, Vol. 42, pp. 3285-3297.

Crowe, C.T., Donald, F.E. \& Roberson, J.A., 2001, Engineering Fluid Mechanics, $7^{\text {th }}$ Edition, New York, John Wiley.

CSIR, 2003, Certificate of Calibration, CSIR National Metrology Laboratory (NHL), Certificate Number TH/RT-5266, Pretoria, South Africa.

Dan, P.D. and Chinappa, J.C.V., 1989, The cooling of water flowing over an inclined surface exposed to the night sky, Solar and Wind Technology, Vol. 6, Issue 1, pp. 41-50.

Dascalaki, E., Santamouris, M., Balaris, C. \& Asimakopoulos, D., 1994, Natural convection heat transfer coefficients from vertical and horizontal surfaces for building applications, Energy and Buildings, Vol. 20, Issue 1, pp. 243-249.

Dobson, R.T., 2005, Thermal modelling of a night sky radiation cooling system, Journal of Energy in South Africa, Vol. 16, Issue 2, pp. 56-67.

Erell, E. and Etzion, Y., 1996, Heating experiments with a radiative cooling system, Building and Environment, Vol. 31, Issue 6, pp. 509-517.

Esmore, S., 2005, Innovative design - batiso and night sky cooling, [Online]. Available: www.umowlai.com.au. [2007, August 21]

Feustel, H.E., De Almeida, A. \& Blumstein, C., 1992, Alternatives to compressor cooling in residences, Energy and Buildings, Vol. 18, Issues 3-4, pp. 269-286.

Figliola, R.S. and Beasley, D.E., 2000, Theory and Design for Mechanical Measurements, $4^{\text {th }}$ Edition, New York, John Wiley.

Finn, D., Connolly, D. \& Kenny, P., 2007, Sensitivity analysis of a maritime located night ventilated library building, Solar Energy, Vol. 81, pp. 697-710.

Fredriksson, J. and Sandberg, M., 2008, The effect of false ceiling on the cooling capacity of passive chilled beams, Building and Environment, Vol. 17, pp. 1-5.

Geros, V., Santamouris, M., Tsangrasoulis, A. \& Guarracino, G., 1999, Experimental evaluation of night ventilation phenomena, Energy and Buildings, Vol. 29, pp. 141-154.

Givoni, B., 1991, Performance and applicability of passive and low-energy cooling systems, Energy and Buildings, Vol. 17, Issue 3, pp. 177-199. 
Givoni, B., 1998, Effectiveness of mass and night ventilation in lowering the indoor daytime temperatures, Energy and Buildings, Vol. 28, Issue 1, pp. 25-32.

Green building council of south Africa, [Online]. Available: www.gbcsa.org.za. [2009, October 24]

Grobler, L.J., 2002, Energy usage in buildings: A strategy to reduce their usage, SBID Solar Academy, Potchefstroom University for CHE, pp. 1-10.

Hewitt, A., 2001, A summary of tank mix and nozzle effects on droplet size, Spray Drift Task Force, [Online]. Available: http:// www.agdrift.com/PDF_FILES/Tankmix.pdf. [2008, August 30]

Holder, L.H., 1957, Automative roof cooling, April Showers, Washington, DC, pp. 2.

Holterman, H.J., 2003, Kinetics of evaporation of water drops in air, Institute of Agriculture and Environmental Engineering, IMAG Report 2003-12, Wageningen, Netherlands.

Holterman, H.J., Van de Zande, J.C., Porskamp, H.A.J. \& Huijsmans, J.F.M., 1997, Modeling spray drift from boom sprayers, Computers and Electronics in Agriculture, Vol. 19, pp. 1-22.

Holterman, H.J, Van de Zande, J.C., Porskamp, H.A.J. \& Michielsen, J.M.G.P., 1998, IDEFICS: A physical model of spray drift from boom sprayers in agriculture, Institute of Agriculture and Environmental Engineering, Wageningen, Netherlands.

Houghten, F.C., Olsen, H.T. \& Gutberlet, C., 1940, Summer cooling load as affected by heat gain through dry sprinkled and water covered roofs, American Society of Heating and Ventilation, Engineers Transcripts, Vol. 46, pp. 231.

Hughes, W.F., Brighton, J.A. \& Winowich, N., 1999, Schaum's Outline on Fluid Dynamics, New York, McGraw Hill.

Incropera, F.P. and DeWitt, D.P., 2002, Fundamentals of Heat and Mass Transfer, $5^{\text {th }}$ Edition, New York, John Wiley.

Jain, D., 2006, Modeling of solar passive techniques for roof cooling in arid regions, Building and Enviroment, Vol. 41, Issue 1, pp. 277-287.

Jain, S.P. and Rao, K.R., 1974, Experimental study on the effect of roof-spray cooling on unconditioned and conditioned buildings, Building Science, Vol. 9, Issue 9, pp. 9-16.

Kharrufa, S.N. and Adil, Y., 2006, Roof-pond cooling of buildings in hot acid climates, Building and Environment, Vol. 43, pp. 82-89.

Keller, G. and Warrack, B., 2000, Statistics for Management and Economics, $5^{\text {th }}$ Edition, Pacific Grove, USA, Brooks/Cole. 
Kolokotroni, M., Webb, B.C. \& Hayes, S.D. 1998, Summer cooling with night ventilation for office buildings in moderate climates, Energy and Buildings, Vol. 27, pp. 231-237.

Koschenz, M. and Dorer, V., 1999, Interaction of an air system with concrete core conditioning, Energy and Buildings, Vol. 30, pp. 139-145.

Lehmann, B., Dorer, V. \& Koschenz, M., 2007, Application range of thermally activated building systems tabs, Energy and Buildings, Vol. 39, pp. 593-598.

Mackey, C.O. and Wright, L.T., 1944, American Society of Heating and Ventilating Engineers, Vol. 50, pp. 292.

Miller, P., 2003, The measurement of spray drift, Pesticide Outlook, Vol. 14, pp. 205-209.

Miller, P.C.H., 1993, Spray drift and its measurement, Application Technology for Crop Protection, Wallingford, UK, pp. 101-102.

Mills, A.F., 2000, Heat Transfer, $2^{\text {nd }}$ Edition, New Jersey, Prentice Hall

Mull, T.E., 1997, HVAC Principles and Applications Manual, New York, McGraw Hill.

Pfafferott, J., Herkel, S. \& Jäschke, M., 2003, Design of passive cooling by night ventilation: Evaluation of a parametric model and building simulation with measurements, Energy and Buildings, Vol. 35, pp. 1129-1143.

Pfafferott, J., Herkel S. \& Wambsganß, M., 2004, Design, monitoring and evaluation of a low energy office building with passive cooling by night ventilation, Energy and Buildings, Vol. 36, pp. 455-465.

Potter M.C. and Wiggert, D.C., 2001, Mechanics of Fluids, $3^{\text {rd }}$ Edition, Pacific Grove, USA, Brooks/Cole.

Riley, M., 2004, Commercialisation strategy for innovative cooling technologies for northern countries like Canada, [Online]. Available: www.iea.org/Textbase/work/2004/cooling/Mark_Riley. [2008, August 30].

Rumsey Engineers Inc., 2001, Missouri Department of Natural Resources, Schematic design report, HVAC System, Revision 1.1, [Online]. Available: http://www.dnr.mo.gov/greenbldg/docs/hvac-design.pdf. [2001, June 14].

Ruud, M.D., Mitchell, J.W. \& Klein, S.A., 1990, Use of building thermal mass to offset cooling loads, ASHRAE Transactions, Vol. 96, Issue 2, pp. 820-829.

SAIRAC, 2006, South African Institute of Refrigeration and Airconditioning.

SABS 0400-1990, The Application of the National Building Regulations, Pretoria, South Africa, The Council of the South African Bureau of Standards 
Sayers, A.T., 1990, Hydraulic and Compressible Flow Turbomachines, Britian, Library Cataloging in Publication Data.

Schick, R.J., undated b, An engineer's practical guide to drop size, Wheaton Illinois, USA, Spraying Systems Cooperation.

Seed Urban, 2002, What is an energy audit?, Sustainable energy for environment \& development programme update, Vol. 1, Issue 1, pp. 1-12.

Sodha M.S., Govind, D.P., Bansal, P.K. \& Kaushik, S.C., 1980:1, Reduction of heat flux by a flowing water layer over an insulated roof, Building and Environment, Vol. 15, pp. 133-140.

Sodha, M.S., Kumar, A., Singh, U. \& Tiwari, G.N., 1980:2, Periodic theory of an open roofpond, Applied Energy, Vol. 7, Issue 4, pp. 305-319.

Sodha, M.S., Singh, U \& Tiwari G.N.,1982, A thermal model of a roof-pond system with moveable insulation for heating a building, Building and Enviroment, Vol. 17, No.2, pp. 135144.

Southcombe, E.S.E., Miller, P.C.H., Ganzelmeier, H., Van de Zande, J.C., Miralles, A. \& Hewit, A.J., 1997, The international (BCPC) spray classification system including a drift potention factor, The 1997 Brighton Crop Protection Conference - Weeds.

Spoormaker, H.J. and Kohler, P.A.J., 2002, HVAC evaporative cooling and energy conservation, Sustainable Buildings and Integrated Design, Southern African Solar Academy, Johannesburg, 9-14 September, pp. 1-14.

Stetiu, C., 1999, Energy and peak power savings potential of radiant cooling systems in US commercial buildings, Energy and Buildings, Vol. 30, pp. 127-138.

Stewart, I., Massingham, J.D. \& Hayes, J.J., 1995, Heat transfer coefficient effects on spray cooling, AISE Annual Convention \& Iron and Steel Exposition, Pittsburg, Pennsylvania.

Stoecker, W.F. and Jones, J.W., 1982, Refrigeration and Air Conditioning, $2^{\text {nd }}$ Edition, Singapore, McGraw Hill.

Sutton, G.E., 1950, American society heat ventilation engineers guide, pp. 131.

Tanner, G. and Knasiak, K.F., 2003, Spray characterization of typical fire suppression nozzles, Third International Water Mist Conference, Madrid, Spain, 22-24 September, pp. 116.

Thappen, A.B., 1943, Excessive temperature in flat-top building, Refrigeration Engineering, Vol. 1, pp. 163.

Technology Installation Review, White cap roof-spray cooling system, [Online]. Available: www.pnl.gov/TechReview/whitecap/whitecap.html. [2007, March 14] 
The Innovation Chain, Sustainable development technology Canada, [Online]. Available: http://www.wikipedia.com/theinnovationchain. [2008, August 30]

Tian, Z. and Love, J.A., 2009, Energy performance optimization of radiant slab cooling using building simulation and field measurements, Energy and Buildings, Vol. 41, pp. 320-330.

Tiwari, G.N., Kumar, A. \& Sodha, M.S., 1981, A review - cooling by water evaporation over roof, Energy Conversion and Management, Vol. 15, Issue 2, pp. 133-140.

Toolbase Services, Phase change materials, [Online]. Available: www.toolbase.org [2007, June 21]

United nations framework convention of climate change, [Online]. Available: www.UNFCCC.int. [2009, October 24]

Vanderplaats, G.N., 2005, Numerical Optimization Techniques for Engineering Design, $4^{\text {th }}$ Edition, Colorade Springs, Vanderplaats Research \& Development Inc.

Van de Zande, J.C., Holterman, H.J. \& Porskamp, H.A.J., undated b, Influence of reference nozzle choice on spray drift classification, Wageningen University and Research Centre Agrotechnology \& Food Innovations, Wageningen, Netherlands.

Vangtook, P. and Chirarattananon, S., 2007, Application of radiant cooling as a passive cooling option in hot humid climate, Building and Environment, Vol. 42, pp. 543-556.

Van Wyk, L.(editor), 2009, Green Building Handbook South Africa, A guide to ecological design, [Online]. Available: http://greenbuildingfocus.com/images/handbook/gbf $\% 20$ handbook\%20abstract.pdf. [2009, October 24]

WBCSD, World business council for sustainability, [Online]. Available:

http://www.wikipedia.com/theinnovationchain. [2009, October 16] 


\section{APPENDIX A: COMMERCIALISATION CYCLES AND SURVEY QUESTIONNAIRE}

The degree of commercialisation was employed in Chapter 2 as an evaluation criterion to reduce the identified sustainable cooling alternatives to three methods that could be researched further. The degree of commercialisation refers to the stage in which a technology finds itself in the commercialisation cycle (Wikipedia Encyclopedia, 2009).

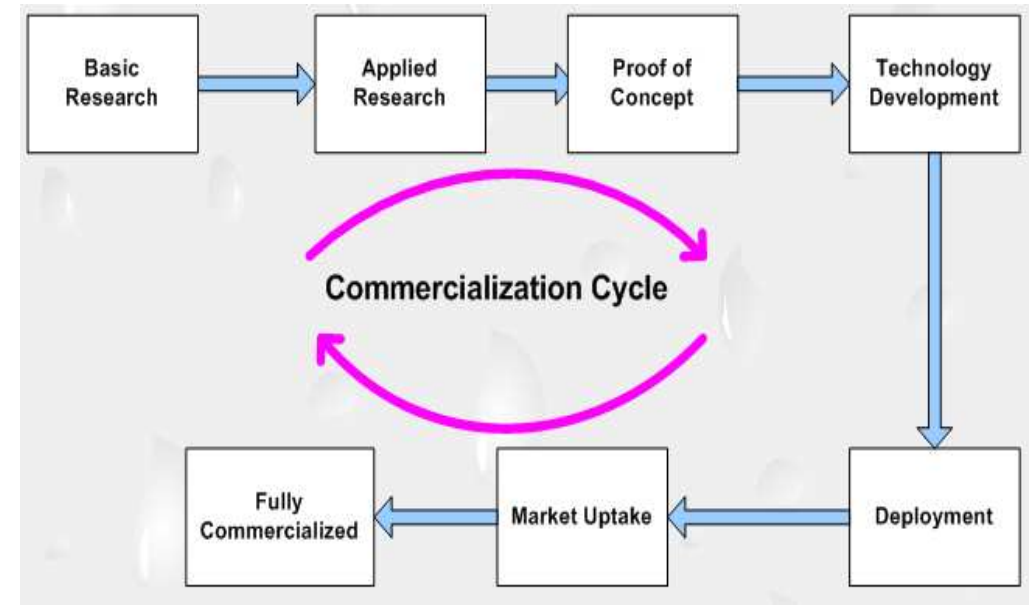

Figure A.1: Various Stages of the Commercialisation Cycle
The commercialisation cycle extends from the basic research to the fully commercialised stage (Riley, 2004). The various stages of the commercialisation cycle are depicted in figure A.1

The repetitive nature of product commercialisation is not depicted. The commercialisation cycle stages takes place iteratively and usually not in sequence with a definite start and stop

as shown on the figure A.1. The stages of the commercialisation cycle are explained below.

i. The 'basic research' stage involves the examination of an initial concept that can theoretically work. The 'basic research' stage is followed by the 'applied research' stage where further research on the concept is conducted.

ii. The 'proof of concept' stage involves the construction of a pilot to full scale prototype to prove the feasibility of the concept. The 'technology development' stage implements variations on the concept to optimise and refine the technology.

iii. During the 'deployment' stage industry awareness on the technology grows. The industry prepares itself to cope with the new demands of the upcoming product. Industry training will typically be enhanced and industry capacity developed.

iv. The 'market uptake' stage is the final and most vital stage. The new concept is introduced into the market when the following questions are answered: (Wikipedia Encyclopedia, 2009)

When? Is the introduction and time to market correct?

Where? Where is the technology launched? Single location, national or international? 
To Whom? Who is the target customer? Can the hub be found? Who are the early adopters?

How? What is the marketing strategy to be followed and what action plan will be taken?

\section{A.1 Industry Stakeholders in the Commercialisation Cycle}

Each stage of the commercialisation cycle hosts different industry stakeholders. This implies that if a certain industry sector is well acquainted with a new concept the concept most probably lies in the corresponding stage of that industry sector or at a more developed stage.

Figure A.2 below depicts the various industry stakeholders as they appear at the different stages of the commercialisation cycle. Figure A.2 was derived from an original graph by Sustainable Development Technology Canada (The Innovation Chain, Sustainable Development Technology Canada, 2008).

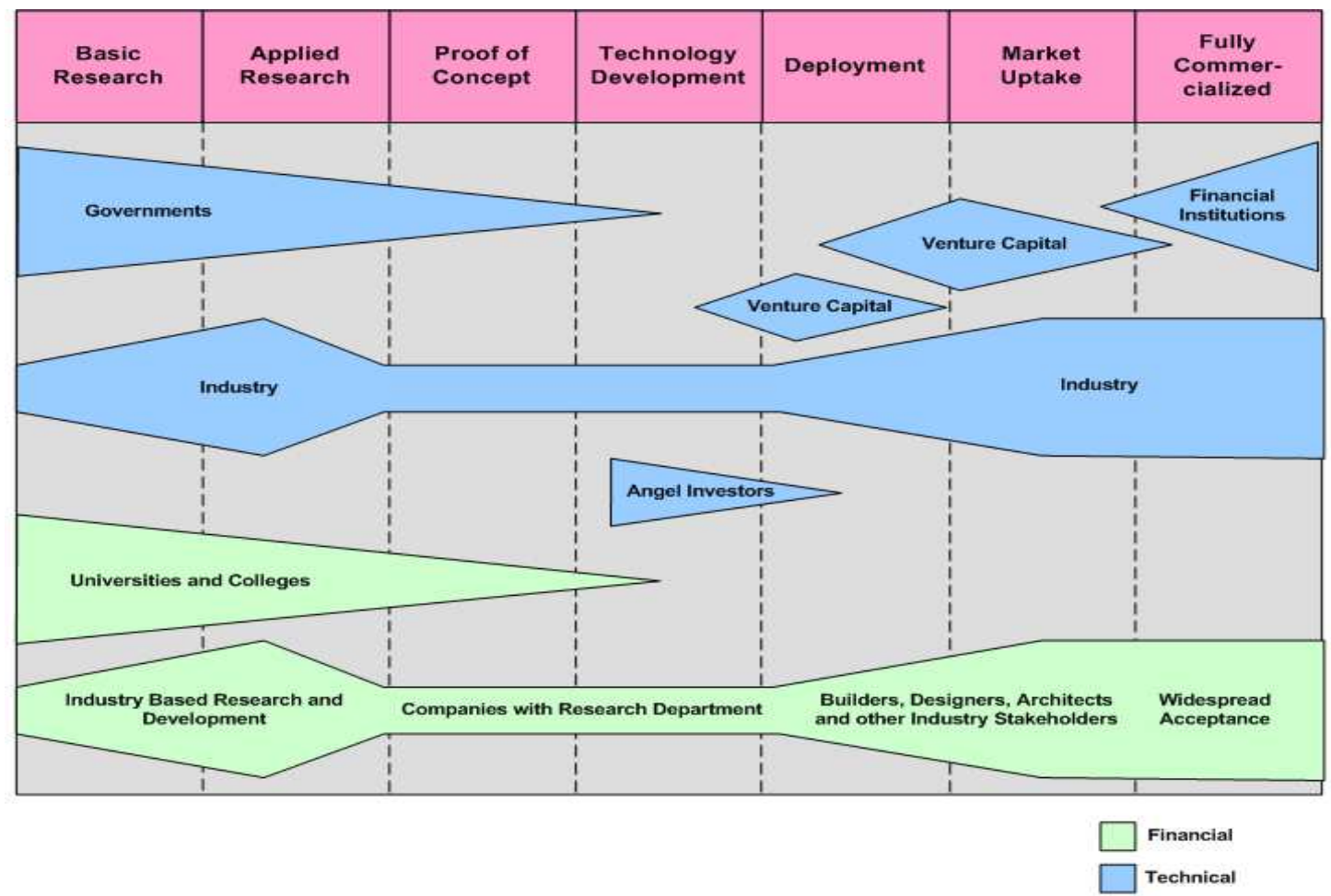

Figure A.2: Industry Stakeholders in the Commercialisation Cycle

The financial and technical involvement of the various industry stakeholders in the commercialisation cycle is illustrated in figure A.2. The following observations can be made from figure A.2

i. Universities and colleges, funded by government and private sector companies, are involved in the 'basic research' and 'applied research' stages of the commercialisation cycle. Industry based research also occurs during these two stages. 
ii. The financial and technical involvement from education institutions decline as the new concept approaches the 'proof of concept' and 'technology development' stages. During these periods the concept has to rely on companies and investors to make unsafe investments in a concept that has not yet proved itself.

iii. As the technology starts to mature, small early private investors (early adopters) start to invest. The survival of the new concept in the 'technology development' stage comes to an end as venture capital promotes greater financial involvement from industry. The increase in development of the concept prepares the concept for market entry.

In the context of this thesis this implies that each industry stakeholder group would have a different view of the degree of commercialisation of the sustainable cooling alternatives.

\section{A.2 Stratified Random Sampling}

As explained in Chapter 2, a sampling procedure has been followed to determine the degree of commercialisation of the various sustainable cooling alternatives. According to Keller and Warrack (2000) stratified random sampling should be followed when information on a certain subject is required from different groups with different views. Stratified random sampling involves the separation of the sampling population into mutually exclusive ${ }^{1}$ groups followed by the drawing of simple random samples from each group. The application of this sampling technique to the sustainable cooling alternatives may be explained as follows

i. Information is not only acquired from the total population but also from each particular group in the population.

ii. The sample population in this case refers to the South African Building Industry whilst the mutually exclusive groups are the different industry stakeholders such as architects, engineers, builders, etc.

iii. Each industry stakeholder group reveals a different sustainable cooling alternative as the method with the highest degree of commercialisation.

iv. Industry stakeholders in the 'market entry' and 'fully commercialised' stages of the commercialisation cycle should disclose the sustainable cooling alternative with the highest degree of commercialisation.

The stratified random sampling technique is a promising technique in determining the degree of commercialisation but does however require a large sample size from each industry group to produce useful information. With the limited response from the thesis survey, stratified random sampling could not be employed.

As an alternative to stratified random sampling, simple random sampling was applied to all the groups in the sample population. A simple random sample is a sample selected in such a way that every possible sample with the same number of observations is equally likely to be chosen (Keller \& Warrack, 2000).

\footnotetext{
${ }^{1}$ Mutually exclusive groups refers to non overlapping subpopulations within the sample population.
} 


\section{A.3 Survey Design and Questions}

A major drawback of self-administered questionnaires is the low response rate and the relatively high number of incorrect responses (Keller and Warrack, 2000). To get as many responses as possible the questionnaire must be well designed. A well designed questionnaire is clear and understandable, minimises thinking effort and does not take long to complete. The survey used in thesis was structured in the following way:

i. A brief description of the sustainable cooling alternatives is given in a column on the right hand side of the questionnaire. The description of each green building cooling alternative was made as short as possible. The description was written such that it refreshes a respondent's memory only if the respondent bears knowledge on the sustainable cooling alternative method.

ii. The questionnaire comprises a set of eight questions with option tick boxes to ease answering. A tick box labelled 'none of the above' or 'I don't know' was included for those respondents who did not know the answer to a particular question.

The survey questionnaire is given in section A.5

\section{A.3.1 Survey Questions Explained}

Each question in the survey was structured such that certain information from the respondent could be obtained. The questions are explained below

\section{i. Question 1: 'Indicate your occupation by ticking in the relevant box below'}

The objective of this question was to categorise respondents in the relevant stakeholder groups. This question was originally included to make stratified random sampling possible.

\section{ii. Question 2: 'Indicate the three most well known sustainable cooling alternative methods'}

This question determined which sustainable cooling method is developed furthest in the commercialisation cycle. An indication of how far the sustainable cooling alternative has been developed is obtained. A well-known cooling alternative is clearly not in the basic research stage.

iii. Question 3: 'Based on your experience, which three of the following sustainable cooling alternatives could work?'

By asking whether the concept can work, it is ascertained which sustainable cooling alternatives have passed the 'proof of concept' stage. The alternatives that score high on this question must have been proved before and lies somewhere in the region from 'technology development' to 'fully commercialised'.

iv. Question 4: 'Which of the following sustainable cooling alternatives have been implemented the most?' 
This question seeks for the sustainable cooling alternatives that have been implemented most. The result from this question should coincide with the response from questions 1 and 2. The sustainable cooling alternative with the highest degree of commercialisation should be selected most.

v. Question 5: 'What would be the two most attractive benefits of these sustainable cooling alternatives?'

The greatest benefits of the sustainable cooling alternatives are determined with this question. The benefits highlighted with this question reveals why the commercialisation of sustainable cooling alternatives is possible.

vi. Questions 6: 'Which two sustainable cooling alternatives address the two selected benefits the best?'

The sustainable cooling methods that address the benefits of sustainable green building design best are obtained from the response of this question.

vii. Question 7: 'Should a financial analysis show that the payback period for all the sustainable alternatives ranges from 3 to 5 years, which sustainable cooling alternatives would you install in a building?'

The response to this question should give an indication of the sustainable cooling alternative with the greatest potential for further development from a financial perspective.

viii. Question 8: 'Which of the following sustainable cooling alternatives would attract the greatest amount of funds for investment?'

Question 8 was formulated in conjunction with figure A.2. If the technology is at a stage where industry would start to investing, one can be sure the technology is reasonably mature and close to market entry. It should give an indication of the degree of commercialisation.

\section{A.4 Determination of the Degree of Commercialisation from the Survey Response}

The response from the survey questionnaire gave an indication of the degree of commercialisation of the sustainable cooling alternatives. The degree of commercialisation was determined by combining the feedback of the eight questions by means of the question weightings. The question weightings were determined by a two pair forced decisions procedure.

The two pair force decision procedure is illustrated in table A.1 below. Each question was compared with another and the most important question marked with a cross. The crosses from all the questions were added and weightings determined. 
Table A.1: Two Pair Force Decision Procedure

\begin{tabular}{|l|c|c|c|c|c|c|c|c|}
\hline & Q1 & Q2 & Q3 & Q6 & Q7 & Q8 & Weight & Weight \% \\
\hline Question 2 & - & - & - & - & $\mathrm{x}$ & $\mathrm{x}$ & $2 / 15$ & $13 \%$ \\
\hline Question 3 & $\mathrm{x}$ & - & - & $\mathrm{x}$ & $\mathrm{x}$ & $\mathrm{x}$ & $4 / 15$ & $27 \%$ \\
\hline Question 4 & $\mathrm{x}$ & $\mathrm{x}$ & - & $\mathrm{x}$ & $\mathrm{x}$ & $\mathrm{x}$ & $5 / 15$ & $33 \%$ \\
\hline Question 6 & $\mathrm{x}$ & - & - & - & - & - & $1 / 15$ & $7 \%$ \\
\hline Question 7 & - & - & - & $\mathrm{x}$ & - & - & $1 / 15$ & $7 \%$ \\
\hline Question 8 & - & - & - & $\mathrm{x}$ & $\mathrm{x}$ & - & $2 / 15$ & $13 \%$ \\
\hline
\end{tabular}

The degree of commercialisation is determined by multiplying the response from each question with its corresponding weight percentage. The weighting percentages of the questions that make up the degree of commercialisation are depicted in the pie chart below.

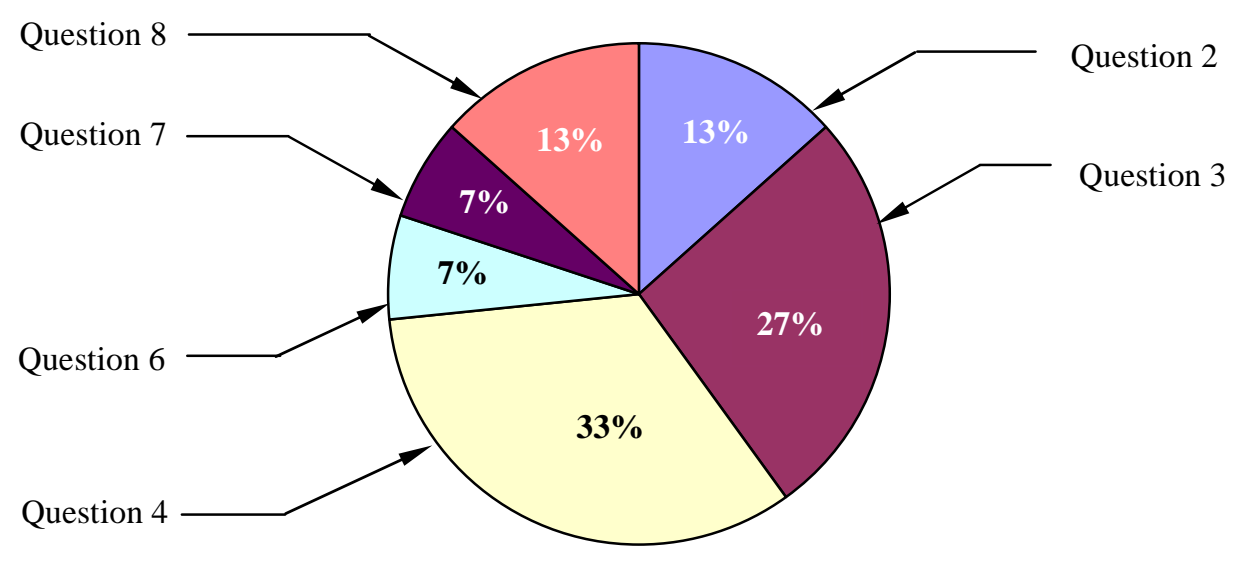

Figure A.3: Pie Chart Depicting the Weight Percentages of the Survey Questions to determine the Degree of Commercialisation

This methodology outlined above in determining the degree of commercialisation yielded satisfactory results even though simple random sampling was used. Stratified random sampling should give a more accurate result but requires a larger sampling population from each mutually exclusive group. 


\section{A.5 Sample Questionnaire}

1) Indicate your occupation by ticking in the relevant box below

Student

Engineer / Technologist

Building Developer

Designer

Project Manager
Architect/Quantity Surveyor

$\square$ Involved at tertiary institution

Financial involvement

Contractor / Builder

Other

2) Indicate the three most well known sustainable cooling alternative methods.

Active Mass Cooling

Phase Change Materials

Evaporative Cooling With Chimney

Night Flushing/Purging
Night Sky Radiative Cooling

Adsorption Cooling

Thermal Chimney

for Natural Ventilation

Earth Cooling Tubes with water/air

The options provided above are unfamiliar to me

3) Based on your experience, which three of the following sustainable cooling alternatives could work?

Active Mass Cooling

Phase Change Materials

Evaporative Cooling With Chimney

Night Flushing/Purging

None of the above

4) Which of the following sustainable cooling alternatives have been implemented the most?

Active Mass Cooling

Phase Change Materials

Evaporative Cooling With Chimney

Night Flushing/Purging

I am not sure
1)

Active Mass Cooling

Active mass cooling uses the structural mass of a building to offset building heat loads during daytime by cooling the structure during night time with cold water in a pipe network embedded in the structure. The cold water is obtained from a cooling tower or roof spray system.

2) Night Sky Radiative Cooling / Roof Spray Cooling

Water is cooled during night time with water sprays on the roof of a building. Cooling is achieved with evaporation, convection and night sky radiation. The water is collected and stored, ready to cool the building structure the next day.

3) Thermal Chimney for Natural

Ventilation

Natural ventilation uses the principle of buoyancy (whereby an air pressure difference is created) to induce airflow into a building naturally. Building heat loads are thereby reduced through convective cooling and fresh air is admitted to the cooling space lowering ventilation fan duties.

4) Night Purging / Flushing

Night purging is the process whereby a building is flushed with cool night air for several hours each night by means of a mechanical ventilation system. The idea is to lower the heat stored in the building structure during daytime and to replace it with 'coolth' for the next day.

5) Earth Heat Exchangers

Earth-tube heat exchangers are installed below ground level and are connected to a hydronic pipe network embedded in the structural mass of a building. Water is cooled by the exchangers and pumped to the structure for cooling and to reduce building heat loads.

6) Phase Change Materials
(PCM's)

The latent heat of PCM's is utilised to increase the thermal storage capacity of building materials, thereby lowering the air conditioner heat load. [At room temperature (approx. $20^{\circ} \mathrm{C}$ ), a typical PCM would be in the solid state and upon room temperature increase, the PCM would liquefy, absorbing and storing heat. When the temperature drops again, the PCM solidifies, giving off heat that can be removed via ventilation] 
5) What would be the two most attractive benefits of these sustainable cooling alternatives?

$\mathrm{CO}_{2}$ Emission Reduction

Better Building Energy Efficiency

Small scale contribution to lower global warming
Building Running Cost Reduction

Green Building "Image"

Shifting the mindsets of the relevant stakeholders
6) Which two sustainable cooling alternatives address the two selected benefits the best?

Active Mass Cooling

Phase Change Materials

Evaporative Cooling with Chimney

Night Flushing/Purging

I am not sure

7) Should a financial analysis show that the payback period for all the sustainable alternatives ranges from 3 to 5 years, which sustainable cooling alternatives would you install in a building?

\section{Active Mass Cooling \\ Phase Change Materials \\ Evaporative Cooling with Chimney}

Night Flushing/Purging
Night Sky Radiative Cooling

Adsorption Cooling

Thermal Chimney for Natural Ventilation

Earth Cooling Tubes with water/air
Adsorption cooling involves a thermochemical process of sorption (adsorption) whereby a liquid or gaseous substance is absorbed by a material (e.g. silica gel) when heat is added. Outside air is dried through sorption, pre-cooled with a heat exchanger and finally cooled through evaporationhumidification before discharged into a cooling space.

8) Evaporative Cooling with
Chimney

A Chimney is attached to a building with an upwind scoop and evaporative pads. As the wind blows, the scoop catches the dry hot air. The hot air is evaporatively cooled and the denser air flows downwards to cool the spaces below by pushing the warmer air out.
Night Sky Radiative Cooling

Adsorption Cooling

Thermal Chimney

for Natural Ventilation

Earth Cooling Tubes with water/air

8) Which of the following sustainable cooling alternatives would attract the greatest amount of funds for investment?

Active Mass Cooling

Phase Change Materials

Evaporative Cooling with Chimney

Night Flushing/Purging

None of the above
Night Sky Radiative Cooling

Adsorption Cooling

Thermal Chimney for Natural Ventilation

Earth Cooling Tubes with water/air 


\section{APPENDIX B: INPUT VARIABLES TO THE ONE-ROOM BUILDING SIMULATION}

The following input parameters to the One-Room Building where employed.

Table B.1: Input Parameters for the Base Case Simulation of the One-Room Building

\begin{tabular}{|l|l|l|l|}
\hline \multicolumn{1}{|c|}{ Description } & Symbol & \multicolumn{1}{|c|}{ Units } & \\
\hline Building Dimensions & & & \\
\hline Width & $w_{b u i l d}$ & $\mathrm{~m}$ & 6 \\
\hline Length & $l_{\text {build }}$ & $\mathrm{m}$ & 6 \\
\hline Height & $h_{b u i l d}$ & $\mathrm{~m}$ & 3 \\
\hline Wall thickness (single brick) & $t_{w l}$ & $\mathrm{~mm}$ & 230 \\
\hline Roof slab thickness & $t_{r s}$ & $\mathrm{~mm}$ & 200 \\
\hline & & & \\
\hline Window (North Facing) & & & \\
\hline Width & $w_{w d}$ & $\mathrm{~mm}$ & 1200 \\
\hline Height & $h_{w d}$ & $\mathrm{~mm}$ & 1000 \\
\hline Window thickness & $t_{w d}$ & $\mathrm{~mm}$ & 6 \\
\hline Internal Shading Coefficient & $I A C$ & $\#$ & 0.68 \\
\hline Overall Heat Transfer Coefficient & $U_{w d}$ & $\mathrm{~W} / \mathrm{m}^{2} \mathrm{~K}$ & 5.24 \\
\hline & & & \\
\hline Building Properties & & & \\
\hline Wall thermal conductivity & $k_{s b w}$ & $\mathrm{~W} / \mathrm{mK}$ & 0.72 \\
\hline Wall density & $\rho_{s b w}$ & $\mathrm{~kg} / \mathrm{m}^{3}$ & 1920 \\
\hline Specific heat & $C_{s b w}$ & $\mathrm{~J} / \mathrm{kgK}$ & 835 \\
\hline Roof slab thermal conductivity & $k_{r s}$ & $\mathrm{~W} / \mathrm{mK}$ & 1.1 \\
\hline Roof slab density & $\rho_{r s}$ & $\mathrm{~kg} / \mathrm{m}^{3}$ & 2100 \\
\hline Roof slab specific heat & $C_{r s}$ & $\mathrm{~J} / \mathrm{kgK}$ & 880 \\
\hline Solar wall absorbtivity & $\alpha_{w l}$ & & 0.63 \\
\hline Roof-slab absorbtivity & $\alpha_{r s}$ & & 0.7 \\
\hline Wall emissivity & $\varepsilon_{w l}$ & & 0.9 \\
\hline Roof emissivity & $\varepsilon_{r s}$ & & 0.91 \\
\hline & & & \\
\hline Internal Building Characteristics & & & \\
\hline Lighting heat contribution & $\dot{q}_{l}$ & $\mathrm{~W} / \mathrm{m}^{2}$ & 5 \\
\hline Occupancy & $\#$ & 1 \\
\hline
\end{tabular}




\begin{tabular}{|l|l|l|l|}
\hline $\begin{array}{l}\text { Sensible heat gain from a human } \\
\text { performing office work }\end{array}$ & $\dot{q}_{p, i}$ & W/person & 66 \\
\hline Infiltration air flow rate & $A C P D$ & $\#$ & 6 \\
\hline Equipment Heat Load & $\dot{Q}_{h e, t o t}$ & $\mathrm{~W}$ & 5 \\
\hline
\end{tabular}

Table B.2: Design Parameters for the Sustainable Cooling Alternatives Applied to the OneRoom Building

\begin{tabular}{|l|l|l|l|}
\hline \multicolumn{1}{|c|}{ Sustainable Cooling Alternatives } & Symbol & Units & \\
\hline Night Flushing (NF) & & & \\
\hline NF air change rate & $A C H$ & $\#$ & 32 \\
\hline Hour of the day NF activated & & & $24 \mathrm{~h} 00$ \\
\hline Hour of the day NF deactivated & & & $06 \mathrm{~h} 00$ \\
\hline & & & \\
\hline Roof Pond (RP) & & & \\
\hline RP water thickness & $z_{r p}$ & $\mathrm{~mm}$ & 100 \\
\hline RP water mass & $m_{r p}$ & $\mathrm{~kg}$ & 3600 \\
\hline Water absorbtivity & $\alpha_{s, w}$ & & 0.98 \\
\hline Water emissivity & $\varepsilon_{w}$ & & 0.9 \\
\hline Water transmissivity & $\tau_{w}$ & & 0.01 \\
\hline Water reflectvity & $\rho_{w}$ & & 0.01 \\
\hline & & & \\
\hline Active Mass Cooling & & & \\
\hline Water mass flow rate & $\dot{m}_{w}$ & $\mathrm{~kg} / \mathrm{s}$ & 1 \\
\hline $\begin{array}{l}\text { Heat resistance between water in } \\
\text { tubes and slab }\end{array}$ & $R_{w, r s}$ & $\mathrm{~m}{ }^{2} \mathrm{~K} / \mathrm{W}$ & 0.05 \\
\hline Embedded Pipe Diameter & & & \\
\hline Pipe Spacing & $D_{p}$ & $\mathrm{~mm}$ & 20 \\
\hline & $l_{p}$ & $\mathrm{~mm}$ & 300 \\
\hline Roof Cooling System & & & \\
\hline Water mass flow rate & $\dot{m}_{r c}$ & $\mathrm{~kg} / \mathrm{s}$ & 1 \\
\hline Storage tank water volume & & & 1000 \\
\hline & & \\
\hline & & & \\
\hline
\end{tabular}

Figure B.1 gives the ambient temperature and relative humidity for the typical summers day in Stellenbosch. 


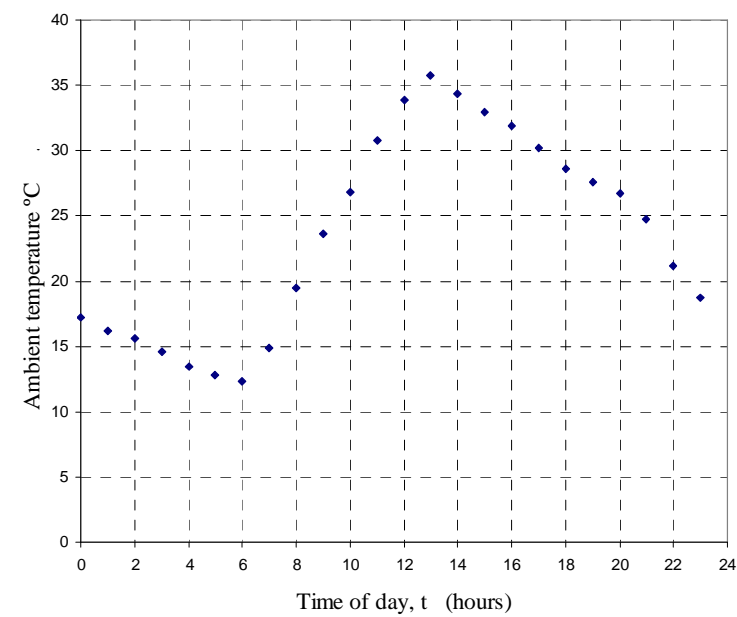

(a)

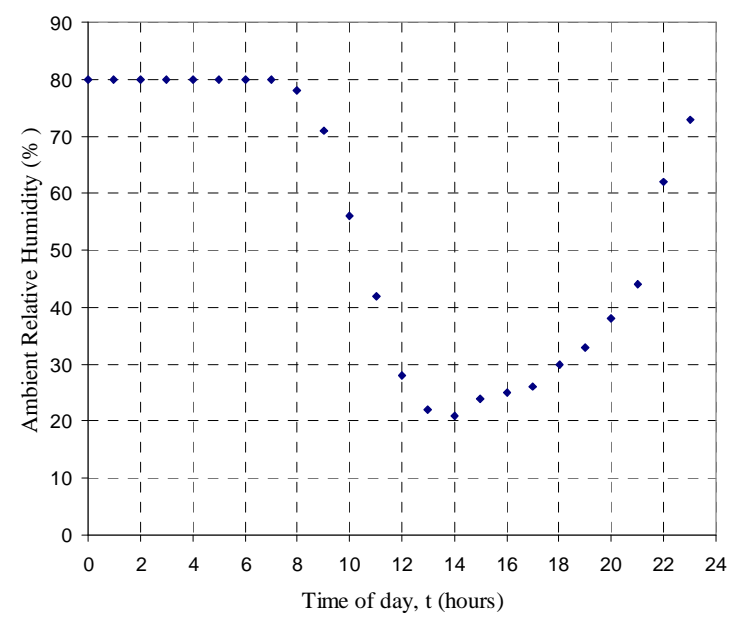

(b)

Figure B.1: (a) Ambient Temperature and (b) Relative Humidity for a Typical Summers Day in Stellenbosch, South Africa

The solar radiation for the 03 March 2009 at Stellenbosch may be calculated with the procedure outlined in Appendix E. Table B.2 below gives the hourly solar radiation for north, east, south and west facing surfaces. The solar radiation incident on a horizontal surface is also presented.

Table B.3: Solar Radiation for Stellenbosch on 03 March 2009

\begin{tabular}{|c|c|c|c|c|c|c|c|c|c|c|c|c|}
\hline & 07:00 & 08:00 & 09:00 & $10: 00$ & $11: 00$ & $12: 00$ & 13:00 & $14: 00$ & $15: 00$ & $16: 00$ & $17: 00$ & 18:00 \\
\hline \multicolumn{13}{|c|}{ Direct Normal Solar Radiation, $I_{\text {solar }, D N}\left(\mathrm{~W} / \mathrm{m}^{2}\right)$} \\
\hline North & 0.00 & 26 & 147. & 266 & 360 & 420 & 440 & 418 & 357. & 261 & 141 & 21 \\
\hline East & 181 & 686 & 751 & 660 & 481 & 250 & 0 & 0 & 0 & 0 & 0 & 0 \\
\hline South & 19 & 0 & 0 & 0 & 0 & 0 & 0 & 0 & 0 & 0 & 0 & 0 \\
\hline West & 0 & 0 & 0 & 0 & 0 & 0 & 6.14 & 262 & 491 & 666 & 752. & 677 \\
\hline Horizontal & 14 & 209 & 431 & 625. & 776 & 870 & 902 & 868 & 770 & 617 & 420. & 198 \\
\hline \multicolumn{13}{|c|}{ Ground Reflected Radiation , $I_{\text {solar }, r}\left(\mathrm{~W} / \mathrm{m}^{2}\right)$} \\
\hline North & 3 & 28 & 52 & 73 & 88 & 98 & 101 & 97 & 87 & 72 & 51 & 27 \\
\hline East & 3 & 28 & 52 & 73 & 88 & 98 & 101 & 97 & 87 & 72 & 51 & 27 \\
\hline South & 3 & 28 & 52 & 73 & 88 & 98 & 101 & 97 & 87 & 72 & 51 & 27 \\
\hline West & 3 & 28 & 52 & 73 & 88 & 98 & 101 & 97 & 87 & 72 & 51 & 27 \\
\hline Horizontal & 0 & 0 & 0 & 0 & 0 & 0 & 0 & 0 & 0 & 0 & 0 & 0 \\
\hline \multicolumn{13}{|c|}{ Diffuse Solar Radiation , $I_{\text {solar }, d}\left(\mathrm{~W} / \mathrm{m}^{2}\right)$} \\
\hline North & 10 & 43 & 59 & 70 & 78 & 83 & 85 & 83 & 78 & 69 & 58 & 42 \\
\hline East & 25 & 95 & 107 & 101 & 87 & 72 & 58 & 48 & 47 & 45 & 42 & 34 \\
\hline South & 12 & 41 & 45 & 45 & 47 & 48 & 48 & 48 & 47 & 45 & 45 & 40 \\
\hline West & 9 & 34 & 42 & 45 & 47 & 48 & 59 & 72 & 88 & 101 & 107 & 94 \\
\hline Horizontal & 19 & 76 & 93 & 100 & 104 & 106 & 106 & 106 & 104 & 100 & 92 & 75 \\
\hline
\end{tabular}




\section{APPENDIX C: DERIVATION OF CONSERVATION EQUATIONS AND HEAT TRANSFER CORRELATIONS}

This appendix commences with the derivation of the conservation equations for the droplet and roof-pond control volumes. In the second part of the appendix, the correlations for convection heat transfer coefficients are presented. The correlations for the calculation of the mass transfer rates during evaporation and condensation are also presented.

\section{C.1 Derivation of Conservation Equations}

\section{C1.1 Derivation of the Equation 4.2 to 4.4, the water droplet momentum equations}

Newton's Second Law of motion states that the resultant force acting on a system equals the rate of change of momentum of the system when measured in an inertial reference frame (Potter and Wiggert, 2001)

$$
\sum F=\frac{D}{D t} \int_{s y s} \rho u d V
$$

Equation C.1 pertains to a system as a whole and can be transformed to quantities that pertain to the control volume of a specific system

$$
\sum F=\frac{d}{d t} \int_{c v} \rho u d V+\int_{c s} \rho u(u \hat{n}) d A
$$

where $u \hat{n}$ is a scalar for each differential area $d A$. The system-to-control transformation from equation C. 1 to equation C.2 is also known as the Reynolds Transport Theorem and may be found in Potter and Wiggert (2002). The element mass is calculated as the product of density and the element volume, i.e. $d m=\rho d V$. The product of the element mass and velocity gives the momentum of the volume element, i.e. $u d m=\rho u d V$. Applying the first term on the right hand side to the water droplet control volume and integrating gives

$$
\frac{d}{d t} \int_{c v} \rho u d V=\frac{d\left(u m_{d}\right)}{d t}
$$

The second term on the right hand side of equation C.2 gives the net rate at which momentum flows across the water droplet control surface. Assuming a constant evaporation and condensation velocity gives

$$
\int_{c s} \rho u(u \hat{n}) d A=\sum_{c s} \dot{m}_{o} u_{o}-\sum_{c s} \dot{m}_{i} u_{i}=\dot{m}_{\text {evap }} u_{o}-\dot{m}_{\text {cond }} u_{i}
$$

Substituting equation C.4 and equation C.3 into equation C.2 gives

$$
\sum F=\frac{d\left(u m_{d}\right)}{d t}+\dot{m}_{\text {evap }} u_{o}-\dot{m}_{\text {cond }} u_{i}
$$

The forces acting on the water droplet comprise a drag force and a gravitational force (refer to figure 4.2 in Chapter 4), i.e. 
$\sum F=F_{d}+F_{g}$

where the drag force for the water droplet is calculated as (Potter and Wiggert, 2002)

$F_{d}=C_{d} A_{d, p} \frac{\rho u_{d, r e l}^{2}}{2}$

$C_{d}$ in equation C.7 denotes the drag coefficient and $A_{d, p}$ the projected area of the water droplet. If the water droplet takes the form of a sphere equation C.7 becomes

$F_{d}=C_{d} \pi r_{d}^{2} \frac{\rho u_{d, r e l}^{2}}{2}$

The gravitational force $F_{g}$ is calculated as the product of the droplet mass and gravitational constant, i.e. $m_{d} g$. Substituting the vertical component of the drag force and gravitational force into equation C.5 and discretising the momentum term gives

$$
\left(m_{d} u_{d, y}\right)^{\text {new }}=\left(m_{d} u_{d, y}\right)^{\text {old }}+\left(C_{d} \pi r_{d}^{2} \frac{\rho u_{d, y}^{2}}{2} \sin \beta-m_{d} g-\dot{m}_{d, \text { evap }} u_{o, y}+\dot{m}_{d, \text { cond }} u_{i y}\right) \Delta t
$$

Likewise, substituting the horizontal component of drag force into equation C.5, discretising and rearranging gives

$$
\left(m_{d} u_{d, x}\right)^{\text {new }}=\left(m_{d} u_{d, x}\right)^{\text {old }}+\left(C_{d} \pi r_{d}^{2} \frac{\rho u_{d, \text { rel }}^{2}}{2} \cos \beta-\dot{m}_{d, \text { evap }} u_{o, x}+\dot{m}_{d, \text { cond }} u_{i, x}\right) \Delta t
$$

\section{C1.2 Derivation of Equation 4.5, the water droplet energy equation}

Crowe et al. (2001) gives the following differential form of the energy equation

$\frac{d E_{s y s}}{d t}=\dot{Q}-\dot{W}$

where the term on the left denotes the rate of system total energy change, $\dot{Q}$ the rate of heat transfer to the system and $\dot{W}$ the rate of work done by the system. Applying the Reynolds Transport Theorem to express the rate of system energy change in terms of the rate of energy change within the control volume and the energy flow across the control surface gives

$$
\frac{d E_{s y s}}{d t}=\dot{Q}-\dot{W}=\frac{d}{d t} \int_{c v} e \rho d V+\sum_{c s} e \rho u A
$$

where $e$ denotes the energy per unit mass, $\rho$ the fluid density, $d V$ the elemental volume, $u$ the fluid velocity across the control surface and $A$ the control surface area. Integrating the first term on the right of equation C.12 over the control volume of the water droplet and substituting into equation C.12 gives 


$$
\frac{d E_{s y s}}{d t}=\dot{Q}-\dot{W}=\frac{d E_{d}}{d t}+\sum_{c s} e \rho u A
$$

where $E_{d}$ denotes the total energy of the water droplet comprising of internal, kinetic and potential energy. Summing flows across the entire control surface of the water droplet, neglecting kinetic and potential energy terms and acknowledging that no work is done by or on the water droplet reduces equation C.13 to

$$
\frac{d U_{d}}{d t}=\dot{Q}_{d, t o t}+\dot{m}_{d, \text { cond }} h_{g}-\dot{m}_{d, \text { evap }} h_{g}
$$

where the energy $e$ released during evaporation and absorbed during condensation was set equal to the enthalpy of water vapour in the ambient air $h_{g}$. It must be noted that condensation and evaporation will not occur simultaneously but rather in response to the difference between the saturated water vapour density at the water droplet surface and the water vapour in the ambient air. Rewriting the internal energy as the product of constant pressure specific heat $C_{p}$ and droplet temperature $T_{d}$ and differentiating gives

$$
\frac{d U_{d}}{d t}=\frac{d\left(m_{d} C_{p} T_{d}\right)}{d t}=m_{d} C_{p} \frac{d T_{d}}{d t}+T_{d} C_{p} \frac{d m_{d}}{d t}
$$

Substituting equation 4.1 into equation C.15 and expressing $T_{d} C_{p}$ as the fluid enthalpy $u_{f}$ gives

$T_{d} C_{p} \frac{d m_{d}}{d t}=u_{f} \dot{m}_{d, \text { cond }}-u_{f} \dot{m}_{d, \text { evap }}$

Substituting equation C.15 and C.16 into equation C.14 gives

$$
m_{d} C_{v} \frac{d T_{d}}{d t}=\dot{Q}_{d, \text { tot }}+\dot{m}_{d, \text { cond }}\left(h_{g}-u_{f}\right)-\dot{m}_{d, \text { evap }}\left(h_{g}-u_{f}\right)
$$

The total rate of energy transfer to the water droplet control volume $\dot{Q}_{d, t o t}$ comprises radiation $\dot{Q}_{d, \text { rad }}$ and convection, $\dot{Q}_{d, \text { conv }}$ heat transfer mechanisms. Substituting these terms into equation C.18 gives

$$
m_{d} C_{v} \frac{d T_{d}}{d t}=\dot{Q}_{d, \text { conv }}+\dot{Q}_{d, \text { rad }}+\dot{m}_{d, \text { cond }}\left(h_{g}-u_{f}\right)-\dot{m}_{d, \text { evap }}\left(h_{g}-u_{f}\right)
$$

The convection energy transfer to the water droplet is calculated by

$$
\dot{Q}_{d, c o n v}=h_{d} A_{d}\left(T_{a m b}-T_{d}\right)
$$

where $h_{d}$ denotes the convection heat transfer between the water droplet and the ambient air. The correlations employed for the calculation of $h_{d}$ are presented in the second part of Appendix C. The radiation heat transfer rate, which is the difference between the thermal 
energy that is released due to radiation emission and the energy gained due to radiation absorption, is given by

$$
\dot{Q}_{d, r a d}=\varepsilon A_{d} \sigma\left(T_{s u r}^{4}-T_{d}^{4}\right)
$$

Substituting equation C.18 and C.19 into equation C.17 and rearranging gives

$$
m_{d} C_{v} \frac{\partial T_{d}}{\partial t}=h_{d} A_{d}\left(T_{a m b}-T_{d}\right)+\varepsilon A_{d} \sigma\left(T_{\text {sur }}^{4}-T_{d}^{4}\right)-\dot{m}_{d, \text { evap }}\left(h_{g}-u_{f}\right)+\dot{m}_{d, \text { cond }}\left(h_{g}-u_{f}\right)
$$

Note that an order of magnitude analysis in Appendix D showed that the $\dot{Q}_{d, \text { rad }}$ may be discarded from equation C.21 as its value is in order of 1000 less than $\dot{Q}_{d, c o n v}$.

\section{C1.3 Derivation of Equation 4.7, the roof-pond energy equation}

Applying the conservation of energy to the roof-pond control volume gives the following general form of the Reynolds Transport Theorem

$$
\frac{d E_{s y s}}{d t}=\frac{d E_{r p}}{d t}+\sum_{c s} e \rho u A=\dot{Q}-\dot{W}
$$

The term $E_{r p}$ denotes the total energy of the roof-pond control volume comprising of internal, kinetic and potential energy. Summing flows across the entire control surface of the roof-pond, neglecting kinetic and potential energy terms and acknowledging that no work is done by or on the roof-pond, reduces equation C.22 to

$$
\frac{d U_{r p}}{d t}=\dot{Q}_{r p, t o t}+h_{f, i} \dot{m}_{r c, i}-h_{f, o} \dot{m}_{r c, o}+h_{g} \dot{m}_{r p, c o n d}-h_{g} \dot{m}_{r p, e v a p}
$$

Expression the term on the left hand side of equation C.23 in terms of constant pressure specific heat and assuming the water mass of the roof-pond remains constant gives

$$
m_{r p} C_{v} \frac{\partial T_{r p}}{\partial t}=\dot{Q}_{r p, t o t}+h_{f, i} \dot{m}_{r c, i}-h_{f, o} \dot{m}_{r c, o}+h_{g} \dot{m}_{r p, c o n d}-h_{g} \dot{m}_{r p, e v a p}
$$

The first term on the right hand side of equation C.24 represents the total rate of energy transfer to and from the roof-pond and comprises the following heat transfer mechanisms

$\dot{Q}_{r p, t o t}=\dot{Q}_{\text {solar }}-\dot{Q}_{s k y}-\dot{Q}_{b u i l d}-\dot{Q}_{r p, c o n v}$

where the $\dot{Q}_{\text {solar }}$ denotes the rate of solar energy absorbed by the roof-pond, $\dot{Q}_{s k y}$ the radiation heat exchange between the sky and roof-pond, $\dot{Q}_{\text {build }}$ the convection heat loss to the roof slab below and $\dot{Q}_{r p, c o n v}$, the convection heat loss to the ambient air. Substituting equation C.25 into equation C.24 gives 
$m_{r p} C_{v} \frac{\partial T_{r p}}{\partial t}=\dot{Q}_{s o l a r}-\dot{Q}_{s k y}-\dot{Q}_{b u i l d}-\dot{Q}_{r p, c o n v}+h_{f, i} \dot{m}_{r c, i}-h_{f, o} \dot{m}_{r c, o}+h_{g} \dot{m}_{r p, c o n d}-h_{g} \dot{m}_{r p, e v a p}$

The solar heat gain is calculated by

$\dot{Q}_{\text {solar }}=\alpha_{s, r p} A_{r p} I_{\text {solar }}$

where the term $I_{\text {solar }}$ gives the incident solar irradiation flux on the roof-pond surface, $\alpha_{s, r p}$ the roof-pond solar absorbtivity and $A_{r p}$ the surface area of the roof-pond. The value of $I_{\text {solar }}$ depends on the orientation of the roof-pond surface, the angle of the solar rays relative to the surface normal, the geographic latitude as well as the time of day and day of the year. The calculation procedure for $I_{\text {solar }}$ is given in Appendix E.

The term designated as $\dot{Q}_{s k y}$ comprises of the earth's irradiation due to atmospheric emission and the emissive power associated with the roof-pond surface

$\dot{Q}_{s k y}=\varepsilon_{r p} \sigma T_{r p}^{4}-\alpha_{s k y} \sigma T_{s k y}^{4}$

where $\alpha_{s k y}$ is the sky absorbtivity and $\varepsilon_{r p}$ the roof-pond emissivity, $T_{s k y}$ the sky temperature and $T_{r p}$ the roof-pond water temperature and $\sigma$ the Stefan Boltzman constant. Since the sky radiation is concentrated in approximately the same spectral region as that of roof-pond surface emission, it may be assumed that (Incropera and DeWitt, 2002)

$\alpha_{s k y} \approx \varepsilon_{r p}$

Incorporating the above into equation C.28 and expressing equation C.28 in terms of a radiation heat transfer coefficient $h_{s k y}$ gives

$\dot{Q}_{s k y}=\left(T_{r p}-T_{s k y}\right) h_{s k y} A_{r p}$

The heat transfer radiation coefficient is calculated by

$h_{s k y}=\varepsilon_{r p} \sigma\left(T_{r p}^{2}+T_{s k y}^{2}\right)\left(T_{r p}+T_{s k y}\right)$

The sky temperature and emissivity is calculated with the correlations given by Mills (2000)

$T_{s k y}=\left(\varepsilon_{s k y} T_{a m b}{ }^{4}\right)^{1 / 4}$

where $T_{a m b}$ denotes the temperature of the ambient air and $\varepsilon_{s k y}$ the sky emissivity. For nocturnal hours $\varepsilon_{s k y}$ is calculated by

$\varepsilon_{s k y}=0.741+0.00162 T_{d p}$ 
and for diurnal hours calculated by

$\varepsilon_{\text {sky }}=0.727+0.00160 T_{d p}$

$T_{d p}$ in equations C.33 and C.34 denotes the dew point temperature of the ambient air.

The heat transfer from the roof-pond to the roof slab below is calculated by

$\dot{Q}_{\text {build }}=h_{r s, w} A_{r p}\left(T_{r p}-T_{0}\right)$

where $T_{0}$ denotes the roof slab temperature and $h_{r s, w}$ the heat transfer coefficient between the roof-pond water and the roof slab. The calculation of $h_{r s, w}$ is given in the section C2.3. The convection heat transfer between the roof-pond water and the ambient air is calculated by

$\dot{Q}_{r p, c o n v}=h_{r p, a m b} A_{r p}\left(T_{r p}-T_{a m b}\right)$

where $h_{r p, a m b}$ denotes the convection heat transfer coefficient between the roof-pond water and the ambient air. Substituting equations C.27, C.30, C.35 and C.36 into equation C.26 gives

$$
\begin{gathered}
m_{d} C_{p} \frac{\partial T_{r p}}{\partial t}=\alpha_{s, r p} A_{r p} I_{s o l a r}-\left(T_{r p}-T_{s k y}\right) h_{s k y} A_{r p}-h_{r s, w} A_{r p}\left(T_{r p}-T_{0}\right)-h_{r p, a m b} A_{r p}\left(T_{r p}-T_{a m b}\right)+ \\
h_{f, i} \dot{m}_{r c, i}-h_{f, o} \dot{m}_{r c, o}+h_{g} \dot{m}_{r p, c o n d}-h_{g} \dot{m}_{r p, e v a p}
\end{gathered}
$$

\section{C.2 Correlations for the Convection Heat Transfer Coefficients}

\section{C2.1 Water Droplet Heat and Mass Transfer Coefficient}

The convection heat transfer coefficient designated as $h_{d}$ and employed in equations C.19, C.21, 4.5 and 4.6 is calculated from the Nusselt number

$$
h_{d}=\overline{N u}_{D} \frac{k_{a m b}}{D_{d}}
$$

where $k_{a m b}$ denotes the thermal conductivity of the ambient air and $D_{d}$ the characteristic diameter of the water droplet. Ranz and Marshall (Incropera and DeWitt, 2002) gives the following Nusselt correlation for free falling water droplets

$\overline{N u}_{D}=2+0.6 \operatorname{Re}_{D}^{1 / 2} \operatorname{Pr}^{1 / 3}$

where $R e_{D}$ denotes the water droplet Reynolds number and $\operatorname{Pr}$ the Prandtl number. The droplet Reynolds number is calculated by 
$\operatorname{Re}_{D}=\frac{u_{d} D_{d}}{v_{a m b}}$

where $u_{d}$ is the droplet velocity and $v_{a m b}$ the kinematic viscosity of the ambient air. The Prandtl number is calculated by

$$
\operatorname{Pr}=\frac{v_{a m b}}{\alpha_{a m b}}
$$

where $\alpha_{a m b}$ denotes the thermal diffusivity of the ambient air. The mass transfer coefficient is calculated from the Sherwood number (Incropera and DeWitt, 2002)

$$
h_{m}=\frac{S h_{D} D_{A B}}{2 r_{d}}
$$

where $D_{A B}$ is the binary mass diffusion coefficient. The Sherwood number is calculated from the following analogy that relates the convection heat transfer coefficient to the convection mass transfer coefficient

$$
\frac{N u_{D}}{\operatorname{Pr}^{n}}=\frac{S h_{D}}{S c^{n}}
$$

where $S c$ denotes the Schmidt number calculated by

$$
S c=\frac{v_{a m b}}{D_{A B}}
$$

According to Incropera and DeWitt a value of $1 / 3$ is reasonable for the exponent $n$ in equation C.43.

\section{C2.2 Roof-pond to Air Heat and Mass Transfer Coefficients}

The convection heat transfer coefficient, $h_{r p, a m b}$ employed in equation C.36 and C.37 may be calculated by

$$
h_{r p, a m b}=\overline{N u}_{L} \frac{k_{a m b}}{L_{r p}}
$$

where $L_{r p}$ denotes the roof-pond characteristic length and $k_{a m b}$ the thermal conductivity of the ambient air. Analogous to the calculation of the heat transfer coefficient, the mass transfer coefficient is calculated from the Sherwood Number and the Binary Mass Diffusion coefficient as

$$
h_{m}=\frac{\bar{S} h_{L} D_{A B}}{L_{r p}}
$$


The convection heat transfer from the roof-pond may either be forced when windy conditions prevail or natural under stagnant conditions. Natural convection is negligible if

$$
\frac{G r_{L}}{R e_{L}^{2}}<<1
$$

where $G r_{L}$ is the Grashof number and $R e_{L}$ the Reynolds number. Forced convection may be regarded as negligible when

$$
\frac{G r_{L}}{R e_{L}^{2}}>>1
$$

and a combined natural and forced convection regime prevails when

$$
\frac{G r_{L}}{R e_{L}^{2}} \approx 1
$$

The correlations for the Nusselt number under forced convection differ from the correlations for natural convection and are presented in section C.2.2.1. The correlations for natural convection are presented in section C.2.2.2 and the correlations for both forced and natural convection are given in section C.2.2.3

\section{C2.2.1 Correlations for Nusselt and Sherwood Number Under Forced Convection}

The boundary layer condition may either be laminar, turbulent or mixed which plays a role in the value of the heat transfer coefficient (Incropera and DeWitt, 2002). The prevailing condition depends on the location of transition from laminar to turbulent flow. The distance from the roof-pond leading edge where transition occurs may be calculated as

$$
x_{c}=L_{r p}\left(\frac{R e_{x, c}}{R e_{L}}\right)
$$

where $R e_{x, c}$ denotes the critical Reynolds number where transition occurs. Incropera and DeWitt (2002) assumes a value of $5 \times 10^{5}$ for $R e_{x, c}$. If transition from turbulent to laminar flow occurs at the end of the roof-pond, the roof-pond Nusselt, $N u_{L}$, and Sherwood Number, $S h_{L}$, are calculated from the laminar flow correlations, i.e. if $\frac{x_{c}}{L_{r p}}>0.95$ then

$$
\begin{aligned}
& \bar{N} u_{L}=0.664 \operatorname{Re}_{L}^{1 / 2} \operatorname{Pr}^{1 / 3} \\
& \bar{S} h_{L}=0.664 R e_{L}^{1 / 2} S c^{1 / 3}
\end{aligned}
$$

If the transition occurs at the initial part of the roof-pond $\bar{N} u_{L}$ and $\bar{S} h_{L}$ are calculated from turbulent flow correlations, i.e. if $\frac{x_{c}}{L_{r p}}<0.05$ or $L_{r p}>>x_{c}$ then 
$\bar{N} u_{L}=0.037 \operatorname{Re}_{L}^{4 / 5} \operatorname{Pr}^{1 / 3}$

$\bar{S} h_{L}=0.037 R e_{L}^{4 / 5} S c^{1 / 3}$

If transition from laminar to turbulent flow occurs more to the centre of the roof-pond then mixed flow boundary conditions applies; i.e. if $0.05<\frac{x_{c}}{L_{r p}}<0.95$ then

$$
\begin{aligned}
& \bar{N} u_{L}=\left(0.037 R e_{L}^{4 / 5}-871\right) \operatorname{Pr}^{1 / 3} \\
& \bar{S} h_{L}=\left(0.037 R e_{L}^{4 / 5}-871\right) S c^{1 / 3}
\end{aligned}
$$

where the above equations are limited to the following conditions

$$
0.6<\operatorname{Pr}<60 ; \quad 5 \times 10^{5}<\operatorname{Re}_{L} \leq 10^{8} ; \quad 0.6<S c<3000 ; \quad \operatorname{Re}_{x, c}=5 \times 10^{5}
$$

\section{C2.2.2 Correlations for Nusselt and Sherwood Numbers under Natural Convection}

Unlike forced convection, flow in stagnant air conditions occurs due to buoyancy forces as a result of a temperature difference between the roof-pond surface temperature and the ambient air. The buoyancy driven flow depends on whether the roof-pond is at a higher or lower temperature than the ambient air. When the roof-pond temperature is lower than that of the ambient air, the natural airflow moves horizontal to the sides of the pond before it can descend. This results in an ineffective heat transfer coefficient calculated from the $\bar{N} u_{L}$ of the following correlation (Incropera and De Witt, 2002)

$$
\bar{N} u_{L}=0.27 R a_{L}^{1 / 4}
$$

where $R a_{L}$ gives the Rayleigh number. Equation C.54 only applies to Rayleigh numbers in the range $10^{5} \leq R a_{L} \leq 10^{10}$. The Rayleigh number in equation C.54 is calculated by

$$
R a_{L}=G r_{L} P_{r}=\frac{g \beta\left(T_{r p}-T_{a m b}\right) L_{r p}^{3}}{v_{a m b} \alpha_{a m b}}
$$

where $G r_{L}$ denotes the Grasshof number, $\beta$ is the volumetric thermal expansion coefficient, $\alpha$ the ambient air thermal diffusivity, $v$ the kinematic viscosity, $T_{r p}$ the roof-pond temperature and $T_{a}$ the ambient air temperature. The Sherwood number may be obtained from the analogous form of equation C.54

$$
\overline{S h}_{L}=0.27\left(G r_{L} S c\right)^{1 / 4}
$$


When the roof-pond temperature is higher than that of the ambient air the buoyancy force acts to move fluid from the surface, interrupting boundary layer development that results in increased convection. Under this situation the $\bar{N} u_{L}$ and $\bar{S} h_{L}$ are calculated as

$\bar{N} u_{L}=0.54 R a_{L}^{1 / 4}$

$\overline{S h}_{L}=0.54\left(G r_{L} S c\right)^{1 / 4}$

when $10^{4} \leq R a_{L} \leq 10^{7}$ and

$\bar{N} u_{L}=0.15 R a_{L}^{1 / 3}$

$\overline{S h}_{L}=0.54\left(G r_{L} S c\right)^{1 / 3}$

when $10^{7} \leq R a_{L} \leq 10^{11}$

\section{C2.2.3 Combination of Natural and Forced Convection}

The combined Nusselt Number for conditions where both natural and forced convection prevail ,may be calculated by

$\bar{N} u_{L}^{n}=\left(\bar{N} u_{L}^{n}\right)_{F} \pm\left(\bar{N} u_{L}^{n}\right)_{N}$

where $\left(N u_{L}^{n}\right)_{F}$ is the Nusselt number for forced convection and $\left(N u_{L}^{n}\right)_{N}$ the Nusselt number for natural convection. Incropera and DeWitt (2002) claims the best correlation of data is most often obtained when $n=3$.

\section{C2.3 Roof-pond Water to Roof Heat Transfer Coefficients}

The convection heat transfer coefficients between the roof-pond water and roof slab surface $h_{r s, w}$ is calculated from the Nusselt Number correlations for natural convection conditions. When the roof-pond temperature is higher than that of the roof slab, equation C.54 applies. When the roof slab surface temperature is higher than that of the roof-pond water equation C.57 and C.59 applies. The Rayleigh Number $R a_{L}$ in these equation takes the form

$R a_{L}=G r_{L} P_{r}=\frac{g \beta\left(T_{r p}-T_{0}\right) L_{r p}^{3}}{v_{w} \alpha_{w}}$

where $T_{0}$ is the temperature of the roof slab surface, $v_{w}$ the kinematic viscosity of water and $\alpha_{w}$ the thermal diffusivity of water. 
Sodha et al. (1980:2), Sodha et al. (1982) and Jain (2006) utilises a value of $135 \mathrm{~W} / \mathrm{mK}$ for the heat transfer convection coefficient between the roof slab surface and the roof-pond. Where $R a_{L}$ falls outside the validity range of equation C.54 and C.59 a value of $135 \mathrm{~W} / \mathrm{mK}$ is employed for the convection heat transfer coefficient between the roof slab surface and roof-pond

\section{C.3 Correlations for Mass Transfer Rates}

\section{C3.1 Mass Transfer due to Evaporation}

The mass transfer during the process of evaporation may be calculated by the following equation given by Incropera and DeWitt (2002)

$\dot{m}_{r p, e v a p}=h_{m} A_{r p}\left(\rho_{v a p, r p}-\phi_{a m b} \rho_{v a p, a m b}\right)$

where $\rho_{\text {vap, } r p}$ is the saturation density of water vapour at the roof-pond temperature, $\rho_{\text {vap }, \text { amb }}$ the saturation density of water vapour at the ambient air temperature, $\phi_{a m b}$ the relative humidity of the ambient air and $h_{m}$ the mass transfer coefficient calculated from the Sherwood Number. The Sherwood Number pertaining to the roof-pond is calculated by

$h_{m}=\frac{S h_{L} D_{A B}}{L_{r p}}$

Equation C.63 is also applicable for the rate of mass evaporated from the water droplet.

\section{C3.2 Mass Transfer due to Condensation}

The rate of mass transfer for both evaporation and condensation may be calculated with the following equation (Mills, 2000)

$$
\dot{m}_{r p, c o n d}=2 A_{r p}\left[\frac{\phi_{a m b} p_{v a p, a m b}}{\left(2 \pi R T_{a m b}\right)^{1 / 2}}-\frac{p_{v a p, r p}}{\left(2 \pi R T_{r p}\right)^{1.2}}\right]
$$

where $R$ is the universal gas constant and $T_{r p}$ the roof-pond surface temperature, $p_{\text {vap,amb }}$ the vapour pressure of the ambient air and $p_{\text {vap,rp }}$ the saturated vapour pressure at the roof pond water temperature. Equation C.65 may also be employed for the rate mass condensation on the water droplet. In his case, $T_{r p}$ would be substituted by $T_{d}$ and $A_{r p}$ by $A_{d}$. From equation C.65 it can be seen that for evaporation to occur the saturation vapour pressure $p_{v a p, r p}$ must be greater than the vapour pressure $p_{v a p, r p}$. For the condensation to occur the opposite must be true. 


\section{APPENDIX D: ORDER OF MAGNITUDE ANALYSIS}

In the spray cloud of the roof-spray system some droplets are located in the centre while others are situated at the outer edge of the cloud, refer to figure D.1. The droplets located in the centre are surrounded by droplets of similar temperature and the radiation heat exchange is essentially zero. For the droplets situated at the outer edge of the spray cloud some part of the droplet area would be exposed to the surroundings, night sky and solar radiation. The radiation heat transfer from these droplets is negligible as will be shown below.

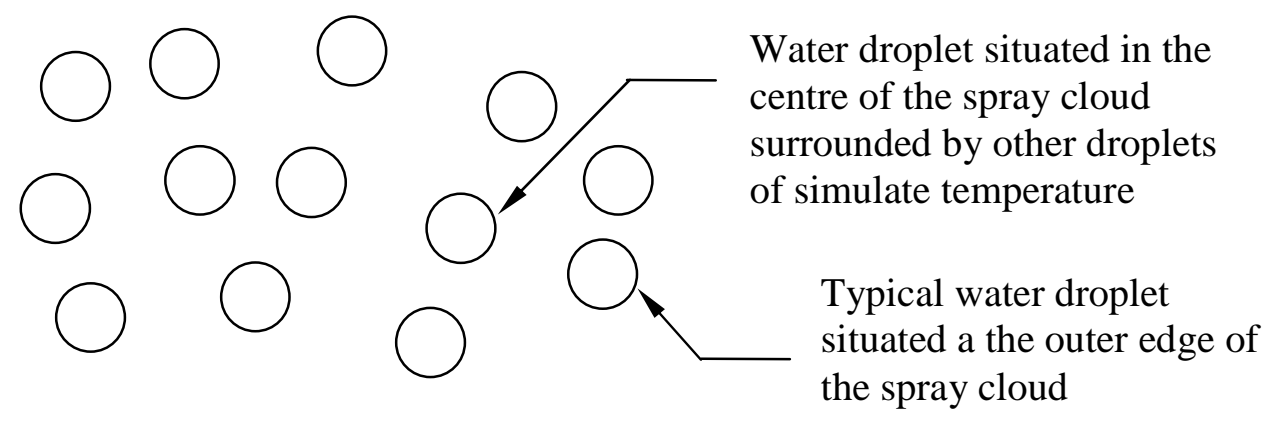

Figure D.1: Location of Water Droplets in a Spray Cloud

Suppose a droplet with a diameter of $2000 \mu \mathrm{m}$ is situated at the outer edge of the cloud with $50 \%$ of its surface area exposed to the night sky and 50\% to the surroundings. As illustrated in Appendix $\mathrm{C}$, the three mechanisms of heat transfer from the water droplet are convection, evaporation and radiation. For $T_{a m b}=T_{\text {sur }}=15^{\circ} \mathrm{C}, \phi_{a m b}=80 \%, T_{s k y}=0{ }^{\circ} \mathrm{C}$ and $T_{d}=20^{\circ} \mathrm{C}$ and a water droplet travelling at $10 \mathrm{~m} / \mathrm{s}$ through the air, the water droplet convection heat transfer coefficient $h_{d}$, calculated from the correlations presented in Appendix C, becomes 274.5 $\mathrm{W} / \mathrm{m}^{2}$ and the water mass transfer $\dot{m}_{d, \text { evap }}=2.22 \times 10^{-8} \mathrm{~kg} / \mathrm{s}$. The calculation of $h_{d}$ and $\dot{m}_{d, \text { evap }}$ is illustrated in the sample calculation of Appendix G and will not be repeated here. The convection heat transfer, calculated from equation C.18, becomes

$\dot{Q}_{d, \text { conv }}=h_{d} A_{d}\left(T_{\text {amb }}-T_{d}\right)=274.5 \times 1.26 \times 10^{-5} \times(288.15-293.15)=-0.0174 \mathrm{~W}$

As shown in Appendix C, the evaporation heat transfer is calculated by

$\dot{Q}_{d, \text { evap }}=\dot{m}_{d, \text { evap }}\left(h_{g}-u_{f}\right)=2.22 \times 10^{-8} \times(2465900-83950)=0.0529 \mathrm{~W}$

The radiation heat transfer to the surroundings and night sky is calculated by equation C.19

$$
\begin{aligned}
\dot{Q}_{d, \text { rad }} & =0.5\left(\varepsilon A_{d} \sigma\left(T_{\text {sur }}^{4}-T_{d}^{4}\right)+\varepsilon A_{d} \sigma\left(T_{s k y}^{4}-T_{d}^{4}\right)\right)=0.5 \varepsilon A_{d} \sigma\left(\left(T_{s u r}^{4}-T_{d}^{4}\right)+\left(T_{s k y}^{4}-T_{d}^{4}\right)\right) \\
& =0.5 \times 0.9 \times 1.26 \times 10^{-5} \times 5.67 \times 10^{-8} \times\left(\left(288.15^{4}-293.15^{4}\right)+\left(273.15^{4}-293.15^{4}\right)\right) \\
& =-0.000754145
\end{aligned}
$$

From the above it can be seen that $\dot{Q}_{d, \text { rad }}$ is an order 1000 times smaller than $\dot{Q}_{d, \text { evap }}$ and $\dot{Q}_{d, c o n v}$ and may consequently be neglected in further calculations. 


\section{APPENDIX E: INCIDENT SOLAR RADIATION CALCULATION}

\section{E.1 Solar Radiation Components}

The mathematical model of the one-room building utilises the incident solar flux on the walls and through the window. The following procedure for calculating the incident solar flux on a surface was formulated after consulting ASHRAE Fundamentals (2005), Chapter 31.

Solar radiation is reflected, scattered and absorbed by dust, gas molecules, ozone, water vapour and water droplets as it passes through the earth's atmosphere. The scattered portion of the beam solar radiation directed downward to the earth's surface is termed diffuse sky radiation. Another component that constitutes to the total solar radiation is ground reflected radiation. The total solar radiation incident on a surface is therefore calculated by

$I_{\text {solar }, \text { tot }}=I_{\text {solar }, D N} \cos \theta+I_{\text {solar }, d}+I_{\text {solar }, r}$

where $I_{\text {solar }, D N}$ is the direct normal beam solar radiation, $I_{\text {solar }, d}$ the diffuse solar radiation, $I_{\text {solar, } r}$ the ground reflected solar radiation and $\theta$ is the angle of incidence between the incoming solar rays and a line normal to the surface.

\section{E.2 Determining the Angel of Incidence}

The angle of incidence is dependent on the solar altitude $\beta$, the latitude $L$ and the solar declination $\delta$ angle. These angles are depicted figure E.1.

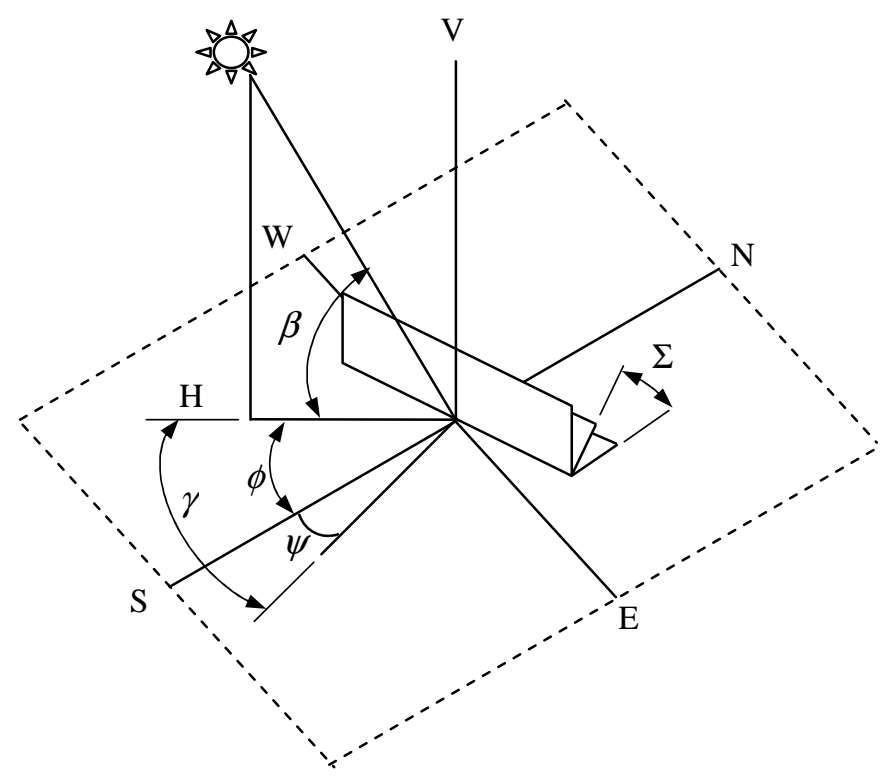

Figure E.1: Relevant Angles for Describing the Position of the Sun Relative to a Plane 
The solar altitude $\beta$ gives the angle of the sun above the horizontal and is calculated by

$\sin \beta=\cos L \cos \delta \cos H+\sin L \sin \delta$

where $L$ gives the local latitude, $\delta$ the solar declination and $H$ the hour angle. The latitude for any location on the earth is measured from the equator with the North Pole at 90 degrees and the South Pole at -90 degrees. The solar declination is the angle between the earth-sun line and the equatorial plane. The earth's equatorial plane is tilted at an angle of 23.45 degrees and varies throughout the year. ASHRAE gives the following equation to estimate the declination from the day of year $N$

$$
\delta=23.45 \sin \left(\frac{360(284+N)}{365}\right)
$$

The hour angle $H$ is the angle of the sun east or west from the local standard meridian for the specific time zone. The whole of South Africa is two hours ahead of the Greenwich which means the local standard meridian, LSM is 30 degrees. The hour angle is calculated by

$H=15(A S T-12)$

where AST is the apparent solar time. The apparent solar time is different from the local solar time, $L S T$, due to the earth's orbital velocity that varies throughout the year. The apparent solar time is calculated by

$$
A S T=L S T+E T / 60+(L S M-L O N) / 15
$$

where ET gives the equation of time, $L S M$ the local standard meridian and $L O N$ the local longitude. Longitude degrees east of the Greenwich are positive and longitudes west of the Greenwich are negative. SAIRAC (2006) gives the following approximation for the equation of time

$$
E T=0.165 \sin (2 B)-0.126 \cos B-0.025 \sin B
$$

where

$$
B=360(N-81) / 364
$$

The incidence angle $\theta$ is calculated by

$$
\cos \theta=\cos \beta \cos \gamma \sin \Sigma+\sin \beta \cos \Sigma
$$

where $\Sigma$ is the tilt angle of the surface and $\gamma$ surface solar azimuth. For a horizontal surface the tilt angle is 0 degrees and for a vertical surface the tilt angle is 90 degrees. The surface solar azimuth is defined by

$$
\gamma=|\phi-\psi|
$$


where $\phi$ denotes the solar azimuth and $\psi$ the surface azimuth. The solar azimuth $\phi$ is calculated by

$$
\cos \phi=\frac{\sin \beta \sin L-\sin \delta}{\cos \beta \cos L}
$$

The surface azimuth is measured from south in a clockwise direction. That means a surface facing west would have a surface azimuth of 90 degrees.

\section{E.3 Determination of the Solar Radiation Components}

The direct solar radiation normal to the earth's surface is represented by

$$
I_{\text {solar }, D N}=\frac{A}{\exp (B / \sin \beta)}
$$

where $A$ is the apparent solar irradiation and $B$ the atmospheric extinction coefficient. Values for $A$ and $B$ vary during the year due to the seasonal changes of dust and water content in the atmosphere and the ever changing distance between the earth and sun (ASHRAE Fundamentals, 2005). Table E.1 gives values for $A$ and $B$.

Table E.1: Values for $A, B$ and $C$ for the 21st day of each Month of the Year (Values taken from ASHRAE Fundamentals, 2005, Chapter 31)

\begin{tabular}{|c|c|c|c|}
\hline Month & $\mathbf{A}\left(\mathbf{W} / \mathbf{m}^{2}\right)$ & $\mathbf{B}$ & $\mathbf{C}$ \\
\hline 21 January & 1202 & 0.141 & 0.103 \\
\hline 21 February & 1187 & 0.142 & 0.104 \\
\hline 21 March & 1164 & 0.149 & 0.109 \\
\hline 21 April & 1130 & 0.164 & 0.120 \\
\hline 21 May & 1106 & 0.177 & 0.130 \\
\hline 21 June & 1092 & 0.185 & 0.138 \\
\hline 21 July & 1093 & 0.186 & 0.134 \\
\hline 21 August & 1107 & 0.182 & 0.121 \\
\hline 21 September & 1136 & 0.165 & 0.111 \\
\hline 21 October & 1166 & 0.152 & 0.106 \\
\hline 21 November & 1190 & 0.144 & 0.103 \\
\hline 21 December & 1204 & 0.141 & \\
\hline
\end{tabular}


The diffuse radiation $I_{\text {solar }, d}$ is given by

$I_{\text {solar }, d}=C Y I_{\text {solar }, D N}$

for vertical surfaces and

$I_{\text {solar }, d}=C Y I_{\text {solar }, D N} \frac{(1+\cos \Sigma)}{2}$

where $C$ is a dimensionless coefficient given in table E.1. $Y$ denotes the ratio of sky diffuse radiation on a vertical surface to sky diffuse radiation on a horizontal surface and is calculated by

$Y=0.55+0.437 \cos \theta+0.313 \cos ^{2} \theta$

for $\cos \theta>-0.2$ and

$Y=0.45$

for $\cos \theta \leq-0.2$ and

The ground reflected radiation $E_{r}$ for all surface at all orientations is given by

$I_{\text {solar }, r}=I_{\text {solar }, D N}(C+\sin \beta) \rho_{g} \frac{(1-\cos \Sigma)}{2}$

$\rho_{g}$ denotes the ground reflectivity. The ground reflectivity is often taken as 0.2 for typical mixture of ground surfaces (ASHRAE Fundamentals, 2005). 


\section{APPENDIX F: UNCERTAINTY ASSOCIATED WITH ENERGY LOSS CALCULATIONS}

The error involved in the measurement of temperature and water flow rate propagates to an uncertainty in the calculated convection, evaporation and radiation energy loss from the water droplets, storage volume and roof-pond. The uncertainty associated with the energy losses is calculated through the numerical procedure of sequential perturbation. Sequential perturbation uses a finite-difference method to approximate derivates. The approach is described in Figiola and Beasley (2000). The uncertainty associated with the system parameters such as the water flowrate, droplet sizes, humidity measurements etc. are taken into consideration in this calculation.

\section{F.1 Uncertainty Associated with Convection Energy Loss Calculations}

The convection energy loss for a water droplet may be written as

$Q_{\text {spray_conv }}=f\left(D_{d}, u_{d}, T_{d}, T_{a m b}\right)$

where $D_{d}$ denotes the water droplet diameter, $u_{d}$ the water droplet velocity relative to the ambient air, $T_{d}$ the storage tank temperature and $T_{a m b}$ the ambient air temperature. The convection energy loss from the roof-pond may be written as

$Q_{r p_{-} \text {conv }}=f\left(A_{r p}, u_{w}, T_{r p}, T_{a m b}\right)$

where $A_{r p}$ denotes the roof-pond surface area, $u_{w}$ the wind velocity and $T_{r p}$ the roof-pond temperature. Combining equations F.1 and F.2 gives the total convection energy transfer for the roof cooling system, i.e.

$Q_{\text {conv }}=\left(Q_{\text {spray_conv }}+Q_{r p_{-} \text {conv }}\right) d t=f\left(A_{r p}, D_{d}, u_{d}, u_{w}, T_{r p}, T_{d}, T_{\text {amb }}\right)$

Inserting the measured temperatures into equation F.3 gives the operating point for the numerical approximation of the uncertainty in the result. Thus

$Q_{0, \text { conv }}=f\left(A_{r p}, D_{d}, u_{d}, u_{w,}, T_{r p, m s d}, T_{d, m s d}, T_{a m b, m s d}\right)$

The convection heat transfer is recalculated with the temperature measurements increased with their respective uncertainties to give

$$
\begin{aligned}
& Q_{1, \text { conv }}^{+}=f\left(A_{r p}, D_{d}, u_{d}, u_{w}, T_{r p, m s d}+u_{T, t o t}, T_{d, m s d}, T_{a m b, m s d}\right) \\
& Q_{2, \text { conv }}^{+}=f\left(A_{r p}, D_{d}, u_{d}, u_{w}, T_{r p, m s d}, T_{d, m s d}+u_{T, t o t}, T_{a m b, m s d}\right) \\
& Q_{3, \text { conv }}^{+}=f\left(A_{r p}, D_{d}, u_{d}, u_{w}, T_{r p, m s d}, T_{d, m s d}, T_{a m b, m s d}+u_{T, t o t}\right)
\end{aligned}
$$


In a similar manner the convection heat transfer is also recalculated with the temperature measurements decreased with their respective temperature uncertainties to give

$$
\begin{aligned}
& Q_{1, \text { conv }}^{-}=f\left(A_{r p}, D_{d}, u_{d}, T_{r p, m s d}-u_{T, t o t}, T_{d, m s d}, T_{a m b, m s d}\right) \\
& Q_{2, c o n v}^{-}=f\left(A_{r p}, D_{d}, u_{d}, T_{r p, m s d}, T_{d, m s d}-u_{T, t o t}, T_{a m b, m s d}\right) \\
& Q_{3, \text { conv }}^{-}=f\left(A_{r p}, D_{d}, u_{d}, T_{r p, m s d}, T_{d, m s d}, T_{a m b, m s d}-u_{T, t o t}\right)
\end{aligned}
$$

The differences between equations F.5 to F.10 and the operating point, equation F.4, may now be calculated as

$$
\begin{aligned}
& \delta Q_{1, \text { conv }}^{+}=Q_{1, \text { conv }}^{+}-Q_{0, \text { conv }} \\
& \delta Q_{2, \text { conv }}^{+}=Q_{2, \text { conv }}^{+}-Q_{0, \text { conv }} \\
& \delta Q_{3, \text { conv }}^{+}=Q_{3, \text { conv }}^{+}-Q_{0, \text { conv }} \\
& \delta Q_{1, \text { conv }}^{-}=Q_{1, \text { conv }}^{-}-Q_{0, \text { conv }} \\
& \delta Q_{2, \text { conv }}^{-}=Q_{2, \text { conv }}^{-}-Q_{0, \text { conv }} \\
& \delta Q_{3, \text { conv }}^{-}=Q_{3, \text { conv }}^{-}-Q_{0, \text { conv }}
\end{aligned}
$$

The uncertainty contribution from each variable can now be approximated as

$$
\begin{aligned}
& \delta Q_{1, \text { conv }}=\frac{\left|Q_{1, \text { conv }}^{+}\right|+\left|Q_{1, \text { conv }}^{-}\right|}{2} \approx \theta_{1, \text { conv }} u_{1, \text { conv }} \\
& \delta Q_{2, \text { conv }}=\frac{\left|Q_{2, \text { conv }}^{+}\right|+\left|Q_{2, \text { conv }}^{-}\right|}{2} \approx \theta_{2, \text { conv }} u_{2, \text { conv }} \\
& \delta Q_{3, \text { conv }}=\frac{\left|Q_{3, \text { conv }}^{+}\right|+\left|Q_{3, \text { conv }}^{-}\right|}{2} \approx \theta_{3, \text { conv }} u_{3, \text { conv }}
\end{aligned}
$$

The uncertainty in the calculated convection energy loss becomes

$$
u_{\text {conv }}= \pm\left(\theta_{1, \text { conv }} u_{1, \text { conv }}^{2}+\theta_{2, \text { conv }} u_{2, \text { conv }}^{2}+\theta_{3, \text { conv }} u_{3, \text { conv }}^{2}\right)^{\frac{1}{2}}
$$

\section{F.2 Uncertainty Associated with Evaporation Energy Loss Calculations}

The energy loss from the water droplet due to evaporation may be written as 
$Q_{\text {spray_evap }}=f\left(D_{d}, u_{d}, T_{d}, T_{\text {amb }}, \phi_{\text {air }}\right)$

where $\phi_{a i r}$ denotes the ambient relative humidity. The evaporation energy loss from the roofpond is

$Q_{r p_{e} \text { evap }}=f\left(A_{r p}, T_{r p}, T_{a m b}, \phi_{\text {air }}\right)$

Combining equations F.21 and F.22 gives the total evaporation energy loss from the roof cooling system

$Q_{\text {evap }}=f\left(A_{r p}, D_{d}, u_{d}, T_{d}, T_{a m b}, \phi_{\text {air }}\right)$

Following the same procedure as outlined from equations F.4 to F.20 gives the uncertainty associated with the evaporation heat loss calculation. Inserting the measured temperatures into equation F.23 gives the operating point for the numerical approximation of the uncertainty in the result. Thus

$Q_{0, \text { evap }}=f\left(A_{r p}, D_{d}, u_{d}, T_{d, \text { msd }}, T_{\text {amb,msd }}, \phi_{\text {air }}\right)$

The evaporation heat transfer is recalculated with the temperature measurements increased with their respective uncertainties. This gives

$Q_{1, \text { evap }}^{+}=f\left(A_{r p}, D_{d}, u_{d}, u_{w}, T_{d, \text { msd }}+u_{T, \text { tot }}, T_{\text {amb }, \text { msd }}, \phi_{\text {air }}\right)$
$Q_{2, \text { evap }}^{+}=f\left(A_{r p}, D_{d}, u_{d}, u_{w}, T_{d, \text { msd }}, T_{\text {amb }, \text { msd }}+u_{T, \text { tot }}, \phi_{\text {air }}\right)$

In a similar manner the evaporation heat transfer is also recalculated with the temperature measurements decreased with their respective temperature uncertainties to give

$Q_{1, \text { evap }}^{-}=f\left(A_{r p}, D_{d}, u_{d}, u_{w}, T_{d, m s d}-u_{T, t o t}, T_{a m b, m s d}, \phi_{\text {air }}\right)$
$Q_{2, \text { evap }}^{-}=f\left(A_{r p}, D_{d}, u_{d}, u_{w}, T_{d, \text { msd }}, T_{a m b, m s d}-u_{T, \text { tot }}, \phi_{\text {air }}\right)$

The differences between equations F.25 to F.28 and the operating point, equation F.24, may now be calculated as

$$
\begin{aligned}
& \delta Q_{1, \text { evap }}^{+}=Q_{1, \text { evap }}^{+}-Q_{0, \text { evap }} \\
& \delta Q_{2, \text { evap }}^{+}=Q_{2, \text { evap }}^{+}-Q_{0, \text { evap }} \\
& \delta Q_{1, \text { evap }}^{-}=Q_{1, \text { evap }}^{-}-Q_{0, \text { evap }} \\
& \delta Q_{2, \text { evap }}^{-}=Q_{2, \text { evap }}^{-}-Q_{0, \text { evap }}
\end{aligned}
$$


The uncertainty contribution from each variable can now be approximated as

$$
\begin{aligned}
& \delta Q_{1, \text { evap }}=\frac{\left|Q_{1, \text { evap }}^{+}\right|+\left|Q_{1, \text { evap }}^{-}\right|}{2} \approx \theta_{1, \text { evap }} u_{1, \text { evap }} \\
& \delta Q_{2, \text { evap }}=\frac{\left|Q_{2, \text { evap }}^{+}\right|+\left|Q_{2, \text { evap }}^{-}\right|}{2} \approx \theta_{2, \text { evap }} u_{2, \text { evap }}
\end{aligned}
$$

The uncertainty in the calculated evaporation energy loss calculation becomes

$$
u_{\text {evap }}= \pm\left(\theta_{1, \text { evap }} u_{1, \text { evap }}^{2}+\theta_{2, \text { evap }} u_{2, \text { evap }}^{2}\right)^{\frac{1}{2}}
$$

\section{F.3 Uncertainty Associated with Radiation Energy Loss Calculations}

The radiation heat exchange between the roof-pond water surface and the night sky is calculated as

$$
Q_{r p_{-} r a d}=f\left(A_{r p}, T_{r p}, T_{a m b}, \phi_{a i r}\right)
$$

Similar to the procedures outlined for the evaporation and convection energy loss calculations inserting the measured temperatures into equation F.36 gives the operating point of the uncertainty in the radiation energy loss result

$$
Q_{0, r p_{-} r a d}=f\left(A_{r p}, T_{r p, m s d}, T_{a m b, m s d}, \phi_{a i r}\right)
$$

The radiation heat loss from the roof-pond is recalculated with the temperature measurements increased with their respective uncertainties

$$
\begin{aligned}
& Q_{1, r p_{-} r a d}^{+}=f\left(A_{r p}, T_{r p, m s d}+u_{T, t o t}, T_{a m b, m s d}, \phi_{a i r}\right) \\
& Q_{1, r p_{-} r a d}^{+}=f\left(A_{r p}, T_{r p, m s d}, T_{a m b, m s d}+u_{T, t o t}, \phi_{a i r}\right)
\end{aligned}
$$

The radiation heat loss from the roof-pond is also recalculated with the temperature measurements decreased with their respective uncertainties

$$
\begin{aligned}
& Q_{1, r p_{-} r a d}^{-}=f\left(A_{r p}, T_{r p, m s d}-u_{T, t o t}, T_{a m b, m s d}, \phi_{a i r}\right) \\
& Q_{1, r p_{-} r a d}^{-}=f\left(A_{r p}, T_{r p, m s d}, T_{a m b, m s d}-u_{T, t o t}, \phi_{a i r}\right)
\end{aligned}
$$

The differences between equations F.38 to F.41 and the operating point, equation F.37, is calculated as

$$
\delta Q_{1, r p_{\_} \text {rad }}^{+}=Q_{1, r p_{\_} \text {rad }}^{+}-Q_{0, r p_{-} \text {rad }}
$$


$\delta Q_{2, r p_{-} \text {rad }}^{+}=Q_{2, r p_{-} r a d}^{+}-Q_{0, r p_{-} \text {rad }}$

$\delta Q_{1, p_{-} \text {rad }}^{-}=Q_{1, r p_{-} r a d}^{-}-Q_{0, r p_{-} r a d}$

$\delta Q_{2, r p_{-} r a d}^{-}=Q_{2, p_{-} r a d}^{-}-Q_{0, r p_{-} r a d}$

The uncertainty contribution from each variable can now be approximated as

$\delta Q_{1, r p_{-} r a d}=\frac{\left|Q_{1, r p_{-} r a d}^{+}\right|+\left|Q_{1, p_{-} r a d}^{-}\right|}{2} \approx \theta_{1, r p_{-} r a d} u_{1, r p_{-} r a d}$

$\delta Q_{2, r p_{-} r a d}=\frac{\left|Q_{2, r p_{-} \text {rad }}^{+}\right|+\left|Q_{2, r p_{-} \text {rad }}^{-}\right|}{2} \approx \theta_{2, r p_{-} \text {rad }} u_{2, r p_{-} \text {rad }}$

The uncertainty in the calculated radiation energy loss calculation becomes

$u_{\text {rad }}= \pm\left(\theta_{1, r p_{-} \text {rad }} u_{1, r p_{-} \text {rad }}^{2}+\theta_{2, r p_{-} r a d} u_{2, r p_{-} \text {rad }}^{2}\right)^{\frac{1}{2}}$

\section{F.4 Uncertainty Values for the Experimental Tests}

Table F.1 gives the energy loss and uncertainty values for the convection, evaporation and radiation heat transfers. The energy loss was calculated with the procedure outlined in Chapter 5 and the associated uncertainty with sequential perturbation procedure outlined in Section F.3

Table F.1: Uncertainty Values for Convection, Evaporation and Radiation Energy Losses of the Experimental Tests

\begin{tabular}{|l|c|c|c|c|c|}
\hline & 25 May 2008 & 12 July 2008 & 02 August 2008 & 03 May 2009 & 04 May 2009 \\
\hline $\begin{array}{l}\text { Total Convection } \\
\left(\dot{Q}_{r s, c o n v} d t\right)\end{array}$ & $-319.9 \pm 24.22 \mathrm{~kJ}$ & $-376.91 \pm 55.9 \mathrm{~kJ}$ & $-218.09 \pm 69.1 \mathrm{~kJ}$ & $-114.8 \pm 9.22 \mathrm{~kJ}$ & $34.75 \pm 13.70 \mathrm{~kJ}$ \\
\hline $\begin{array}{l}\text { Total Evaporation } \\
\text { Energy Loss } \\
\left(\dot{Q}_{r s, \text { evap }} d t\right)\end{array}$ & $-645.8 \pm 2.36 \mathrm{~kJ}$ & $-1095.1 \pm 7.03 \mathrm{~kJ}$ & $-2064 \pm 15.72 \mathrm{~kJ}$ & $-644.29 \pm 59.9 \mathrm{~kJ}$ & $-465.77 \pm 50.2 \mathrm{~kJ}$ \\
\hline $\begin{array}{l}\text { Total Radiation } \\
\text { Energy Loss } \\
\left(\dot{Q}_{r p, s k y} d t\right)\end{array}$ & $-210.9 \pm 16.12 \mathrm{~kJ}$ & $-68.21 \pm 13.73 \mathrm{~kJ}$ & $-1939.14 \pm 9.29 \mathrm{~kJ}$ & $-2089 \pm 167.20 \mathrm{~kJ}$ & $1491.8 \pm 151.1 \mathrm{~kJ}$ \\
\hline
\end{tabular}




\section{APPENDIX G: SAMPLE CALCULATIONS}

The sample calculations are included to add confidence in the accuracy and correctness of the calculation simulations and computer program. Sample calculations for the mathematical model of the roof cooling system are presented in Sections G.1 and G.2. Sample calculations for the mathematical model of the one-room building are presented in Sections G.3 and G.4. The sample calculations were initially performed on 30 October 2009 and modified on 21 February 2010.

\section{G.1 Sample Calculations for the Droplet-Flowchart as given in Figure 4.14}

The sample calculations hereunder follow the same logic as presented in the dropletflowchart given in figure 4.14. It is advised that the sample calculations be read in conjunction with figure 4.14 .

\section{Ambient Dependant Variables, System Variables and System Design Parameters}

When the calculations for the water droplet travelling through the air are preformed it is advised that the air properties be evaluated at the film temperature for more accurate results. However for the purpose of illustration the ambient dependant properties given below are employed in the sample calculations.

$$
\begin{array}{lll}
v_{a m b}=14.84 \times 10^{-6} \mathrm{~m}^{3} / \mathrm{s} & k_{\text {amb }}=0.025 \mathrm{~W} / \mathrm{mK} ; & \phi_{\text {amb }}=80 \% ; \\
p_{a m b}=100230 \mathrm{~Pa} & u_{w}=3 \mathrm{~m} / \mathrm{s} ; & \gamma=0^{\circ} ; \\
T_{a m b}=288.15 \mathrm{~K} ; & h_{g}=2465900 \mathrm{~J} / \mathrm{kg} ; & u_{f}=83.95 \times 10^{3} \mathrm{~J} / \mathrm{kg} \\
C_{v}=4177.053 \mathrm{~J} / \mathrm{kgK} ; & R=8315 \mathrm{~J} / \mathrm{molK} ; & M_{a}=18.015 \mathrm{~kg} / \mathrm{kmol} ; \\
\rho_{w}=995.95 \mathrm{~kg} / \mathrm{m}^{3} & P r=0.71 ; & S c=0.5706 ; \\
n=0.3 ; & \rho_{\text {vap }, d}=0.0134 \mathrm{~kg} / \mathrm{m}^{3} ; & \rho_{\text {vap }, \text { amb }}=0.0105 \mathrm{~kg} / \mathrm{m}^{3} \\
\rho_{\text {air }}=1.217 \mathrm{~kg} / \mathrm{m}^{3} & D_{A B}=0.26 \times 10^{-4} \mathrm{~m} / \mathrm{s} &
\end{array}
$$

The initial conditions for the droplet are:

$T_{d, \text { ini }}=303.15 \mathrm{~K} ; r_{d, i n i}=750 \mu \mathrm{m} ; u_{d, i n i}=10 \mathrm{~m} / \mathrm{s} ; \Delta t=0.05 \mathrm{~s}$

Nozzle height from the roof-pond water surface level is $0.15 \mathrm{~m}$.

\section{Sub Calculations}

The sub calculations are performed to calculate the convective and mass transfer coefficients. The correlations for the Nusselt and Sherwood numbers may be found in Appendix C 


$$
\begin{aligned}
& A_{d}=4 \pi r^{2}=4 \times \pi \times\left(750 \times 10^{-6}\right)^{2}=7.07 \times 10^{-6} \mathrm{~m}^{2} ; \\
& V_{d}=4 / 3 \pi r^{3}=(4 / 3) \times \pi \times\left(750 \times 10^{-6}\right)^{2}=1.77 \times 10^{-9} \mathrm{~m}^{3} ; \quad m_{d}=\rho_{u} V_{d}=1.76 \times 10^{-6} \mathrm{~kg} \\
& \operatorname{Re}_{d}=\frac{V_{d} \times 2 r_{d}}{v_{a m b}}=\frac{\left(1.77 \times 10^{-6}\right) \times 2 \times\left(750 \times 10^{-6}\right)}{14.84 \times 10^{-6}}=1011.1 ;
\end{aligned}
$$

Since $\operatorname{Re}_{d}>500$ the drag coefficient for the water droplet becomes $C_{d}=0.44$. The Nusselt number for the water droplet is calculated from equation C.39. $N u_{d}=2+0.6 \operatorname{Re}_{d}^{1 / 2} \operatorname{Pr}^{1 / 3}=2+0.6 \times(1011.1)^{1 / 2} \times(0.71)^{1 / 3}=19.021$

The convective heat transfer coefficient may now be calculated by $h_{w d}=N u_{d} \times \frac{k_{a m b}}{2 r_{d}}=19.021 \times \frac{0.025}{2 \times\left(750 \times 10^{-6}\right)}=321.48 \mathrm{~W} / \mathrm{m}^{2} \mathrm{~K}$;

In order to calculate the mass transfer coefficient the Sherwood number is calculated from equation C.43, i.e.

$S h_{d}=N u_{d} \times\left(\frac{S c}{\operatorname{Pr}}\right)^{n}=19.021 \times\left(\frac{0.5706}{0.710}\right)^{0.3}=17.81 ; \quad$ The mass transfer coefficient is calculated from equation C. 42 , that is

$$
\begin{aligned}
& h_{m}=S h_{d} D_{A B} /\left(2 \times r_{d}\right)=\frac{17.81 \times\left(0.26 \times 10^{-4}\right)}{2 \times\left(750 \times 10^{-6}\right)}=0.31 \mathrm{~m} / \mathrm{s} \\
& \dot{m}_{r p, e v a p}=h_{m} A_{r p}\left(\rho_{v a p, r p}-\phi_{\text {amb }} \rho_{\text {vap }, a m b}\right)=0.31 \times\left(7.07 \times 10^{-6}\right) \times(0.0134-0.8 \times 0.0105) \\
& =6.19 \times 10^{-9} \mathrm{~kg} / \mathrm{s}
\end{aligned}
$$

Since $\dot{m}_{d, \text { evap }}>0$ thus $\dot{m}_{d, \text { cond }}=0$

\section{Calculation of Equation 4.7 - Energy Equation}

$$
\begin{aligned}
& T_{d}^{\text {new }}=T_{d}^{\text {old }}+\frac{\Delta t}{m_{d} C_{p}}\left(h_{w d} A_{d}\left(T_{\text {amb }}-T_{d}\right)-\dot{m}_{d, \text { evap }}\left(h_{g}-u_{f}\right)+\dot{m}_{d, \text { cond }}\left(h_{g}-u_{f}\right)\right) \\
&=303.15+\frac{0.05}{\left(1.76 \times 10^{-6}\right) \times 4177.053}\left(321.48 \times 7.069 \times 10^{-6} \times(288.15-303.15)-\right. \\
&\left.6.19 \times 10^{-9}\left(2465900-83.95 \times 10^{3}\right)+0\right) \\
&= 302.055 \mathrm{~K}
\end{aligned}
$$

\section{Calculation of Equation 4.2 - Continuity Equation}

$m_{d}^{\text {new }}=m_{d}^{\text {old }}+\left(\dot{m}_{d, \text { cond }}-\dot{m}_{d, \text { evap }}\right) \Delta t$ 


$$
\begin{aligned}
& =1.76 \times 10^{-6}+\left(0-6.19 \times 10^{-9}\right) \times 0.05=1.758 \times 10^{-6} \mathrm{~kg} \\
& r_{d}^{\text {new }}=\left(\frac{3 m_{d}}{4 \pi \rho_{w}}\right)^{1 / 3}=\left(\frac{3 \times 1.758 \times 10^{-6}}{4 \times \pi \times 995.95}\right)^{1 / 3}=749.7 \mu \mathrm{m} \\
& \frac{u_{o}=\left(r_{d}^{\text {old }}-r^{\text {new }}\right)}{\Delta t}=\frac{(750-749.71) \times 10^{-6}}{0.05}=5.97 \times 10^{-6} \mathrm{~m} / \mathrm{s}
\end{aligned}
$$

\section{Calculation of Equation 4.4 and 4.5}

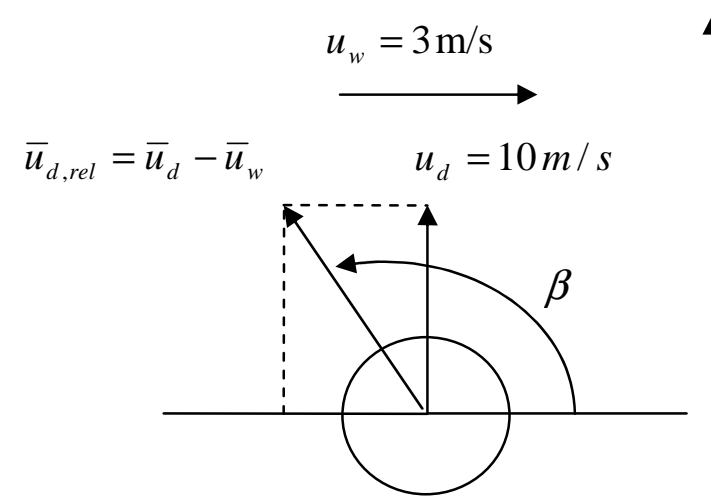

Figure G.1: Velocity Diagram of Water Droplet
Figure G.1 depicts the velocity diagram of the water droplet travelling through the air. The droplet velocity relative to the wind velocity may now be calculated as

$$
\begin{aligned}
\bar{u}_{d, r e l} & =\sqrt{\left(\bar{u}_{d}^{2}-\bar{u}_{w}^{2}\right)}=\sqrt{10^{2}+3^{2}} \\
& =10.44 \mathrm{~m} / \mathrm{s}
\end{aligned}
$$$$
\beta=180^{\circ}-\operatorname{atan}\left(\frac{10}{3}\right)=106.69^{\circ}
$$

The water droplet momentum in the $\mathrm{x}$-direction becomes

$$
\begin{aligned}
& \left(m_{d} u_{d, x}\right)^{\text {new }}=\left(m_{d} u_{d, x}\right)^{\text {old }}+\left(C_{d} \pi r_{d}^{2} \frac{\rho u_{d, r e l}^{2}}{2} \cos \beta-\dot{m}_{d, \text { evap }} u_{o}+\dot{m}_{d, \text { cond }} u_{i}\right) \Delta t \\
& =0+\left(0.44 \times \pi \times 0.0007497^{2} \times \frac{1.217 \times 10.44^{2}}{2} \cos (106.69)-6.19 \times 10^{-9} \times 5.97 \times 10^{-6}+0\right) 0.05 \\
& =-3 \times 10^{-7} \mathrm{mkg} / \mathrm{s}
\end{aligned}
$$

The water droplet momentum in the y-direction becomes

$$
\left(m_{d} u_{d, y}\right)^{n e w}=\left(m_{d} u_{d, y}\right)^{o l d}+\left(C_{d} \pi r_{d}^{2} \frac{\rho u_{d, y}^{2}}{2} \sin \beta-m_{d} g-\dot{m}_{d, e v a p} u_{o}+\dot{m}_{d, \text { cond }} u_{i}\right) \Delta t
$$




$$
\begin{aligned}
= & \left(1.75 \times 10^{-6} \times 10\right)+\left(0.44 \times \pi \times 0.00075^{2} \times \frac{1.217 \times 10.44^{2}}{2} \sin (106.69)\right. \\
& \left.-\left(1.76 \times 10^{-6} \times 9.81\right)-6.19 \times 10^{-9} \times 5.97 \times 10^{-6}\right) 0.05 \\
= & 1.7 \times 10^{-5} \mathrm{mkg} / \mathrm{s}
\end{aligned}
$$

Calculation of the new velocity components after time step $\Delta t$

$u_{d, x}^{\text {new }}=\left(m_{d} u_{d, x}\right)^{\text {new }} / m_{d}=-3 \times 10^{-7} /\left(1.76 \times 10^{-6}\right)=-0.17 \mathrm{~m} / \mathrm{s}$

$u_{d, y}^{\text {new }}=\left(m_{d} u_{d, y}\right)^{\text {new }} / m_{d}=1.7 \times 10^{-5} /\left(1.76 \times 10^{-6}\right)=9.7 \mathrm{~m} / \mathrm{s}$

$\bar{u}_{d, r}=\left(\left(u_{d, y}^{\text {new }}\right)^{2}+\left(u_{d, x}^{\text {new }}\right)^{2}\right)^{1 / 2}=\left((-0.17)^{2}+(9.7)^{2}\right)^{1 / 2}=9.7 \mathrm{~m} / \mathrm{s}$

$\beta$ may now be calculated as

$\beta=\mathrm{a} \cos \left(\frac{-0.17}{9.7}\right)=91.01^{\circ}$

Calculation of water droplet displacement for time step $\Delta t$

$$
\begin{aligned}
& \Delta s_{x}=u_{d, x, a v g} \Delta t=(-0.17+0) \times 0.5 \times 0.05=-4.57 \times 10^{-2} \mathrm{~m} \\
& \Delta s_{y}=u_{d, y, a v g} \Delta t=(10+9.7) \times 0.5 \times 0.05=0.217 \mathrm{~m} \\
& s_{x, \text { tot }}=s_{x, \text { ot }}^{\text {old }}+\Delta s_{x}=0-4.57 \times 10^{-2}=-4.57 \times 10^{-2} \mathrm{~m} \\
& s_{y, \text { tot }}=s_{y, \text { oto }}^{\text {old }}+\Delta s_{y}=0.15+0.217=0.367 \mathrm{~m}
\end{aligned}
$$

Note that at the initial iteration $s_{y, \text { ot }}^{\text {old }}$ was set equal to the nozzle height.

As shown in figure 4.14, the droplet flowchart, the above calculations are repeated until $s_{y, t o t}<0$. From the computer simulation program the iteration for a drop size of $r_{d, i n i}=750 \mu \mathrm{m}$ is repeated for 1.3 seconds before $s_{y, t o t}$ become less than 0 . The end temperature of the droplet was calculated as $293.31 \mathrm{~K}$. 


\section{G.2 Sample Calculations for the Roof Cooling Flowchart given by Figure 4.15}

The sample calculations hereunder follow the same logic as presented in the roof cooling flowchart given in figure 4.15. It is advised that the sample calculations be read in conjunction with figure 4.15 . The sample calculations were performed from the $28^{\text {th }}$ to $30^{\text {th }}$ October 2009.

\section{Ambient Dependant Variables and System Constant Design Parameters}

The following ambient properties and system variables are used in the sample calculations

$$
\begin{aligned}
& \operatorname{Pr}=0.71 ; D_{A B}=0.000026 \mathrm{~m}^{2} / \mathrm{s} ; v_{a m b}=14.84 \times 10^{-6} \mathrm{~m}^{3} / \mathrm{s} ; k_{a m b}=0.025 \mathrm{~W} / \mathrm{mK} ; \phi_{a m b}=80 \% \\
& p_{a m b}=100230 \mathrm{~Pa} ; u_{w}=3 \mathrm{~m} / \mathrm{s} ; \gamma=0^{\circ} ; T_{a m b}=288.15 \mathrm{~K} ; T_{m k}=290 \mathrm{~K} ; h_{g}=2465900 \mathrm{~J} / \mathrm{kg} \\
& u_{f}=83.95 \times 10^{3} \mathrm{~J} / \mathrm{kg} ; C_{p}=4186.76 \mathrm{~J} / \mathrm{kgK} ; R=8315 \mathrm{~J} / \mathrm{molK} ; M_{a}=18.015 \mathrm{~kg} / \mathrm{mol} \\
& \rho_{a m b}=1.2167 \mathrm{~kg} / \mathrm{m}^{3} ; \rho_{w}=995.95 \mathrm{~kg} / \mathrm{m}^{3} ; \eta_{o}=70 \% ; H_{p}=27 \mathrm{~m} ; T_{d p}=10.84{ }^{\circ} \mathrm{C} .
\end{aligned}
$$

Initial conditions

$$
T_{r p, i n i}=290 \mathrm{~K} ; T_{s t, i n i}=290 \mathrm{~K} ; t_{t o t, i n i}=0 ; \dot{m}_{r c}=1 \mathrm{~kg} / \mathrm{s} ; T_{r f}=295 \mathrm{~K} ; T_{m k}=295 \mathrm{~K}
$$

\section{Pump Energy Equation - Equation 4.15}

The water temperature flowing into the pump equals the temperature of the water leaving the storage tank, i.e.

$T_{p, i}=T_{s t, i n i}=290 \mathrm{~K}$

The shaft input power per unit weight may now be calculated as

$$
\dot{W}_{\text {shaft }}=\frac{\dot{w}_{\text {shaft }}}{\dot{m}_{r c}}=\frac{H_{g}}{\eta_{o}}=\frac{27 \times 9.81}{0.7}=378.4 \mathrm{~J} / \mathrm{kg}
$$

The temperature of the water leaving the pump becomes

$$
T_{p, o}=T_{p, i}+\frac{\left(1-\eta_{o}\right) \dot{w}_{\text {shaft }}}{\dot{m}_{r c} C_{p}}=290+\frac{(1-0.7) \times 378.4}{1 \times 4186.76}=290.023 \mathrm{~K}
$$

\section{Rosin Rammler Distribution}

The roof-spray comprise droplets with various diameters that are distributed in accordance with the Rosin Rammler function. The fraction of the $i i^{\text {th }}$ droplet to the total number of droplets $n_{t o t, R R}$ in the spray is given by $w_{i i}$ and calculated by the Rosin Rammler distribution function, $R R\left(r_{d, i i}, \lambda, k\right)$. The sample calculations performed in Section G.1 is repeated for all the droplets in the spray, i.e. for droplets 0 to $n_{t o t, R R}$ in the Rosin Rammler Distribution. The temperature contribution of each drop size is then weighed in accordance with it's fraction 
$w_{i i}$. The fraction $w_{i i}$ of a droplet with radius $r_{d, i i}$ may be calculated from the Rosin Rammler probability function (equation 4.18), i.e. $R R\left(r_{d, i i}, \lambda, k\right)=\frac{k}{\lambda}\left(\frac{r_{d, i i}}{\lambda}\right) \exp ^{(-x / \lambda)^{k}}$. Take for example the droplet radius $750 \mu \mathrm{m}$ on which the sample calculations were performed in Section G.1. For $\lambda=1500 \mu \mathrm{m}$, a characteristic nozzle $V M D=1200 \mu \mathrm{m}$ and shape factor of $k=2.35$ the Rosin Rammler probability becomes

$$
R R\left(r_{d, i i}, \lambda, k\right)=\frac{2.35}{1500}\left(\frac{1500}{1500}\right)^{2.35-1} \exp ^{\left(-\frac{1500}{1500}\right)^{2.35}}=w_{i i}=0.00576
$$

The temperature contribution of the drop size $r_{d, i i}=750 \mu \mathrm{m}$ to a representative temperature of all the water droplets is calculated by $w_{i i} T_{d, i i}=0.00576 \times 293.3127=1.69 \mathrm{~K}$. Repeating the above for all the droplet diameters in the distribution gives a representative temperature from the roof-spray. From the computer simulation this comes to $T_{d, \text { out }}=296.318 \mathrm{~K}$.

\section{Sub calculations for the Roof-pond Energy Equation - Equation 4.8}

The sub calculations for the roof-pond energy equation includes the calculation of the convection heat transfer, the sky heat transfer, the solar heat gain, the heat transfer due to evaporation and heat transfer to the building below. The calculation of these heat transfer mechanisms are presented below.

\section{Convection Heat Transfer Calculation}

Air properties are evaluated at the film temperature of the roof-pond.

$$
\begin{aligned}
& T_{f}=\left(T_{r p}+T_{a m b}\right)^{1 / 2}=(290+288.15)^{1 / 2}=289.075 \mathrm{~K} \\
& \beta=\frac{1}{T_{f}}=\frac{1}{289.075}=3.46 \times 10^{-3} \mathrm{~K}^{-1} \\
& v_{t f}=14.9 \times 10^{-6} \mathrm{~m}^{2} / \mathrm{s} ; k_{t f}=0.025426 \mathrm{~W} / \mathrm{mK} ; P_{r t f}=0.7098 \\
& \alpha_{t f}=0.000021058 ; \varepsilon_{r p}=0.9
\end{aligned}
$$

Before the heat transfer coefficient may be calculated it must be ascertained whether the convection heat transfer is natural of forced. The Grashof number is calculated by

$$
G r_{L}=\frac{g \beta\left(T_{r p}-T_{a m b}\right) L_{r p}^{3}}{r_{t f}}=\frac{9.81 \times\left(3.46 \times 10^{-3}\right)((290-288.15)) \times 6^{3}}{14.9 \times 10^{-6}}=10^{4.15}
$$

The Reynolds number is calculated as $\operatorname{Re}_{L}=\frac{u_{w} L_{c}}{r_{t f}}=\frac{3 \times 6}{\left(14.9 \times 10^{-6}\right)}=10^{6.082}$ 
$\frac{G r_{L}}{\operatorname{Re}_{L}^{2}}=\left(\frac{10^{4.15}}{\left(10^{6.082}\right)^{2}}\right)=9.746 \times 10^{-9}$

$\frac{G r_{L}}{R e_{L}^{2}}<<1$ thus natural convection is negligible. The value of the critical Reynolds number is $5 \times 10^{5}$ and $x_{c}$ may be calculated from $x_{c}=\frac{R e_{c}}{R e_{L}} \times 6=2.49 \mathrm{~m}$.

Since $\frac{x_{c}}{L}=0.414>0.05$ and $\frac{x_{c}}{L}=0.414<0.95$ the Nusselt number correlation where a transition from laminar to turbulent flow occurs applies, i.e.

$$
\begin{aligned}
& \bar{N} u_{L}=\left(0.037 R e_{L}^{4 / 5}-871\right) \operatorname{Pr}^{1 / 3}=\left(0.037 \times\left(10^{6.082}\right)^{4 / 5}-871\right) 0.71^{1 / 3}=1643.19 \\
& h_{r p}=\frac{\bar{N} u_{L} k_{t f}}{L_{r p}}=\frac{1654.06 \times 0.025}{6}=6.96 \mathrm{~W} / \mathrm{m}^{2} \mathrm{~K} \\
& \bar{S} h_{L}=\left(0.037 R e_{L}^{4 / 5}-871\right) S c^{1 / 3}=\left(\left(0.037 \times 10^{6.082}\right)^{4 / 5}-871\right) 0.5706=1527.84 \\
& h_{r m}=\frac{S h_{L} D_{A B}}{L_{r p}}=1527.84 \times \frac{0.000026}{6}=6.62064 \times 10^{-3} \mathrm{~m} / \mathrm{s}
\end{aligned}
$$

The convection heat transfer now becomes

$\dot{Q}_{r p, c o n v}=h_{r p} A_{r p}\left(T_{r p}-T_{a m b}\right)=6.96 \times 36 \times(290-288.15)=463.76 \mathrm{~W}$

\section{Night Sky Radiation Calculation}

Before $\dot{Q}_{s k y}$ may be calculated, $\varepsilon_{s k y}, T_{s k y}$ and $h_{s k y}$ needs to be determined

$$
\begin{aligned}
\varepsilon_{s k y} & =0.741+0.00162 T_{d p}=0.741+0.00162 \times 10.84=0.7586 \\
T_{s k y} & =\left(\varepsilon_{s k y} T_{a m b}{ }^{4}\right)^{1 / 4}=\left(0.759 \times 288.15^{4}\right)^{1 / 4}=268.92 \mathrm{~K} \\
h_{s k y} & =\varepsilon_{r p} \sigma\left(T_{r p}^{2}+T_{s k y}^{2}\right)\left(T_{r p}+T_{s k y}\right)=0.9 \times 5.67 \times 10^{-8} \times\left(290^{2}+268.92^{2}\right) \times(290+268.92) \\
& =4.46 \mathrm{~W} / \mathrm{m}^{2} \mathrm{~K}
\end{aligned}
$$

The night sky radiation heat loss may now be calculated as

$$
\dot{\mathrm{Q}}_{\text {sky }}=\left(\mathrm{T}_{\mathrm{rp}}-\mathrm{T}_{\text {sky }}\right) \mathrm{h}_{\mathrm{sky}} \mathrm{A}_{\mathrm{rp}}=36 \times 4.46 \times(290-26892)=338614 \mathrm{~W}
$$




\section{Solar Heat Gain}

Since the sample calculations are performed for nocturnal hours, $I_{\text {solar }}$ had a zero value and thus $\dot{Q}_{\text {solar }}=0 \mathrm{~W}$

\section{Evaporation Energy Transfer}

The vapour density at the roof-pond surface is $\rho_{v a p, r p}=1.456 \times 10^{-2} \mathrm{~kg} / \mathrm{m}^{3}$ and the ambient density $\rho_{\text {vap }, a m b}$ evaluated at $T_{a m b}$ is $10.6 \times 10^{-2} \mathrm{~kg} / \mathrm{m}^{3}$

Since $\rho_{v a p, r p}>\rho_{\text {vap,amb }}$ evaporation occurs on the roof-pond surface

$$
\begin{aligned}
\dot{m}_{r p, e v a p} & =h_{m} A_{r p}\left(\rho_{v a p, r p}-\phi_{a m b} \rho_{\text {vap }, a m b}\right) \\
& =\left(6.62064 \times 10^{-3}\right) \times(6 \times 6) \times(0.0146-0.8 \times 0.00106)=9.58 \times 10^{-4} \mathrm{~kg} / \mathrm{s} \\
\dot{Q}_{\text {evap }}= & h_{g} \dot{m}_{r p, \text { evap }}=2465.9 \times 10^{3} \times 9.58 \times 10^{-4}=2294.86 \mathrm{~W}
\end{aligned}
$$

\section{Heat Transfer to the Building}

The convection heat transfer between the roof-pond water and the building below is $h_{r p, w}=135 \mathrm{~W} / \mathrm{m}^{2} \mathrm{k}$ (Jain, 2006). The convection heat transfer to the building may now be calculated as

$$
\begin{aligned}
\dot{Q}_{b u i l d} & =h_{r p, w} A_{r p}\left(T_{r p, w}-T_{r}\right) ; \\
& =135.05 \times(6 \times 6) \times(290-295) \\
& =-24309 \mathrm{~W}
\end{aligned}
$$

\section{Roof-pond Energy Equations}

By substituting the various energy transfer terms as derived above into the energy equation the new roof-pond temperature may be calculated from equation 4.8

$$
\begin{aligned}
& T_{r p}^{\text {new }}=T_{r p}^{\text {old }}+\frac{\Delta t}{m_{d} C_{v}}\left(\dot{Q}_{\text {solar }}-\dot{Q}_{s k y}-\dot{Q}_{\text {build }}-\dot{Q}_{r p, \text { conv }}+h_{f, i} \dot{m}_{r c, i}-h_{f, o} \dot{m}_{r c}+h_{g} \dot{m}_{r p, \text { cond }}-h_{g} \dot{m}_{r p, \text { evap }}\right) \\
& m_{r c, i}=\dot{m}_{r c, i}-\dot{m}_{d, \text { evap }}=1-5.492 \times 10^{-8} \approx 1
\end{aligned}
$$

Evaluate $h_{f, i}$ at $T_{d, \text { out }}$, thus $h_{f, i}=9.71 \mathrm{~kJ} / \mathrm{kg}$

$$
h_{f, 0} \text { at } T_{r p}^{o l d} \text {, thus } h_{f, 0}=70.6 \mathrm{~kJ} / \mathrm{kg}
$$




$$
\begin{aligned}
T_{r p}^{\text {new }} & =290+\frac{360}{3600 \times 4185}\left(0-3386.14-463.757-(-24309)+97.1023 \times 10^{3} \times 1-70.6646 \times 10^{3} \times 1\right. \\
& -2294.8647) \\
& =290.264 \mathrm{~K}
\end{aligned}
$$

\section{Storage Tank Energy Equation}

The make-up water mass flow rate is equal to the sum of the water mass evaporated from the roof-pond and droplet surfaces, i.e.

$\dot{m}_{m w}=\dot{m}_{r p, e v a p}+\dot{m}_{d, \text { evap }}$

where $\dot{m}_{d, \text { evap }}$ represents the rate of evaporation from all the droplets in the roof-spray

$$
\begin{aligned}
& =5.49 \times 10^{-8}+9.58 \times 10^{-4} \mathrm{~kg} / \mathrm{s}=9.58 \times 10^{-4} \mathrm{~kg} / \mathrm{s} \\
& T_{s t}^{\text {new }}=T_{s t}^{o l d}+\frac{\Delta t}{m_{s t}}\left(T_{w, i} \dot{m}_{r c, i}+T_{m w} \dot{m}_{m w}-T_{w, o} \dot{m}_{r c, o}\right) \\
& \quad=290+\frac{360}{500}\left(290.12 \times\left(1-9.58 \times 10^{-4}\right)+295 \times 9.58 \times 10^{-4}-290 \times 1\right)=290.19 \mathrm{~K} \\
& t_{t o t, n}=0+360 / 60=5 \mathrm{~min}
\end{aligned}
$$

The calculations from the pump energy equation to the storage tank equation are repeated until $t_{t o t, n}=1$ hour. Values for $T_{p u m p}, T_{d, o u t}, T_{r p}$ and $T_{s t}$ from these calculations are given in the table below.

Table G.1: Temperature Values for the Roof Cooling System

\begin{tabular}{|c|c|c|c|c|c|c|c|c|c|c|c|}
\hline Time(min) & 0 & 6 & 12 & 18 & 24 & 30 & 36 & 42 & 48 & 54 & 60 \\
\hline$T_{p u m p}(\mathrm{~K})$ & 290 & 290.27 & 290.23 & 290.55 & 290.84 & 291.09 & 291.25 & 291.45 & 291.54 & 291.68 & 271.72 \\
\hline$T_{d, o}(\mathrm{~K})$ & 290 & 288.56 & 288.70 & 288.9 & 289.09 & 289.25 & 289.37 & 289.4 & 289.56 & 289.62 & 289.67 \\
\hline$T_{r p}(\mathrm{~K})$ & 290 & 290.26 & 290.63 & 290.9 & 291.15 & 291.33 & 291.48 & 291.59 & 291.68 & 291.76 & 291.8 \\
\hline$T_{s t}(\mathrm{~K})$ & 290 & 290.19 & 290.51 & 290.80 & 291.05 & 291.25 & 291.41 & 291.54 & 291.64 & 291.72 & 291.79 \\
\hline
\end{tabular}

The increase in $T_{r p}$ and $T_{s t}$ may be ascribed to the warmer roof surface temperature of $295 \mathrm{~K}$. 


\section{G.3 Sample Calculations for the One-Room Building Cooling load}

The one-room building flowchart as given in figure 5.12 comprises three calculation loops namely Loop3_min, Loop2_hrs and Loop1_day. Loop3_min performs cooling load calculations on the one-room building at minute intervals for a duration of one hour. Loop2_hrs repeats the hourly calculations of Loop3_min for a time period of 24 hours while Loop1_day performs the calculations for a preselected number of days. To illustrate the calculation procedure, the calculations will be presented for a minute in the $10^{\text {th }}$ hour of a day. The one-room building properties as presented in Appendix B, applies.

The initial room temperature at the start of the $10^{\text {th }}$ hour is taken as:

$T_{r m}=22.15^{\circ} \mathrm{C}=299.15 \mathrm{~K}, T_{s k y}=280.69 \mathrm{~K}$

Initial temperatures of nodes in the control volumes of the northern wall and roof slab are taken as presented the below.

$\begin{array}{ccc}\text { Node Index } & \text { Temperature, } T_{w l, N, i} & \text { Temperature, } T_{r s, i} \\ 0 & 300.234 \mathrm{~K} & 301.324 \mathrm{~K} \\ 1 & 298.17 \mathrm{~K} & 298.59 \mathrm{~K} \\ 2 & 296.83 \mathrm{~K} & 296.49 \mathrm{~K} \\ 3 & 296.17 \mathrm{~K} & 294.994 \mathrm{~K} \\ 4 & 296.01 \mathrm{~K} & 294.05 \mathrm{~K} \\ 5 & 296.16 \mathrm{~K} & 293.53 \mathrm{~K} \\ 6 & 296.424 \mathrm{~K} & 293.31 \mathrm{~K} \\ 7 & 296.7 \mathrm{~K} & 293.28 \mathrm{~K} \\ 8 & 296.9 \mathrm{~K} & 293.33 \mathrm{~K} \\ 9 & 296.993 \mathrm{~K} & 293.414 \mathrm{~K} \\ 10 & 296.96 \mathrm{~K} & 293.5 \mathrm{~K}\end{array}$

The incident solar radiation on the northern wall and horizontal roof slab is calculated with the procedure outlined in Appendix E. These values of 03 March 2009 at 10:00 in the morning are presented below. 


\begin{tabular}{|c|c|c|c|c|c|c|}
\hline & $\begin{array}{l}\text { Ground Reflected } \\
\text { Radiation } I_{\text {solar }, r}\end{array}$ & Solar & $\begin{array}{l}\text { Diffuse } \\
I_{\text {solar }, d}\end{array}$ & Solar & Radiation & $\begin{array}{ll}\text { Direct } & \text { Normal } \\
\text { Radiation } & I_{\text {solar }, D N}\end{array}$ \\
\hline Northern Wall & $72.55 \mathrm{~W} / \mathrm{m}^{2}$ & & 69.854 & $\mathrm{~W} / \mathrm{m}^{2}$ & & $265.7 \mathrm{~W} / \mathrm{m}^{2}$ \\
\hline $\begin{array}{l}\text { Horizontal Roof } \\
\text { slab }\end{array}$ & $0 \mathrm{~W} / \mathrm{m}^{2}$ & & 100.19 & $\mathrm{~W} / \mathrm{m}^{2}$ & & $625.34 \mathrm{~W} / \mathrm{m}^{2}$ \\
\hline
\end{tabular}

The ambient air properties $T_{a m b}=299.95 \mathrm{~K}$ are as follows

$\rho_{a m b}=1.162 \mathrm{~kg} / \mathrm{m}^{3} ; C_{p a}=1005 \mathrm{~kJ} / \mathrm{kgK} ; \omega=1.2139 \times 10^{-2} C_{p v}=1820 \mathrm{~kJ} / \mathrm{kg}$

$v=6 \times 6 \times 3=108 \mathrm{~m}^{3}$;

Under the base case conditions the natural air changes per hour is 0.25 , thus $\dot{V}=0.0075 \mathrm{~m}^{3} / \mathrm{s}$

\section{Cooling Load Calculations for the Base Case}

The cooling load calculation includes the calculation of the various heat transfer mechanisms to the air in the one-room building. These heat transfer mechanisms include the infiltration heat gain, the heat gain through the walls, the heat gain through the roof slab, the heat gain from people, the heat gain from the window, the lighting and equipment heat gain. Once all these heat gains are calculated they are used in equation 5.3 to calculate the room air temperature.

\section{Evaporation Energy Transfer}

The infiltration load may be calculated from equation 5.43

$$
\begin{aligned}
\dot{Q}_{h i f} & =\rho_{a} \dot{V}\left(C_{p, a}+\omega C_{p, v a p}\right) \Delta T \\
& =1.162 \times 0.0075 \times\left(1005+1.214 \times 10^{-2} \times 1820\right) \times(299.95-295.15)=42.95 \mathrm{~W}
\end{aligned}
$$

\section{Heat Gain through the Walls}

The heat gain through the walls will be illustrated by calculating the heat transmitted through the northern wall. From Appendix B the following properties for the brick wall are obtained

$k_{s b w}=0.72 \mathrm{~W} / \mathrm{mK}, C_{s b w}=835 \mathrm{~J} / \mathrm{kgK} \rho_{s b w}=1920 \mathrm{~kg} / \mathrm{m}^{3}, h=0.023 \mathrm{~m}, L_{\text {build }}=6 \mathrm{~m}$.

The outside surface film temperature of the northern wall is calculated by

$T_{f}=(299.95+300.23) \times 0.5=300.091 \mathrm{~K}$

From the film temperature the air properties may be evaluated as

$$
v_{t f}=1.59 \times 10^{-5} \mathrm{~m}^{2} / \mathrm{s} ; \quad P_{r}=0.707 ; \quad k_{a m b}=0.026 \mathrm{~W} / \mathrm{mK} ;
$$


$\operatorname{Re}_{c}=5 \times 10^{5}$ (Incropera and Dewitt, 2002)

$\operatorname{Re}_{L}=\frac{u_{w} L}{v_{t f}}=\frac{3 \times 6}{1.583 \times 10^{-3}}=10^{6.054} ; x_{c}=L \times \frac{\operatorname{Re}_{c}}{\operatorname{Re}_{L}}=6 \times \frac{5+10^{5}}{10^{6.054}}=2.647$

Since $\frac{x_{c}}{L}<0.95$ and $\frac{x_{c}}{L}>0.05$ the Nusselt number correlation where a transition from laminar to turbulent flow occurs, applies. The Nusselt number is calculated by equation C.52 $\bar{N} u_{L}=\left(0.037 \operatorname{Re}_{L}^{4 / 5}-871\right) \operatorname{Pr}^{1 / 3}=1520.87$

The outside wall heat transfer coefficient is calculated from the Nusselt number $h_{\text {cconv_o }}=\bar{N} u_{L} \times \frac{k_{a m b}}{L}=1520.87 \times \frac{0.0263}{6}=6.68 \mathrm{~W} / \mathrm{m}^{2} \mathrm{~K}$

The wall thermal diffusivity is calculated as $\alpha_{s b w}=\frac{k_{s b w}}{\rho_{s b w} C_{s b w}}=\frac{0.72}{1920 \times 835}=4.49 \times 10^{-7}$ and the Fourier number by $F o=\frac{\alpha_{s b w} \Delta t}{h^{2}}=\frac{\left(4.49 \times 10^{-7}\right) \times 60}{0.023^{2}}=5.094 \times 10^{-2}$

The outside wall surface temperature for the base case may now calculated from equation 5.14, i.e.

$$
\begin{aligned}
& T_{0}^{n+1}=2 F o T_{1}^{n}+\left(1-2 F o-\frac{2 h F o \varepsilon_{w l} \sigma T_{0}^{n^{3}}}{k_{s b w}}-\frac{2 h F o h_{c o n v_{-} o}}{k_{s b w}}\right) T_{0}^{n}+\left(\frac{2 h F o h_{c o n v_{-} o}}{k_{s b w}}+\frac{2 h F o \varepsilon_{w l} \sigma T_{a m b}^{3}}{k_{s b w}}\right) T_{a m b} \\
& \quad+\frac{2 h F o \alpha_{\text {solar }, \text { } w l} I_{\text {solar }, \text { tot }}}{k_{s b w}} \\
& =2 \times\left(5.094 \times 10^{-2}\right) \times 298.17+\left(1-2 \times\left(5.094 \times 10^{-2}\right)_{-}\right. \\
& \left.-\frac{2 \times 0.023 \times\left(5.094 \times 10^{-2}\right) \times 0.9 \times 5.67 \times 10^{-8} \times 300.23^{3}}{0.72}-\frac{2 \times 0.023 \times\left(5.054 \times 10^{-2}\right) \times 6.67}{0.72}\right) \times 300.23- \\
& +\left(\frac{2 \times 0.023 \times 5.0937 \times 10^{-2} \times 6.67}{0.72}+\frac{2 \times 0.023 \times 5.094 \times 10^{-2} \times 0.9 \times 5.67 \times 10^{-8} \times 299.95^{3}}{0.72}\right) \times 299.95 \\
& +\left(\frac{2 \times 0.023 \times 5.094 \times 10^{-2} \times 0.45 \times(72.552+265.7+69.85)}{0.72}\right) \\
& =300.61 \mathrm{~K}
\end{aligned}
$$

The above calculation is repeated for all the nodes of the western, eastern and southern walls. The temperatures of the internal nodes are calculated from equation 5.5. The temperature calculation for the first node of the northern wall is illustrated below.

$T_{1}^{n+1}=F o T^{n}+(1-2 F o) T_{1}^{n}+F o T_{2}^{n}$ 


$$
\begin{aligned}
& =\left(5.0937 \times 10^{-2}\right) \times 300.23+\left(1-2 \times 5.094 \times 10^{-2}\right) \times 298.17+\left(5.094 \times 10^{-2}\right) \times 296.83 \\
& =298.204 \mathrm{~K}
\end{aligned}
$$

The above calculation is repeated for temperature nodes 2 to 9 .

Before the inside wall surface temperature can be calculated, the convection coefficient needs to be determined. This is done from the Nusselt number. Evaluating the air properties at the inner wall film temperature

$T_{r}=295.15 \mathrm{~K} ; \quad T_{M}=T_{10}=296.2 \mathrm{~K} ; \quad T_{f}=(295.15+296.96) \times 0.5=296.05 \mathrm{~K}$ $\beta=\frac{1}{T_{f}}=3.3777 \times 10^{-3} ; k_{t f}=0.0259 \mathrm{~W} / \mathrm{mK} ; \operatorname{Pr}=0.708 ; v_{t f}=1.55 \times 10^{-5} \mathrm{~m}^{2} / \mathrm{s}$

The inner wall convection coefficient is calculated from natural convection correlations

$G r_{L}=\frac{g \beta\left(T_{M}-T_{r}\right) L^{3}}{v_{t f}^{2}}=\frac{9.81 \times\left(3.382 \times 10^{-3}\right) \times(296.96-295.15) \times 6^{3}}{\left(1.55 \times 10^{-5}\right)^{2}}=10^{10.73}$

$R a_{L}=G r_{L} \operatorname{Pr}=10^{10.8} \times 0.708=10^{10.579}$

$N u_{L}=\left(0.825+\frac{0.387 \times R a_{L}^{1 / 6}}{\left[1+(0.492 / \operatorname{Pr})^{9 / 16}\right]^{8 / 27}}\right)^{2}$

$N u_{L}=\left(0.825+\frac{0.387 x\left(10^{10.579}\right)^{1 / 6}}{\left[1+(0.492 / 0.708)^{9 / 16}\right]^{8 / 27}}\right)^{2}=385.29$

$h_{c o n v, i}=\frac{\bar{N} u_{L} \times k_{r m, a}}{L}=\frac{405.863 \times 0.0259}{6}=1.67 \mathrm{~W} / \mathrm{m}^{2} \mathrm{~K}$

The inside wall surface temperature may be calculated from equation 5.19

$$
\begin{aligned}
T_{M s}^{n+1} & =2 F o T_{M-1}^{n}+\left(1-2 F o-\frac{2 h F o h_{c o n v, i}}{k_{s b w}}\right) T_{M}^{n}+\frac{2 h F o h_{c o n v, i}}{k_{s b w}} T_{r m} \\
& =2\left(5.094 \times 10^{-2}\right) 296.993+\left(1-2 \times 5.094 \times 10^{-2}-\frac{2 \times 0.023 \times 1.67 \times 5.094 \times 10^{-2}}{0.72}\right) 296.96 \\
& +\left(\frac{2 \times 0.023 \times 5.094 \times 10^{-2} \times 1.67}{0.72}\right) 295.15 \\
& =296.95 \mathrm{~K}
\end{aligned}
$$

The above calculation is repeated for all the nodes of the northern, eastern, western and southern walls. 
Heat transferred to the room air may be calculated from equation 5.20, i.e.

$$
\begin{aligned}
\dot{Q}_{w, t r} & =h_{\text {conv }, i} A_{w l}\left(T_{M}-T_{r m}\right) \\
& =1.67 \times(6 \times 6-1.21 \times 1) \times(296.952-295.15) \\
& =50.53 \mathrm{~W}
\end{aligned}
$$

The above calculation is repeated for all walls of the one-room building. For the eastern, southern and western walls the heat transfer were calculated as $49.8 \mathrm{~W}, 12.59 \mathrm{~W}$, $68.42 \mathrm{~W}$ respectively.

\section{Roof Slab Heat Gain}

From Appendix B, the roof slab properties are $k_{r s}=1.1 \mathrm{~W} / \mathrm{mK}, \rho_{r s}=2100 \mathrm{~kg} / \mathrm{m}^{3}$ and $C_{r s}=$ $880 \mathrm{~J} / \mathrm{kgK}$. The control volume thickness is $h_{s}=0.02 \mathrm{~m}$. The thermal diffusivity and Fourier number are calculated as

$$
\alpha_{r s}=\frac{k_{r s}}{\rho_{r s} C_{r s}}=\frac{1.1}{2100 \times 880}=5.95 \times 10^{-7} \text { and } F o=\frac{\alpha_{r s} \Delta t}{h_{s}^{2}}=\frac{\left(5.95 \times 10^{-7}\right) \times 60}{0.02^{2}}=8.93 \times 10^{-2}
$$

At the outside surface of the roof slab the film temperature is calculated as $T_{f}=(299.95+301.324) \times 0.5=300.64 K$. Evaluating the air properties at this film temperature gives

$v_{t f}=1.595 \times 10^{-5} \mathrm{~m}^{2} / \mathrm{s} ; k_{\text {amb }}=0.026 \mathrm{~W} / \mathrm{mK} ; \operatorname{Pr}=0.707$.

The Nusselt number on the outside roof slab is calculated similarly to that of the outer wall; $N u_{L}=1514.5$. From this Nusselt number the outside convection coefficient is calculated as

$$
h_{\text {conv_o }}=\frac{N u_{L} k_{t f}}{L}=\frac{1514.5 \times 0.026}{6}=6.65 \mathrm{~W} / \mathrm{m}^{2} \mathrm{~K}
$$

The temperature at the outer roofslab surface is calculated by equation 5.21 , i.e

$$
\begin{aligned}
T_{0}^{n+1}= & 2 F o T_{1}^{n}+\left(1-2 F o-\frac{2 h F o \varepsilon_{r s} \sigma T_{0}^{3}}{k_{r s}}-\frac{2 h F o h_{r, c o}}{k_{r s}}\right) T_{0}^{n}+\frac{2 h F o h_{c o n v, r s, o}}{k_{r s}} \\
& +\frac{2 h F o \alpha_{\text {solar } r s s} I_{\text {solar }, \text { tot }}}{k_{r s}}+\frac{2 h F o \varepsilon_{r s} \sigma T_{s k y}^{4}}{k_{r s}} \\
= & 2 \times\left(8.93 \times 10^{-2}\right) 298.59+\left(1-2\left(8.93 \times 10^{-2}\right)-\frac{2 \times 0.02 \times 8.93 \times 10^{-2} \times 0.91 \times 5.67 \times 10^{-8} \times 301.324^{3}}{1.1}\right. \\
- & \left.\frac{2 \times 0.02 \times\left(8.93 \times 10^{-2}\right) \times 6.464}{1.1}\right) 301.324+\left(\frac{2 \times 0.02 \times\left(8.93 \times 10^{-2}\right) 6.46}{1.1}\right) 299.95
\end{aligned}
$$




$$
\begin{aligned}
& +\frac{2 \times 0.02 \times\left(8.93 \times 10^{-2}\right) 0.6 \times(0+625.37+100.188)}{1.1} \\
& +2 \times 0.02 \times\left(8.93 \times 10^{-2}\right) \times 0.91 \times 5.67 \times 10^{-8} \times 280.69^{4} \\
& =301.88 \mathrm{~K}
\end{aligned}
$$

At the inner slab control volumes, the temperature is calculated from equation 5.5. The calculation for the first control is shown here

$$
\begin{aligned}
T_{1}^{n+1} & =F o T_{0}^{n}+(1-2 F o) T_{1}^{n}+F o T_{2}^{n} \\
T_{1} & =\left(8.93 \times 10^{-2}\right) \times 301.324+\left(1-2 \times 8.93 \times 10^{-2}\right) \times 298.59+\left(8.93 \times 10^{-2}\right) \times 296.48 \\
& =298.64 \mathrm{~K}
\end{aligned}
$$

The above calculation of the inner roof slab temperature is repeated for all the inner control volumes of the roof slab. Before the inside roof slab surface temperature can be calculated, the convection coefficient needs to be determined from the Nusselt number. The film temperature at the inner roof slab surface is calculated as the average between the inner roof slab temperature and the room temperature. For $T_{r s}=293.49 \mathrm{~K}$ and $T_{r m}=295.95 \mathrm{~K}$ the film temperature becomes

$T_{f}=(295.15+293.49) \times 0.5=294.32 \mathrm{~K} ;$

Evaluating properties at this film temperature

$\beta=3.3976 \mathrm{~K}^{-1} v_{\text {tf }}=1.538 \times 10^{-5} \mathrm{~m}^{2} / \mathrm{s} ; \operatorname{Pr}=0.708$

The inner wall convection coefficient is calculated from natural convection correlations

$$
\begin{aligned}
& G r_{L}=\frac{g \beta\left(T_{r s}-T_{r m}\right) L^{3}}{v^{2}}=\frac{9.81 \times 3.3976 \times(293.48-295.15) \times 1.5^{3}}{\left(1.538 \times 10^{-5}\right)^{2}}=10^{8.89} \\
& R a_{L}=G r_{L} \operatorname{Pr}=10^{8.89} \times 0.708=10^{8.74} \\
& N u_{L}=0.15 R a_{L}^{1 / 3}=0.15 \times\left(10^{8.74}\right)^{1 / 3}=123.62 \\
& h_{c_{-} o}=\frac{N u_{L} \times k_{t f}}{L}=\frac{123.62 \times 0.0258}{1.5}=2.13 \mathrm{~W} / \mathrm{m}^{2} \mathrm{~K}
\end{aligned}
$$

The temperature at the inner control volume is now calculated from equation 5.26

$$
T_{M_{s}}^{n+1}=2 F o T_{M s-1}^{n}+\left(1-2 F o-\frac{2 h F o h_{r, c o}}{k_{r s}}\right) T_{M s}^{n}+\left(\frac{2 h F o h_{c o n v, r s, o}}{k_{r s}}\right) T_{r m}
$$




$$
\begin{aligned}
& =2 \times 8.93 \times 10^{-2} \times 293.14+\left(1-2 \times 8.93 \times 10^{-2}-\frac{2 \times 0.02 \times 8.93 \times 10^{-2} \times 3.15}{1.1}\right) 293.5 \\
& +\left(\frac{2 \times 0.02 \times 8.93 \times 10^{-2} \times 3.15}{1.1}\right) 295.15 \\
& =293.49 \mathrm{~K}
\end{aligned}
$$

The heat transferred from the roof to the space air is calculated from equation 5.27

$Q_{r s, t r}=A_{r p} h_{c o n v, r s, i}\left(T_{r s}-T_{r m}\right)=6 \times 6 \times 2.13 \times(293.49-295.15)=-127.6 \mathrm{~W}$

\section{Heat Gain from People}

The heat released from the person occupying the one-room building is assumed $q_{p i}=66$ $\mathrm{W} / \mathrm{m}^{2}$. The instantaneous heat gain from the radiation energy released from the person in the one-room building is 58\% of the total heat released (Ashrae Fundamentals, 2005). This instantaneous radiation energy release may be calculated from equation 5.47, i.e

$\dot{Q}_{h_{p, r a d}, i}=0.58 N_{p} F_{p o} \dot{q}_{p, i}=0.58 \times 1 \times 1 \times 66=38.28 \mathrm{~W}$

The radiation energy release for the remaining hours of the day is given below. These values where generated from the computer simulation program for an occupancy schedule of 07:00 to 19:00.

$$
\begin{aligned}
& \dot{Q}_{9 p, \text { rad }, i}=38.38 \mathrm{~W} \quad \dot{Q}_{24 p, r a d}=0 \mathrm{~W} \quad \dot{Q}_{15 p, \text { rad }}=38.38 \mathrm{~W} \\
& \dot{Q}_{8 p, r a d}=38.38 \mathrm{~W} \quad \dot{Q}_{23 p, r a d}=0 \mathrm{~W} \quad \dot{Q}_{14 p, r a d}=38.38 \mathrm{~W} \\
& \dot{Q}_{7 p, r a d}=38.38 \mathrm{~W} \quad \dot{Q}_{22 p, r a d}=0 \mathrm{~W} \quad \dot{Q}_{13 p, r a d}=38.38 \mathrm{~W} \\
& \dot{Q}_{6 p, \text { rad }}=38.38 \mathrm{~W} \quad \dot{Q}_{21 p, \text { rad }}=0 \mathrm{~W} \quad \dot{Q}_{12 p, r a d}=38.38 \mathrm{~W} \\
& \dot{Q}_{5 p, r a d}=11.49 \mathrm{~W} \quad \dot{Q}_{20 p, r a d}=0 \mathrm{~W} \quad \dot{Q}_{11 p, r a d}=38.38 \mathrm{~W} \\
& \dot{Q}_{4 p, r a d}=0 \mathrm{~W} \quad \dot{Q}_{19 p, r a d}=0 \mathrm{~W} \\
& \dot{Q}_{3 p, r a d}=0 \mathrm{~W} \quad \dot{Q}_{18 p, r a d}=11.49 \mathrm{~W} \\
& \dot{Q}_{2 p, r a d}=0 \mathrm{~W} \quad \dot{Q}_{17 p, r a d}=38.38 \mathrm{~W} \\
& \dot{Q}_{1 p, \text { rad }}=0 \mathrm{~W} \quad \dot{Q}_{16 p, \text { rad }}=38.38 \mathrm{~W}
\end{aligned}
$$

The radiation cooling load for the current hour may be calculated from equation 5.46. The radiant time factors may be found in table 5.2.

$\dot{Q}_{h p, r a d}=r_{0} \dot{Q}_{h p, r a d, i}+r_{1} \dot{Q}_{h-1 p, r a d, i}+r_{2} \dot{Q}_{h-2 p, r a d, i}+r_{3} \dot{Q}_{h-3 p, r a d, i}+\ldots+r_{23} \dot{Q}_{h-23 p, r a d, i}$ 


$$
\begin{aligned}
& =(0.46 \times 38.28)+(0.18 \times 38.28)+(0.1 \times 38.28)+(0.06 \times 38.28)+(0.04 \times 11.484)+(0.04 \times 38.28) \\
& +(0.02 \times 0)+(0.01 \times 0)+(0.01 \times 0)+(0.01 \times 0)+(0.01 \times 0)+(0.01 \times 0)+(0.01 \times 0)+(0.01 \times 0) \\
& +(0.01 \times 0)+(0.01 \times 0)+(0.01 \times 11.484)+(0.01 \times 38.28)+(0.01 \times 38.28)+(0.01 \times 38.28)+(0 \times 38.28) \\
& +(0 \times 38.28)+(0 \times 38.28)+(0 \times 38.28)+(0 \times 38.28) \\
& =31.96 \mathrm{~W}
\end{aligned}
$$

The convection cooling load makes up $42 \%$ of the total instantaneous heat released and is calculated by equation 5.45

$$
\dot{Q}_{h p, c o n v}=0.42 N_{p} F_{p o o} \dot{q}_{p, i}=0.42 \times 1 \times 1 \times 66=27.72 \mathrm{~W}
$$

For the current hour, the total heat released from the person comprises the radiation and convection components. This is calculated from equation 5.40

$\dot{Q}_{h p, t o t}=\dot{Q}_{h p, \text { conv }}+\dot{Q}_{h p, r a d}=27.72+31.96=59.68 \mathrm{~W}$

\section{Heat Gain from Lighting}

The calculation of the cooling load from lighting is similar to the cooling load calculation from people. The heat released from the lighting comprises a radiation and a convection component. For the one-room building a lighting load $\dot{q}_{l}$ of $5 \mathrm{~W} / \mathrm{m}^{2}$ is assumed. The convection heat released is $33 \%$ of the total heat released and may be calculated by substituting equation 5.36 into equation 5.37. This becomes

$$
\dot{Q}_{h l, c o n v}=0.33 \dot{q}_{l} A_{f l} F u_{l}=0.33 \times 5 \times 36 \times 1=59.4 \mathrm{~W}
$$

The instantaneous heat gain from lighting is the remaining $67 \%$ of the total heat gain and may be calculated from equation 5.38

$$
\dot{Q}_{h l, r a d, i}=0.67 \dot{q}_{l} A_{f l} F u_{l}=0.67 \times 5 \times 36 \times 1=120.6 \mathrm{~W}
$$

Similar to the calculation of the cooling load for people, the radiation component of the cooling load for lighting is calculated by applying the non solar radiant time factors to the instantaneous radiation heat gain $\dot{Q}_{h l, \text { rad }, i}$. This gives a radiation cooling load $\dot{Q}_{h l, \text { rad }}$ of 100.7 W. The total cooling load comprises the convection and radiation load calculated from equation 5.40 becomes

$\dot{Q}_{h l, t o t}=\dot{Q}_{h l, r a d}+\dot{Q}_{h l, c o n v}=100.7+59.4=160.101 \mathrm{~W}$

\section{Heat Gain through Window}

The radiation heat transfer through the window comprises direct beam solar radiation, diffuse solar radiation as well as heat gain through the window by means of conduction and convection. At 10:00 in the morning the solar incident angle, $\theta_{\text {solar }}$, is $73.7^{\circ}$ for a north facing wall. The $S H G C$ that corresponds to this angle is 0.535 (ASHRAE Fundamentals, 2005). The $S H G C$ corresponding to diffuse incident solar radiation is 0.73 . The IAC for the 
one-room building is 0.68 . The direct beam solar heat gain is calculated from equation 5.29, i.e

$$
\begin{aligned}
\dot{Q}_{h_{w d, b}} & =A_{w d} I_{\text {solar }, b} \operatorname{SHGC}\left(\theta_{\text {solar }}\right) I A C \\
& =1.2 \times 1 \times 265.7 \times 0.73 \times 0.68=115.93 \mathrm{~W}
\end{aligned}
$$

The diffuse and ground reflected solar heat gain is calculated from equation 5.30

$$
\begin{aligned}
\dot{Q}_{h_{w d}, d} & =A_{w d}\left(I_{\text {solar }, d}+I_{\text {solar }, r}\right) S H G C(d) I A C \\
& =1.2 \times 1 \times(69.85+72.55) \times 0.73 \times 0.68=84.83 \mathrm{~W}
\end{aligned}
$$

Heat Gain through the window due to conduction and convection is calculated from equation 5.31, i.e

$$
\begin{aligned}
\dot{Q}_{h_{w d}, c o n d} & =U_{w d} A_{w d}\left(T_{a m b}-T_{r m}\right) \\
& =5.24 \times 1.2 \times 1 \times(299.95-295.15)=30.182 \mathrm{~W}
\end{aligned}
$$

The portion of the window heat gain that becomes an actual cooling load in the current hour is $37 \%$. Applying equation 5.32 gives

$$
\dot{Q}_{h_{w d, c o n v}}=0.37\left(\dot{Q}_{h_{w d, b}}+\dot{Q}_{h_{w d, d}}+\dot{Q}_{h_{w d, c o n d}}\right)=0.37(115.93+84.83+30.182)=85.45 \mathrm{~W}
$$

The instantaneous radiative portion forms $63 \%$ of the total heat gain, i.e

$$
\dot{Q}_{h_{w d, r a d, i}}=0.63\left(\dot{Q}_{h_{w d, b}}+\dot{Q}_{h_{w d, d}}+\dot{Q}_{h_{w d, c o n d}}\right)=0.63(115.93+84.83+30.182)=145.5 \mathrm{~W}
$$

The actual radiative cooling load from the window is calculated by the application of the non solar radiative time series similar to the way it has been applied to the radiative cooling load from people. This gives $\dot{Q}_{h_{w d}, \text { rad }}=81.35 \mathrm{~W}$. The total load through the window may now be calculated from equation 5.35

$$
\dot{Q}_{h_{w d, t o t}}=\dot{Q}_{h_{w d, r a d}}+\dot{Q}_{h_{w d, c o n v}}=81.35+85.45=166.8 \mathrm{~W}
$$

\section{Total Heat Transferred to the One-Room Building for the Base Case}

The total heat transfer to the one-room building is calculated by adding the heat gains as calculated in the previous sections, i.e

$$
\begin{aligned}
\dot{Q}_{t o t} & =\dot{Q}_{h i f}+\dot{Q}_{r s, t r}+\dot{Q}_{w l, t r}+\dot{Q}_{h p, t o t}+\dot{Q}_{h w d, t o t}+\dot{Q}_{h l, t o t}+\dot{Q}_{h e, t o t} \\
& =42.95-127.6+(50.52+49.78+12.59+68.419)+59.68+166.8+160.1+5 \\
& =488.26 \mathrm{~W}
\end{aligned}
$$

\section{Room Temperature for the Next Time Step $(\Delta t=60 \mathrm{~s})$}

The room temperature for the next time step may now be calculated from equation 5.3

$$
\text { G-18 }
$$


$T_{r m}^{n+1}=T_{r m}^{n}+\frac{\Delta t}{m_{r m, a} C_{r m, a}} \times \dot{Q}_{t o t}=295.15+\frac{60}{132.84 \times 1044.75} \times 488.26=295.36 \mathrm{~K}$

\section{Sample Calculations for Night Flushing}

With the application of night flushing ambient air is circulated through the building between 24:00 and 07:00. The infiltration load is calculated from equation 5.43

$\dot{Q}_{h_{i f}}=\rho_{a} \dot{V}\left(C_{p, a}+\omega C_{p, v a p}\right) \Delta T$

where $\dot{V}$ denotes the night flushing air flow rate.

For an air change rate of $32 \mathrm{ACH}, \dot{V}=\frac{32 V_{r m}}{3600}=0.96 \mathrm{~m}^{3} / \mathrm{s}$.

Take for example the infiltration load at 01:00 in the morning. $T_{a m b}=289.35 \mathrm{~K}$ and $T_{r m}=292.5 \mathrm{~K}$. The corresponding room air properties are $\rho_{a}=1.21 \mathrm{~kg} / \mathrm{m}^{3} ; C_{p, a}=1005$ $\mathrm{J} / \mathrm{kg} ; C_{p, v a p, a}=1820 \mathrm{~J} / \mathrm{kg}$ and $\omega=9.3697 \times 10^{-3} \mathrm{~kg} / \mathrm{kg}$. The infiltration load under these conditions become

$$
\begin{aligned}
\dot{Q}_{h i f} & =\rho_{a} \dot{V}\left(C_{p, a}+\omega C_{p, v a p}\right) \Delta T \\
& =1.211 \times 0.96 \times\left(1005+9.37 \times 10^{-3} \times 1820\right)(289.35-292.662) \\
& =-3741.55 \mathrm{~W}
\end{aligned}
$$

When night flushing is applied the heat transfer from the walls and roof slab is calculated similarly to the way illustrated for the base case. The only difference is that the room air temperature is much lower resulting in increased heat transfer rates. Repeating the cooling load calculation procedure for the one-room building under the same base case conditions with $T_{r m}=292.5 \mathrm{~K}$ and $T_{a m b}=289.35 \mathrm{~K}$ gives
$\dot{Q}_{h i f}=-3741.55 \mathrm{~W}$
$\dot{Q}_{w l, t r, N}=355.22 \mathrm{~W}$
$\dot{Q}_{w l, t r, E}=353.03 \mathrm{~W}$
$\dot{Q}_{w l, t r, S}=243.59 \mathrm{~W}$
$\dot{Q}_{w l, t r, W}=412.3 \mathrm{~W}$
$\dot{Q}_{r s, t r}=1146 \mathrm{~W}$
$\dot{Q}_{h p, t o t}=4.32 \mathrm{~W}$
$\dot{Q}_{h l, t o t}=13.62 \mathrm{~W}$
$\dot{Q}_{h w d, t o t}=3.013 \mathrm{~W}$
$\dot{Q}_{h e, t o t}=0 \mathrm{~W}$
$\dot{Q}_{\text {tot }}=-1210.47 \mathrm{~W}$

The room temperature for the next step is now calculated

$$
\begin{aligned}
T_{r m}^{n+1} & =T_{r m}^{n}+\frac{\Delta t}{m_{r m, a}\left(C_{p, r m}+\omega_{r m} C_{p, v a p}\right)} \times \dot{Q}_{t o t} \\
& =292.662+\frac{60}{132 \times\left(1022+9.3697 \times 10^{-3} \times 1820\right)} \times(-1204.47)
\end{aligned}
$$




$$
=291.973 \mathrm{~K}
$$

\section{Sample Calculations for Active Mass Cooling}

When active mass cooling is applied to the one-room building water is circulated through pipes embedded in the roof slab. Heat is transferred from the roof slab to the water and the roof slab is cooled. The roof slab acts as a heat sink, reducing the heat entry to the one-room building. The roof slab is partitioned into 6 control volumes along the route of the embedded pipes (refer to figure 5.7). The temperature of the water flowing into the pipe embedded in the first control volume is $T_{w, i}=15^{\circ} \mathrm{C}$.

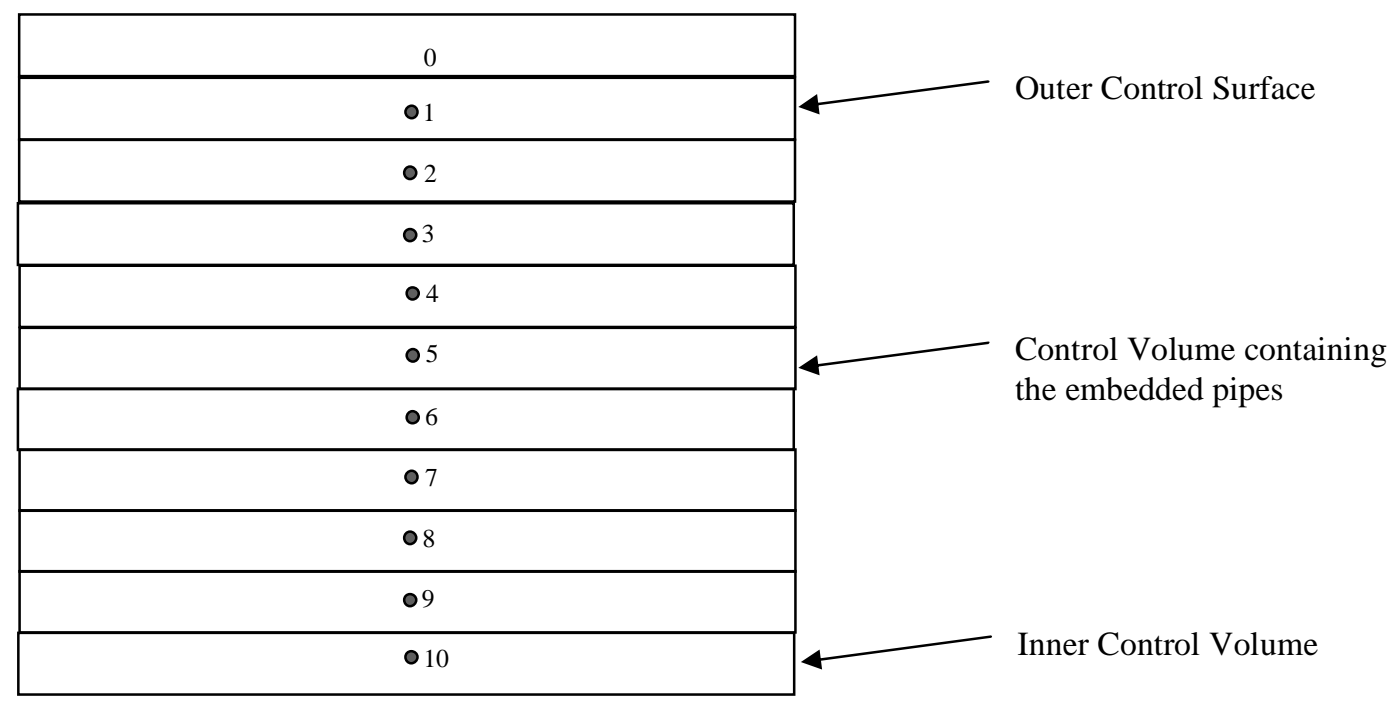

Figure G.2: Cross Section of Roof Slab that Depicts Ten Control Volumes and Temperature Nodes

Figure G.2 gives a cross section of the roof slab with eleven control volumes and corresponding temperature nodes. Node 0 is situated in the control volume at the roof slab outside surface, node 5 at the centre where the cooling pipes for active mass cooling are located and node 10 at the control volume located on the inside surface of the roof slab. The temperature at the control volume at the outside surface of the roofslab, denoted by node 0 in figure G.2, is calculated similar to that of the outside roof slab temperature of the base case, i.e. $T_{s, 0}=299.504 \mathrm{~K}$. For the internal node 1 the temperature is calculated by equation 5.5

$$
\begin{aligned}
T_{s 1,1}^{n+1} & =F o T_{s 1,0}^{n}+(1-2 F o) T_{s 1,1}^{n}+F o T_{s 1,2}^{n} \\
& =\left(8.93 \times 10^{-2}\right)(298.94)+(1-2 \times 8.93) 295.71+8.93 \times 293.135 \\
& =295.765 \mathrm{~K}
\end{aligned}
$$

The above calculation for the internal node is repeated for nodes 2 to 4 and nodes 6 to 9 . At node 5, the centre of the slab, the temperature of the slab is calculated from equation 5.61, i.e. 


$$
\begin{aligned}
T_{s 1,5}^{n+1} & =F o T_{s 1,6}^{n}+\left(1-2 F o-\frac{\Delta t}{h R \rho_{s} C_{s}}\right) T_{s 1,5}^{n}+F o T_{s 1,4}+\frac{\Delta t T_{w}}{h R \rho_{s} C_{s}} \\
& =\left(8.93 \times 10^{-2}\right) 289.9+\left(1-\left(2 \times 8.93 \times 10^{-2}\right)+\frac{60}{0.02 \times 0.05 \times 2100 \times 880}\right) 289 \\
& +\left(8.93 \times 10^{-2}\right) \times 288.76+\frac{60 \times 288}{0.05 \times 2100 \times 880 \times 0.02} \\
& =289.033 \mathrm{~K}
\end{aligned}
$$

The temperature at the inside surface denoted by node 10 in figure G.2 is calculated similar to that of the base case. This calculation gives $T_{s 1,10}^{n+1}=291.54 \mathrm{~K}$. As explained in Chapter 5, the roofslab is discretised along the pipe route to take the variation of the water temperature along the route of the pipe into account. Figure 5.7 in Chapter 5 illustrates this concept. The temperature of the water flowing out of the first roof slab control volume is calculated from equation 5.64

$$
\begin{aligned}
T_{w, o} & =\frac{T_{w, i}\left(R_{w, r s} \dot{m}_{w} C_{p}-A_{c v}\right)+A_{c v} T_{s, m}}{R_{w, r s} \dot{m}_{w} C_{p}} \\
& =\frac{288 \times(0.05 \times 1 \times 4186-6)+6 \times 289.033}{0.05 \times 1 \times 4186} \\
& =288.03 \mathrm{~K}
\end{aligned}
$$

The temperature of water entering the second control volume would then be equal to this temperature, i.e. $288.03 \mathrm{~K}$. The calculation of the temperature at the various nodes of the roof slab is repeated for the remaining 5 control volumes situated along the route of the embedded pipes in the roof slab (see figure 5.7).

The temperature of the control volume at the inner surface of the roof slab is calculated similarly to the way it has been done for the base case. If these temperatures are taken as $T_{s 1,10}=289.28 \mathrm{~K} . T_{s 2,10}=289.3 \mathrm{~K}, T_{s 3,10}=289.29 \mathrm{~K}, T_{s 4,10}=289.296 \mathrm{~K}, T_{s 5,10}=289.3 \mathrm{~K}$ and $T_{s 6,10}=289.31 \mathrm{~K}$ for the six control volumes along the route of the pipe the heat transfer to the room air may be calculated as follows

$$
\begin{aligned}
\dot{Q}_{r s, t r}= & \frac{A_{r s}}{6} h_{c, i}\left(T_{s 1,10}-T_{r m}\right)+\frac{A_{r s}}{6} h_{c, i}\left(T_{s 2,10}-T_{r m}\right)+\frac{A_{r s}}{6} h_{c, i}\left(T_{s 3,10}-T_{r m}\right)+\frac{A_{r s}}{6} h_{c, i}\left(T_{s 4,10}-T_{r m}\right) \\
+ & \frac{A_{r s}}{6} h_{c, i}\left(T_{s 5,10}-T_{r m}\right)+\frac{A_{r s}}{6} h_{c, i}\left(T_{s 6,10}-T_{r m}\right) \\
= & 6 \times 3.12 \times(289.28-295.15)+6 \times 3.12 \times(289.29-295.15)+6 \times 3.12 \times(289.3-295.15) \\
& +6 \times 3.12 \times(289.296-295.15)+6 \times 3.12 \times(289.3-295.15)+6 \times 3.12 \times(289.31-295.15) \\
= & -583.655 \mathrm{~W}
\end{aligned}
$$


The room temperature for the next time step may now be calculated with the following cooling loads

$$
\begin{array}{lll}
\dot{Q}_{h i f}=48.944 \mathrm{~W} & \dot{Q}_{w l, t r, N}=69.23 \mathrm{~W} & \dot{Q}_{w l, t r, E}=69.64 \mathrm{~W} \\
\dot{Q}_{w l, t r, S}=28.5478 \mathrm{~W} & \dot{Q}_{w l, t r, W}=89.23 \mathrm{~W} & \dot{Q}_{r s, t r}=-583.655 \mathrm{~W} \\
\dot{Q}_{h p, t o t}=59.7 \mathrm{~W} & \dot{Q}_{h l, t o t}=160.101 \mathrm{~W} & \dot{Q}_{h w d, t o t}=170.8 \mathrm{~W} \\
\dot{Q}_{h e, t o t}=5 \mathrm{~W} & \dot{Q}_{t o t}=117.51 \mathrm{~W} &
\end{array}
$$

The room temperature for the next time becomes

$T_{r m}^{n+1}=T_{r m}^{n}+\frac{\Delta t}{m_{r m, a}\left(C_{p, r n}+\omega_{r m} C_{p, v a p}\right)} \times \dot{Q}_{t o t}=294.48+\frac{60}{132.4 \times\left(1022.76+\left(1.214 \times 10^{-2}\right) \times 1820\right)} \times 117.51$

$$
=294.53 \mathrm{~K}
$$

\section{Sample Calculations for Roof-spray}

When the roof-spray is applied to the one-room building, heat entry to the one-room building through the roof slab is minimised since the roof slab surface is cooled by means of evaporation. The outside roofslab temperature will be calculated for 10:00 to illustrate the calculation procedure.

From the computer simulation program, performed under the same conditions as that of base, the roof slab temperature for the previous timestep (09:59) was calculated as $294.98 \mathrm{~K}$. At 10:00 the ambient temperature is $299.95 \mathrm{~K}$ and the relative humidity $56 \%$. The air properties are evaluated at the film temperature, i.e.

$$
\begin{aligned}
& T_{f}=(294.98+299.95) \times 0.5=297.47 \mathrm{~K} \text { and } \\
& v_{t f}=1.5664 \times 10^{-5} \mathrm{~m}^{2} / \mathrm{s} ; \rho_{t f}=1.17322 \mathrm{~kg} / \mathrm{m}^{3} k_{a m b}=0.026 \mathrm{~W} / \mathrm{mK} ; \operatorname{Pr}=0.707
\end{aligned}
$$

Before the convection heat transfer coefficient is calculated it is important to determine whether the flow is laminar, turbulent or both. ASHRAE Fundamentals (2005) gives the critical Reynolds number where transition from turbulent to laminar flow occurs as $\operatorname{Re}_{L}=5 \times 10^{5}$. The Reynolds number for the air flow is

$$
\operatorname{Re}_{L}=\frac{u_{w} L_{r p}}{v_{t f}}=\frac{3 \times 6}{1.5664 \times 10^{-5}}=10^{6.06}
$$

The distance from the leading edge where transition from turbulent to laminar flow occurs may be calculated from equation C.47, i.e.

$$
x_{c}=L_{r p}\left(\frac{R e_{x, c}}{R e_{L}}\right)=6\left(\frac{5 \times 10^{5}}{10^{6.06}}\right)=2.61
$$


Since $\frac{x_{c}}{L}=0.414>0.05$ and $\frac{x_{c}}{L}=0.414<0.95$ the correlation for the Nusselt number given by equation C.52 applies, i.e.

$$
N u_{L}=\left(0.037 \operatorname{Re}_{L}^{4 / 5}-871\right) \operatorname{Pr}^{1 / 3}=\left(0.037 \times\left(10^{6.06}\right)^{4 / 5}-871\right) 0.707=1548.86
$$

The convective heat transfer coefficient may be calculate from equation C.45, i.e.

$$
h_{c o n v, o}=\frac{N u_{L} k_{a m b}}{L}=\frac{1481.42 \times 0.0266}{6}=6.7368 \mathrm{~W} / \mathrm{m}^{2} \mathrm{~K}
$$

For the purpose of this study the evaporative heat transfer coefficient used by Tiwari (1981) will be employed, i.e. $h_{\text {evap }}=5.678 \mathrm{~W} / \mathrm{m}^{2} \mathrm{~K}$

The outer roof slab temperature may now be calculated by equation 5.69

$$
\begin{aligned}
T_{0}^{n+1} & =2 F o T_{1}^{n}+\left(1-2 F o-\frac{2 h F o \varepsilon_{r s} \sigma T_{0}^{n^{3}}}{k}-\frac{2 h F o h_{c o n v, r s, o}}{k}\right) T_{0}^{n}+\frac{2 h F o h_{c o n v, r s, o}}{k} T_{a m b} \\
& +\frac{2 h F o \alpha_{\text {solar }, r s} I_{\text {solar }, \text { tot }}}{k}+\frac{2 h F o \varepsilon_{r s} \sigma T_{s k y}^{4}}{k}-\frac{0.026 h F_{o} h_{\text {evap }}\left(p_{w}-\phi p_{a}\right)}{k}
\end{aligned}
$$

Substituting the values for the relevant variables give

$$
\begin{aligned}
T_{0}^{n+1}= & 2 x\left(8.93 \times 10^{-2}\right) \times 292.08+\left(1-2 \times\left(8.93 \times 10^{-2}\right)\right. \\
& -\frac{2 \times 0.02 \times\left(8.93 \times 10^{-2}\right) \times 0.91 \times 5.67 \times 10^{-8} \times 294.98^{3}}{1.1} \\
& \left.-\frac{2 \times 0.02 \times\left(8.93 \times 10^{-2}\right) \times 6.7368}{1.1}\right) \times 294.98+\frac{2 \times 0.02 \times\left(8.93 \times 10^{-2}\right) \times 6.7368 \times 299.95}{1.1} \\
& +\frac{2 \times 0.02 \times\left(8.93 \times 10^{-2}\right) \times 0.6 x(625.38+100.88)}{1.1} \\
& +\frac{2 \times 0.02 \times\left(8.93 \times 10^{-2}\right) \times 0.91 \times 5.67 \times 10^{-8} \times 280.69^{4}}{1.1} \\
& -\frac{0.026 \times 0.02 \times\left(8.93 \times 10^{-2}\right) \times 5.678 \times(2972.43-0.56 \times 3524.4)}{1.1} \\
& =295.517 \mathrm{~K}
\end{aligned}
$$


The temperature for the other nodes in the roof slab is calculated similar to that of the base case. The room temperature for the next time step may now be calculated with the following cooling loads

$$
\begin{array}{lll}
\dot{Q}_{h i f}=52.436 \mathrm{~W} & \dot{Q}_{w l, t r, N}=85.52 \mathrm{~W} & \dot{Q}_{w l, t r, E}=86.84 \mathrm{~W} \\
\dot{Q}_{w l, t r, S}=42.87 \mathrm{~W} & \dot{Q}_{w l, t r, W}=107.396 \mathrm{~W} & \dot{Q}_{r s, t r}=-663.613 \mathrm{~W} \\
\dot{Q}_{h p, t o t}=59.7 \mathrm{~W} & \dot{Q}_{h l, t o t}=160.101 \mathrm{~W} & \dot{Q}_{h w d, t o t}=172.52 \mathrm{~W} \\
\dot{Q}_{h e, t o t}=5 \mathrm{~W} & \dot{Q}_{t o t}=108.755 \mathrm{~W} &
\end{array}
$$

The room temperature for the next time step can now be calculated as

$$
\begin{aligned}
T_{r m}^{n+1} & =T_{r m}^{n}+\frac{\Delta t}{m_{r m, a}\left(C_{p, r m}+\omega_{r m} C_{p, v a p}\right)} \times \dot{Q}_{t o t}=295.15+\frac{60}{132.4 \times\left(1022.76+\left(1.214 \times 10^{-2}\right) \times 1820\right)} \times 108.755 \\
& =294.137 \mathrm{~K}
\end{aligned}
$$

\section{Sample Calculations for the Roof-pond and Roof Cooling System}

With the inclusion of a roof-pond on the roof slab the heat entry to the one-room building through the roof slab is lowered since the roof-pond water absorbs solar heat during diurnal hours and radiates energy to the sky during nocturnal hours. When a roof-pond is present on the roof slab, the roof slab surface absorbtivity is given by

$$
\alpha_{r s, r p}=\frac{\tau_{w} \alpha_{r s}}{1-\rho_{r, r s} \rho_{r, w}}=\frac{0.01 \times 0.6}{1-0.01 \times 0.4}=6.024 \times 10^{-3}
$$

At node 0 , the outer roof slab temperature is calculated from $5.73, T_{1}^{n}=295.69 \mathrm{~K}$ and $T_{0}^{n}=296.463 \mathrm{~K}$

$$
\begin{aligned}
& T_{0}^{n+1}=2 F o T_{1}^{n}+\left(1-2 F o-\frac{2 h F o h_{r s, w}}{k}\right) T_{0}^{n}+\frac{2 h F o I_{s o l a r, t o t} \alpha_{r s, r p}}{k}+\frac{2 h F o h_{r s, w}}{k} T_{w} \\
& =2 \times\left(8.93 \times 10^{-2}\right) \times 295.69+\left(1-2 \times 8.93 \times 10^{-2}-\frac{2 \times 0.02 \times 8.93 \times 10^{-2} \times 135.05 \times 8.93 \times 10^{-2}}{1.1}\right) 296.463 \\
& +\frac{2 \times 0.02 \times(0+100.18834+625.34) \times 6.024 \times 10^{-3}}{1.1}+\left(\frac{2 \times 0.02 \times 135.05 \times 8.93 \times 10^{-2} \times 296.79}{1.1}\right) \\
& =296.48 \mathrm{~K}
\end{aligned}
$$

The temperature for the other nodes in the roof slab is calculated similar to that of the base case. The roof-pond temperature is calculated from the roof-pond control volume as illustrated in the Section G.2 for the roof cooling system. The remainder of the cooling load calculation procedure for both the roof-pond and roof cooling systems are similar to that of the base case. 


\section{APPENDIX H: ADDITIONAL INFORMATION ON THE EXPERIMENTAL WORK}

In the first section of Appendix $\mathrm{H}$ the oil bath calibration procedure required for the evaluation of the data acquisition and reduction errors are given. In Section H.2 the procedure followed to determine the storage tank water volume, water mass flow rate, droplet characteristic volume mean diameter and the initial droplet nozzle velocity are described. In the final section the temperature and humidity levels measure during each of the five experiments are given.

\section{H.1 Oil Bath Calibration Procedure}

An effective method to evaluate the data acquisition and reduction errors associated with multiple thermocouples is to provide a known temperature to which the thermocouples may be compared to. In this case the thermocouples employed in the experiment where referenced to the same temperature by inserting them into an oil bath of which the temperature was measured with a calibrated platinum resistance thermometer (CSIR, 2003).

\section{Set-Up}

The oil bath experiment comprised of a platinum resistance thermometer (PRT), an insulated container filled with oil, an oil mixer, ohm meter, rheostat controlled heating elements and the thermocouples employed in the roof cooling experiment. The platinum resistance thermometer and the seven thermocouples were inserted in the oil bath as shown in figure 6.2 below. The ohm meter was used to measure the resistance of the platinum resistance thermometer.

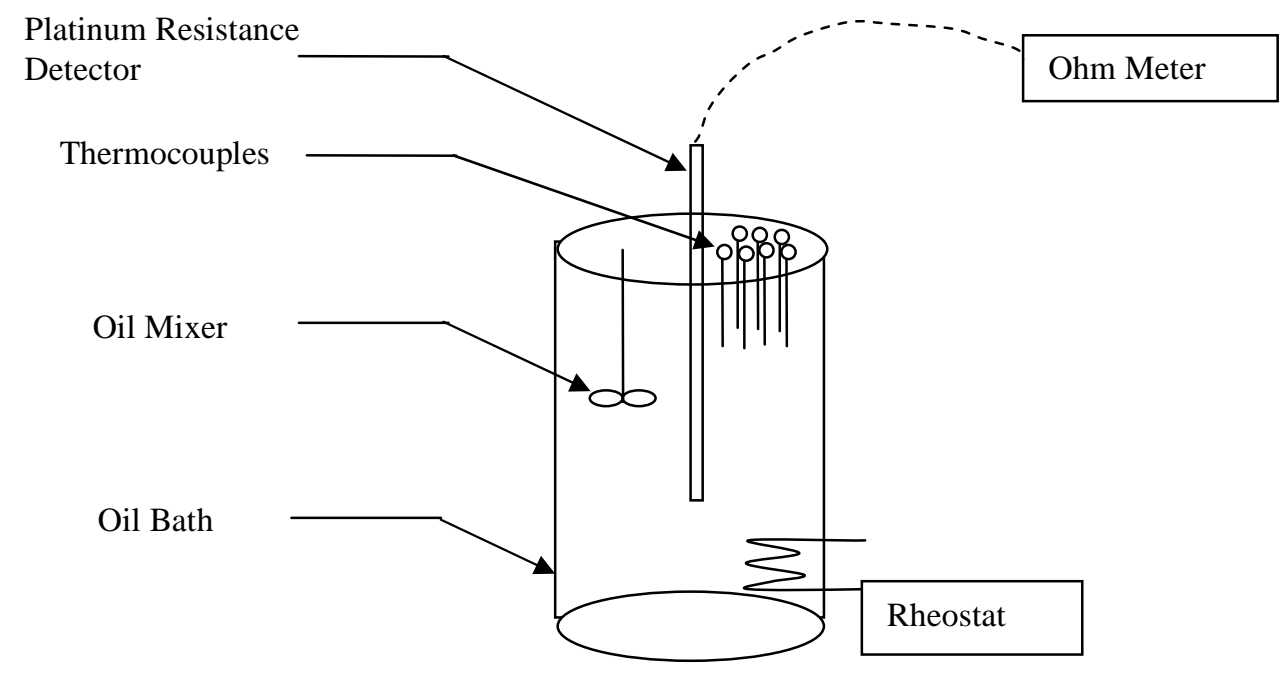

Figure H.1: Set-up of Oil Bath with Thermocouples

\section{Procedure}

The oil was heated with the rheostat heating element whilst being stirred continuously with the oil mixer. The thermocouples and the platinum resistance thermometer were inserted in 
the oil bath. The oil bath was left in the latter state for an hour before any measurements were taken. This was done to reduce the effect of temperature gradients and to allow temperature readings in an oil bath of uniform temperature. The temperature of the oil was determined by measuring the electrical resistance of the platinum resistance thermometer and reading the corresponding temperature from the calibration chart. The procedure was repeated at various oil bath temperatures ranging from 20 to $50{ }^{\circ} \mathrm{C}$. Figure 6.3 gives a photograph of the experiment.

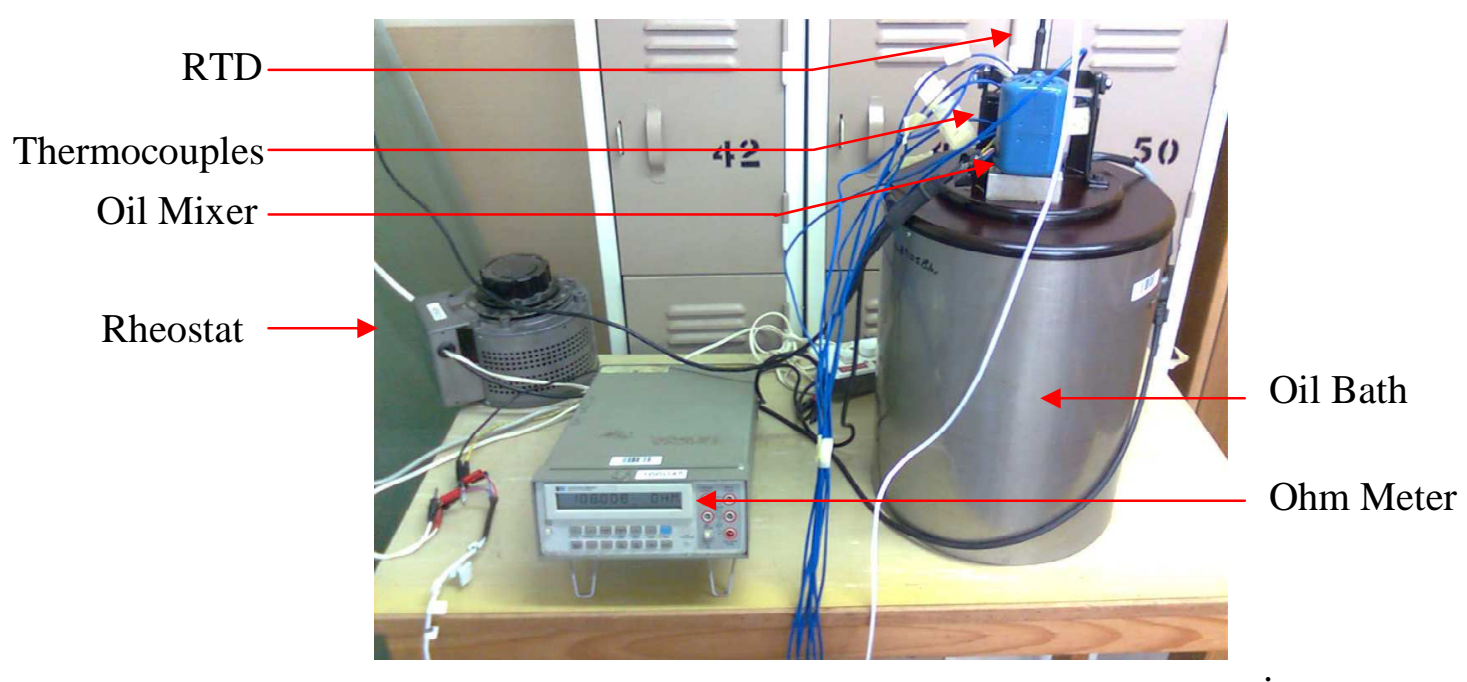

Figure H.2: Photograph Depicting the Set-up of the Oil Bath for the Calibration of the Thermocouples

In order to repeat the experiment at $0{ }^{\circ} \mathrm{C}$ an insulated container was filled with ice water and slush in lieu of oil and a rheostat controlled heating element. The ice water and slush was well mixed and left for one hour to allow the water to settle and to achieve a uniform temperature.

\section{H.2 Procedure for Determining Experimental Variables}

The methodology followed to determine the storage tank water volume, water mass flow rate, droplet characteristic volume mean diameter and the initial droplet nozzle velocity are described below.

\section{H.2.1 Procedure for Determining the Storage Tank Water Volume}

The storage tank water volume was determined by measuring the outside circumference of the tank, the wall thickness, the tank height and the height of the water level. These dimensions are depicted in the figure below 


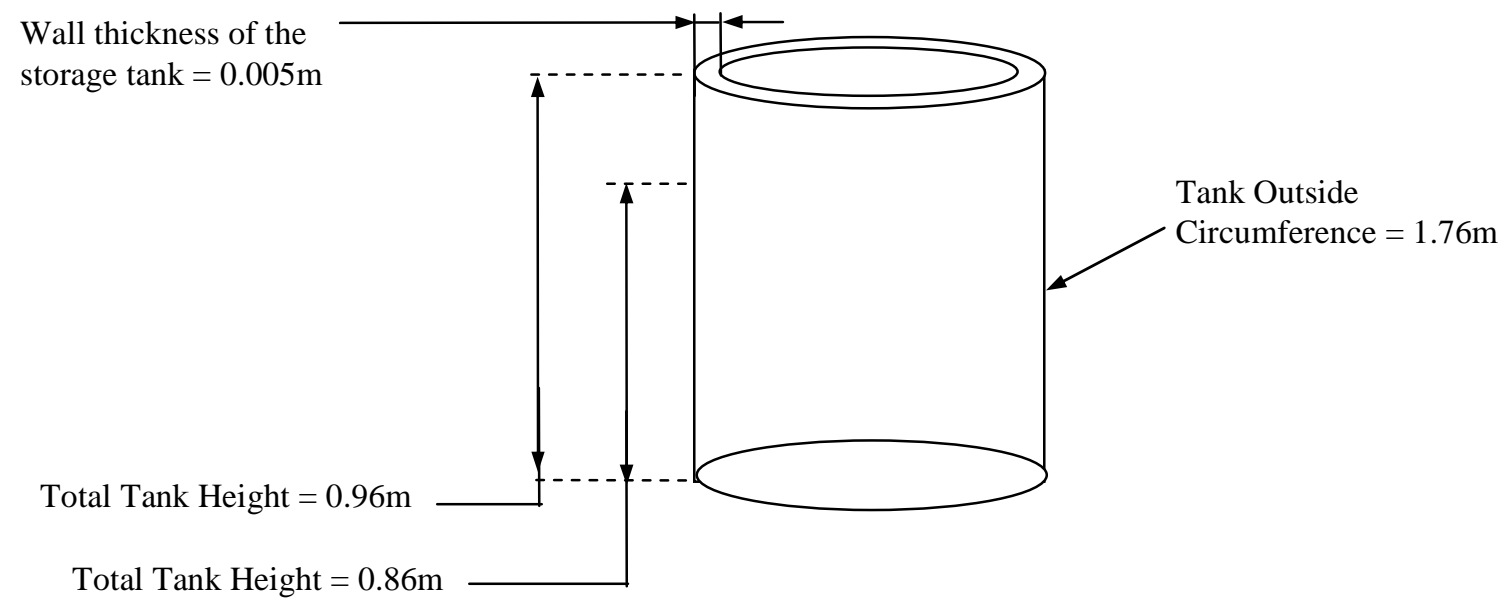

Figure H.3: Dimensions of the Water Storage Tank

The $L_{t}$ denotes the circumference of the water tank and $t_{t}$ the wall thickness of the tank then the tank diameter $D_{t, o}$ may be calculated by the following relation

$$
L_{t}=\pi D_{t, o}
$$

Rearranging equation H.1 and inserting the relevant dimensions gives

$$
D_{t, o}=\frac{L_{t}}{\pi}=\frac{1.76}{\pi}=0.56 \mathrm{~m}
$$

The inner diameter $D_{t, i}$ of the tank may now be calculated by subtracting the tank wall thickness $t_{t}$, i.e.

$$
D_{t, i}=D_{t, o}-2 t_{t}=0.56-2 \times 0.005=0.55
$$

The total tank volume may be calculated by multiplying the tank inside surface area $A_{t, i}$ with the total tank height $H_{t, t o t}$

$$
V_{t, t o t}=\frac{\pi D_{t, i}^{2}}{4} H_{t, i}=\frac{\pi 0.55^{2}}{4} 0.96=0.228 \mathrm{~m}^{3}
$$

and similarly the water volume in the tank is determined by multiplying $A_{t, i}$ with the water volume height $H_{t, w}$

$V_{t, t o t}=\frac{\pi D_{t, i}^{2}}{4} H_{t, i}=\frac{\pi 0.55^{2}}{4} 0.86=0.204 \mathrm{~m}^{3}$ 


\section{H.2.2 Procedure for Determining the Water Mass Flow Rate}

For the experimental tests performed on 25 May 2008, 12 July 2008 and 02 August 2008 the pump operated at a pressure of $420 \mathrm{kPa}$.

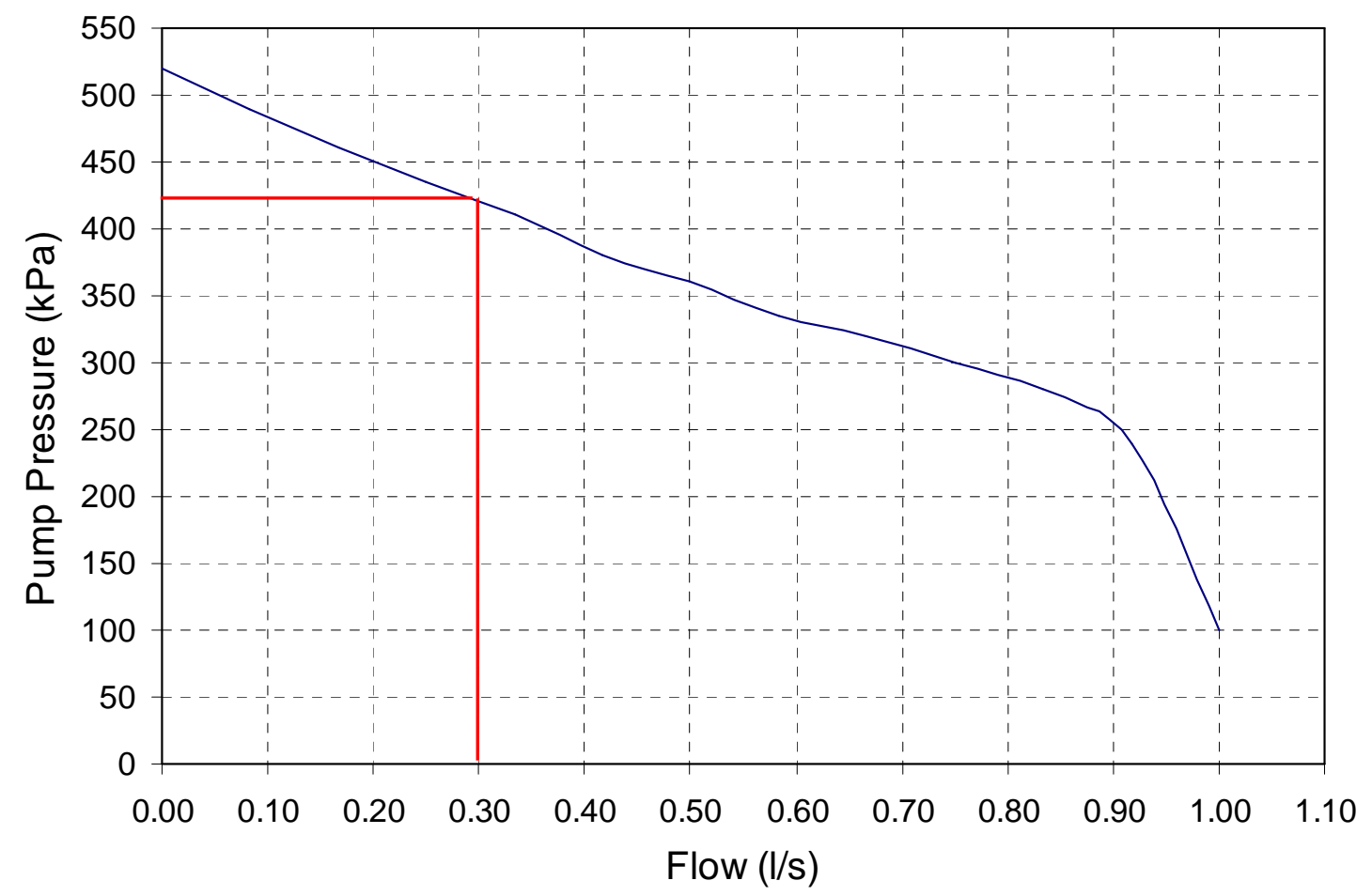

Figure H.4: Pump Curve for a 0.75 kW Foras JA-100 pump

From the above it can be seen that the pump delivers approximately $0.31 / \mathrm{s}$ at $420 \mathrm{kPa}$. If it is estimated that the bypass low was set at $0.05 \mathrm{l} / \mathrm{s}$ the flow to the spray nozzles becomes 0.25 1/s. It should however be remembered that even though this approach seems to be crude does it not have large impact on the result. Take for example the conditions for the 02 August 2008 test. When a flow rate of $0.25 \mathrm{l} / \mathrm{s}$ is utilised the calculate end temperature of the water storage tank becomes $9.44{ }^{\circ} \mathrm{C}$ whereas a temperature of $9.38^{\circ} \mathrm{C}$ iss calculated when a flow rate of $0.3 \mathrm{l} / \mathrm{s}$ is utilised. The difference in result is $0.054{ }^{\circ} \mathrm{C}$ which may be regarded negligible.

The water flowrates for the 03 May 2009 and 04 May 2009 tests were determined by measuring the quantity of water sprayed in a tank of water during a given time period. In both cases 5.6 litres of water was sprayed into a tank within a time of 30 seconds. This gives a flow equal to $0.1867 \mathrm{l} / \mathrm{s}$.

\section{H.2.3Procedure for Determining the Volume Mean Diameter of the Spray Nozzles}

The VMD of the spray nozzles were estimated by taking random samples of the droplets sprayed from each nozzle type. The sampling procedure involved spraying the water droplets 
on a piece of paper, measuring and counting the various droplet sizes. The VMD were taken as the droplet size where approximately fifty percent of the total water volume or mass sprayed was made up of water droplets with diameters smaller than the VMD and fifty percent of the water droplets larger than the VMD. The results are shown in Table H.1 below

Table H.1: VMD from the Spray Nozzles Utilised in the Experimental Work

\begin{tabular}{|l|l|l|}
\hline & Nozzle Type 1 Hunter 6Q & Nozzle Type 2 Hunter 2H \\
\hline Sample Set 1 & $1800 \mu \mathrm{m}$ & $2000 \mu \mathrm{m}$ \\
\hline Sample Set 2 & $2000 \mu \mathrm{m}$ & $1800 \mu \mathrm{m}$ \\
\hline Sample Set 2 & $1300 \mu \mathrm{m}$ & $1300 \mu \mathrm{m}$ \\
\hline Sample Set 3 & - & $1300 \mu \mathrm{m}$ \\
\hline
\end{tabular}

A representative VMD for the nozzles were taken as the average of the above results, which is $1700 \mu \mathrm{m}$. Note that the actual VMD of the spray nozzle is expected to fall within the tolerance of $\pm 400 \mu \mathrm{m}$. The deviation seems large but the influence on the simulation result is negligible. When the 02 August 08 test is for example simulated with a droplet size of 1700 $\mu \mathrm{m}$ the final storage tank temperature becomes $9.44^{\circ} \mathrm{C}$ while a simulation with a droplet size of $1300 \mu \mathrm{m}$ gives a final storage tank temperature of $9.31^{\circ} \mathrm{C}$. The deviation in the result is only $0.13{ }^{\circ} \mathrm{C}$ which is less than the measurement uncertainty associated with the thermocouples.

\section{H.2.4Procedure for Determining the Initial Droplet Discharge Velocity}

The initial droplet discharge velocity of the water spray from the nozzles was determined by measuring the time it takes for the water droplets to travel a predetermined distance. The procedure is repeated such that the initial droplet discharge velocity may be determined from the average. Table H.2 shows these times for the two types of nozzles used. 
Table H.2: VMD from the Spray Nozzles Utilised in the Experimental Work

\begin{tabular}{|l|l|l|l|l|l|}
\hline \multirow{2}{*}{$\begin{array}{l}\text { Sample } \\
\text { Number }\end{array}$} & \multirow{2}{*}{ Distance $(\mathrm{m})$} & \multicolumn{3}{l}{ Nozzle Type 1 Hunter 6Q } & \multicolumn{2}{l|}{ Nozzle Type 2 Hunter $\mathrm{H}$} \\
\cline { 3 - 6 } & & $t(\mathrm{sec})$ & $u_{i}(\mathrm{~m} / \mathrm{s})$ & $t(\mathrm{sec})$ & $u_{i}(\mathrm{~m} / \mathrm{s})$ \\
\hline 1 & 0.5 & 0.44 & 1.14 & 0.28 & 1.79 \\
\hline 2 & 0.5 & 0.29 & 1.73 & 0.23 & 2.17 \\
\hline 3 & 0.5 & 0.36 & 1.4 & 0.1 & 5 \\
\hline 4 & 0.5 & 0.25 & 2 & 0.2 & 2.5 \\
\hline 5 & 0.5 & 0.25 & 2 & 0.24 & 2.1 \\
\hline 6 & 0.5 & 0.27 & 1.9 & 0.24 & 2.1 \\
\hline 7 & 0.9 & & & 0.39 & 2.31 \\
\hline 8 & 0.9 & & & 0.2 & 4.5 \\
\hline 9 & 0.9 & & & 0.39 & 2.31 \\
\hline 10 & 0.9 & & & 0.36 & 2.5 \\
\hline 11 & 0.9 & & & 0.27 & 3.33 \\
\hline 12 & 0.9 & & & 0.21 & 4.3 \\
\hline 13 & 0.9 & & & 0.42 & 2.14 \\
\hline 14 & 0.9 & & & 0.42 & 2.14 \\
\hline Average Velocity (m/s) & & 1.7 & & 2.8 \\
\hline
\end{tabular}

Based on the average velocities determined for the two types of nozzles a representative velocity of $2.3 \mathrm{~m} / \mathrm{s}$ will be employed for all the nozzles of the experiments. The actual velocity may be within a $0.5 \mathrm{~m} / \mathrm{s}$ of $2.3 \mathrm{~m} / \mathrm{s}$. This deviation in velocity does not however have a noticeable difference in the end result.

\section{H.3 Measured Humidity and Ambient Temperature Levels of the Experimental Tests}

Table H.3 gives the ambient temperature and humidity levels measured at 6 minute intervals during the five experiments. Where humidity levels could only be measured at some intervals they were extrapolated for the remaining times. 
Table H.3: Ambient Temperature and Humidity Levels Measured at 6 Minute Intervals During the Five Experiments

\begin{tabular}{|c|c|c|c|c|c|c|c|c|c|c|c|c|c|c|}
\hline \multicolumn{3}{|c|}{25 May 2008} & \multicolumn{3}{|c|}{12 July 2008} & \multicolumn{3}{|c|}{02 August 2008} & \multicolumn{3}{|c|}{03 Мау 2009} & \multicolumn{3}{|c|}{04 May 2009} \\
\hline Time & $\begin{array}{l}T_{a m b} \\
\left({ }^{\circ} \mathrm{C}\right)\end{array}$ & $\begin{array}{l}\phi_{a m b} \\
(\%)\end{array}$ & Time & $\begin{array}{l}T_{a m b} \\
\left({ }^{\circ} \mathrm{C}\right)\end{array}$ & $\begin{array}{l}\phi_{a m b} \\
(\%)\end{array}$ & Time & $\begin{array}{l}T_{a m b} \\
\left({ }^{\circ} \mathrm{C}\right)\end{array}$ & $\begin{array}{l}\phi_{a m b} \\
(\%)\end{array}$ & Time & $\begin{array}{l}T_{a m b} \\
\left({ }^{\circ} \mathrm{C}\right)\end{array}$ & $\begin{array}{c}\phi_{a m b} \\
(\%)\end{array}$ & Time & $\begin{array}{l}T_{a m b} \\
\left({ }^{\circ} \mathrm{C}\right)\end{array}$ & $\begin{array}{c}\phi_{a m b} \\
(\%)\end{array}$ \\
\hline $19: 15$ & 14.5 & 85 & 06:07 & 4.82 & - & $19: 42$ & 9.76 & 60 & $18: 58$ & 16.08 & 77 & 06:04 & 11.54 & 82 \\
\hline $19: 21$ & 14.7 & - & $06: 13$ & 4.08 & - & $19: 48$ & 9.57 & - & 19:04 & 15.88 & 77 & $06: 10$ & 11.6 & 81 \\
\hline $19: 27$ & 14.5 & - & $06: 19$ & 3.63 & - & $19: 54$ & 9.47 & - & $19: 10$ & 15.7 & 78 & $06: 16$ & 11.48 & 81 \\
\hline $19: 33$ & 14.4 & - & $06: 25$ & 4.44 & - & 20:00 & 9.27 & - & $19: 22$ & 15.46 & 78 & $06: 22$ & 11.32 & 82 \\
\hline $19: 39$ & 14.3 & - & $06: 31$ & 6.63 & - & 20:06 & 9.18 & - & $19: 28$ & 15.28 & 79 & $06: 28$ & 11.08 & 83 \\
\hline $19: 45$ & 14.2 & - & $06: 37$ & 3.71 & - & $20: 12$ & 9.06 & - & $19: 34$ & 15.22 & 79 & $06: 34$ & 10.96 & 83 \\
\hline $19: 51$ & 14.1 & 85 & $06: 43$ & 5.05 & - & $20: 18$ & 8.92 & - & $19: 40$ & 15.16 & 80 & $06: 40$ & 10.9 & 84 \\
\hline $19: 57$ & 14.0 & 85 & $06: 49$ & 5.0 & 78 & $20: 24$ & 8.75 & - & $19: 46$ & 15.1 & 80 & $06: 46$ & 10.84 & 84 \\
\hline $20: 03$ & 13.9 & 85 & $06: 55$ & 4.89 & - & $20: 30$ & 8.70 & 71 & $19: 52$ & 14.98 & 80 & $06: 52$ & 10.86 & 82 \\
\hline 20:09 & 13.8 & 85 & 07:01 & 4.85 & - & $20: 36$ & 8.46 & 71 & $19: 58$ & 14.76 & 80 & $06: 58$ & 11.04 & 82 \\
\hline $20: 15$ & 13.8 & 85 & 07:07 & 4.97 & - & $20: 42$ & 8.28 & 71 & 20:04 & 14.64 & 80 & 07:04 & 11.1 & 82 \\
\hline $20: 21$ & 13.8 & 85 & $07: 13$ & 5.00 & - & $20: 48$ & 8.19 & 71 & $20: 10$ & 14.48 & 80 & $07: 10$ & 11.1 & 82 \\
\hline $20: 27$ & 13.8 & 85 & $07: 19$ & 5.04 & - & $20: 54$ & 7.97 & 71 & $20: 16$ & 14.3 & 80 & $07: 16$ & 11.1 & 80 \\
\hline $20: 33$ & 13.7 & 85 & $07: 25$ & 5.11 & & $21: 00$ & 7.83 & & $20: 22$ & 14.24 & 81 & & & \\
\hline $20: 39$ & 13.7 & - & $07: 31$ & 5.033 & & 21:06 & & & $20: 28$ & 14.2 & 82 & & & \\
\hline $20: 45$ & 13.5 & - & $07: 37$ & 5.09 & & & & & $20: 34$ & 14.12 & 82 & & & \\
\hline & & & $07: 43$ & 4.46 & & & & & & & & & & \\
\hline & & & $07: 49$ & 4 & & & & & & & & & & \\
\hline & & & $07: 55$ & 4.09 & & & & & & & & & & \\
\hline & & & 08:01 & & 77 & & & & & & & & & \\
\hline
\end{tabular}

